\title{
NEEDS ANALYSIS OF ENGLISH FOR MECHANICAL ENGINEERS IN THE VIETNAMESE CONTEXT
}

\author{
By
}

\author{
Le Cao Tinh
}

\begin{abstract}
A thesis
submitted to the Victoria University of Wellington in fulfilment of the requirements for the degree of Doctor of Philosophy in Education
\end{abstract}

Victoria University of Wellington

2018 



\section{ACKNOWLEDGEMENTS}

First and foremost, my sincere appreciation goes to my supervisors, Dr Gillian Hubbard, Dr John Dickie, and Dr Carolyn Tait for their excellent and dedicated supervision, patience, encouragement and understanding, and for accompanying me in my $\mathrm{PhD}$ journey. Without their invaluable contribution, this work would have been impossible.

I would like to express my gratitude to Dr Michael Johnston who has given me useful feedback on the questionnaire instrument. I am very grateful to Victoria University of Wellington student advisers, particularly Dr Xiaodan Gao, who has given me advice and feedback on the drafts of the chapters, and Dennis Dawson, who has guided me to analyse the quantitative data of the thesis. My sincere thanks also go to Madeleine Collinge who has proofread the thesis.

I am very grateful for the scholarships from the Vietnamese government and Victoria University of Wellington.

I would like to acknowledge Vinh University of Technology Education for supporting my studies at Victoria University of Wellington, New Zealand. I am also indebted to Le Duc Loi, the former dean of my faculty, for his trust in my ability and his encouragement to pursue this $\mathrm{PhD}$.

I am indebted to employers, managers and mechanical engineers who participated in this study. Their enthusiastic sharing and cooperation have provided valuable data that gave an insight into the English communication needs of mechanical engineers in the workplace.

My sincere thanks to all my friends who have cheered me up throughout this journey, especially when I was faced with health problems.

Finally, I would like to thank all my family members, whose love and support have powered me to complete the $\mathrm{PhD}$ journey. Especially, I would like to dedicate this work to my parents, who have sacrificed their whole life to me, and my siblings. Their unconditional love and trust have always strengthened me throughout the years I have lived overseas. My wholehearted appreciation goes to my beloved wife, Mrs Phung Thi Thanh Hoai, and my children, Le Minh Phuc (Thomas) and Le Minh Lam (Ben) for their love and sacrifice throughout the years we have lived in New Zealand.

To you all, my love and thankfulness. 


\section{ABSTRACT}

This study examines the English language needs of mechanical engineers in Vietnam. A high demand for proficiency in English is increasing in ASEAN countries, including Vietnam. Vietnam in general and the important field of mechanical engineering, in particular, attracts many foreign investors and multinational organisations and this creates plurilingual and pluricultural workplaces where English is used as a lingua franca.

Drawing on sociolinguistic theory, this pragmatic mixed method needs analysis study examines the English language communication needs of Vietnamese mechanical engineers at four workplaces in Vietnam. It investigates the kinds of real-world English skills required by Vietnamese mechanical engineers to function effectively in the workplace, the social factors that affect the use of English and the effects of breakdowns or other issues in communication in English. It draws on needs analysis models which have evolved from English for Specific Purposes, including those devised by Munby (1978) and more recently by The Common European Framework (CEF) Professional Profiles to establish key communicative events. To answer the study's pragmatic questions about language use for practical purposes in the lingua franca, plurilingual and pluricultural workplace it also borrows from the theoretically eclectic model of the Wellington Workplace Project, a model grounded in the first language context (L1), and other more sociological studies of the relationship of language and power in international workplaces.

The study employed questionnaire, semi-structured interview and observation for data collection. Questionnaires were completed by 22 managers of mechanical engineers and 71 professional mechanical engineers. Based on the initial questionnaire analysis, 12 participants from the two groups took part in the follow-up semi-structured interviews. Observations in four worksites provided rich data about the real-world use of English.

The findings indicated a high frequency of English language use and the range of real-world English required by Vietnamese mechanical engineers for a range of communicative events including ordering spare parts, interpreting technical drawing and bidding for contracts. Mechanical engineers needed plurilingual and pluricultural competence to negotiate a range of accent, intonation and idiom in the lingua franca and plurilingual context. Minimal use of functional occupational language was sometimes sufficient for communication for the purpose of 'getting things done', but not always. Communication issues had financial consequences for the company, sometimes disastrous ones. Looking at the findings through the lens of arising communication issues helped to 
reveal some of the underlying power relationships in the workplace and some negative impacts on workplace solidarity.

These findings demonstrate the urgency of the need for increased English language skills for mechanical engineers in Vietnam and for the wider economy of Vietnam. English was found to function as a source of 'expert power' and in a wider implication this revealed a hidden or 'shadow' power structure within the workplace affected by English language proficiency. People were empowered when they possessed a good level of English, which could help them save not only their own face but also the face of the company.

More positively adaptive communicative strategies helped both mechanical engineers and their managers avoid communication issues. Adapting language for the purpose of 'getting things done' in turn interacted with low and high solidarity relationships. There was arguably an acceptance of a level of rudeness or abruptness in these workplace contexts. A high tolerance for the need to negotiate meaning in what could be described as not only a lingua franca but also a 'poor English' workplace context was sometimes observed. This tolerance sometimes but not always extended to the mobility of plurilingual repertoires such as code-switching, and some code-switching into Vietnamese was also observed on the part of long-term foreign managers. Humour also emerged as a dimension of high solidarity longer-term workplace relationships between Vietnamese mechanical engineers and foreign managers, even when all parties had limited English.

The study argues that understanding why mechanical engineers needed specific types of English and the effect of the social dimensions of this language could help lessen issues in communication. The consequences of miscommunication should be addressed in the English-language training process. Students should be strategically prepared to meet the the high communication demands of the lingua franca and plurilingual workplace which requires both English for technical communication and English for social communication. 


\section{TABLE OF CONTENTS}

ACKNOWLEDGEMENTS

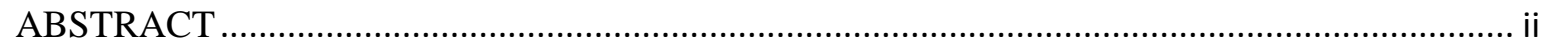

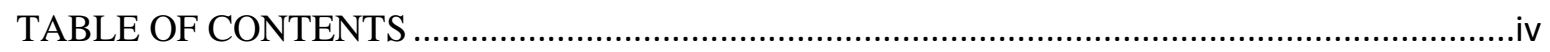

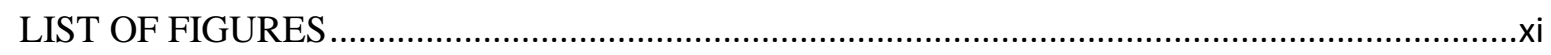

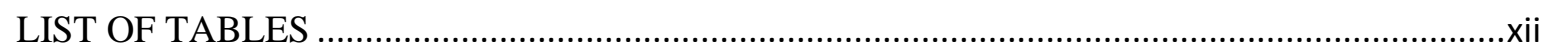

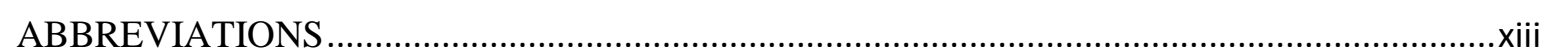

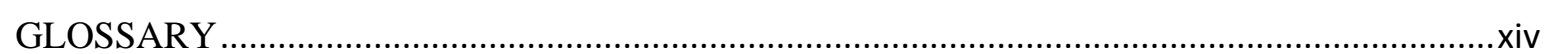

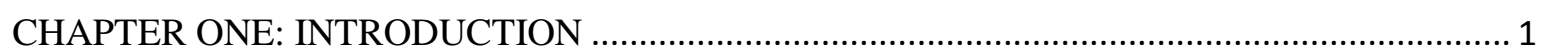

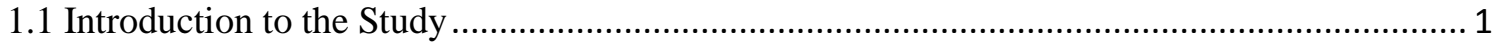

1.1.1 The social and political environment of Vietnam .......................................................... 1

1.1.2 The development of needs analysis frameworks ............................................................. 5

1.2 English language education in Vietnam ......................................................................... 7

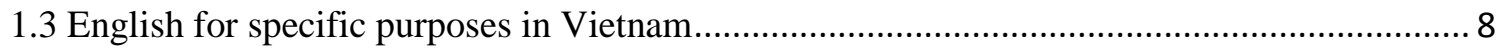

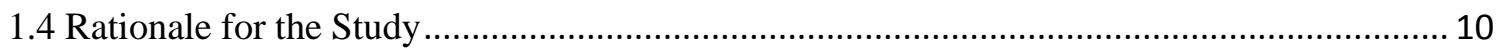

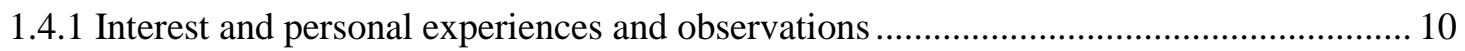

1.4.2 The development of theoretical frameworks to address communication needs ............... 11

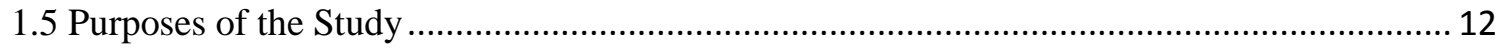

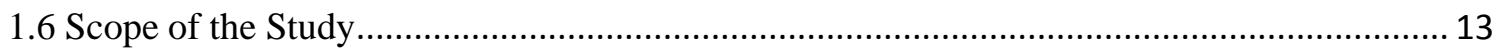

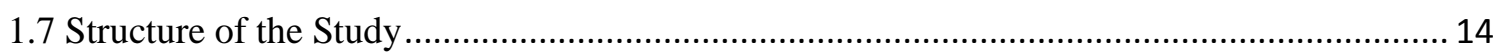

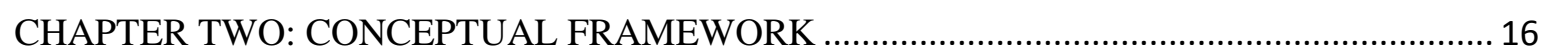

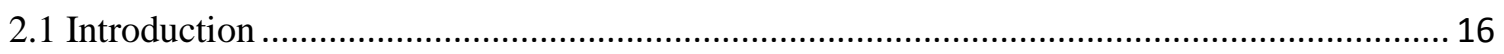

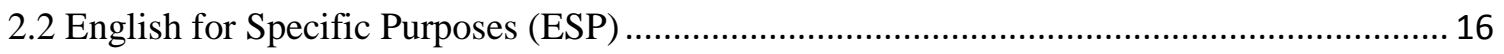

2.2.1 The development of English for Specific Purposes........................................................ 16

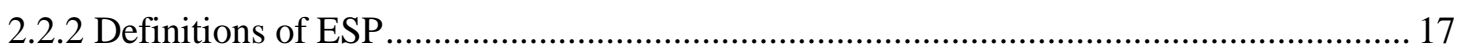

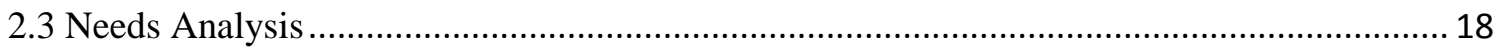

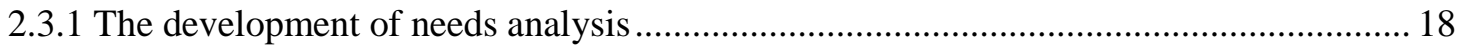

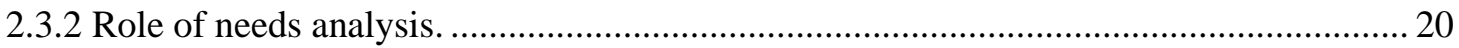

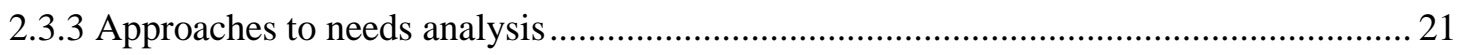

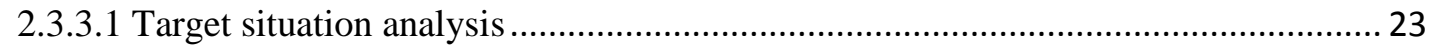

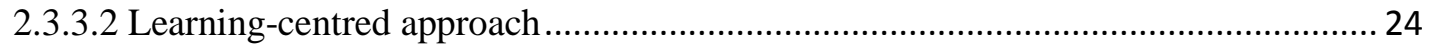

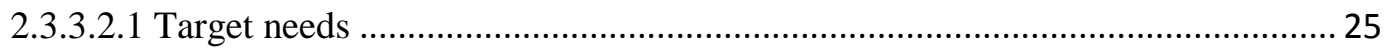

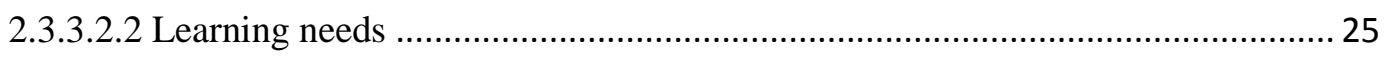

2.3.3.3 Common European Framework (CEF) Professional Profile .................................... 26

2.4 Methodological Approaches to Explore Workplace Communication..................................... 31

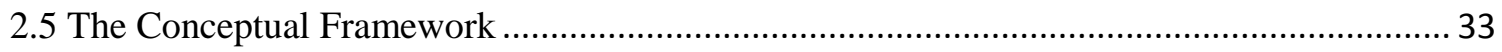


CHAPTER THREE: STUDIES OF LANGUAGE NEEDS AND WORKPLACE COMMUNICATION

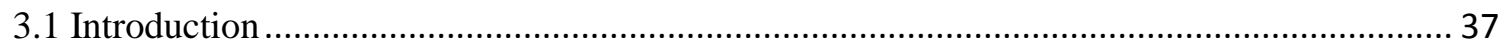

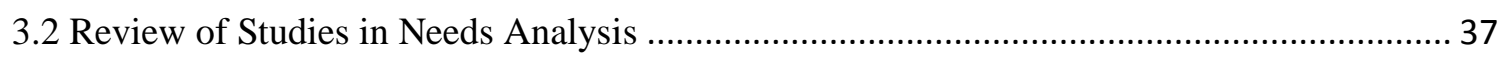

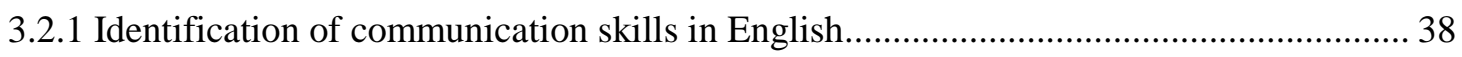

3.2.1.1 Oral communication skills in English ................................................................. 43

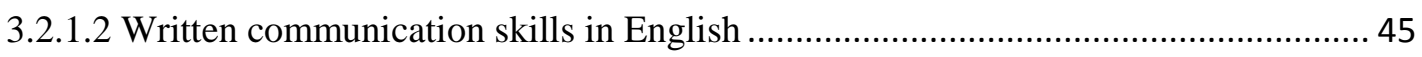

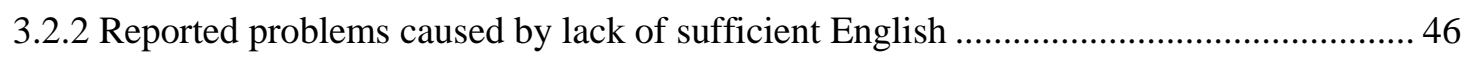

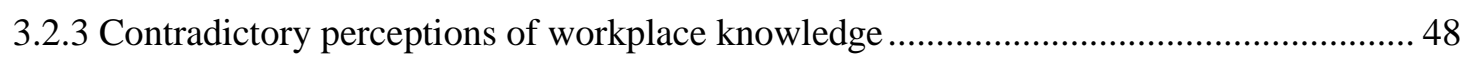

3.2.4 The reported gaps between needs analysis and actual teaching programmes ................ 49

3.2.5 Interaction and adaptation to different linguistic and cultural conditions ....................... 50

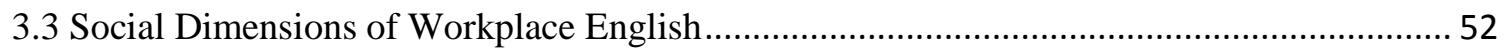

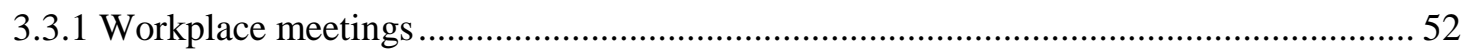

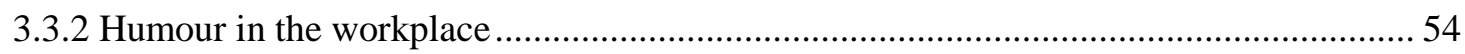

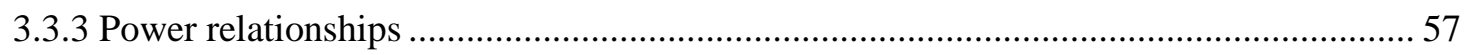

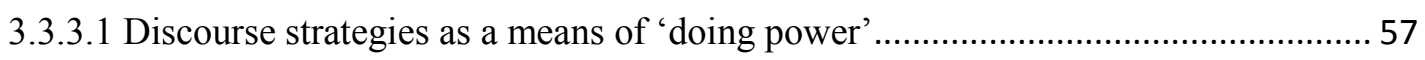

3.3.3.2 Language as a source of "expert power" .............................................................. 60

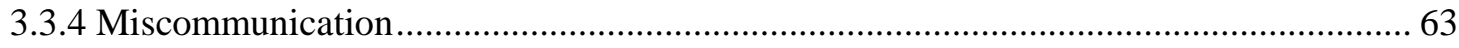

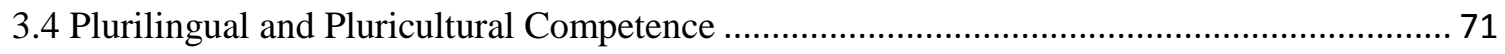

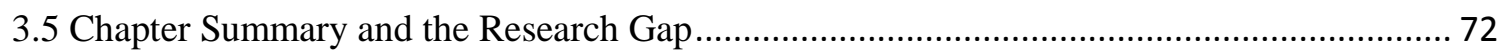

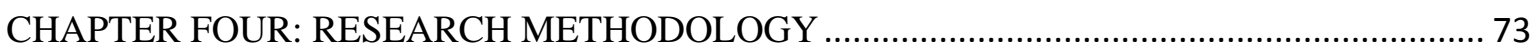

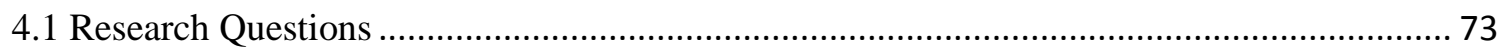

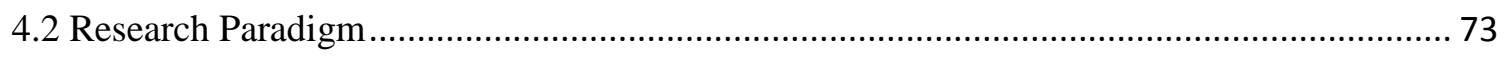

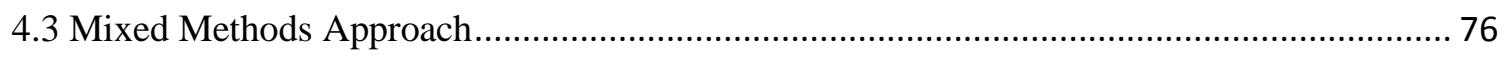

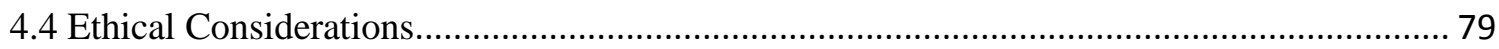

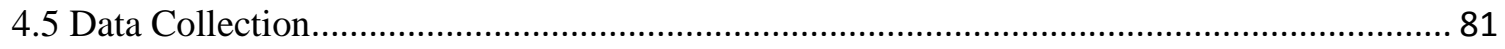

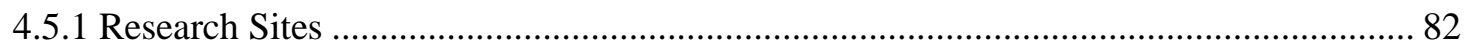

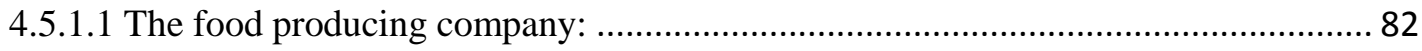

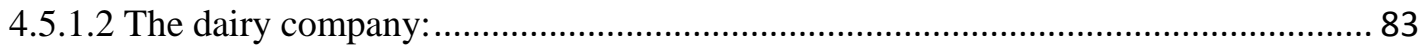

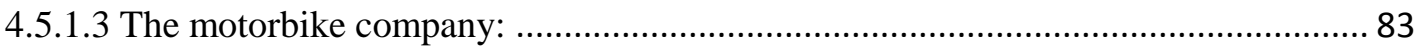

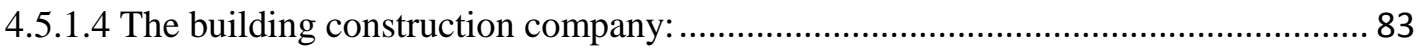

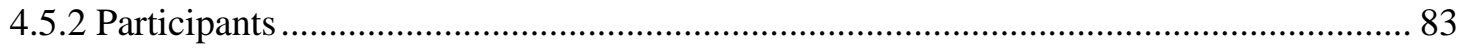

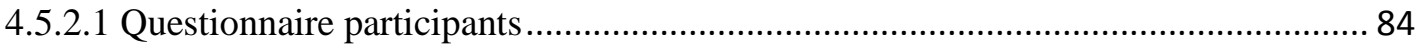

4.5.2.1.1 Managers of mechanical engineers ................................................................. 84

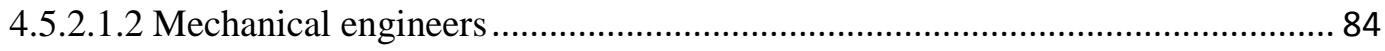

4.5.2.2 Semi-structured interview participants .............................................................. 86 
4.5.2.3 Observation participants ....................................................................... 86

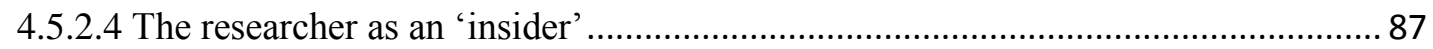

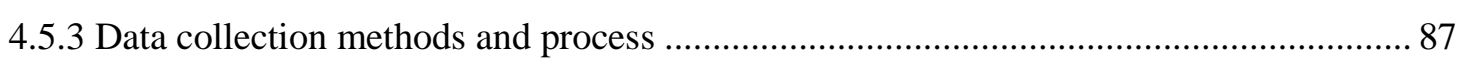

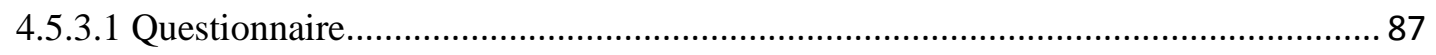

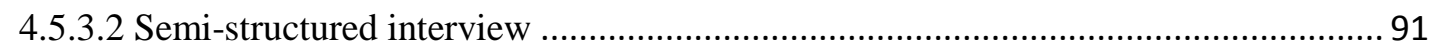

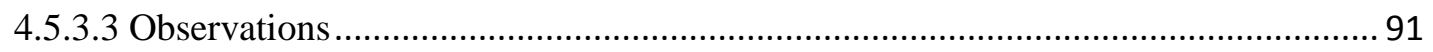

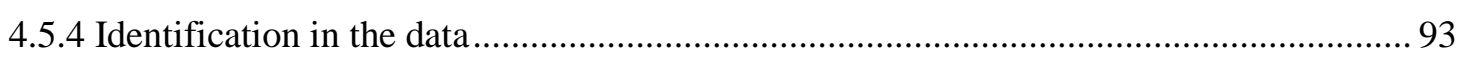

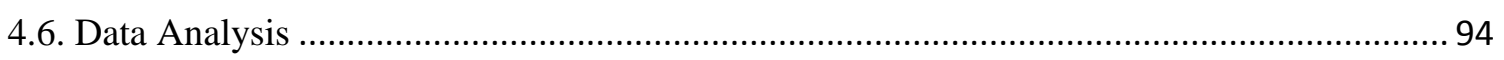

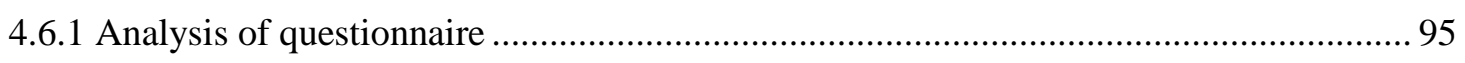

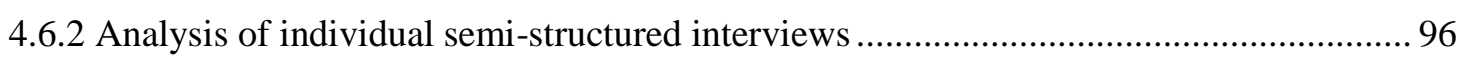

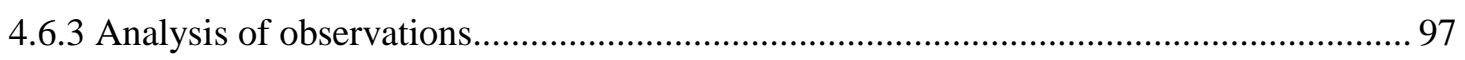

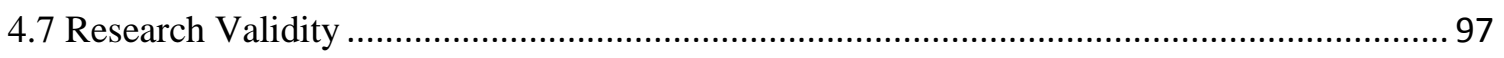

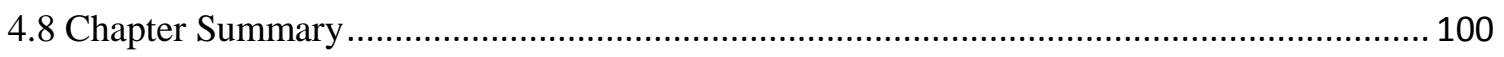

CHAPTER FIVE: QUESTIONNAIRE FINDINGS OF REAL-WORLD ENGLISH SKILLS REQUIRED BY VIETNAMESE MECHANICAL ENGINEERS ....................................... 102

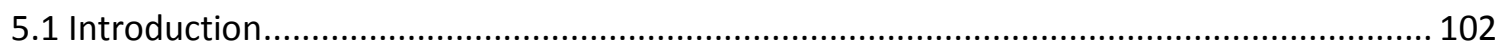

5.2 The Frequency of English Use ......................................................................... 103

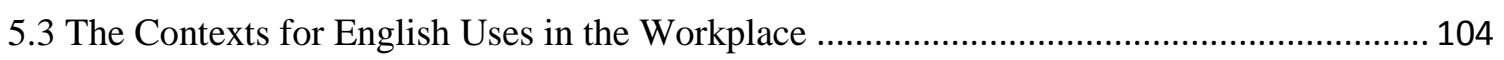

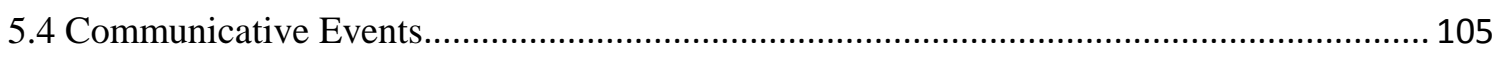

5.4.1 Managers' perceptions of their mechanical engineers' communicative events ............ 107

5.4.2 Mechanical engineers' perceptions about their communicative events ...................... 109

5.5 Work Related English Language Skills Reported in the Questionnaire............................ 111

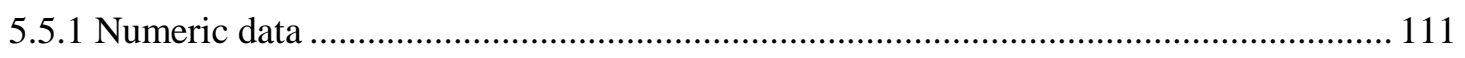

5.5.2 Qualitative data from open questions in the questionnaire....................................... 113

5.5.2.1 The requirements of all macro English language skills ................................... 113

5.5.2.2 The importance of listening and speaking skills ................................................ 113

5.5.2.3 General English for communication and English for technical communication .... 114

5.5.2.4 Combination of listening, speaking and reading or writing ................................ 115

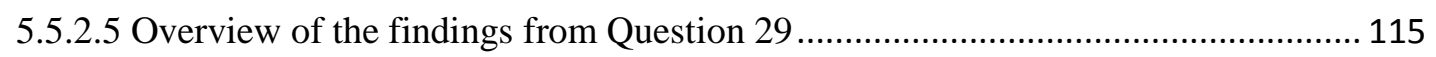

5.6 Questionnaire Findings about the Formality of English Use in the Workplace .................. 115

5.6.1 Managers' responses about the types of English used by their mechanical engineers.. 116

5.6.2 Managers' comments about the types of English used by their mechanical engineers. 117

5.6.3 Mechanical engineers' responses about the type of English they use ........................ 118

5.6.4 Mechanical engineers' comments about the type of English they used ...................... 119

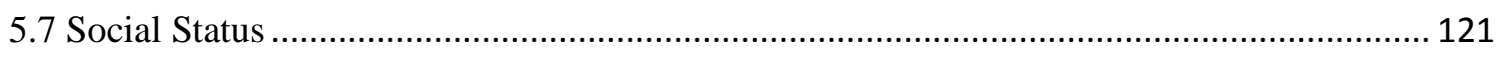

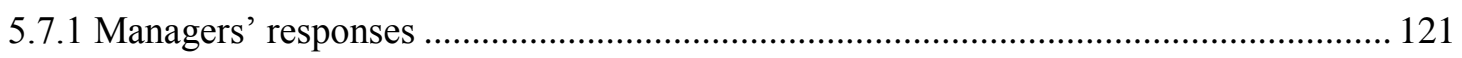

5.7.2 Managers' view of language and social status ................................................... 122 
5.7.3 Mechanical engineers' responses

5.7.4 Mechanical engineers' comments about the importance of adapting the workplace use of English. 123

5.8 Chapter Summary..... 125

CHAPTER SIX: QUALITATIVE FINDINGS OF REAL-WORLD ENGLISH LANGUAGE SKILLS REQUIRED BY MECHANICAL ENGINEERS ....................................................... 126

6.1 Introduction 126

6.2 Interview Data 128

6.2.1 The contexts for English uses in the workplace. 128

6.2.1.1 Locations 129

6.2.1.2 Using English to communicate with foreigners . 129

6.2.2 Communicative events 130

6.2.3 Work related English language skills that emerged from the interview data 133

6.2.3.1 Listening skills .... 133

6.2.3.2 Speaking skills. 134

6.2.3.3 Reading skills 135

6.2.3.4 Writing skills 137

6.2.4 The purposes, forms and levels of English used in the workplace. 139

6.2.4.1 English for technical communication 139

6.2.4.2 Varying forms of English uses ..... 141

6.3 Observation Data 143

6.3.1 Setting and communicative events 143

6.3.1.1 In the office 144

6.3.1.2 In the workshop and garage, on the production line and construction site. 144

6.3.1.3 Daily supervision tasks. 145

6.3.2 Work related English language skills observed being used by the managers and supervisors...

6.3.2.1 Work related English language listening and speaking skills 148

6.3.2.2 Work related English reading and writing skills 148

6.3.3 Work related English language skills observed being used by the mechanical engineers

6.3.3.1 Work related English language listening and speaking skills 149

6.3.3.1.1 Listening to the manager's requests, questions and instructions 149

6.3.3.1.2 Listening to presentations and discussions in meetings 150

6.3.3.2 Other work related communicative events that required English speaking skills .. 158

6.3.3.2.1 Safety talks 158

6.3.3.2.2 Talking about everyday tasks and duties. 158

6.3.3.2.3 Other communicative events that required speaking skills 159 
6.3.3.3 Work related English language reading and writing skills ................................... 159

6.3.3.3.1 Reading memos, notices and work schedules on the notice board................. 159

6.3.3.3.2 Reading product specifications and descriptions.......................................... 160

6.3.3.3.3 Other communicative events requiring reading skills ................................... 160

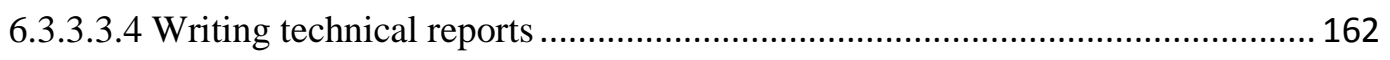

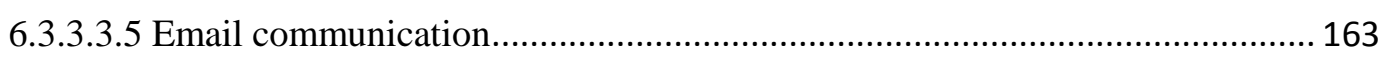

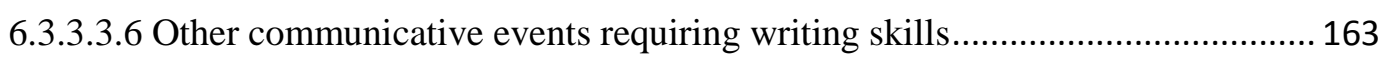

6.3.4 Successful interactive uses of English observed and adaptive communicative events . 164

6.3.4.1 Successful interactive uses of English observed ................................................... 164

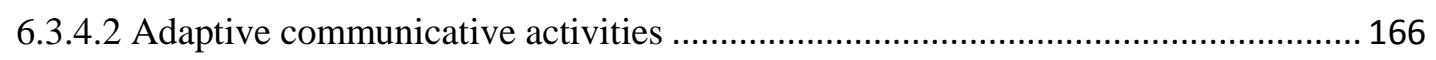

6.3.5 List of technical words, technical word phrases and academic words observed being used

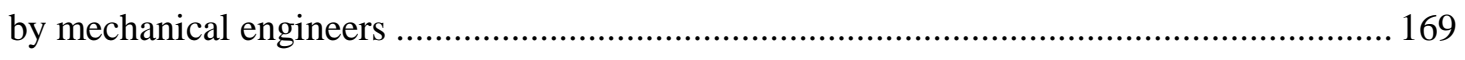

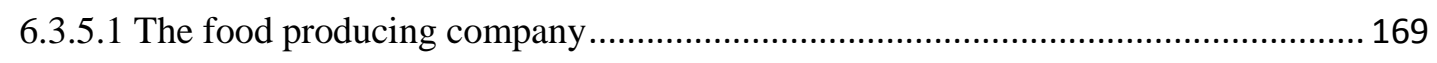

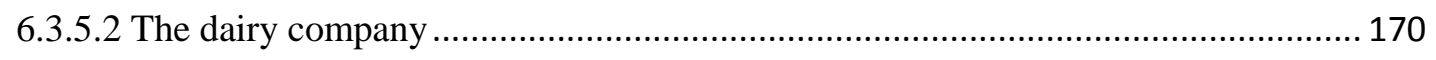

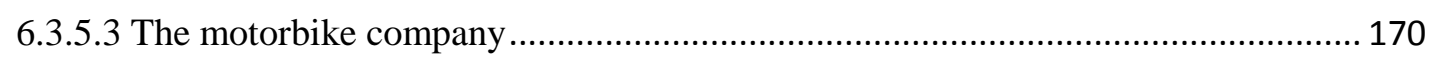

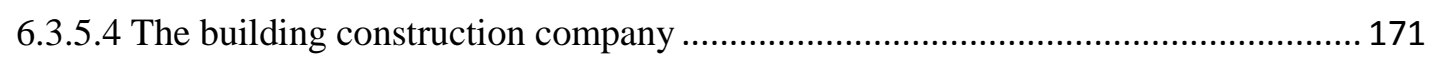

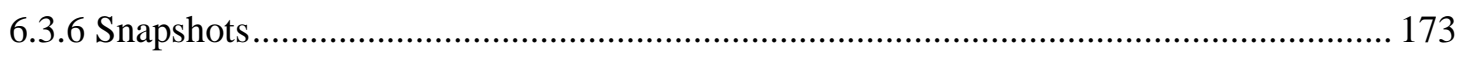

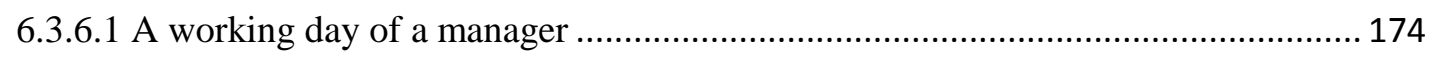

6.3.6.2 Snapshot: Overview of the day for the manager ................................................. 175

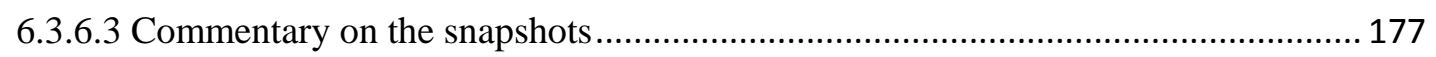

6.3.6.4 A working day of a mechanical engineer ............................................................. 178

6.3.6.5 Snapshot: Overview of the day for the mechanical engineer as a narrative ............ 180

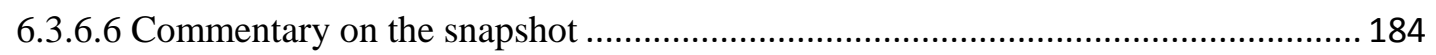

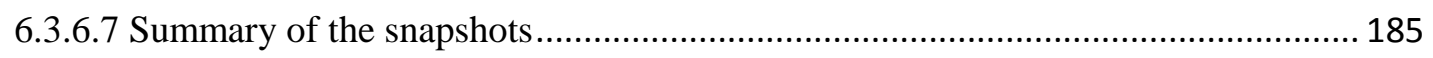

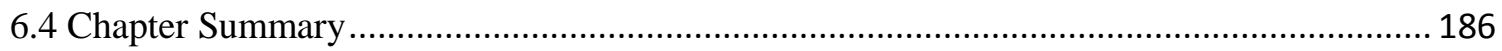

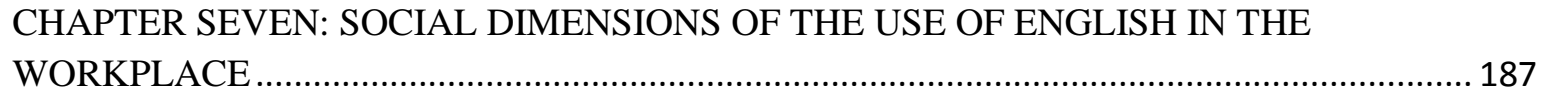

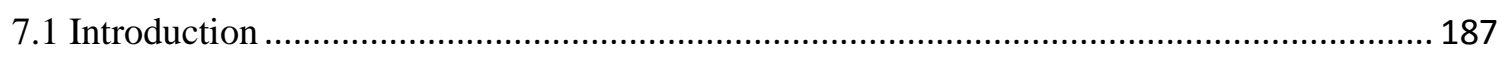

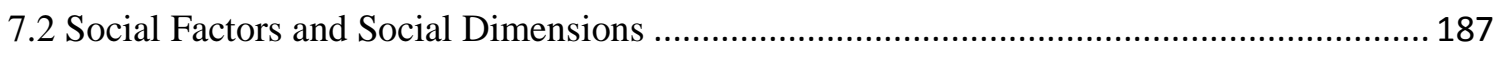

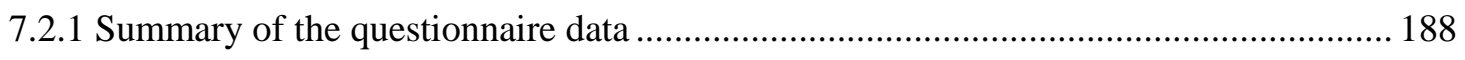

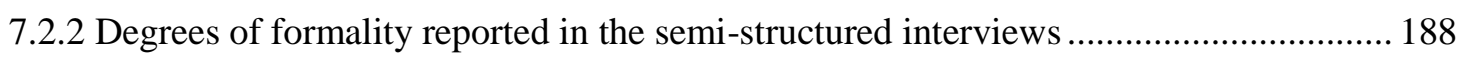

7.2.2.1 The use of formal and standard written English.................................................. 189

7.2.2.2 Simplifying the use of English ......................................................................... 190

7.2.2.3 Showing politeness, formality and informality .................................................. 190

7.2.2.4 The potential for misunderstanding caused by limited English ............................. 193

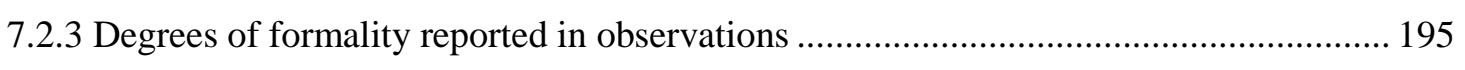

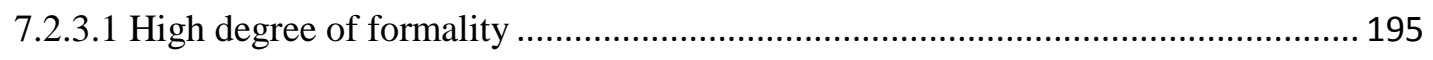


7.2.3.2 Low degree of formality. 196

7.2.4 Humour in the workplace, informality and high solidarity ......................................... 197

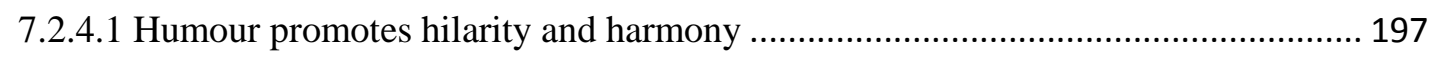

7.2.4.2 Understanding each other well results in low formality and high solidarity.......... 198

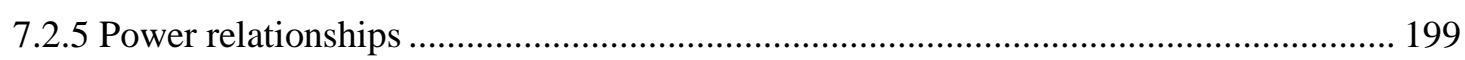

7.3 Communication Issues and Their Consequences ............................................................. 201

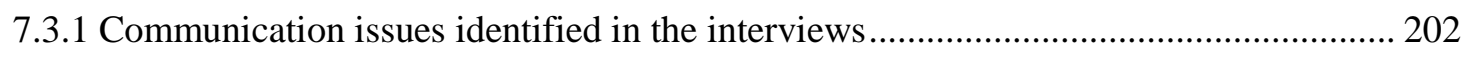

7.3.2 Communication issues and underlying power relationships identified in the observations

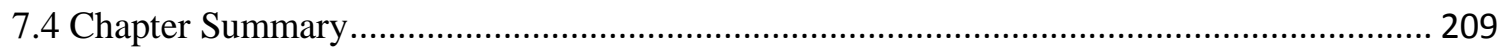

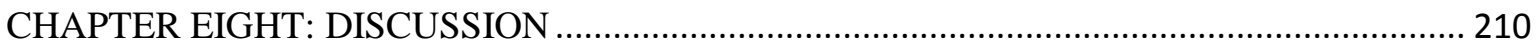

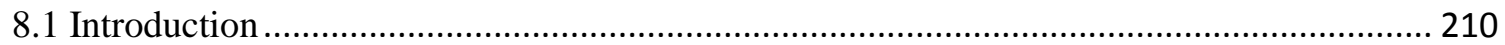

8.2 Summary of Key Needs Analysis Findings in Relation to Research Literature .................. 212

8.3 The Demand for English Courses for Specific Purposes ..................................................... 216

8.4 The Underlying Power and Social Relationships in the Workplaces.................................. 217

8.4.1 English language knowledge is a source of power in the 'poor English' workplace.... 218

8.4.2 Communication issues, losing face and low solidarity relationships ........................... 220

8.4.3 Avoiding communication issues: adaptive strategies, saving face and high solidarity. 223

8.4.4 Humour and the high solidarity relationship in the lingua franca workplace ............... 226

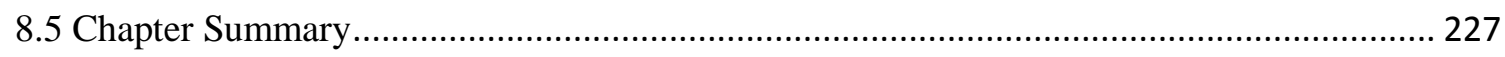

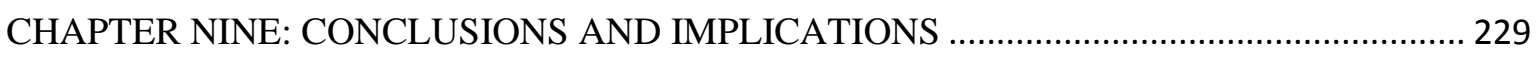

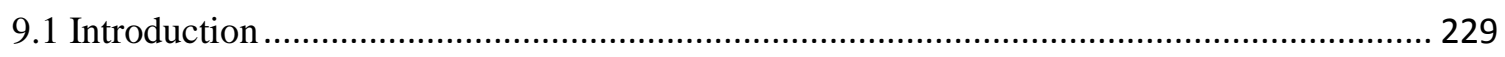

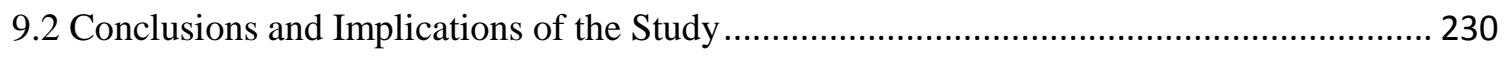

9.3 What are the implications of these recommendations for the language teacher of vocational

English in Vietnam?.

9.3.1 Preparing people strategically to cope with the communication demands of the lingua franca and plurilingual workplace

9.3.2 Articulating the balance between technical communication and social communication

9.3.3 Mobilizing plurilingual repertoires in the workplace................................................ 237

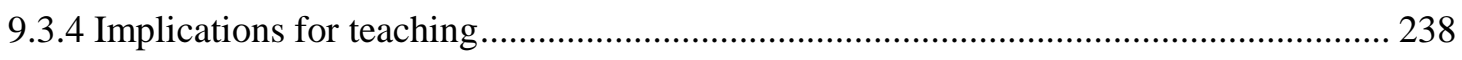

9.4 Limitations of the Study and Suggestions for Further Research....................................... 240

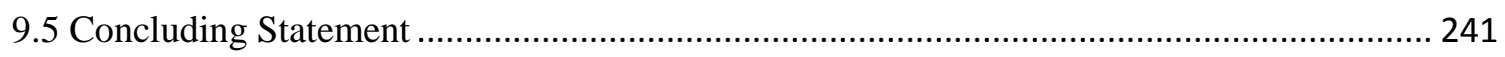

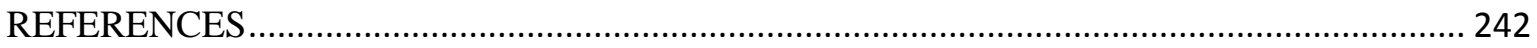

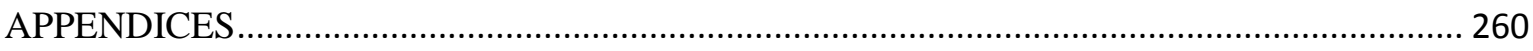

Appendix A: Needs analysis questionnaire for employers and managers of mechanical engineers 
Appendix B: Needs analysis questionnaire for mechanical engineers

Appendix C: Interview schedule for employers and managers of mechanical engineers .....

Appendix D: Interview schedule for mechanical engineers ........................................ 270

Appendix E: Observational protocol: Field notes and checklist .................................... 271

Appendix F: Letter of invitation for the director of the selected company/factory ..................272

Appendix G: Consent form for directors of the selected companies..................................... 275

Appendix H: Information sheet for employers and managers of mechanical engineers and mechanical engineers

Appendix I: Questionnaire consent form for employers and managers of mechanical engineers and mechanical engineers.

Appendix J: Interview consent form for employers and managers of mechanical engineers and mechanical engineers

Appendix K: Observation consent form for managers of mechanical engineers and mechanical engineers.

Appendix L: Transcriber and translator's confidentiality agreement.

Appendix M: Sample of data coding process. 


\section{LIST OF FIGURES}

Figure 1: The development of approaches to needs analysis

Figure 2: Framing a multi-perspectived and interdiscursive research agenda (adopted from Candlin

and Crichton (2011))

Figure 3: Methodological approaches to workplace communication.............................................. 33

Figure 4: A conceptual framework for investigating learner needs ............................................... 34

Figure 5: Scope of needs analysis ..................................................................................... 72

Figure 6: Mixed methods sequential explanatory design procedures (adapted from Ivankova and

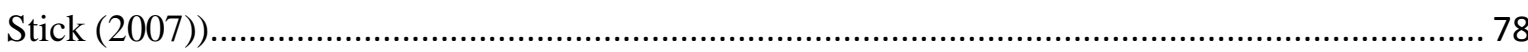

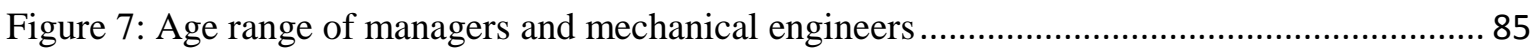

Figure 8: Work experience of managers and mechanical engineers ............................................ 85

Figure 9: Participants' perception of the frequency of English use of mechanical engineers........ 104

Figure 10: Managers' perceptions about the kind of English their mechanical engineers

communicated with them (the 'boss'), their colleagues, and clients and business partners........... 116

Figure 11: Mechanical engineers' perceptions about the type of English they used with their 'boss',

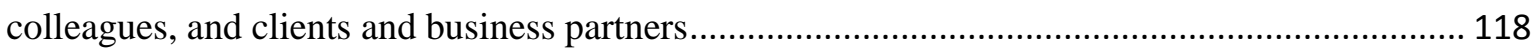

Figure 12: Managers' perception about the importance for mechanical engineers to adapt the workplace use of English for someone of higher/lower status

Figure 13: Mechanical engineers' perception about the importance of adapting their workplace use

of English for someone of higher/lower status. 


\section{LIST OF TABLES}

Table 1: The four stages of needs analysis developments (West, 1994) ......................................... 19

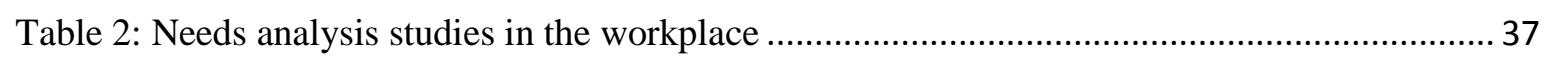

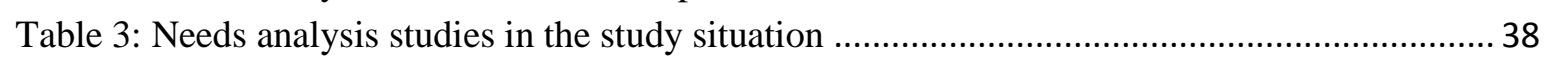

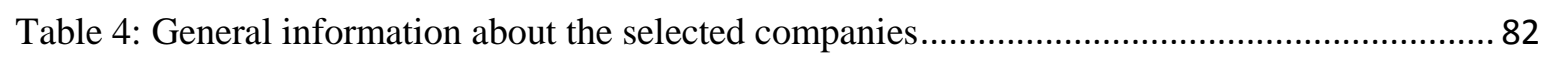

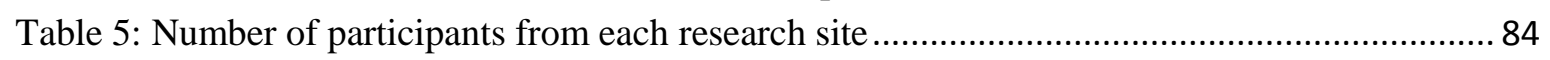

Table 6: Reliability statistics of the questionnaire for managers................................................. 90

Table 7: Reliability statistics of the questionnaire for mechanical engineers ................................. 90

Table 8: Identification of participants in the study .................................................................... 93

Table 9: Threats to the validity of the quantitative data and mitigation of these threats................. 98

Table 10: Threats to the validity of the qualitative data and mitigation of these threats (adapted

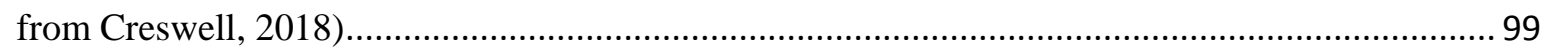

Table 11: Number of questionnaire participants from each research site ................................... 103

Table 12: The frequency of communicative events adapted from Kaewpet (2008) as perceived by

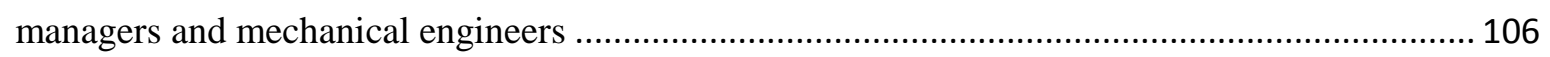

Table 13: Managers' perceptions about the frequency of communicative events that their mechanical engineers were likely to be engaged in ................................................................ 108

Table 14: Mechanical engineers' perceptions about the frequency of communicative events that

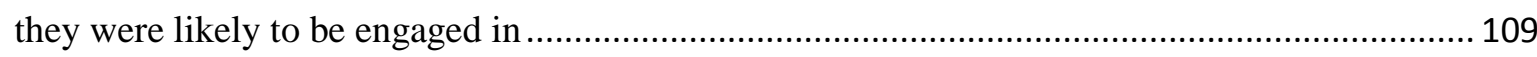

Table 15: Question 27 - The frequency of the English language skills perceived by the managers

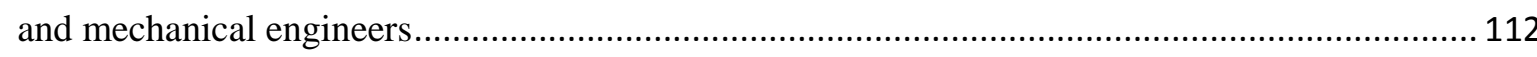

Table 16: Question 28 - The most lacking English language skills perceived by the managers and

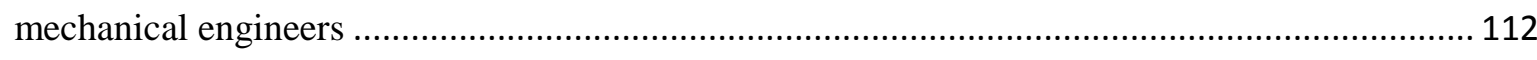

Table 17: Number of interview participants from each research site .......................................... 128

Table 18: Observed and reported communicative events and the required English language skills in

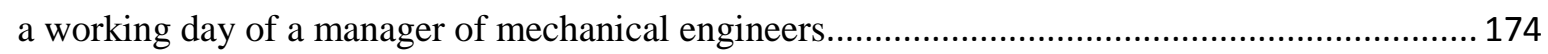

Table 19: Observed and reported communicative events, formality and relationship in a working day of the manager of mechanical engineers ........................................................................... 177 Table 20: Observed and reported communicative events and the required English language skills in a working day of the mechanical engineer..... 179

Table 21: Observed and reported communicative events, formality and code sharing in a working day of the mechanical engineer 183 


\section{ABBREVIATIONS}

ASEAN: Association of Southeast Asian Nations

AWL: $\quad$ Academic Word List

CDA: Critical Discourse Analysis

CEFR: Common European Framework of Reference

CEF: $\quad$ Common European Framework

CNP: $\quad$ Communication Needs Processor

DM: $\quad$ Deputy manager

EAP: $\quad$ English for Academic Purposes

EBE: $\quad$ English for Business and Economics

EFL: $\quad$ English as a Foreign Language

ELF: $\quad$ English as a lingua franca

ESP: $\quad$ English for Specific Purposes

EOP: $\quad$ English for Occupational Purposes

EST: $\quad$ English for Science and Technology

IELTS: International English Language Testing System

IT: Information Technology

LWP: Language in the Workplace Project

L1: $\quad$ First language

ME: $\quad$ Mechanical engineer

MOET: $\quad$ Ministry of Education and Training

NA: $\quad$ Needs Analysis

TBLT: $\quad$ Task-Based Language Teaching

TOEFL: $\quad$ Test of English as a Foreign Language

TOEIC: $\quad$ Test of English for International Communication

TPP: $\quad$ Trans-Pacific Partnership

VAMI: $\quad$ Vietnam Association of Mechanical Industry 


\section{GLOSSARY}

\begin{tabular}{|c|c|}
\hline Accent & $\begin{array}{l}\text { Refers to merely to features of pronunciation which is included in } \\
\text { dialect (Finch, 2005). }\end{array}$ \\
\hline Broken English & $\begin{array}{l}\text { Refers to anything from speech with frequent pauses to } \\
\text { incomprehensible or very low-proficiency speech (Linderman, } \\
\text { 2005) }\end{array}$ \\
\hline $\begin{array}{l}\text { Communication } \\
\text { issue }\end{array}$ & $\begin{array}{l}\text { Refers to failure in exchanging information or lack of } \\
\text { communication (Hanks \& McLeod, 1986). Miscommunication in } \\
\text { this study are described as communication issues or problems that } \\
\text { prevent the speakers understanding and being understood. }\end{array}$ \\
\hline Code-switching & $\begin{array}{l}\text { Refers to second language users reverting to talking between } \\
\text { themselves in their native language (Harzing et al., 2011). Code- } \\
\text { switching in this study refers to Vietnamese employees who revert } \\
\text { to taking in Vietnamese between themselves when they have } \\
\text { difficulties in talking in English with their foreign managers. }\end{array}$ \\
\hline $\begin{array}{l}\text { Common } \\
\text { European } \\
\text { Framework } \\
\text { (CEF) } \\
\text { Professional } \\
\text { Profile }\end{array}$ & $\begin{array}{l}\text { A needs analysis model proposed by Huhta, Vogt, Johnson, Tulkki, } \\
\text { and Hall (2013) which consists of six parts in order to examine the } \\
\text { communication needs of a particular group of participants in a } \\
\text { holistic way. This framework was used to draw on the data analysis } \\
\text { in the current study. }\end{array}$ \\
\hline $\begin{array}{l}\text { Common } \\
\text { European } \\
\text { Framework of } \\
\text { Reference for } \\
\text { Languages } \\
\text { (CEFR) }\end{array}$ & $\begin{array}{l}\text { This is a framework that "provides a common basis for the } \\
\text { elaboration of language syllabuses, curriculum guidelines, } \\
\text { examinations, textbooks, etc. across Europe. It describes in a } \\
\text { comprehensive way what language learners have to learn to do in } \\
\text { order to use a language for communication and what knowledge and } \\
\text { skills they have to develop so as to be able to act effectively" } \\
\text { (Council of Europe, 2001, p. 1). The framework defines six levels } \\
\text { of language proficiency (A1, A2, B1, B2, C1, C2) which were used } \\
\text { in this study to refer to the English proficiency of the participants. } \\
\text { For example, very basic English or limited English ability was equal } \\
\text { to A1 level in the framework and similarly equal to Level One in } \\
\text { the six levels framework of reference for language for Vietnam. }\end{array}$ \\
\hline $\begin{array}{l}\text { Communicative } \\
\text { event }\end{array}$ & $\begin{array}{l}\text { Refers to situations in which the participants use English to } \\
\text { communicate (Munby, 1978). In this study, communicative event is } \\
\text { described as a situation in which the participants combine both } \\
\text { verbal and non-verbal interaction to communicate. }\end{array}$ \\
\hline $\begin{array}{l}\text { Communicative } \\
\text { key }\end{array}$ & $\begin{array}{l}\text { Refers to the manner of the participant in communication. In this } \\
\text { study, communicative key is described in the degree of formality } \\
\text { (formal and informal), solidarity and power relationship. }\end{array}$ \\
\hline $\begin{array}{l}\text { Communicative } \\
\text { Needs Processor } \\
(\text { CNP) }\end{array}$ & $\begin{array}{l}\text { A needs analysis model proposed by Munby (1978) which consists } \\
\text { of eight sociolinguistic parameters to examine communication } \\
\text { needs to build a profile of communication needs for a particular } \\
\text { group of participants. This framework contributed to the design of } \\
\text { the current study. }\end{array}$ \\
\hline Dialect & $\begin{array}{l}\text { Refers to the variety of English (Munby, 1978). In this study dialect } \\
\text { refers to a language variety with distinct syntactic forms and } \\
\text { vocabulary items that are geographically based (Finch, 2005). }\end{array}$ \\
\hline $\begin{array}{l}\text { English for } \\
\text { specific purposes }\end{array}$ & $\begin{array}{l}\text { A focus on English that is learned and taught for particular } \\
\text { purposes, such as electronics or mechanical engineering (Huhta, et } \\
\text { al., 2013). }\end{array}$ \\
\hline
\end{tabular}




\begin{tabular}{|c|c|}
\hline Face & Refers to a person's positive self-image. \\
\hline $\begin{array}{l}\text { Face-threatening } \\
\text { act }\end{array}$ & $\begin{array}{l}\text { A speech act which can potentially damage the face of the speaker } \\
\text { of addressee. }\end{array}$ \\
\hline Instrumentality & $\begin{array}{l}\text { Refers to the medium, mode, and channel of communication } \\
\text { (Munby, 1978). }\end{array}$ \\
\hline Plurilingualism & $\begin{array}{l}\text { Refers to the competences in a number of languages that individuals } \\
\text { develop from desire or necessity to meet the need to communicate } \\
\text { with others (Coste, Moore, \& Zarate, 2009). }\end{array}$ \\
\hline Multilingual & $\begin{array}{l}\text { A person able to speak more than one language, or the situation in } \\
\text { which speakers can or do speak more than one language. }\end{array}$ \\
\hline Needs analysis & $\begin{array}{l}\text { The formal process of establishing the particular (language or } \\
\text { language learning) requirement of a particular target group (Huhta } \\
\text { et al., 2013). }\end{array}$ \\
\hline $\begin{array}{l}\text { Plurilingual and } \\
\text { pluricultural } \\
\text { competence }\end{array}$ & $\begin{array}{l}\text { Refers to "the ability to use languages for the purposes of } \\
\text { communication and to take part in intercultural interaction, where a } \\
\text { person, viewed as a social agent has proficiency, of varying degrees, } \\
\text { in several languages and experience of several cultures." (Council } \\
\text { of Europe, 2001, p. 168). }\end{array}$ \\
\hline Power & $\begin{array}{l}\text { Refers to the ability to control the actions of one's self and others } \\
\text { (Holmes \& Stubbe, 2015). Power in this study refers to the language } \\
\text { ability that helps a person to have more power than his / her actual } \\
\text { position in an organisation. This is known as "expert power". }\end{array}$ \\
\hline Positive face & $\begin{array}{l}\text { In Politeness Theory, the want of every member that his wants be } \\
\text { desirable to at least some others (Brown \& Levinson, 1987) }\end{array}$ \\
\hline Purposive domain & $\begin{array}{l}\text { Refers to the occupational or educational purpose for which the } \\
\text { target language is required (Munby, 1978). }\end{array}$ \\
\hline Setting & $\begin{array}{l}\text { Refers to both physical and psychosocial setting (Munby, 1978). } \\
\text { Setting in this study refer to the time, place and a description of a } \\
\text { particular communicative event. }\end{array}$ \\
\hline Social distance & $\begin{array}{l}\text { Refers to a means of evaluating the relationship between two people } \\
\text { based on affect, solidarity, and familiarity (Wardhaugh \& Fuller, } \\
\text { 2015). }\end{array}$ \\
\hline Solidarity & $\begin{array}{l}\text { Refers to a common bond between individuals, usually associated } \\
\text { with identification with the same social group (Wardhaugh \& } \\
\text { Fuller, 2015). }\end{array}$ \\
\hline Snapshot & $\begin{array}{l}\text { Is one of the categories in the CEF needs analysis model to provide } \\
\text { a narrative description of a working day of the participants. }\end{array}$ \\
\hline $\begin{array}{l}\text { Standard } \\
\text { language }\end{array}$ & $\begin{array}{l}\text { Refers to a dialect of a language which is considered superior to } \\
\text { other dialects (Wardhaugh \& Fuller, 2015). }\end{array}$ \\
\hline Target level & $\begin{array}{l}\text { Refers to the required English ability to perform a communicative } \\
\text { event. }\end{array}$ \\
\hline $\begin{array}{l}\text { Workplace } \\
\text { discourse }\end{array}$ & $\begin{array}{l}\text { Refers to interactions occurring across a wide range of occupational } \\
\text { settings such as factories, offices, hospitals, governments, the } \\
\text { private sector and non-profit organisations (Koester, 2010). In this } \\
\text { study, workplace discourse refers to interactions that include } \\
\text { company meetings, group meetings, office talk, construction site } \\
\text { communication and contract bidding ceremonies. }\end{array}$ \\
\hline
\end{tabular}





\section{CHAPTER ONE: INTRODUCTION}

\subsection{Introduction to the Study}

This mixed method needs analysis study examined the real-world English communication needs of Vietnamese mechanical engineers in the workplace. The primary aim of the study was to inform curriculum design for teachers and students by seeking insight into the complexity of today's plurilingual and pluricultural workplaces where English is used as a lingua franca.

\subsubsection{The social and political environment of Vietnam}

To understand the rise of plurilingual and pluricultural worksites in Vietnam, it is necessary to describe the position of Vietnam in the development of internationalisation and regional politics. Vietnam has opened its doors to the outside world in 1986 and has been a member of the Association of Southeast Asian Nations (ASEAN) since 1995, a member of World Trade Organisation (WTO) since 2007, and recently became a member of the TransPacific Partnership Agreement (TPP) in January 2018. English has become the lingua franca among ASEAN countries and has been adopted to be the official working language of the Association since 2009 (Kirkpatrick, 2010). This adoption has important implications for policy and language education (Kirkpatrick, 2012). The English language in Vietnam belongs to the English language use of 'expanding circle' countries together with Cambodia, Laos, Indonesia and Thailand, based on Kachru's Three-circle Model (Kachru 1985: cited in Kirkpatrick 2012). Kirkpatrick (2012) argues that "it is no longer only used in English as an EFL context, but rather as a major medium of communication or lingua franca between the countries" (p. 336). This development aligns with communication trends of the world. Piccardo (2013) claims that "language proficiency is no longer seen as a monolithic phenomenon that occurs independently of the linguistic repertoires and trajectories of learners and teachers, but rather shaped by uneven and ever-changing competences, both linguistic and cultural" (p. 600). The notion of 'plurilingualism' is now considered of importance in language learning (Council of Europe, 2001) and the idea of plurilingualism arose as a result of over 20 years of research in the multilingual realities of European local communities and societies. The concept of plurilingualism has opened up new perspectives in language education (Piccardo, 2013). English language connects to internationalism and globalisation.

Interacting through English in the multinational companies in Vietnam, in which people from different countries work, has become a reality as Vietnam was opened to 
international investment and trade. Many of these people are non-native speakers of English who may not speak Vietnamese. For this reason English has become the language of communication at work between them and with the local people. When people speak English (as a lingua franca) which is not their mother tongue for the practical purpose of 'getting things done', they may have to become more tolerant of mistakes (Aichhorn \& Puck, 2017) because they may be working in what may be described as a 'poor English' workplace (Govindarajan \& Gupta, 2001). The plurilingual and pluricultural environment requires English users in the workplace to have the ability to deal with different languages and to effectively use appropriate language strategies to conduct communication (Aichhorn \& Puck, 2017). Anh (2010) states that the demand for employees with a good command of English in Vietnam has increased as a result of international integration.

Vietnam is becoming an active member of these international and regional organisations and this has brought numerous opportunities to Vietnamese enterprises and the Vietnamese people for economic development and employment, but it has also brought a demand for proficiency in the English language, especially for engineering graduates. The target of the Vietnamese government is to become a fully developed industrial country by 2020. Mechanical engineering plays a very important role in the country's industrialisation and modernisation process (Chung, 2014). In 2002, the Vietnamese Prime Minister issued Decision number 186/2002/QĐ-TTg, which approved the development strategies for the mechanical engineering industry to the year 2010 and the vision to 2020. According to the Investment and Trade Promotion Centre of Ho Chi Minh City, Vietnam was striving to produce goods to meet 40-50 percent of the national demand and to export 30 percent of the total output, but these goals were determined to be unreachable in practice (Investment \& Trade Promotion Centre, n.d.). Despite this, the mechanical engineering market in Vietnam has a huge potential for growth and attracts considerable foreign investment. This leads to an urgent need to find out the types of English that engineers require and how these types of English are used in various workplace contexts and also to explore the social contexts and social uses of English in these contexts.

There are about 1,700 mechanical engineering enterprises throughout Vietnam. Of these, 393 are state-owned, over 100 enterprises are privately owned, 127 are foreign investments, and about 1000 are mechanical collective units. Beside these, it is estimated that there are 29,000 informal machining establishments and workshops. The total workforce of these mechanical enterprises is about 253,000 people (Investment \& Trade Promotion Centre, n.d.). 
The Vietnam Association of Mechanical Industry (VAMI) was founded in 2002 as an association for mechanical engineering enterprises throughout the country. VAMI's role is strengthening mechanical engineering in Vietnam. It now has more than 200 members. The actual number of engineering enterprises is much higher. In her newspaper article about the Vietnamese mechanical engineering enterprises, Phuong (2014) reports that the mechanical engineering of Vietnam is a few centuries more outdated than the mechanical engineering industry in the rest of the world. At the moment, much of the mechanical engineering market in Vietnam belongs to foreign enterprises, while local enterprises function as sub-contractors. Vietnamese mechanical firms often fail in bidding for such big contracts as national projects and factory buildings. One reason is the level of engineers' educational qualifications. In another newspaper article about mechanical engineering in Vietnam, Hung (2006) reports a claim made by the former chairman of VAMI, Nguyen Xuan Chuan, that the mechanical engineering field requires its workers to have high educational qualifications. However, only $19 \%$ of workers hold vocational training qualifications in Vietnam while those who have a university bachelor degree or postgraduate degree constitute only $15 \%$ of the total workforce in the field. Therefore the mechanical engineering field of Vietnam requires considerable time and effort to overcome the pressure of competition when integrating with the world marketplace.

In an article about the unemployment of graduates, Thanh (2016) reviewed the statistics of the Ministry of Labour, War Invalids, and Social Welfare, indicating that over 200,000 people with bachelor and postgraduate degrees were unemployed in Vietnam in 2015 , constituting $20 \%$ of the total of unemployed people. Thanh reports that, according to experts in the field, one of the reasons was that tertiary institutions were training majors in the subjects they offered, but these qualifications were not what society actually required for the workforce. Thus, what graduates have been trained and prepared for does not meet the needs of the employers.

Thanh (2006) reported a speech made the director of the Hanoi Centre for Job Service, Mrs. Nguyen Thi Ngoc Trinh, that the training quality of some colleges and universities is not good, with a low proportion of practical lessons, and a lack of the development of soft skills such as foreign languages, group work, and communication. This has resulted in graduates encountering difficulties when applying for jobs (Singh \& Singh, 2008).

The government has been applying different policies and solutions to support the development of mechanical engineering. These include policies on marketing, capital, taxes, research and development, and personnel training (MOIT, 2002). The government prioritises 
upgrading mechanical engineering training institutions to improve personnel training, as well as sponsoring and sending qualified staff and technicians to study and practise overseas (MOIT, 2002).

In this era of integration and internationalisation, with much of the mechanical engineering market belonging to foreign enterprises and many enterprises having joint venture ownership, the requirement for high-quality mechanical engineering graduates is urgent. This includes a need for graduates who possess a sufficient level of English language proficiency, especially those who have the communicative competence, to function in different languages and cultures (Coste et al., 2009). They need in other words a better understanding of today's plurilingual and pluricultural workplaces.

The concept of plurilingual and pluricultural competence arose in Europe and "refers to the ability to use languages for the purposes of communication and to take part in intercultural interaction, where a person, viewed as a social agent has proficiency, of varying degrees, in several languages and experience of several cultures" (Council of Europe, 2001, p. 168). This competence enables the language users to switch codes during a conversation. They can choose bilingual forms of speech, and use a kind of repertoire of language varieties which allows them to choose the appropriate linguistic variation in a specific circumstance (Coste et al., 2009). The aims of the language education policy of the Council of Europe include the promotion of plurilingualism, in order to "strengthen linguistic diversity and language rights, deepen mutual understanding, consolidate democratic citizenship and sustain social cohesion" (Council of Europe, 2006, p. 4). These aims meet the changing needs and priorities of member states within Europe. The CEFR developed to help professionals overcome the barriers to communication in the field of modern languages (Council of Europe, 2001). This framework gained its popularity in the field of language teaching and learning because,

it provides the means for educational administrators, course designers, teachers, teacher trainers, examining bodies, etc., to reflect on their current practice, with a view to situating and co-ordinating their efforts and to ensuring that they meet the real needs of the learners for whom they are responsible (Council of Europe, 2001, p. 1).

Plurilingual education is essential because it promotes:

- an awareness of why and how one learns the language one has chosen

- an awareness of and the ability to use transferable skills in language learning

- a respect for the plurilingualism of others and the value of languages and varieties irrespective of their perceived status in society

- a respect for the cultures embodied in languages and the cultural identities of others 
- an ability to perceive and mediate the relationships which exist among languages and cultures

- a global integrated approach to language education in the curriculum

(Council of Europe, 2006, p. 5).

In the context of globalisation, individuals have to develop their plurilingual and pluricultural competence and this development should be included in the policies of the language education because plurilingual and pluricultural competence can promote the emergence of linguistic awareness which helps language users to negotiate tasks involving linguistic dimensions. This competence also helps language users to refine the knowledge they learn and how to learn, and the ability to build relations with others and to handle new situations (Coste et al., 2009). That explains why "communication studies take a more holistic approach toward competence compared to the characterizations of competence in linguistically oriented studies" (Louhiala-Salminen \& Kankaanranta, 2011, p. 247). This holistic approach emphasises the context of communication which is a key feature in the work of Huhta, Vogt, Johnson, Tulkki, and Hall (2013) in the development of their approach to needs analysis and has become the main focus in the CEFR of the Council of Europe. Thus, language education should emphasise not only linguistic competence (i.e., how to use a language) but also communicative competence (i.e., knowledge about how to perform one's language knowledge suitably) (Spitzberg \& Cupach 1984: cited in Louhiala-Salminen \& Kankaanranta 2011). A thorough needs analysis study conducted in the real-world workplace to examine what mechanical engineers actually need in terms of English communication for the sake of their job could be helpful.

\subsubsection{The development of needs analysis frameworks}

Needs analysis has long been considered to be of crucial importance not only in English for Specific Purposes (ESP), but also in general English courses. For example, in their seminal study of English for specific purposes, Hutchinson and Waters (1987) claim that any English course should be based on an analysis of learners' needs. Needs analysis has also been considered a prerequisite for planning and developing courses, and the development of syllabuses and materials as well (Brown, 1995; Dudley-Evan \& St John, 1998; Hutchinson \& Waters, 1987; Jordan, 1997; Long, 2005b).

This study was first designed based on a seminal work needs analysis framework developed by Munby (1978) namely the Communication Needs Processor (CNP). The strengths of this framework is the various sociolinguistic variables which ask questions about the target language use of the participants so that the real-world communicative needs and 
the requirements of the learners can be identified. The model also looks at the complexity of workplace communication and reveals rich information about the context of language use.

During the process of this doctoral study which started in 2012, needs analysis frameworks took a more holistic turn. After the data collection process, a more holistic model of needs analysis namely the Common European Framework (CEF) Professional Profile proposed by Huhta et al. (2013) was published. The data analysis of the current study then also drew on this new model. The strengths of this framework are the holistic approach that takes different contextual factors into account. CEF recommends collecting both quantitative and qualitative data and carefully links these data to the language proficiency level described in the Common European Framework of Reference for Languages (CEFR) (Hadley, 2014). This model views language use in a holistic way which closely relates its use to context, including the use of a 'snaphot' to give an overview of language use in a day for pedagogical purposes. The snapshot sets the scene for language design and it shows how language tasks are related to the context of what happens in a day.

One of the aims of the CEFR is to prepare plurilingual and pluricultural competence for language users for the sake of intercommunication and interaction between the peoples of Europe. According to Council of Europe (2006), a plurilingual person is the one who has "a repertoire of language and language varieties and competence of different kinds and levels within the repertoire" (p. 5).

The Ministry of Education and Training (MOET) has developed a Six Level Framework of Reference for Language for Vietnam based on the CEFR (MOET, 2014). This model is applied to foreign language training programmes, in foreign language training institutions and foreign language learners in the national education system. The six levels from Level One to Level Six are equal to $\mathrm{A} 1$ to $\mathrm{C} 2$ in the CEFR. There is a general functional description of each level. For example, people who are at Level One can understand and use simple daily sentence structures and basic words to meet the demand for specific communication needs. They can also introduce themselves and others, can answers questions about the place where they live and about relatives and friends. They can produce basic communication if the speaker speaks slowly and clearly as well as is willing to cooperate. Then each level is described in terms of language skills (listening, speaking, reading and writing). The framework also takes the social aspects of language use into consideration as one of the purposes of the framework is to facilitate Vietnamese people to cooperate and exchange education, certify qualifications and certificates with countries that use the CEFR.

The analysis of the data was also informed by the Language in the Workplace Project (LWP) (Holmes, 2000) and drew on the approach and way of examining the social 
dimensions of the use of English in the workplace used in this study such as its closer examination of meetings, power and solidarity relationships, and humour.

By combining the two models of needs analysis (CNP and CEF) and being supported by LWP, a picture of English communication needs of professional mechanical engineers was identified in which communicative events were central. Communication within the system of a workplace seen through communicative events, together with the social characteristics of workplace language use, can provide useful information about language use which can then be examined in terms of its pedagogical implications .

\subsection{English language education in Vietnam}

English has been identified as one of the most important foreign languages in Vietnam since 1986. However, the teaching and learning of this language have always been a concern of policymakers, curriculum designers as well as teachers and students. According to Hoang (2010), the history of English language education in Vietnam can be divided into two periods: before 1986, and from 1986 till now. The former can be further divided into three periods, namely English in Vietnam before 1954, from 1954 to 1975, and from 1975 to 1986. The latter is the period of the English language boom when this language became "the first (and nearly the only) foreign language to be taught in Vietnam" (Hoang, 2010, p. 9), the most important and popular foreign language (Anh, 2010; Canh, 2011; Ha, 2004).

English has been a compulsory subject at the upper-secondary level since 1982 and then at the lower secondary level since 2001. It is also an elective subject at primary level (years 3-5). In total, students study English for 805 periods (a period is a 45-minute lesson in the classroom) of English in the whole Vietnamese formal general education system (Hoang, 2010).

At the tertiary level, English plays a very important role (Huong \& Hiep, 2010) and it is studied nationally both as a discipline and as a subject (Hoang, 2010). The former refers to English major students who study English to get their bachelor, masters and doctorate degrees in English. The latter refers to non-English major students who have to study 240 hours of general English and 60 to 90 hours of English for Specific Purposes (ESP) as determined by the Ministry of Education and Training (MOET) (Tien, 2013).

However, despite several years' study at these levels, Vietnamese students' English ability remains limited (Anh, 2010; Canh, 2011; Huong, 2015; Loi, 2011; Tien, 2013), especially their communicative competence. According to Anh (2010), "the communicative competence in English of the Vietnamese workforce has not met the requirements of the employers" (p. 119). This, as Canh (2011) points out, is a result of "an unsystematized 
patchwork with a lack of an effective secondary-through-university pipeline" (p. 21). For Hiep (2005), this problem results from a traditional pedagogy which emphasises the acquisition of vocabulary and grammar rather than communicative competence. It is for these reasons that the teaching and learning of English in Vietnam have been the interest of many teachers, educators and researchers.

In 2008, the Vietnamese Prime Minister issued Decision number 1400/ QĐ-TTg on Approving the 10-year National Plan for "Teaching and Learning Foreign languages in the National Formal Educational System in the period of 2008-2020". The general objective of this project is that by the year 2020 almost all Vietnamese young people who graduate from colleges and universities can use foreign languages independently, be confident in communication, study and work in a plurilingual and pluricultural environment and that foreign languages will be an advantage to Vietnamese people.

In a very recent conference on orienting strategies in teaching and learning foreign languages in the period 2016 to 2020, the Minister of the Ministry of Education and Training said that the teaching and learning of foreign languages, especially English should be put in the context of integrating with the region and the world, especially when Vietnam joins the TPP and ASEAN economic community (Hanh, 2016).

\subsection{English for specific purposes in Vietnam}

English for specific purposes (ESP) has long been the research interest of many researchers and scholars in the world. Hoai and Binh (2016) claim that ESP was introduced in Vietnam in the 1990s and it is gaining in popularity. According to Duyen (2014), ESP teaching in Vietnam is still in its early stage, and ESP courses are mostly being delivered by teachers of English who are not trained to teach this specific discipline. There are, in fact, no official documents about the date when ESP was first introduced at the tertiary level in Vietnam.

The only document which mentions ESP was issued by the MOET on 22 December 2009 and is the training framework for engineering majors at the undergraduate level (MOET, 2009). There are a total of 16 engineering majors such as mechanical engineering, manufacturing engineering, and electronic engineering. According to this framework, students have to study 150 credits in five years. There are two sets of knowledge, namely elective subjects and compulsory subjects, and foreign language training belongs to the latter set. General foreign language education constitutes six credits out of 150 in total. Of the total 16 majors, only three majors, namely engineering mechanics, petrochemical engineering, and multimedia and communication engineering, specify ESP in their training programmes. 
The ESP training credits are taken from the credits determined for general foreign language training. These specified contact hours for an ESP course are very limited for students to master the knowledge, contents, and skills in the course.

The training framework also instructs institutions to design their own training curriculum for each major. Thus English training programmes vary among institutions. Some leading engineering universities, such as Ha Noi University of Science and Technology and Hung Yen University of Technology, no longer teach ESP because many universities are applying different standards in assessing the students' English ability, such as TOEIC, TOEFL, IELTS, and CEFR (Common European Framework of Reference). For example, Dong (2011) states that Hanoi National University focuses on training general English for its students so that they can reach level B1 of CEFR or IELTS 4.0. It is the students' responsibility to study ESP themselves. This causes difficulties for both students and lecturers of English at tertiary level (Dong, 2011) because students have to learn ESP themselves or take ESP courses at English language centres without the lecturers' guidance. As for lecturers of English who used to teach ESP courses, they had to spend considerable time to study and prepare for their teaching, but they will no longer continue teaching ESP courses.

Some other universities, such as Ha Noi University of Communications and Transport and the university where this study took place still specify two credits for ESP training in their programme. Students study ESP in semester three of the undergraduate programme after studying general English in semester one and semester two.

Dong (2011) reviews the definition and history of ESP and claims that, though ESP has been in Vietnam for a long time, this area of teaching has some limitations and is not fully recognised. He identified three issues concerning ESP in Vietnam: Insufficient needs analysis, the students' low level of general English, and their lack of subject knowledge. Although lecturers of English were aware of the importance of needs analysis, they did not interview experts in the field or conduct a needs analysis for their students, and they used out-of-date textbooks without assessing the suitability for students (Dong, 2011). As discussed in section 1.2.2, students, in general, have a poor English ability, which prevents them from studying ESP effectively. Despite studying general English, students are still not qualified enough to study ESP, which requires them to reach intermediate or a higher level of general English (Dong, 2011). Finally, there is a heated argument among scholars, lecturers of English and subject lecturers about how to teach ESP, and importantly who should teach ESP - lecturers of English or subject lecturers. Dong also suggests that the curriculum design of a specific major should be based on authentic specific situations which 
require the specific kinds of the language of that major. This curriculum should also focus on developing a corpus of technical words for students, and guide them to learn technical words themselves based, for example, on understanding word formation.

To summarise, while ESP in Vietnam is attracting more and more researchers and scholars because of its urgent importance, there is relatively little research on this topic that has been published to date.

\subsection{Rationale for the Study}

There two main categories in the rationale behind undertaking this study. The first is my interest and personal experiences and observations, and the second is the development of theoretical frameworks to address communication needs.

\subsubsection{Interest and personal experiences and observations}

My interest in needs analysis evolved since I started as an English instructor at tertiary level. This interest motivated me to conduct this research. At my university, for example, students in the specialisations of automotive engineering, manufacturing engineering, and mechanical engineering are currently being taught a generic and old course book named English for Technical Students 2 (Bonamy, 1994). This course book was not designed for mechanical engineering in general. Nor was it designed especially for the context of our university which specialises in training engineers. The university attracts hundreds of engineering students annually. There is no clear list of communicative events specified. This course was for technical students in general. As a teacher of the course, I questioned whether the course and its contents continue to be significant and relevant for mechanical engineering students in the present situation and this led me to see a need to conduct a needs analysis to find out the kinds of real-world English skills that mechanical engineering students need for their future jobs. At my university, no formal needs analysis is conducted in the development of the ESP course. This is consistent with a claim made by Talif and Noor (2009) that "one of the main problems in English language teaching at the tertiary level is the lack of information on students' future careers and the language skills needed at work" (P. 66).

My university has recently signed a contract with a major foreign industry to train and provide engineering graduates for their biggest branch in Vietnam. Other large industries, some the largest in Southeast Asia, are being built in the Vung Ang economic zone in Ha Tinh province, together with Son Duong thermal power plant, deep-water ports, Vung Ang 1 and 2, and three thermal power plants. My university also has signed a contract 
with a large joint foreign and Vietnamese workplace in 2015 in which both parties had an agreement about training human resources for this worksite (General Statistics Office of Vietnam, 2015). Vietnamese economic zones will recruit thousands of engineering graduates, including mechanical engineers, to work for many foreign corporations and joint venture enterprises. This will require the university to prepare its engineering graduates to a high level of English proficiency to meet the recruitment criteria. Besides these two large contracts, the university also has many agreements with other business enterprises to provide well-qualified engineering graduates.

\subsubsection{The development of theoretical frameworks to address communication needs}

A literature review of recent needs analysis studies internationally shows that questionnaire and interview are the two most common methods of data collection in investigating learners' needs. There is a need to conduct a mixed methods study to gain a deeper insight into the real-world communication needs of mechanical engineers in the lingua franca workplace context.

In the field of ESP, Munby's (1978) Communication Needs Processor (CNP) has been criticised for its complexity and for being time-consuming (Ha, 2005). Researchers such as Kaewpet (2008) have returned to it because it provides a way of uncovering the complexity of real-world communication in the workplace. My study draws on the strengths of Munby and Huhta's approaches and uses open-ended interview questions and observations to gain a rich view of the complexity of English in the workplace for mechanical engineers. Studies grounded in sociolinguistics show the importance of power relationships and the complexity of cross-cultural understanding and pragmatic aspects, such as politeness strategies. When needs analysis is too narrowly focused, these dimensions of workplace communication may be missed.

Long (2005b) claims that needs analysis is incorporated in any language teaching programmes. It gathers information about the learners' personal, academic or professional, cultural and language background to shape and direct an ESP course (Kumari \& Rahman, 2012). In their book about developments in English for Specific Purposes, Dudley-Evan and St John (1998) argue that the most important aspect of any ESP courses is the way the course content meets the students' use outside the class, such as in the work setting. Khuong and Chi (2008) claim that Vietnamese ESP teachers want to have an appropriate ESP syllabus to help students communicate effectively in their future jobs as electronic engineers. They also argue that any successful course is associated with learners' needs.

There have been different approaches to needs analysis in English language teaching, such as a systemic approach proposed by Richterich and Chancerel (1980), a sociolinguistic 
model (Munby, 1978), a learning-centred approach, a task-based approach (Long, 2005a), genre analysis (Swales, 2004), and narrative frames (Macalister, 2012). These different approaches all aim to investigate learners' needs to support the teaching and learning of English. Since the current study aims to examine the English communication needs of mechanical engineers, such as the real-world types of English and English language skills and the complexity of the social dimensions of these uses in the lingua franca workplace, both Munby's sociolinguistic model of needs analysis and Huhta et al.'s sociological and holistic approach are employed.

Language and communication are considered new vocational skills of employees in the workplace (Lung, 2014). Linguistic structures and lexicon have been examined in designing ESP courses. According to Lung (2014), it is time to bring detailed empirical analysis of actual language use to the fore in the analysis of language situations. By doing this, the specific needs for communication in a real and particular situation are analysed. This will help to answer such questions as why students need to learn this or that language skill, where and when they use what they have learnt, who they interact with, what skills they need to use and what activities they are engaged in. Answers to these questions are sought in a needs analysis study such as the current study and are in line with a claim made by Macalister and Nation (2011) that "the result of needs analysis is a realistic list of language, ideas or skill items that will be covered in the course" (P. 3). Huhta et al. (2013) argue that "language courses must focus very tightly on the specific learning needs of the respective target group of learners" (p. 27) because of the limited time for teaching and learning as well as the learners' availability. Thus, needs analysis can function as a bridge to break the gap between the industry and the universities (Mohamed, Radzuan, Kassim, \& Ali, 2014).

These above reasons explain why this study is conducted to explore the real English communication needs of Vietnamese mechanical engineers.

\subsection{Purposes of the Study}

This research provides both theoretical and practical contributions to literature and approaches to needs analysis worldwide in general and to Vietnam in particular.

First, needs analysis for English for specific purposes in general and mechanical engineering, in particular, is almost non-existent in the Vietnamese context. Understanding the social dimensions of language use in lingua franca contexts has the potential to extend our understanding of language needs for the practical purpose of 'getting things done' in the workplace. 
Second, and the main purpose of this study is that the findings aim to inform curriculum design for teachers and students. This purpose could usefully be extended to implications for communication policies and language training policies in multi-national plurilingual companies. That is, understanding the demands of language use in real-world contexts such as the types of English, the English language skills that of high frequency of use, the communicative events, English for technical communication (especially technical vocabulary) and social communication, adaptive strategies as well as the plurilingual repertoires in the lingua franca workplace can inform policymakers and curriculum designers about policy and the design of English courses for mechanical engineering and other disciplines that meet the students' real needs in their future workplaces. The study also aims to inform the company's policy makers and course designers about what English communication needs their staff actually require to be trained and improved to function effectively in their jobs in the lingua franca workplace.

Finally, it is important to understand the social dimensions of the use of language in the plurilingual and pluricultural workplace (Coste et al., 2009). For example, such an understanding of the communication issues and their consequences can help the design of language courses and the implementing of the language teaching and so improve the motivation of students learning the language. Also, an understanding of the importance of solidarity in maintaining and building social relationships and mitigating the consequences of miscommunication can inform policymakers and curriculum designers as well.

\subsection{Scope of the Study}

This mixed method needs analysis research is conducted in four companies/factories in the centre north and Northern provinces in Vietnam. It focuses on examining real-world uses of English as required by the mechanical engineers to function effectively in their jobs at various workplace contexts as perceived by the managers of mechanical engineers and by mechanical engineers themselves. The study also focuses on exploring the complexity of the use of English in the lingua franca and plurilingual workplace by investigating the issues of social dimensions such as the level of formality, humour, solidarity and power relationships. Initially, this study aimed to also look at the learning needs of mechanical engineering students from the perceptions of these students and their lecturers which were not covered in this thesis. It became clear after returning from data collection that the needs in the workplace was the more important part of the study because these were the target needs from the insiders in the workplace and so the data from students and lecturers were not analysed. The analysis of the data was informed by the CEF which is "participant-focused, process- 
based communication needs analysis and pedagogy" (Huhta et al., 2013, p. 4). So this study only examines language needs in the workplace and not the learning needs of students.

\subsection{Structure of the Study}

This thesis consists of nine chapters. Chapter One presents an introduction to the study. It provides a background to the urgency of the problem of the lack of English language skills among mechanical engineers in Vietnam by describing mechanical engineering and its role in the economy and industrial development of Vietnam. The chapter also gives an overview of English language education in general and ESP in particular. The chapter explains why a study of the needs analysis of the English language needs of mechanical engineers in Vietnam is important and useful.

Chapter Two provides an overview of the history of ESP and needs analysis, and how they are approached and implemented. The chapter then provides a theoretical framework for the study which combines more traditional needs analysis approaches and methodological approaches to exploring workplace discourse and so provides a theoretical model for the study.

Chapter Three reviews needs analysis studies conducted at both workplace and university situations and studies on the social dimensions of workplace English. The chapter also reviews the relevant research in language use in the L1 and L2 workplaces to confirm the research gap in the field.

Chapter Four explains why pragmatism was chosen to be the research paradigm for the study and why mixed methods research was employed. The chapter describes in detail the research procedure, the research sites and participants, how data were collected and analysed, how ethical issues were considered and how I have worked to minimise potential threats to the validity of the study.

Chapter Five presents an overview of the English communication needs of the mechanical engineers from the questionnaires. It reports the perspectives of mechanical engineers and their managers separately. Details of the English language skills and the most common communicative events required by mechanical engineers as well as the participants' perceptions about the issue of formality in communication are all reported.

Chapters Six provides the qualitative findings from the semi-structured interviews and observations about the English communication needs of the mechanical engineers, such as the contexts for English use, the specific English language skills that mechanical engineers needed to engage in numerous communicative events and how they adapted their communicative activities to 'get things done.' The chapter also presents a list of common 
technical words and academic words, as well as two 'snapshots' describing a working day of a manager and a mechanical engineer, reported in the study.

Chapter Seven shifts focus from the communicative events seen through a needs analysis lens to the social dimensions of language use as seen in the Wellington Workplace Project and similar studies. It examines the relationship of formality and informality in both language and social behaviours with high and low solidarity relationships. It also examines how formality and informality and low and high solidarity relationships interact with communication issues in the lingua franca workplace.

Chapter Eight discusses the key findings of this mixed method needs analysis study in relation to the field of research. Then the chapter particularly focuses on discussing the more complex issues of English use in the lingua franca workplace such as the underlying power and social relationships and particularly how communication issues reveal both the urgency of the need for improved English and the effects of limited English on power relationships in a "poor English" worksite.

Chapter Nine, the last chapter in the study, provides the conclusions and implications of the study. It found that high solidarity relationships can mitigate limited communication in English in the "poor English" workplace and recommends that the effect of this be more generally understood. It recommends that potential communication issues could become a stronger part of English language teaching for vocational purposes and that a humorous approach to such issues might be an appropriate way to introduce this topic in the teaching context. Other pedagogical implications include that (i) people should be strategically prepared to cope with the complex communication demands of the lingua franca and plurilingual workplace, (ii) there should be a balance between technical communication and social communication, (iii) policies for education and language education should prepare people with plurilingual repertoires. It also describes the limitations and implications for further research. The chapter provides a concluding statement. 


\section{CHAPTER TWO: CONCEPTUAL FRAMEWORK}

\subsection{Introduction}

This study primarily takes a needs analysis approach to answer its central research question which seeks information on the English communication needs of mechanical engineers in the Vietnamese context. As the interview and observation tools produced thick data about the social dimensions of interaction in the workplace, the analysis was extended to also look more broadly at both the language needed for practical purposes in the workplace in order to get things done, and the way social interactions take place and how power is exercised in the context of a lingua franca workplace. The conceptual framework of the study therefore draws from a range of methodological approaches, including the approaches to needs analysis study by Munby (1978), Hutchinson and Waters (1987) and the Common European Framework (Huhta et al., 2013). It uses a thematic analysis approach to analyse workplace interactions.

\subsection{English for Specific Purposes (ESP)}

\subsubsection{The development of English for Specific Purposes}

English for specific purposes (ESP) arose as a term in the 1960s due to an awareness that general English courses did not meet learners' needs and employers' wants. At first, the design of ESP courses was based on register analysis, but then target situation analysis became dominant because register analysis failed to meet expected outcomes (Brunton, 2009).

ESP emerged due to the demands for English to suit specific needs and developments in the field of linguistics and educational psychology which focuses on the learner (Hutchinson \& Waters, 1987). ESP has undergone five main stages since its beginning in the 1960s. The first stage was register analysis, which took place in the 1960s and early 1970s. The focus of ESP in this first stage was on language at the sentence level, and the aim of the analysis was to "identify the grammatical and lexical features" of specific registers such as the English of Electrical Engineering or Biology (Hutchinson \& Waters, 1987, p. 10). The second stage was rhetorical or discourse analysis, which focused on the level above the sentence, that is, how sentences were combined in discourse to produce meaning. The third stage was target situation analysis. Since the purpose of an ESP course is to help learners function effectively in the target situation, needs analysis is used to identify the target situation in order to form the syllabus. The best-known work is the Communicative 
Syllabus Design by Munby in 1978, which provides a formula for creating a detailed profile of learners' needs (see Section 2.3 Needs Analysis). The fourth stage was the skills and strategies which focused on "the thinking processes that underlie language use" (Hutchinson $\&$ Waters, 1987, p. 13). The last stage is the learning-centred approach, which concerns language learning.

The main purpose of ESP courses is to facilitate students' acquisition of rhetorical skills and strategies to assist their integration into their study environment and to facilitate the transition to the workplace (Artemeva, Logie, \& St-Martin, 1999).

There have been various approaches to text analysis in the history of ESP, from the early register analysis to rhetorical analysis, and now to genre analysis, which Dudley-Evans (2000) claims as the dominant approach today. This genre approach to ESP is based on text because texts have different patterns of organisations in different disciplines.

In today's context, ESP is an important part of English as a Foreign Language (EFL). Under the ESP umbrella, sub-ESP divisions such as English for Academic Purposes (EAP), English for Occupational Purposes (EOP), English for Science and Technology (EST), and English for Business and Economics (EBE) emerged because learners and employers demanded that courses needed to better meet their needs (Brunton, 2009). There are as many types of ESP as the specific learner needs (Belcher, 2009), but all are based on finding out what the learners' needs are. Belcher (2006) argues that current ESP curriculum and materials design owes much to genre theory and corpus-enhanced genre studies, and it is also starting to draw on critical pedagogy and ethnographies in fulfilling this commitment.

\subsubsection{Definitions of ESP}

Munby (1978) emphasised early that the syllabus and materials of ESP courses are "determined in all essentials by the prior analysis of the communication needs of the learner, rather than nonlearner-centred criteria such as the teacher's or institution's predetermined preference for General English or for treating English as part of a general education" (p. 2).

There have been different definitions of ESP. Hutchinson and Waters (1987) see ESP as an approach, not a product, by which they mean that ESP is not a particular kind of language, methodology or teaching material. The critical point for Hutchinson and Waters is that all decisions about the content and method of an ESP course are based on learners' needs or learners' reasons for learning. These needs or reasons can be discovered by conducting a needs analysis study of the learners' needs. Dudley-Evan and St John (1998) stress two aspects of ESP methodology. The first aspect is that the teaching of ESP ought to reflect the methodology of the disciplines and professions it serves. The second feature is that the nature of the interaction between the teacher and learner in the teaching of ESP may 
differ from that in the teaching of general English. Their definition consists of three absolute characteristics and four variable characteristics. Two of these are important to be considered:

- "ESP makes use of the underlying methodology and activities of the disciplines it serves." (Dudley-Evan \& St John, 1998, p. 4)

- "ESP may be related in content to or designed for a specific discipline."

(Dudley-Evan \& St John, 1998, p. 5)

Richards and Schmidt (2010) define ESP as "the role of English in a language course or programme of instruction in which the content and aims of the course are fixed by the specific needs of a particular group of learners" (p. 198). The definition itself claims that ESP is closely linked to the learners' needs. Exploring the specific needs of a specific group of learners is the job of needs analysis. According to Brown (2016), "if there is no needs analysis, there is no ESP" (p. 5).

Needs Analysis (NA) plays a crucial role in ESP. NA functions as the starting point of any ESP programme or course. The following section discusses NA in more detail.

\subsection{Needs Analysis}

\subsubsection{The development of needs analysis}

Though it is dated, Munby's (1978) Communicative Syllabus Design provides the best-known model of needs analysis, namely the Communication Needs Processor (CNP) which places the learners' purposes in the central position. Since then, needs analysis has become crucial to any ESP course design (Hutchinson \& Waters, 1987) and has become "a key instrument in course design" in ESP (West, 1994, p. 2). This is because needs analysis helps to make sure that a designed course will be relevant and satisfy the learner's needs. Munby's model is described in detail in Section 2.4 "Approaches to needs analysis".

'Needs analysis' was first used in the field of language teaching by Michael West in the 1920s. Language teaching at this time has sometimes been described as TENOR (Teaching English for No Obvious Reason), that is, learners learned English because it was a compulsory subject (Abbott, 1980). However, needs analysis attracted little attention in the following decades until its re-emergence during the 1970s (Alshumaimeri, 2009). According to West (1994), needs analysis has undergone four stages in different periods of time with different foci and scope of analysis, which can be seen in the table below: 
Table 1: The four stages of needs analysis developments (West, 1994)

\begin{tabular}{|c|c|c|l|l|}
\hline Stage & Period & \multicolumn{2}{|c|}{ Focus } & \multicolumn{1}{|c|}{ Scope of analysis } \\
\hline 1 & Early 1970s & \multirow{2}{*}{ ESP } & \multicolumn{1}{|c|}{ EOP } & Target situation analysis \\
\cline { 4 - 5 } 2 & Later 1970s & & EAP & Target situation analysis \\
\hline & & & $\begin{array}{l}\text { Target situation analysis } \\
\text { Deficiency } \\
\text { Strategy analysis } \\
\text { Means analysis } \\
\text { Language audits }\end{array}$ \\
\hline 4 & $1980 \mathrm{~s}$ & ESP \& general language teaching & $\begin{array}{l}\text { Integrated/ computer-based } \\
\text { analyses } \\
\text { Material selection }\end{array}$ \\
\hline
\end{tabular}

There are a number of approaches to needs analysis employed more recently by some academics. Morrison, Ross, and Kemp (2004) introduce learner and contextual analysis and task analysis in designing effective instruction. As learners consist of different types of people, we need to understand their characteristics and how these characteristics may provide opportunities or constraints on the designs. Morrison, Ross, and Kemp claim that the context influences all aspects of the learning experience and its factors can inhibit or facilitate both instruction and learning. Task analysis is "a collection of procedures for designing the content of an instructional unit” (Morrison et al., 2004, p. 78). Lambert (2010), for example, conducts a task-based needs analysis by using employment records, interviews and surveys to build a consensus on the English language tasks that graduates face in their lives and careers. By using this type of needs analysis, Lambert aims to provide an empirical basis for asking questions about curriculum renewal to avoid TENOR.

In a slightly different definition, needs analysis or needs assessment is "the process of determining the needs for which a learner or group of learners requires a language and arranging the needs according to priorities" (Richards \& Schmidt, 2010, p. 389). In his study about needs assessment, Berwick (1989) makes a distinction between 'felt' needs and 'perceived' needs. Felt needs are those that learners have and are understood as 'expressed needs'. These needs can be devalued by people who do the assessment by seeing them as 'wants' or 'desires'. Perceived needs are interpretations of qualified experts about what learners say they need. Berwick (1989) also suggests a basic definition of need when he states that a need is a "gap or measurable discrepancy between a current state of affairs and a desired future state" (p. 52). Berwick names this as discrepancy analysis to refer to "what people know and what they ought to know" (p. 53). 
Macalister (2012) employed narrative frames as a needs analysis tool in the design of a specific English language curriculum for Kiribati seamen. His narrative frame consists of a number of sentence starters from which Kiribati seamen can tell their own story of learning and using English, including both challenges and successes. This kind of approach can give course designers an insight into authentic language situations to better prepare for learners' future careers.

\subsubsection{Role of needs analysis.}

As needs analysis plays a crucial role in ESP, it identifies the learners' needs and is very important for course design, teaching methods and learning approach (Berwick, 1989; Brindley, 1989; Brown, 2016; Choi, 2005; Hutchinson \& Waters, 1987; Iwai et al., 1999; John, 1991; Munby, 1978; Nunan, 1988; Songhori, 2008). John (1991) considers it the first step in course design, claiming that needs analysis provides validity and relevance for all activities for designing courses. Similarly, Richards (2001), Fatihi (2003) and Kaur (2007) claim the important role of needs analysis in developing language curricula. ESP teachers must pay attention to needs analysis, the process of collecting and analysing students' information in order to set goals and appropriate content for a language curriculum. As for Belcher (2006), needs assessment is important as it is considered as the foundation in ESP "on which all other decisions are, or should be, made" (p. 135).

In a needs analysis study about Japanese language, Iwai et al. (1999) argue that needs analysis refers to activities that are involved in collecting information which will serve the purpose of developing a curriculum that can meet the needs of a particular group of students. Nation and Macalister (2010) argue that needs analysis mainly directs the goals and content of a course, examines what the learners know already and what they need to know, and makes sure that the course will contain relevant and useful content to learn.

Besides its pre-stage for the design of languages courses, needs analysis needs to be considered an "on-going process" (White, 1988, p. 91) as well as evaluation which can be used to design, improve and carry out language programmes (Garcia, 2013). According to Richards (2001), in language teaching, needs analysis has several purposes, two of which are very important:

- "To find out what language skills a learner needs in order to perform a particular role, such as sales manager, tour guide, or university student.

- To identify a gap between what students are able to do and what they need to be able to do." (p. 52) 
More specifically, in terms of ESL programmes, Linse identifies students' demographic profiles, their level of acquisition in English, their communicative abilities in English, their formal knowledge of English, and their daily use of English as targets for needs analysis (Linse 1993: cited in Richards 2001).

The target population of needs analysis for learning needs must include different groups of perspectives, such as employers, teachers, graduate students, academics, vocational training specialists and students (Dudley-Evan \& St John, 1998; Long, 2005b; Richards, 2001). To collect information or data from these sources, more than one method of data collection needs to be used, such as questionnaire, interview, observation or document analysis (Hutchinson \& Waters, 1987; Jasso-Aguilar, 1999; Long, 2005a; Rahman, 2012; Richards, 2001).

\subsubsection{Approaches to needs analysis}

Needs analysis has been approached from various perspectives, which have been reviewed in previous research (Huong, 2009; Jordan, 1997; Kaewpet, 2009b; Songhori, 2008; West, 1994). Though section 2.3.1 has summarised some approaches to needs analysis, this section further examines in detail the Target situation analysis (Munby, 1978), a Learning-centred approach (Hutchinson \& Waters, 1987), and the Common European Framework (CEF) Professional Profile (Huhta et al., 2013), because they are seminal works on needs analysis. It can be said that, since the CNP model was proposed by Munby (1978), it has set the ground for the development of other approaches. This historical development is illustrated in the flow chart below: 


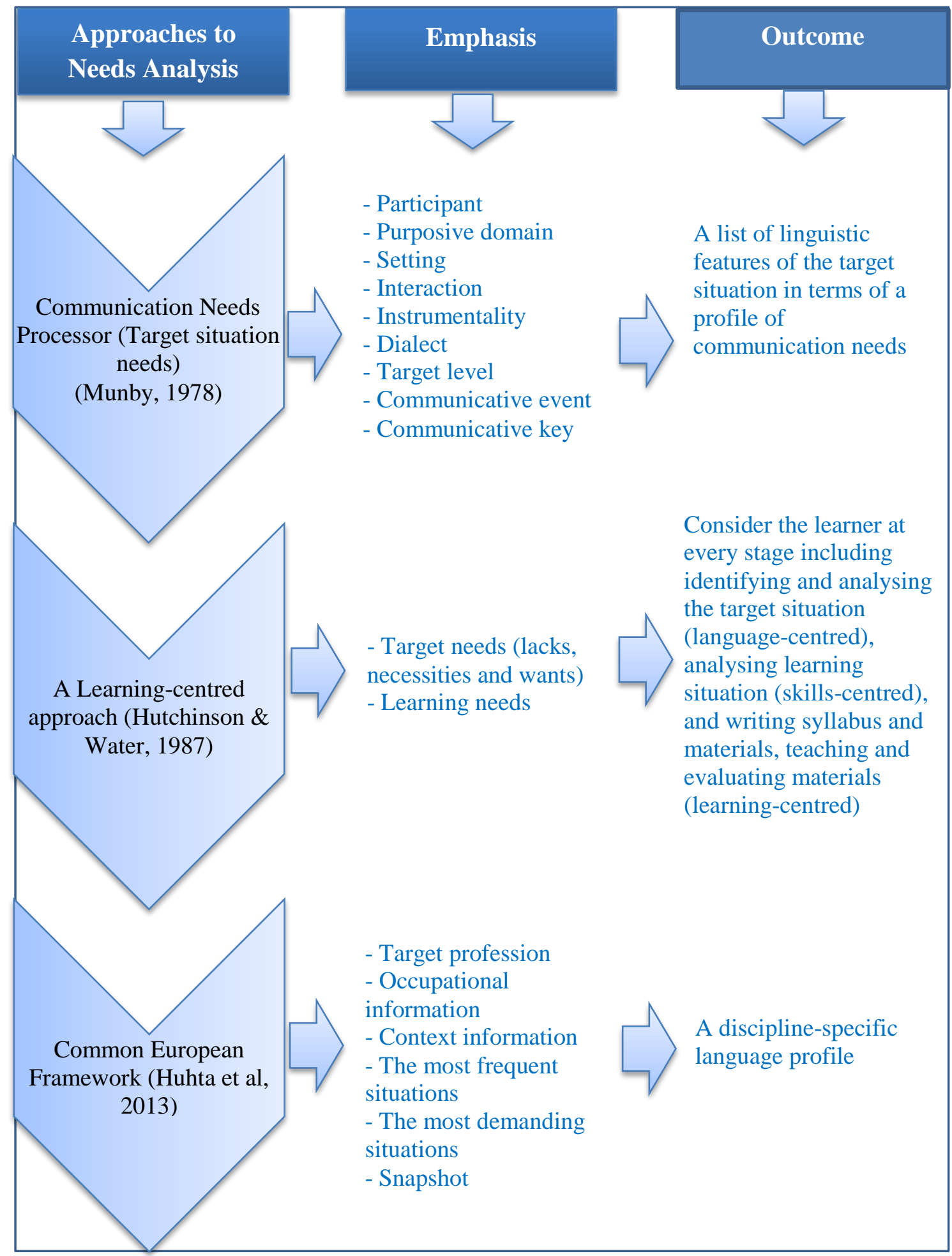

Figure 1: The development of approaches to needs analysis

Detail of each approach is presented in each sub section below: 


\subsubsection{Target situation analysis}

Target situation analysis starts with Munby's (1978) Communication Needs Processor (CNP). The CNP represents a sociolinguistic model that defines the content of a 'purpose-specific programme' (Kaewpet, 2008; Kumari \& Rahman, 2012). This sociolinguistic model aims to give a detailed description of the communicative competence of a learner. Generally, needs analysis aims at finding out the target needs of learners. Munby's CNP model takes into account a set of variables or parameters in a dynamic relationship for discovering the complexity of target situation needs. The CNP analyses language communication in the target situation to build a communicative needs profile for a specific group of learners and then converts these needs into syllabus content. The variables contain information about the participant, purposive domain, setting, interaction, instrumentality, dialect, target level, communicative event and communicative key. The participant refers to a person or a group of people who take part in the interaction. Purposive domain refers to the educational or occupational purposes or both of them. Setting indicates the workplace situation or study situation. Interaction refers to a situation involving a person or a group of people that use English. Instrumentality indicates the medium, mode and channel of communication. Dialect means the variety of English. The target level refers to the required English ability to perform a communicative event, while communicative event refers to a situation in which the participants use languages to communicate. Communicative key means the manner of the participant in communication (See Glossary, p. XII). Besides, information about psychological settings, environments of language used, the role-set, the people with whom the participant will interact, the nature and size of their participation, the attitudinal tones or keys, and how the target communicative acts are performed are examined because they play an important role in deciding the language content and the learning context. Each variable asks questions about the target language use to identify real world communicative needs and the requirements of learners. Jordan (1997) argues that the outcomes of the CNP's variables form a needs profile which "is then converted into a communicative competence specification, from which a sequenced syllabus can be drawn up" (p. 24). In other words, Munby's categories of communicative activity and communicative event are performance related and reflect categories of real-world language use (West, 1994).

Hutchinson and Waters (1987) are positive about Munby's contribution, as his CNP model provides a full profile of the learners' needs in terms of communication purposes, communicative setting, the means of communication, language skills, functions, structures and lexis. That is why they consider it a "highly detailed set of procedures for discovering 
target situation needs" and "the most thorough and widely known work on needs analysis" (p. 54). Employing this model, the four skills (namely listening, speaking, reading and writing) are analysed in job-related activities in terms of receptive and productive skills, from which a general profile of the language situation is generated and used as an input in course design (Jordan, 1997).

However, Munby's model has also been criticised by a number of academics and linguists. Hutchinson and Waters (1987) criticise the CNP model as too language-centred. West (1994) criticises this model as inflexible, complex and time consuming. Jordan (1997) complains that the model is not considering practical constraints at the start of needs analysis procedures and the language items for practice are not derived from the real world. Ha (2005) finds this model time and money consuming, vague and impractical. She finds it difficult to implement the model in her teaching as well as writing her own syllabus.

However, Ha (2005) believes that syllabus design should be partly based on sociolinguistics. Despite being criticised, Munby's model has had an impact on ESP course development because this model still attracts academics' arguments in terms of both theoretical and practical problems and it has been "highly influential in the field of ESL/ESP needs analysis" (Alharby, 2005, p. 18). From the emergence of the CNP, other models of needs analysis have been developed, such as the learning-centred approach

The complexity of the CNP model can lead it to yield rich information about the context of language use. Proposing this model, especially the use of the communicative key variable, which is concerned with how people do the activities, Munby tries to investigate real contexts of language use and argues that workplace communication is complex. The communicative key in the profile suggests that the social context of language use should be taken into account and that examination of the kind of vocabulary and the level of language, for example, is not enough to account for this complexity.

\subsubsection{Learning-centred approach}

The Learning-centred approach was developed by Hutchinson and Waters (1987). It consists of two separate frameworks for studying learner needs, namely Target needs and Learning needs. Hutchinson and Waters developed the Learning-centred approach to needs analysis because they claim that there is much more to an analysis of needs than 'scientific' needs analysis like the CNP model. Hutchinson and Waters criticise Munby's CNP for being too language-centred.

In order to answer the question of what we mean by needs, the learning-centred approach makes a distinction between target needs and learning needs. The former is concerned with language use and means "what the learner needs to do in the target situation" 
(Hutchinson \& Waters, 1987, p. 54), such as the workplace, while the latter is concerned with language learning and means "what the learner needs to do in order to learn" (Hutchinson \& Waters, 1987, p. 54) .

Hutchinson and Waters' view of needs analysis is quite similar to Munby's CNP model in asking questions about the learner's identity, their purpose of learning, the place and time of the study, who they will interact with and the required level of proficiency (Daloglu \& Isik Tas, 2007). If Munby asks these questions in one model of needs analysis, namely the CNP model with eight different variables, Hutchinson and Water separate them into target needs and learning needs as two frameworks to investigate learner needs. Each framework consists of different set of questions as below.

\subsection{Target needs}

Target needs collect information through asking questions about the target situation and the participants' attitudes towards that situation. There are six questions, namely: Why is the language needed? How will the language be used? What will the content areas be? Who will the learner use the language with? Where will the language be used? When will the language be used?

Target needs are broken into necessities, lacks and wants. Necessities are known as "what the learner has to know in order to function effectively in the target situation" (Hutchinson \& Waters, 1987, p. 55) or also mean objective needs (Jordan, 1997). Given this, information about the situations in which the language will be used can be obtained via lectures and seminars, for instance. The discourse components and linguistic features such as functions, structures, and vocabulary used in these situations can also be obtained (Jordan, 1997). Lacks are the gaps between what the learner knows already and what they need to know (necessities). According to Jordan (1997), the necessities that the learner lacks can form the basis of the language syllabus, and both necessities and lacks can be seen as being objective. Wants are "what that destination should be" (Hutchinson \& Waters, 1987, p. 60). Jordan (1997) perceives 'wants' as the learners' subjective needs.

\subsection{Learning needs}

Learning needs are concerned with the learning situation, including who the learners are, why they are taking the course, how they learn, what resources (teachers and materials) are available, where the course will take place, and when the course will take place (Hutchinson \& Waters, 1987). Hutchinson and Waters claim that the analysis of 'lacks' in the target needs is the starting point, and the 'necessities' are the destination. In order to get from the starting point to the destination, learning needs need to be taken into account. Like 
target needs, learning needs influence and affect any ESP programmes from syllabus design to evaluation. Tahir (2011) claims the crucial role of learning needs analysis, as any needs analysis being used for course design will be weak if the learning needs model is not included.

A recent Common European Framework (CEF) Professional Profile model developed by Huhta et al. (2013) provides a different way to explore the needs. Instead of emphasising both target needs and learning needs like Hutchinson and Water's model or picking out single aspects of needs like Munby's model, CEF focuses mostly on the real needs from the worksite in a holistic way.

\subsubsection{Common European Framework (CEF) Professional Profile}

Huhta et al. (2013) have developed a recent needs analysis model namely the Common European Framework (CEF) Professional Profile. The framework is developed due to the following reasons:

First, according to these authors there is an urgent need to design a course that is "efficient, effective and relevant, and that is tailor-made to cater to learners' professional needs" (Hall, 2013, p. 1), especially in the intercultural and global world. Teachers may lack the experience of the relevant professional and organisational contexts. The teachers may also not be expected to understand the social and linguistic complexity as well as heterogeneity in the workplace. The authors think that a coherent analytical framework can help the teachers better understand the problem and wanted to develop a profile of needs which is practical for course planning and design based on findings from a needs analysis study conducted in the modern workplace. Thus, CEF was developed as an innovative sociological and holistic approach, a major development in the ESP theoretical frameworks since Munby’s model (Hall, 2013).

Second, the model was built on an analysis of past models of needs analysis to avoid any shortcomings of these past models. For example, Munby's CNP model has been criticised for being money and time-consuming (Ha, 2005), too language-centred (Hutchinson \& Waters, 1987) or inflexible and complex (West, 1994). The authors see CEF as a dynamic, collaborative and inclusive model to deal with the increasingly complex discourse world of the modern workplace. Like the CNP model, CEF also results in developing a profile of needs. The difference between CEF and CNP lies in the scope of the needs. If the CNP model explores workplace communication in a complex way by looking at different aspects through eight variables, the CEF model tries to look at workplace 
communication in a holistic way instead of dividing it into separate variables. For example, Huhta et al. (2013) look at a key communicative event and what is involved in that event. Within that event, they are able to consider all the social aspects of language use as well. The CEF profile was also based on the seven needs analysis series for industry and business which had been conducted in Finnish and other European projects from 1989 to 2007 which were reviewed in detail in Huhta's (2010) research.

Third, the authors assume that teachers of ESP courses would discover that having adequate language skills is not enough for students of diverse cultural and educational backgrounds and students with varied expectations of appropriate and effective learner behaviour. The students would also need guidance on study skills, and how they take what they learn and acquire into the real-world situations.

Fourth, the model was developed based on a combination of information from different sources such as the three-different levels view of needs introduced by Robinson (1991), the five-perspective model of inter-discursivity developed by (Candlin \& Crichton, 2011) and especially the Common European Framework of Reference (CEFR) for Languages. The three different levels of needs are micro-level (needs of the individual learner), meso-level (needs in the context of the workplace or educational institution) and macro-level (needs of society). Of these CEF focuses most on the meso and macro levels. The five-perspective model that informs CEF has a text perspective, participant perspective, social and institutional perspective, social action perspective and analyst's perspective (see the Figure 2 below). This model allows course designers to examine needs from multiple perspectives and multiple contexts because all of these perspectives are relevant to the examination of discursive practices at a specific site. 


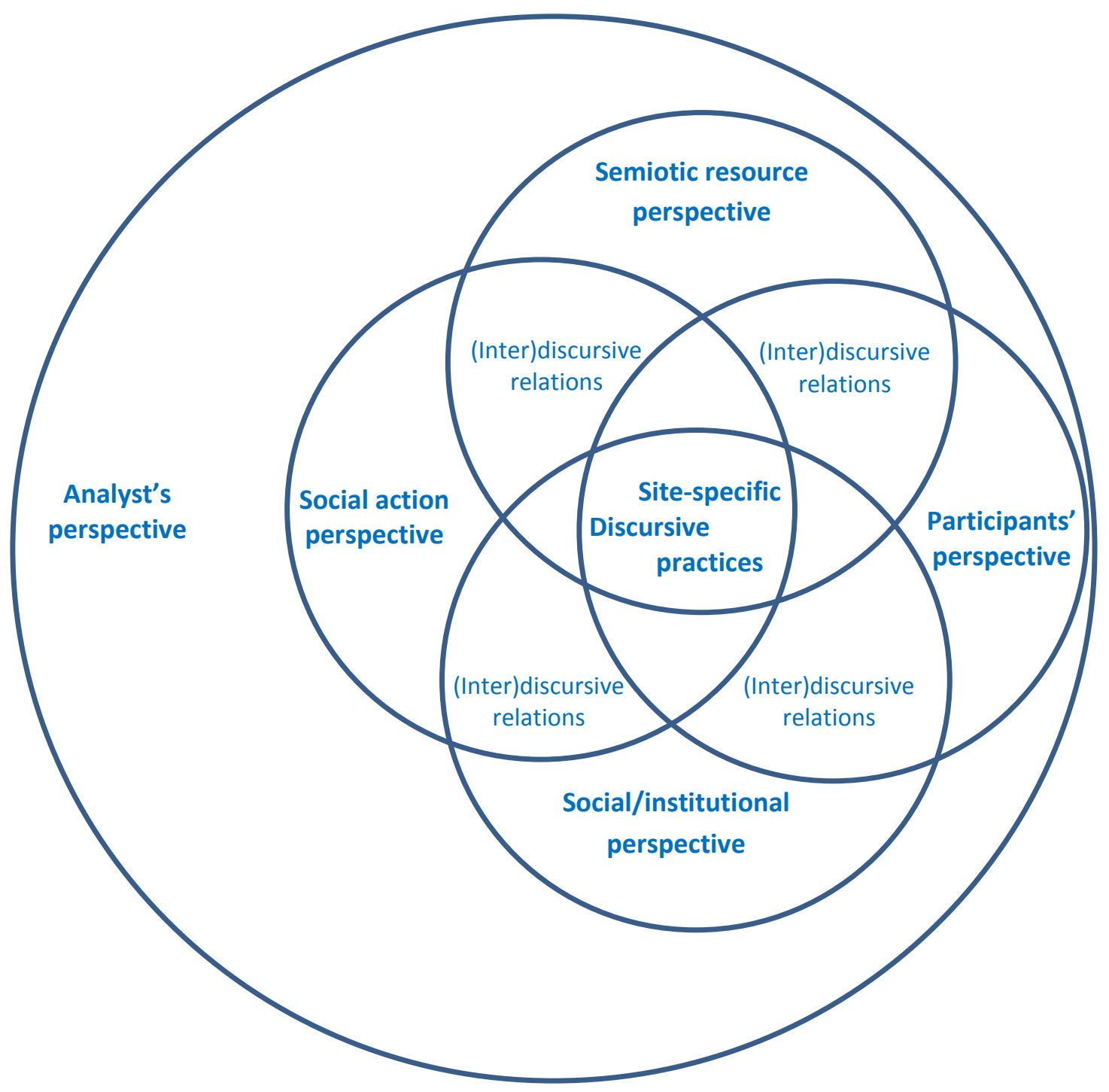

Figure 2: Framing a multi-perspectived and interdiscursive research agenda (adopted from Candlin and Crichton (2011))

According to Council of Europe (2001), CEFR provides a comprehensive description of "what language learners have to learn to do in order to use a language for communication and what knowledge and skills they have to develop so as to be able to act effectively" (p. 1) by using an action-oriented approach. It is comprehensive because it outlines criteria for descriptors for the six common reference levels for the six purposes respectively namely breakthrough (A1 level), waystage (A2 level), threshold (B1 level), vantage (B2 level), effective operation proficiency $(\mathrm{C} 1$ level) and mastery (C2 level). It also presents a selfassessment grid which describes what people can do with each specified English level in terms of listening, speaking, reading and writing skills. It is comprehensive because it specifies the qualitative aspects of spoken language use in terms of reference levels in relation to the range, accuracy, fluency, interaction, and coherence. 
The action-oriented approach views language learners and users as 'social agents' because people often have tasks to do in different circumstances within their field of action. To accomplish the tasks, people have to develop a range of competences including communicative language competences. CEFR presents language competences in terms of components of linguistics (lexical, phonological, syntactical knowledge and skills), sociolinguistics (sociocultural conditions of language use), pragmatics (functional use of linguistic resources) as well as communication strategies and learning strategies (Huhta, 2010). CEFR focuses on the plurilingual and pluricultural competence of the language users which refers to "the ability to use languages for the purposes of communication and to take part in intercultural interaction, where a person, viewed as a social agent has proficiency, of varying degrees, in several languages and experience of several cultures" (Council of Europe, 2001, p. 168).

Taking account of all these dimensions is a pervasive feature in Huhta et al.'s model. Language learners should be able to use their language to fulfil the tasks that are relevant to their professional lives. Thus, any communicative task is closely related to the professional workplace context. Huhta et al. claim that the CEF clearly describes the context where the communication occurs. By this, they and their model stress the importance of tasks in all communication. Huhta et al. (2013) takes advantage of the term 'social agency' used in CEFR to stress the importance of social relationship because language learners are "interwoven socially into diverse networks" (p. 15). This kind of needs analysis requires a holistic approach which views a learner as a whole person who appears in his or her social context (Huhta et al., 2013). This approach will take account of the individual and how he or she interacts in the context of his or her field of action.

Finally, the authors claim the necessity to triangulate sources of methods in conducting a needs analysis research including a combination of quantitative methods and qualitative methods. The lack of varied methods of data collection has been identified as one of the limitations of former needs analysis studies. This kind of triangulation would provide an ethnographic approach to needs analysis.

Based on the above-discussed reasons, the CEF model is developed which consists of six parts as follows:

Target profession: this is to collect background information on the profile, such as training and qualifications. 
Occupational information: collects general information about jobs and job descriptions, organisations or companies, and the role of foreign language in this job.

Context information: includes information about locations, persons, communities, companies and institutions, communicative situations and texts.

The most frequent situations and the most demanding situations: provide descriptions of professional communication situations.

Snapshots: offer the course designers narratives of a 'day-in-the-life' of the professionals (Huhta et al., 2013).

Proposing this model, Huhta et al. (2013) state that the CEF aims to develop a discipline-specific language profile. This profile serves two purposes. The first purpose is to provide "a solid empirical basis for curriculum planning" to course designers of both secondary vocational education and tertiary education. This is because in the context of ESP teaching, classroom contact hours are often limited in a course, and the availability of the leaners are often limited too. Thus, the design of any ESP course should bear in mind the limitation of time. This consideration leads to the second purpose which is to "serve as a foundation for tailor-made language courses in a given field" (p.27). That is, the design of language courses must focus on the specific and real needs of the particular target group of language learners.

Since its emergence, the CEF Professional Profile has been cited by a considerable number of studies such as Nha (2015), Caraiman (2014), Gollin-Kies, Hall, and Moore (2015), and Brown (2016). Brown (2016) views the CEF as a "very elaborate approach to ESP” (p. 100). It is elaborate because Huhta et al. describe a set of core interview questions to collect data about background information, context information (language-specific description, objectives of learning courses, materials, methods and assessment, and general communication objectives. As a result, Huhta et al. (2013) provides guidelines for creating someone's own CEF Professional Profile.

Gollin-Kies et al. (2015) argue that the CEF Professional Profile provides "a holistic picture of professional working life and communication needs, leading into course design characterised by project work, simulations and holistic communicative activities" (p. 124). This profile is a result of the work between the researchers from several European countries and individuals and organisations with different cultural, linguistic and professional fields. Gollin-Kies et al. (2015) see the CEF model such as both specific and inclusive. It is specific because it provides very precise needs analysis instruments. Gollin-Kies et al. think that this 
model also "goes well beyond a model of specificity that implies restriction, limitation, and exclusivity" (p. 124). It is inclusive because of its diversity. It helps the recognition that the kinds of communicative practices, levels of linguistic needs, motivations, and goals of individuals and institutions will vary in dynamic environments.

CEF informed the data analysis of the current study because of three reasons. First, the six parts in its profiles of needs share some common categories as described in Munby's (1978) CNP model. Context information (CEF) for example is similar to setting (CNP). Second, though Huhta et al. proposed the CEF Professional Profile for mechanical engineers in Finland in particular and Europe as well, there are potential differences regarding workplace contexts and especially cultural issues. The difference between CEF and CNP lies in the scope of needs. If the CNP model explores workplace communication in a complex way by looking at different aspects through eight variables, the CEF model tries to look at workplace communication in a holistic way instead of dividing it into separate variables. For example, Huhta et al. (2013) look at a communicative event and what is involved in that event such as the social dimensions of language use. Looking at contextual factors in workplace communication in the way described in the CEF Professional Profile is very useful in helping course designers identify relevant course content and planning course activities that are closely relevant to the learners' future professional job which can differ from places to places and countries to countries. Third, the view of communication needs in a more sociological way also helps identify the more complex dimensions of the language use in the lingua franca workplace, (including what Govindarajan and Gupta (2001) describes as the 'poor English workplace' where everyone's English proficiency is limited) a workplace where plurilingual and pluricultural issues should be taken into consideration. The snapshot can provide a picture of the communication needs of the participant. Though CEF informed the data analysis, the presentation of data findings of this study will be different, except for the borrowed 'snapshot' term.

\subsection{Methodological Approaches to Explore Workplace Communication}

Workplace communication is gaining an increasing focus among researchers worldwide. According to Koester (2010), any interaction, including both spoken and written interaction, occurring in the workplace is known as workplace discourse. These interactions occur in a wide range of occupational settings such as factories, offices, hospitals, government offices, private sectors and non-profit organisations. There are a number of different methodological approaches which have been employed to explore workplace discourse. This collective approach includes conversation analysis, pragmatics and critical 
discourse analysis. These approaches examine workplace discourse in the wider field of sociolinguistics to explore the complexity of the uses of languages in the workplace.

A study using a sociolinguistic approach explores "how language is used in social contexts" (Deckert \& Vickers, 2011, p. 1). Sociolinguists study the relationship between language and society. They are interested in seeking answers to the following questions: why do we speak differently in different social contexts? What are the social functions of language? How is language used to convey social meaning? An investigation into the way people use language in different social contexts can provide rich information about the way language works (Holmes, 1992).

When the intention is to explore the contextually situated uses of English, it is necessary to hear the insider's voice because "insider knowledge is essential to understanding what kinds of communication take place and what their consequences are" (Hall, 2013, p. 6). According to discourse analysts, an outsider analysis of text is insufficient because pieces of transcribed language from physical contexts are claimed to not be able to represent real face to face communication and has the potential of errors in interpretation (Huhta et al., 2013). Roberts, Byram, Barro, Jordan and Street claim that "we need a wider context in which discourses are embedded if we are to understand them from an insider's perspective" (Roberts et al. 2001, p. 84: cited in Hall 2013, p. 5). Such information from the insiders as to who needs to communicate (say or write) what to whom, for what purposes, what channels and modes are used, can tell us how their company works (Hall, 2013; Munby, 1978).

As can be seen in Figure 3 below, all methodological approaches to workplace communication/discourse fall into the domain of sociolinguistics. According to Wardhaugh (2001), sociolinguistics studies the "various functions of language in society" (p. 1). This approach asks important questions concerning the relationship between language and society, "with the goal being a better understanding of the structure of language and how languages function in communication" (Wardhaugh, 2002, p. 12). The understanding of the social practices in which language is situated is an important factor of effective communication (Kaewpet, 2011b; Munby, 1978). The relationship between these are shown in Figure 3 below. The study of workplace communication or workplace discourse has been the focus of numerous methodological approaches as can be seen in Figure 3, such as conversation analysis, pragmatics and critical discourse analysis. Since each workplace is a social context, all approaches that examine workplace discourse belong to the scope of sociolinguistics. It should be noted that these methodological approaches are interrelated, especially in a needs analysis study which aims to explore the English communication needs 
of the participants. Workplace communication can be examined in terms of talk in politeness strategies when the participants use directives or requests, for example. The use of directives and requests can reveal the relationship between the interlocutors.

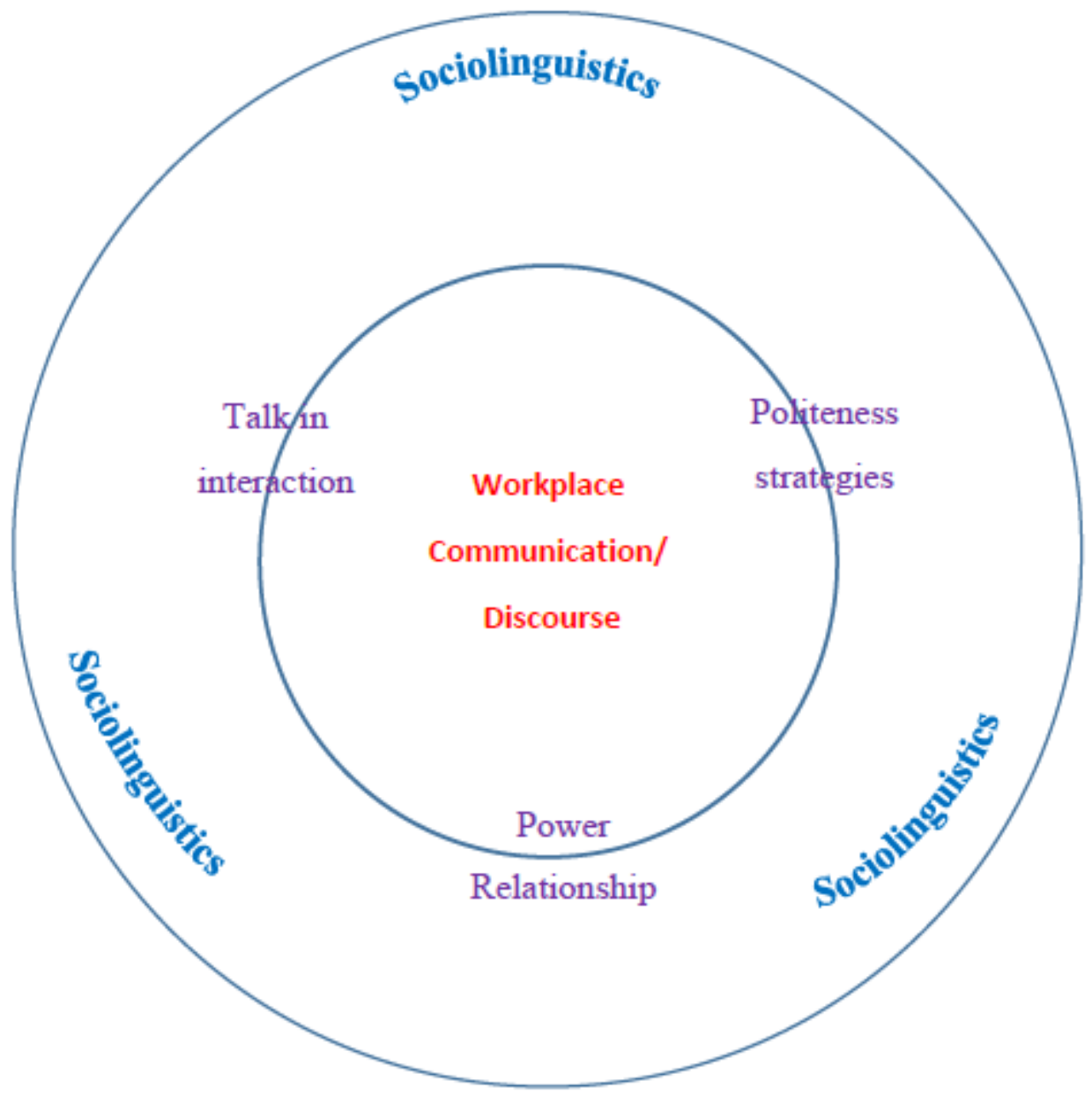

Figure 3: Methodological approaches to workplace communication

\subsection{The Conceptual Framework}

Followed by the review of different approaches and methodological approaches to needs analysis, this section presents the theoretical framework employed in the current study, which is illustrated in the following diagram.

As can be seen in Figure 4 below, which illustrates the conceptual framework for this research, Needs Analysis sits in the middle of the diagram. The framework illustrates how language needs may be investigated not only in terms of daily English (language skills, the types of English, and getting things done practically) which is illustrated through the communicative events the mechanical engineers are engaged in, but also through exploring their workplace relationships (how people negotiate getting things done practically and how they get on with each other also to serve the purpose of getting things done). 


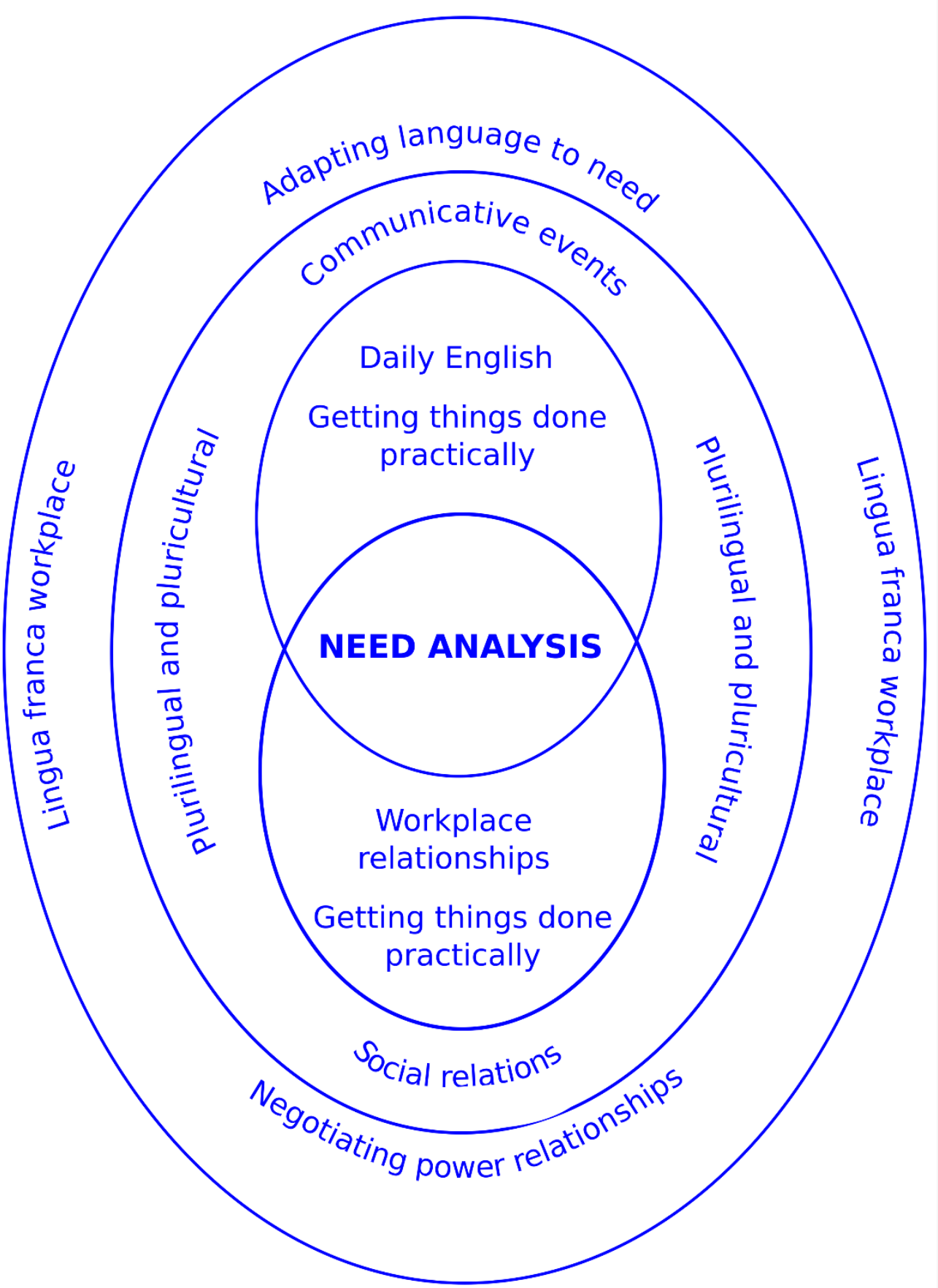

Figure 4: A conceptual framework for investigating learner needs

These two dimension are presented in separate circles intersecting at needs analysis. The circle of daily English illustrates the way that traditional needs analysis studies examine communication needs, while the circle of workplace relationship is the approach that this study uses to seek an insight into the complexity of workplace communication. The former relates to the ability to be adaptive in using English in the workplace. The latter relates to the issue of power brought about by English. That is, participants who have good English ability are empowered. In this case good English language skills could be described as a 
source of 'expert' power, which refers to a particular skill or strength of the participant. A sociolinguistic perspective allows us to investigate these two issues of adaptability and power in today's lingua franca workplace.

Within sociolinguistics, contextual or environmental factors constrain competence, or are involved in the development of people's communicative competence. Munby's CNP model is derived from Hymes's (1971) view on communicative competence. Hymes argues that sociocultural features need to be taken into consideration when assessing a language user's competence (Munby, 1978). Learning a language is not just learning the skills of that language, but also how these skills are used in real-world situations. Hymes is best known for the ethnography of communication which studies language in relation to culture and society, of which non-verbal communication is a part. Huhta et al.'s CEF model also puts contextual and environmental factors in the centre and views communication needs in a holistic way and the 'snapshot' category in the model illustrates the wider context of the communication of the participants in the domain. The worksites in the current study are considered lingua franca workplaces with plurilingual and pluricultural dimensions. The presence of many foreign managers who are non-native speakers of English makes these worksites more dynamic in terms of both workplace communication and social relationships. According to Richards and Schmidt (2010), sociolinguistic theory examines how people in a specified group communicate with each other and how social relationships between these people affect the types of language they use in that situation. Sharing the same view, Bayyurt (2013) states that sociolinguists study "the aims and functions of language in society" and attempt to explain "how language differs from one context to another across geographical borders and how people in one context communicate with people in other contexts" (p. 70). Bayyurt further claims that all "verbal communications among people fall within the realm of sociolinguistics" (p. 69).

Munby (1978) proposes the CNP model originated from "a sociolinguistic view of knowledge and communication" (p. 21). Later on, Kaewpet (2011b) adapted Munby's model to explore the demands for oral and written communication for engineering through a sociolinguistic lens. Boxer (2002) introduces ten methodologies to study face-to-face interaction; of these, the main ones are discourse analysis, conversation analysis, ethnography of communication, interactional sociolinguistics, and sociolinguistic interviews. This is because the data of her study is talk-in-interaction or "naturally occurring talk" (p.10), which allows her to analyse the data through various approaches. Stubbe (2010) claims the need to employ different methodologies in examining miscommunication and problematic talk at work. Stubbe used a flexible multi-layered theoretical and 
methodological framework including sociolinguistic discourse analysis, ethnographic information (data from actual interactions), and a community of practice perspective to critically analyse organisational communication practices. This framework allowed Stubbe to analyse miscommunication and problematic talk at different levels so that she could relate “what is happening sequentially and 'on-line' during particular interactions or sequences of interaction to factors such as social identity, group membership, team culture and other aspects of the wider communicative and socio-cultural context" (p. vii).

Generally, people conduct needs analysis studies to explore the target needs of the participants in the target situation. With this usual way of looking at needs, people can explore the kinds of language skills and the types of language that are required by the participants to function effectively in their work context. However, the data of this research show that there is more than this, that is, language use in the workplace is more complex. Thus, a needs analysis not only examines the linguistic needs but also the social aspects of the language use in the workplace. The examination is both about the 'what' (the types of English and English language skill) and the 'how' (how people adapt their use of English, how they use English for negotiating in communication, building and maintaining solidarity in the workplace). Within a lingua franca workplace, the employment of different methodological approaches allows the researcher to examine the workplace discourse at different levels to find out the actual communication needs of the participants. Therefore, these communication needs include not only linguistic needs such as English for technical communication but also the social needs for social communication, that is, the need to build and maintain relationships and the need to show identity, status and power in the social context.

\subsection{Chapter Summary}

There has been a long history of needs analysis where different approaches became prominent in each period of time with different scopes of research. Needs analysis studies could also examine the dynamics of the social dimensions of workplace communication which could be seen from the wider lens of sociolinguistics applied to the thematic analysis approach. The chapter has come up with a conceptual framework to explore the complexity of English communication needs required by mechanical engineers to function effectively in the lingua franca workplace. 


\section{CHAPTER THREE: STUDIES OF LANGUAGE NEEDS AND WORKPLACE COMMUNICATION}

\subsection{Introduction}

The requirements of English communication in the international workplace has been the focus of much research recently, but no research has examined the real-world English use of mechanical engineers in the Vietnamese context. This chapter reviews both empirical and theoretical literature that relate to the research topic in order to identify the research gap for the study. Section 3.2 reviews the key findings of needs analysis research which prioritises studies that are most relevant to the current study area of examination. Such themes as the importance of communication skills, the problems caused by lack of sufficient English, the participants' perceptions about workplace English, the identified gap between the workplace situation and actual teaching programmes, and interaction and adaptation to different linguistic and cultural conditions are reviewed. What seems to have been lacking in these needs analysis studies is the social aspects of language use in the workplace. Thus Section 3.3 addresses and reviews this in relation to the issues of humour, power relationships and miscommunication as drawn by the Wellington Language in the Workplace Project (LWP).

\subsection{Review of Studies in Needs Analysis}

The following section reviews twenty-nine studies in needs analysis published between 1991 and 2015. The review classifies them into research in the workplace and those in the study situation, which are mostly about students' perceptions of needs. The two tables below summarise the research in terms of author(s), year of publication, and research field and participants.

Table 2: Needs analysis studies in the workplace

\begin{tabular}{|l|l|c|l|}
\hline $\mathbf{N}^{\mathbf{0}}$ & \multicolumn{1}{|c|}{ Author(s) } & $\begin{array}{c}\text { Year of } \\
\text { publication }\end{array}$ & \multicolumn{1}{c|}{ Research field } \\
\hline 1 & So-Mui \& Mead & 2000 & Textile and clothing merchandisers \\
\hline 2 & Alharby & 2005 & Medical and health professionals \\
\hline 3 & Al-Khatib & 2005 & Tourism and banking personnel \\
\hline 4 & Kassim \& Ali & 2010 & Engineers at chemical companies in Malaysia \\
\hline 5 & Spence and Liu & 2013 & Engineers at a manufacturing company in Taiwan \\
\hline 6 & Stapa, Murad, \& Ahmad & 2014 & $\begin{array}{l}\text { Engineering technical oral presentation of } \\
\text { stakeholders }\end{array}$ \\
\hline 7 & Rajprasit and Hemchua & 2015 & Thai computer engineering professionals \\
\hline
\end{tabular}


Table 3: Needs analysis studies in the study situation

\begin{tabular}{|c|c|c|c|}
\hline $\mathbf{N}^{0}$ & Author(s) & $\begin{array}{c}\text { Year of } \\
\text { publication }\end{array}$ & Research field \\
\hline 8 & Chia, Johnson, Chia \& Olive & 1999 & Medical and health professionals \\
\hline 9 & Kittidhaworn & 2001 & Thai undergraduate engineering students \\
\hline 10 & Choi & 2005 & Students of tourism English \\
\hline 11 & Diallo & 2007 & Students of science and technology \\
\hline 12 & Venkatraman \& Prema & 2007 & $\begin{array}{l}\text { Mechanical engineering students with other } \\
\text { groups of participants }\end{array}$ \\
\hline 13 & Ab.Rahim & 2008 & $\begin{array}{l}\text { Engineering undergraduates' communication } \\
\text { skills }\end{array}$ \\
\hline 14 & Rosa & 2008 & Computer science \\
\hline 15 & Khuong \& Chi & 2008 & Electronics students \\
\hline 16 & Kaewpet & 2008 & Engineering students \\
\hline 17 & P'Rayan & 2008 & Engineering English \\
\hline 18 & Kaewpet & 2009 & Thai civil engineering students \\
\hline 19 & Adzmi, Bidin, \& Ibrahim & 2009 & Students of industrial design \\
\hline 20 & Kaneko, Rozycki, \& Orr & 2009 & Computer science \\
\hline 21 & Al-Tamimi \& Shuib & 2010 & Petroleum engineering students \\
\hline 22 & Kaur \& Ayub Khan & 2010 & Art and design students \\
\hline 23 & Salehi & 2010 & $\begin{array}{l}\text { Mechanical engineering students with other } \\
\text { groups of participants }\end{array}$ \\
\hline 24 & Kaewpet & 2011 & Thai civil engineering students \\
\hline 25 & Radzuan \& Kaur & 2011 & Engineering undergraduates \\
\hline 26 & Sattar \& Zahid & 2011 & Textile engineering students \\
\hline 27 & Zaid and Kamarudin & 2011 & $\begin{array}{l}\text { Mechanical engineering undergraduate } \\
\text { students }\end{array}$ \\
\hline 28 & Zohrabi & 2011 & Students and language instructors \\
\hline 29 & Rahman & 2012 & Computer science undergraduate students \\
\hline
\end{tabular}

Though the review reveals different findings for each study, five common major themes were found. They were identification of communication skills in English, reported problems caused by lack of sufficient English, contradictory perceptions of workplace knowledge, the reported gaps between needs analysis and actual teaching programmes, and interaction and adaptation to different linguistic and cultural conditions. These themes are presented as follows:

\subsubsection{Identification of communication skills in English}

English is described as the international communication tool in the engineering world (Kaewpet, 2011b), a lingua franca (ELF) of engineering education (Bjorkman, 2008; Riemer, 2002), and more broadly the lingua franca for professional communication in today's global business (Louhiala-Salminen \& Kankaanranta, 2011). ELF refers to "any use 
of English among speakers of different first languages" (Barbara, 2011, p. 7). ELF is a "flexible, co-constructed, and therefore variable, means of communication" (Cogo, 2015, p. 2). With its important role in international communication, English is now the lingua franca of the ASEAN countries (Kirkpatrick, 2008), an international language (Kaewpet, 2011b; Matsuda, 2003), and the universal lingua franca and predominant tool for global communication (Karimi \& Sanavi, 2014).

In a quantitative study about communication and language use in two international workplaces in Nordic countries where English was used as a lingua franca, LouhialaSalminen, Charles, and Kankaanranta (2005) found that English was the corporate language between the two corporations. Their study also revealed that email messages and meetings were the two most frequent communicative events of the respondents.

Evans (2013) conducted mixed methods research to investigate the use of ELF in key service industries in Hong Kong. The study found out that though the use of English varied according to the company's ownership and professionals' duties, this language played a crucial role in business communication in Hong Kong. In terms of frequency of English use, foreign-owned companies required more English than Hong Kong and Chinese-owned ones. Evans also found that professionals in foreign companies used more spoken English than those who worked in Hong Kong and Chinese companies. Overall, professionals in Hong Kong used more written communication than spoken, that is, they used more English reading and writing skills (especially email) than listening and speaking skills. English was the language of communication between Hong Kong professionals with foreign customers and clients. The study also revealed that the need for spoken English was determined by contextual factors, especially among those who were non-Cantonese speakers. These findings suggested that students should be prepared for English for a real-world lingua franca workplace.

Tasic (2009) examined the issue of English language teaching at the University of Niš, Serbia and claims this language to be the most significant foreign language among students of mechanical engineering. Mohamed et al. (2014) conducted a study to conceptualise and highlight the communicative events required by engineers in Malaysia. They state that graduate engineers needed to have appropriate English language skills and be able to communicate effectively to function well in the workplace context.

Regarding needs in the workplace, Kassim and Ali (2010) conducted a survey using a questionnaire with 65 engineers from 10 multinational chemical companies in Malaysia to examine the English language skills and communicative events required by engineers. In terms of English language skills, the study found that productive skills (speaking and 
writing) were rated as more important than receptive skills (listening and reading). The study reveals that good English communication skills are so important in Malaysia that employers want employees to demonstrate this ability in the job interview. A key finding in Kassim and Ali's research concerns the people with whom engineers communicate in their job. Since English is the major language used in the surveyed organisations, engineers were reported to communicate in English mostly with colleagues from international branches, then with clients or customers. The third most frequent communication in English was with supervisors. The less frequent communicative events were communication with Malaysian colleagues, suppliers and subordinates. On average, Kassim and Ali (2010) report that engineers used English more than $41 \%$ of their working time with all groups of people and almost of $50 \%$ of their total communications were conducted in English.

In terms of communicative events, of 14 communicative events which required English oral communication skills in Kassim and Ali's (2010) study, teleconferencing received the highest mean score with a frequency of $71-80 \%$. This was because oral communication skills were used more in multinational organisations where meetings were often conducted via network and teleconferences were held between international branches. Following teleconferencing, the most important communicative events, which had a mean score of 4.0, were giving oral presentations, discussing work-related matters formally, networking, presenting new ideas and handling external correspondence. This score meant that the frequency that engineers engaged in these communicative events was between $61 \%$ and $81 \%$.

Kassim and Ali (2010) also discovered that the use of English in communicative events was more important for the engineers' daily tasks than for their job promotion. The communicative events included informal conversations, formal presentations, following instructions and responding orally, teamwork, participation in meetings, internal and external networking, and conflict resolution. Though these communicative events were reported to be more important to the engineers' daily tasks than promotion, there was a clear relationship between excellent communication skills and promotion. That is, possessing good communication skills could enhance promotion.

Rajprasit and Hemchua (2015) conducted mixed method research to study the English language and communication of Thai computer engineers at four international workplaces in Bangkok. Questionnaires were completed by 40 engineers and four engineers took part in the interviews. The study revealed that English language proficiency was a necessity for engineers' job recruitment, job routines and job promotion. Computer 
engineers were found to communicate in English mostly with foreign colleagues in Thailand and other countries, then with supervisors, clients, subordinates, and suppliers and contractors. These engineers were more advanced in reading skills compared with other English language skills (listening, speaking and writing skills). They were reported to engage in different English communicative situations among colleagues in the same department, at meetings and in team work. Of these, discussing work-related issues informally, conversing informally and socially, and building relationships were frequent English communicative situations (Rajprasit \& Hemchua, 2015). The ability to understand a variety of English accents was also found to be important for successful international business communication. The study concluded that effective workplace communication in English was crucial for the success of both organisations and individuals. Lack of effective English communication skills was likely to have negative effects on the engineers' job performance in working with international colleagues and clients. Rajprasit and Hemchua (2015) suggested that "English language courses for engineering students should be based on real-world workplace situations" (p. 122) and that these students should be equipped with realistic language skills and be aware of the importance of comprehensibility rather than native-like English speech in communication.

Chia-Jung (1991) examined the English communication skills needs of 1001 Taiwanese professionals of different disciplines in the high technology industry using a survey. Chia-Jung found that of a majority of the respondents perceived the importance of English communication skills to their job performance (67\%) and job promotion (57.9\%). In terms of frequency of English communication with people, foreign customers or suppliers were the ones that these professionals spent nearly $70 \%$ of the time with, followed by visitors $61.7 \%$ of the time, colleagues $45.3 \%$ of the time or people in the same field $48.7 \%$ of the time, and foreign supervisors $20.3 \%$ of the time. The study revealed that these Taiwanese professionals used more reading and writing skills than speaking skills. The predominance of reading and writing were illustrated in the communicative events that they were involved in. Of the 17 identified communication tasks, the most frequently used were reading English professional journals or manuals and reports or letters, and writing letters, memos and reports. Despite this, these respondents believed that English conversation, English lectures/seminar/conference comprehension, English report writing, and English oral presentation were the most important English language courses that could help them improve their job performance. Thus, the study suggested that the English education in Taiwan should emphasise more practice of listening and speaking skills. 
In today's work market, employers prioritise engineering graduates who have good and effective communication skills in English (Lehtonen \& Karjalainen, 2008; Ngah, Radzuan, Fauzi, \& Abidin, 2011; P'Rayan, 2008; Yusoff et al., 2009; Zaid \& Kamarudin, 2011). Kaewpet (2009a) conducted a qualitative study with 25 participants including employers, civil engineers, civil engineering lecturers, and ex-civil engineering students of technical English to examine the communication needs of a group of Thai civil engineering students. Findings from semi-structured interviews showed that civil engineers would have to talk with English-speaking 'bosses' in person, take responsibility for international coordination, or welcome English-speaking visitors. Zaid and Kamarudin (2011) conducted a study with mechanical engineering students at a university in Malaysia by using a questionnaire to examine their oral communication needs. The participants perceived that they did not only take part in ceremonies at the company but also attended external meetings to do business with other national and international companies. In this case, they needed to communicate in English because it is "regarded as the international language" (p. 7). Riemer (2002), in a discussion on English and communication skills for global engineers, considers learning English as one of the important elements in the education of modern engineers.

Today, because technical qualifications seem to be the same among graduates (Zaid \& Kamarudin, 2011), communication skills in English are a significant criterion that makes a difference for future employment prospects. English as a medium of communication is now in growing demand because it plays a crucial role in workers' and their administrators' success in their jobs (Ngah et al., 2011). Lehtonen and Karjalainen (2008) examined employers' perceptions about the language needs of graduates by conducting interviews with 15 Finnish employers of graduates from the University of Helsinki. They found that languages skills were "a highly valued and useful tool" (p. 492) and that graduates needed to be very fluent in languages in a wider perspective. The employers also revealed that graduates needed to be fluent in presentations and interaction, be confident in conducting communication in various contexts and use English as a lingua franca. Though English is considered a 'life skill' or 'survival skill', the number of engineering students who possess good communication skills in this language is in the minority (P'Rayan, 2008). This fact is also reported in the context of Vietnam by Weng (2015) in his study of foreign managers' perceptions about communication at the international workplace. The employees' ability to interact and communicate with foreign managers is a key issue in Vietnamese workplaces (Weng, 2015). Based on an empirical study, Venkatraman and Prema (2007) claim that welldeveloped communication skills and a high level of English language proficiency should be 
incorporated in the profiles of modern qualified engineers because they can help engineers achieve success in today's competitive global work market.

\subsubsection{Oral communication skills in English}

The importance of oral communication skills has been identified in numerous research studies (Ab.Rahim, 2008; Adzmi, Bidin, \& Ibrahim, 2009; Al-Tamimi \& Shuib, 2010; Bhattacharyya, 2014; Chia-Jung, 1991; Chia, Johnson, Chia, \& Olive, 1999; Kaewpet, 2009a; Kakepoto, Omar, Boon, \& Iqbal, 2012; Mohamed et al., 2014; Moslehifar \& Ibrahim, 2012; Radzuan \& Kaur, 2011; Stapa, Murad, \& Ahmad, 2014; Talif \& Noor, 2009; Zaid \& Kamarudin, 2011). If engineers work in a situation where English is a medium of communication, they are expected to use English both formally and informally. In other words, they need English to talk about their daily task and duties with their 'bosses', supervisors, colleagues and customers (Kaewpet, 2009a).

According to Riemer (2002), oral communication skills and presentation skills are considered "one of the best career enhancers" (p. 94) which can determine the success or failure of a student's career. Kassim and Radzuan (2008) conducted a study with 30 chemical engineering students in a university in Malaysia with the aim of resolving conflict and enhancing their English fluency in workplace situations. Kassim and Radzuan claim that all engineers must possess effective oral communication skills to become excellent workers in their field. Young (1995) studied communication skills in the workplace and claims oral communication as "the mode of choice in most workplaces today" (p. 3).

In his study with fifty engineering lecturers, Ab.Rahim (2008) reveals that verbal communication skills such as "the skills of facilitating groups and/ or meetings and responding appropriately to questions are truly important to practising engineers" (p.176). Adzmi et al. (2009) investigated the English language needs of 41 industrial design students, seven industrial design instructors and six industrial design English language instructors. They found that sub-skills in oral communication such as presentation skills, group meetings and public speaking skills are reported as the most frequently used in the design workplace. However, Al-Tamimi and Shuib (2010), in a study of the English language needs of petroleum engineering students at a university in Malaysia, report that students have poor oral communication skills in contexts such as group discussions, meetings, interpersonal conversations and public speaking.

It should be noted that most of the reviewed needs analysis research employs students as the main stakeholders, and may have different perspectives compared to professional engineers. Stapa et al. (2014) conducted a survey with 235 students from six engineering 
faculties at the Universiti Teknologi Malaysia to examine the issue of technical oral presentation skills. The findings show that students have problems with the ability to deliver technical oral presentation skills not only in terms of the content of the presentation and the manner of delivery, but also in language use. 51.5 percent of the students reported that they have poor presentation skills and that their knowledge of presentation skill was inadequate. This knowledge includes the pace of delivery, the intonation in the presentation, the use of non-verbal communication and reading prepared notes. They were also concerned about the lack of clarity and length of the presentation points, how to respond to questions and how to give examples, as well as how to organise the content of the presentation. Another issue was the students' level of confidence in delivering presentations. $56.2 \%$ of the participants said that they were not confident in delivering technical oral presentations because of their worry and feelings of anxiety. A key issue that affected the students' ability in delivering technical oral presentations was their English language proficiency. Of the total students surveyed, $64.7 \%$ indicated their poor command of English ability, especially in regard to their concern about pronunciation. When they were asked to give suggestions to improve this skill, the students suggested reading books and articles, self-study multimedia courseware, watching video clips of successful presentations on the internet, and consulting experts. It is hard to know if these ways of improving technical oral presentation skills are close to the students' future real-world workplaces.

The written skills of reading and writing an additional language can be challenging for the learner, but the oral skills of listening and speaking may hold even greater challenges. According to Radzuan and Kaur (2011), technical oral presentation is a demanding skill for engineering students. By employing qualitative research using six focus-group interviews with a total of 44 students, Radzuan and Kaur (2011) found that the first problem leading to students' worries and anxiety was the evaluation panels made up of faculty lecturers and professional working engineers of the relevant industry. It was the demanding and provocative questions from the panels that made them anxious in their presentations. Again, the command of the English language was the second ranked problem, followed by the limited technical knowledge that students encountered in presenting their Undergraduate Research Project as a part of their graduation requirements. The low level of English proficiency prevented the students from giving a smooth presentation. What concerned them was the possibility of misinterpretation from the evaluation panel because of their use of English. It could also be because of their limited vocabulary that they could not convey the message clearly. The study raised the importance of good preparation of English language 
for engineering students. This would help students to be less anxious and more confident in oral presentations and equip them with relevant skills to enter competitive workplaces.

Zaid and Kamarudin (2011) conducted a study on the oral communication needs of 70 mechanical engineering undergraduate students in a university in Malaysia. The findings show that the most important activity that these students thought useful was classroom presentation because it is one way of practising communication skills. Making telephone conversations was perceived as the most needed activity in the students' future communication at the workplace because they believed that everything started with a phone call. However, more than $50 \%$ of students in the study also stated that they had problems with their communication skills in English, such as pronunciation and lack of confidence.

Spence and Liu (2013) studied an English needs analysis of process integration engineers at a Taiwanese manufacturing company. The study found that the common oral communicative events of these engineers included meetings, teleconferences and presentations. Also, these oral skills were "in particular demand for customer visits and relationship building" (p. 97).

Findings from the literature review show that speaking is perceived as the most important skill by students of almost all fields (Adzmi et al., 2009; Al-Tamimi \& Shuib, 2010; Choi, 2005; Diallo, 2007; Kaur \& Ayub Khan, 2010; Khuong \& Chi, 2008; P'Rayan, 2008; Rosa, 2008). However, the review reports that engineering students are not only weak in communication skills (Al-Tamimi \& Shuib, 2010; Diallo, 2007; Salehi, 2010; Zaid \& Kamarudin, 2011), but also lack confidence (Stapa et al., 2014; Zaid \& Kamarudin, 2011). As well as excellent oral communications skills, a high degree of competence in written communication skills is required by employees.

\subsubsection{Written communication skills in English}

Learners of a language need to understand that written language differs from oral language in how it is used, in its contexts, its structure and in its level of formality. Written communication skills such as writing emails, proposals, and reports are reported to be important for graduates because they need these skills to perform office work effectively, for example, essay writing tasks (Kaur \& Ayub Khan, 2010), and the writing of emails, faxes and business letters (Kaewpet, 2009a). Similarly, writing abilities such as writing effective proposals, writing technical reports, writing informal and formal emails, writing instructions, and writing memos are found to be of importance for communication of practising engineers (Ab.Rahim, 2008). 
In the workplace, So-Mui and Mead (2000) examined the English communication needs of textile and clothing merchandisers and found that written English was of greater use than spoken English. Real-world use of English in the writing of emails, faxes and business letters were found in Kaewpet (2009a) and Kaneko, Rozycki, and Orr (2009). Writing faxes is reported in So-Mui and Mead (2000), and writing an impressive curriculum vitae was perceived as important by professional engineers in P'Rayan (2008).

In their study about the English communicative events and skills needed in the workplace, Kassim and Ali (2010) found that writing reports and writing proposals were the most important written components required and were used most frequently by engineers. Kassim and Ali also report other written communicative skills as writing memos, writing formal letters, minutes of writing and presentation slides. These written components were the most frequently used by the engineers at the workplace. Spence and Liu (2013) reveal that engineers were involved in numerous communicative events; of these, writing and reading of email, reports and memos were highly frequent.

Within written communication skills, technical writing is described as important for effective communication in the field of engineering (Ab.Rahim, 2008; Salehi, 2010). Technical writing is identified as the most important skill for students' future jobs and careers. While note taking is perceived as the least important, searching on the net and writing research papers are perceived the most important (Salehi, 2010). Professional writing skills such as writing business letters, reports, proposals, project and technical articles are also perceived as important by engineering students (Venkatraman \& Prema, 2007). In a study using a questionnaire with 104 employers at Silicon Valley, Stevens (2005) investigated the communication skills required in their workforce. Stevens found that email communication was very important in the professional business communication channel and that the employers stressed the necessity of being aware of and understanding this importance. Kaewpet (2011b) found a competency gap in report writing of new engineers.

\subsubsection{Reported problems caused by lack of sufficient English}

Because English is important in the workplaces of many countries as a lingua franca, workers in different countries need to be skilled in English usage. Proficiency in this language is an employability skill (Ngah et al., 2011; P'Rayan, 2008). Lack of sufficient English can cause some serious problems for graduates internationally. Many graduates in general, and engineering graduates in particular, have been reported as failing when applying for jobs due to their lack of sufficient English language. They face many problems both in the workplace and in the educational setting because most of them are rather weak in 
communicative competence (Zohrabi, 2011). In his needs analysis study of engineering undergraduates' communication skills, Ab.Rahim (2008) reported that 90,000 Malaysian graduates were unemployed due to their lack of soft skills, which included English language and the ability to communicate. Kaur and Ayub Khan (2010) quotes Tan Sri Khaled Nordin, the Higher Education Minister of Malaysia, who claims that excellent English proficiency, together with critical thinking and communication skills, are the common foundations for graduates of all disciplines. Poor English is one of the factors leading to unemployment among graduates. Similarly, Zaid and Kamarudin (2011) state that the reason for unemployment among many graduates is their lack of communication skills, especially the ability to communicate in English even when they possess excellent graduation results. The Malaysian government sees the lack of soft skills as a problem and that it is the responsibility of local universities to help their students meet the needs of industries by further improving methods of training.

Regarding workplace professionals, Rajprasit and Hemchua (2015) found that proficient communication in English was a key to success for both organisations and individuals, while a lack of communication skills tended to result in a negative influence on the engineers' job performance, especially in dealing with international clients and colleagues. Weng (2015) found that Vietnamese employees had difficulty in giving feedback and asking questions in communication with foreign managers. These managers perceived asking questions as their most important language skill, because if the employees did not know what the managers wanted, they might make unnecessary mistakes. The study also found that these employees had a deficit in vocabulary and limited understanding of the many common words used in the workplace, which made it difficult for them to understand the job instructions.

Al-Tamimi and Shuib (2010) found that most graduates in the petroleum industry had failed in getting jobs with oil companies in Yemen. The former Yemen Minister of Oil and Minerals advised petroleum engineering graduates to improve their English to give themselves opportunities for employment. In the context of Saudi Arabia, Alharby (2005) argues that the lack of English language ability prevents many young graduates in different disciplines from being hired by companies.

In his Ph.D. research on engineering English, P'Rayan (2008) found two more problems besides unemployment that were caused by lack of sufficient English. The first problem was the limited opportunities to pursue higher education in English speaking countries such as the United States and Australia, which required engineering graduates to 
have a high score on TOEFL or IELTS. The second problem was job loss. A number of IT engineers, for example, had been dismissed because of their poor communication skills in English.

Another problem for engineering graduates is communication breakdown. This problem is found in the Thai engineering context where English is used for communication in all workplaces (Kaewpet, 2009a) and in the Vietnamese context as well (Le, Wyatt, \& McCullagh, 2016). This breakdown, for example, may happen when an engineer has a job interview with an Australian team leader, or in communications between the 'boss' and his staff (e.g. engineers and supervisors). More detail about miscommunication will be presented in Section 3.3 on the social dimensions of language use.

These above-reported problems are consistent with the findings from needs analysis studies that identify students as having a low level of English proficiency (Al-Tamimi \& Shuib, 2010; Diallo, 2007; Kaewpet, 2009a, 2011a; P'Rayan, 2008; Rahman, 2012). These studies also reported students' contradictory perceptions of workplace knowledge.

\subsubsection{Contradictory perceptions of workplace knowledge}

Students have different beliefs about what skills and knowledge are required in the workplace. While a majority of students perceive the importance of workplace knowledge and express their lacks and wants or needs, some students are confident with their preparation.

In a study conducted by Al-Tamimi and Shuib (2010), students rated their English proficiency as either below average or weak, especially communication skills. This explains why $96.2 \%$ of the students gave their priority to speaking, $81.4 \%$ to communication skills and $90.1 \%$ preferred an EOP course with job-related skills because these could help them function effectively in the workplace.

The crucial importance of English for the sake of work was reported in Chia et al. (1999), Sattar and Zahid (2011), Venkatraman and Prema (2007), and Zaid and Kamarudin (2011). Chia et al. (1999) found that both students and faculty members perceived English to be important for students' medical studies. Venkatraman and Prema (2007) found that engineering students place listening skills first, and professional speaking skills (job interviews, group discussion and debates) second in order of importance. These students were aware of the industry's concern about communication skills as well as the requirement of high English language proficiency for them. In another study, Sattar and Zahid (2011) investigated the linguistic needs of Garment Manufacturing (GM) and Yarn Manufacturing (YM) and found that $34.3 \%$ of GM and $35 \%$ of YM students ranked work as their first need 
when learning the English language, followed by training needs, at $31.4 \%$ and $25 \%$ respectively.

Despite students identifying the importance of workplace knowledge as well as English, a number of students from different disciplines including engineering express their confidence in English preparation for the workplace. Kaur and Ayub Khan (2010) conducted a language needs analysis study of art and design students and found that these students were not only aware of the employers' expectations and requirements for employees' speaking and listening skills when they were at the workplace, but $90 \%$ of them also claimed their confidence in their readiness to use their English in their future jobs. $30 \%$ out of $90 \%$ even strongly agreed with their readiness.

In a study about mechanical engineering, Venkatraman and Prema (2007) found that mechanical engineering students in India considered activities such as making telephone conversations, delivering speeches, giving instructions or briefings, external meetings with clients, giving presentations, internal meetings with staff, and participating in seminars are potential future needs for the workplace. However, these findings were only perceived by students themselves, which may raise the question of whether these perceptions match real workplace needs.

\subsubsection{The reported gaps between needs analysis and actual teaching programmes}

Findings from needs analysis studies show considerable gaps between students' needs of 'real-world' use of English and actual teaching programmes, such as a contrasting preference for English language skills between teachers and students and inappropriate curricula.

Teachers and students sometimes do not have the same preference in teaching and learning the English language. Sattar and Zahid (2011) found that students preferred to learn English communication strategies and wanted to improve listening and speaking skills rather than grammar or translation methods. Their teachers, on the contrary, preferred teaching methods that focused on grammar rules and concentrated on improving students' speaking and writing skills. Similarly, professors and students were reported to have contradictory priorities on speaking skills (Diallo, 2007). While specialist professors rated speaking last, students rated it first. Regarding medical students, Chia et al. (1999) found that students wanted more concentration on developing medical vocabulary, whereas faculty members placed more emphasis on medical research writing and report reading.

The opposite perception of the importance of English language skills between teachers and students can be found in Adzmi et al. (2009) and Rosa (2008). Teachers 
perceived reading as the most important skill to be acquired by students, but students claimed speaking as the most important.

In terms of oral communication, teachers claimed explaining information/ideas/opinion and communication with the public to be the most important, while students claimed presentation and public speaking skills as the most important (Adzmi et al., 2009).

There is a gap between the requirements of the employment market (target situation) and the level of English language proficiency of existing students (P'Rayan, 2008). P'Rayan claimed the "absence of effective syllabus, methodology, course organization, assessment and learning outcome" as reasons for this gap (p. 211).

In addition, English courses at some universities do not meet the students' needs. Kaneko et al. (2009) state that the current university curriculum is not meeting the career needs of the majority of students. Therefore these researchers are incorporating changes in the instructional content of the course lesson plans and preparing students for practical professional needs to include reading and writing memos, emails; and oral skills in social communication such as small talk (Kaneko et al., 2009). Engineering students say that they are 'moderately satisfied' with their current English courses at universities (Alharby, 2005; Diallo, 2007; Kaur \& Ayub Khan, 2010), and students of tourism state that they are not satisfied with the current curriculum (Choi, 2005). Students give their priority to communications skills, such as presentation skills, group meetings, and communicating with customers, and want to have more speaking tasks incorporated into the curriculum (Ab.Rahim, 2008; Al-Tamimi \& Shuib, 2010; Salehi, 2010). Students expect to have adequate programmes, appropriate materials and efficient classes with a focus on their specific needs (Diallo, 2007). These students' wants and expectations are in line with a conclusion made by P'Rayan (2008) that "the absence of standard course books contribute to students' lack of English language and communication skills" (p. 211).

\subsubsection{Interaction and adaptation to different linguistic and cultural conditions}

Lehtonen and Karjalainen (2008) examined the employers' perception of the workplace language needs of university graduates and found that good language skills "included good communication and presentation skills, confidence to use a foreign language, and the ability to interact and adapt to various linguistic and cultural conditions" (p. 497). Good language skills also meant the employees' knowledge of language had to be at a high level so that they could perform such tasks as "negotiating, giving and attending lectures and presentations, writing up contracts and drafting project plans" (p. 497). The study also 
reveals the importance of having the knowledge of culture, particularly in the lingua franca, plurilingual and pluricultural workplace where "the participants are often expected to adapt to the demand of the 'cultura franca', the nature of which depends on the cultures of those present" (Lehtonen \& Karjalainen, 2008, p. 498).

Weng (2015) reports that Vietnamese employees have to adapt to survive in the workplace by showing their willingness to acquire and learn new relevant skills and working hard to perform their job effectively.

This section has reviewed recent studies in needs analysis in different parts of the world. However, most of these were conducted through questionnaire and interview without using observations, to give an in-depth investigation into various workplace contexts where English can be used in various ways. The literature search reveals that needs analysis in these studies tends to be driven by an economic pressure. It is a fact that it is easier and more manageable to collect survey data than to do intensive interviews and observations. Though some important findings have been found and reported above, no needs analysis research has been conducted in Vietnam to study the 'real-world' use of English of mechanical engineers in the workplace. This literature search is consistent with findings of a recent study by Serafini, Lake, and Long (2015), who surveyed needs analysis research in the last 30 years. In total Serafini, Lake, and Long examined 32 studies of different majors and contexts by classifying them into two periods (1984-1999 and 2000-2014). Of these, 18 studies employed a mixed methods design and 11 studies employed observations as one of the methods of data collection. It should be noted that only five out 32 studies were conducted in the field of engineering in general and none of the studies was about mechanical engineering in particular.

Besides the gap identified in the above-reviewed studies, most of the studies cited above focus on the kinds of language skills required in the workplace. The review also reveals that very few needs analysis studies have examined communication issues due to a lack of sufficient English language skills as well as the strategies people use to avoid these issues. Recent studies in workplace communication complicate this picture, as they start to examine the social dimensions of workplace communication in English. The following section will review some of this research on the social factors and social dimensions found in the use of English in the workplace in order to offer important insights to pedagogically orientated needs analysis research. 


\subsection{Social Dimensions of Workplace English}

This section is mostly informed by the Wellington Language in the Workplace Project (LWP). The section discusses workplace meetings where English is frequently spoken. Attending meetings is one of the most common communicative events that professional engineers are likely to engage in in the workplace. Meetings are the place where most of the decisions are made and where the social dimensions of language use such as humour and 'doing power' and solidarity relationships can be seen. Meetings are also the place where breakdowns in communication can happen.

\subsubsection{Workplace meetings}

Meetings in organisations or professional contexts have been the research interest of many researchers. There are different ways of describing or defining what a meeting is. According to Allen, Lehmann-Willenbrock, and Sands (2016), meetings are "work-related interactions between three or more people that have purpose and structure; they are usually scheduled in advance, last between 30 and $60 \mathrm{~min}$, and can be conducted face to face as well as virtually" (p. 4340).

Researchers and scholars have studied the discourse of meetings with different lenses or from different perspectives (Holmes \& Stubbe, 2015; Stubbe, 2010). These include the discursive strategies used to manage the meeting, the realisation of status in meetings (Craig \& Pitts, 1990), unintended impoliteness in meetings (Holmes, Marra, \& Schnurr, 2008), the complexities of things done interactionally through talk in meetings, and especially the issue of power in meetings (Craig \& Pitts, 1990). Holmes and Stubbe (2015) focus on the manifestation of power and politeness in meetings in the workplace.

Holmes and Stubbe's (2015) examination of workplace meetings was a part of the Language in the Workplace Project in New Zealand. The data were collected from 80 meetings in nine different workplaces, which were almost all audio and video recorded by the participants. These meetings varied in terms of degree of formality (both formal and informal) and the goals and purposes. Holmes and Stubbe argue that informal meetings are a crucial way for workplace business to be done. They claimed that meetings are the main sites in a workplace for exercising power and showing politeness, especially in more formal meetings where the manifestation of authority and power is more overt and easier to observe.

Bargiela-Chiappini and Harris (1997) claim that the participants in meetings are "task-oriented" and "assigned to work in teams" (p. 208). Holmes and Stubbe (2015) identify formality, participant relationship, gender, and goals and purposes as variable features of 
meetings. Formality varies in terms of dimensions or scales for comparing meetings, such as the size of the meeting room, whether it is large or small, whether it is a formal setting or unplanned location, whether the starting time is specified or the meeting happens by chance, and whether a finishing time is specified or the meeting finishes naturally. The comparison is also about whether the participants are specified or if it is opened to anyone, whether there is a formal procedure or informal style, an explicit structured agenda or 'rolling' agenda, a tightly integrated group or loosely connected group, and a mixed gender group or samegender group. These dimensions affect the degree of formality of the meetings. For example, small meetings seem to be less formal while larger meetings tend to be more formal.

The participant relationships were reported to affect the degree of formality, for example, the amount of small talk or everyday talk, and the issue of humour in meetings. Holmes and Stubbe (2015) found that a tightly integrated group (people who knew each other well) were likely to engage in more personal talk at the beginning of meetings and they tended to make more jokes or be more humorous. The loosely connected group were those who worked together on a single project and met weekly for a short period of time and then had no further contact after the project ended.

In general, Holmes and Stubbe (2015) classify meetings into three types based on the main purpose of meetings. The first type is the planning or prospective/forward-oriented meeting to assign tasks, request actions and make decisions. The second type is the reporting or retrospective/backward-/backward-oriented meeting to report, classify, give feedback, request information and update information. The last type is the task-oriented or problemsolving/present-oriented meeting to solve problems, complete collaborative tasks and exchange information. Of these, the first and the second types tend to be scheduled in advance while the third type tends to take place spontaneously.

There have been reports on the ineffectiveness of meetings (Geimer, Leach, DeSimone, Rogelberg, \& Warr, 2015) and satisfaction in meetings (Allen et al., 2016). Geimer et al. (2015) conducted a qualitative study to examine the factors that affect perceptions of meeting quality. They recruited 1223 participants who were employees from 41 countries. The participants were invited to offer comments about the effectiveness of meetings and suggest ways to improve their effectiveness. The study employed content analysis and coding themes in analysing the data. Of the total participants, 1065 respondents (87.1\%) provided usable answers to the first open-ended question about the effectiveness of meetings, and 700 people provided recommendations to improve the meeting effectiveness.

Regarding meeting effectiveness, the respondents' comments were coded into four 
main themes. The first theme is people, which refers to behaviours. The second theme is meeting organisation, which refers to structural factors such as meeting agenda and meeting composition. The third theme is meeting activities, which refers to meeting contents. The last theme is meeting outcomes, which refers to decision-making. Across these themes, fewer than half of the respondents $(49.1 \%)$ indicated meetings as positive or effective, nearly one-third of them (30.3\%) described meetings as negative, and $20.5 \%$ of the participants said that they felt neutral or ambivalent about meetings. The themes that received the highest number of negative comments were meeting organisation at $43 \%$ (with 126 respondents out of 197 people commenting) and meeting outcomes at $11.9 \%$ (with 42 respondents out of 353 people commenting).

Regarding the participants' suggestions to improve the effectiveness of meetings, there were 656 agreed-upon time-of-action codes. Of these, more than half of them $54.6 \%$ suggested improving the meeting structure and organisation, while $19.8 \%$ were concerned about the contents and specific activities of meetings. Sixteen percent were concerned about people, $5.6 \%$ were concerned about communicating meeting outcomes and achieving meeting purpose, and $4.0 \%$ were concerned about removing barriers and constraints in order to improve meetings.

Meetings are an essential context for interpreting organisational behaviour and the attitudes of employees. Allen et al. (2016) argue that employees can be empowered by feeling satisfaction in and with meetings. Allen et al. conducted an online survey of 148 participants across the Southeast region of the United States to examine how and when satisfaction with meetings has an impact on employee empowerment. The findings show that meetings have the potential to positively boost employee empowerment. Satisfaction with meetings provides access to information which also boosts empowerment. There is a close link between employees' meeting satisfaction and information availability. Employees who felt satisfied with meetings seem to have all the information necessary to complete their work tasks, and they felt more empowered. The final finding is that the higher the meeting demands are, the stronger the relationship between meeting satisfaction and information availability.

\subsubsection{Humour in the workplace}

When studying peoples' interactions through a sociolinguistic perspective it is useful to consider how humour is used in communication. Humour is prevalent in the everyday communication of human beings (Meyer, 1997). It is "a valuable multifunctional resource in workplace interaction" (Holmes \& Stubbe, 2015, p. 109), which plays a crucial role in 
building and maintaining and improving good relationships at the workplace (Barsoux, 1996; Holmes, 2006; Plester, 2009). Humour also has the ability to promote productivity, functions as a teamwork facilitator and a morale booster, and helps people to face difficulties in their work lives (Caudron, 1992). When it is used effectively in the workplace, humour can help generate new ideas (Holmes, 2007) and facilitate collaboration in business meetings (Rogerson-Revell, 2007), but it can also have negative effect of facilitating collusion (Rogerson-Revell, 2007). Barsoux (1996) identifies two types of humour, these being standardised humour and spontaneous humour. The former includes, for example, the cartoons and jokes that we can find on the office walls. The latter "is very much situationspecific" (p. 500) and can be quite subtle, involving a word, tone of voice, or gesture. Since spontaneous humour arises in a particular context or circumstance, it makes less sense outside that context.

Plester (2009) conducted a qualitative empirical study to examine the impact of humour on the organisation culture of four different companies in New Zealand. The study employed observations, interviews and document analysis to explore how humour is used to deal with the vagaries, stresses, and everyday troubles that people encounter in the context of their work. The study focused on investigating the positive side of humour as "relieving tension, dealing with adversity and softening directives and requests" (p. 94). These were the three main categories identified in the study. In the first category, where humour helped to relieve tension, participants highlighted its use to provide release from stressful work situations, even by using strong swearwords, such as 'fucking dork' or 'fucking bitch' (p. 95). This provoked laughter and gave the participants instant relief. In addition to this, employees reported using humour when they shared information and difficulties with their colleagues. The second category dealt with adversity. In this case, humour was used to share personal problems or distressing news such as a serious illness. The respondents were reported as informing each other of painful news in a humorous manner, probably to hide the fact that they were feeling upset and this was their way of coping with bad news. For example, Jake, a managing director, had a phone conversation with a client who was ill. After that Jake said to his nearby employees, "He's just had a bone marrow transplant so basically he's fucked"...(laughter). "He said he'll be alright in a couple of years! I should have told him every day above ground is a good day" (laughter from the group)". Jake used "he's fucked" and "every day above ground is a good day" to talk about the painful news that his client was ill and this made his employees laugh. 
The third category is a directive and request softener. Humour was reported as being used to soften managerial commands and reprimands or to turn an argument to someone's favour.

Though all the respondents in the study perceived the importance of the role of humour in helping them to feel relief and get rid of stress in their work or difficult workplace situations, the use of humour was more successful when used by people who had a good sense of humour. When it is used unsuccessfully, humour can hurt people's feelings and create group disharmony.

Like Plester (2009), Holmes and Stubbe (2015) identify the good points or good functions of humour in the workplace context. However, according to Holmes and Stubbe, humour does not only function to create and maintain group solidarity, it is also an important resource in constructing and managing power relationships in the workplace. They note that workplace humour is obviously context bound and a meeting is a common place for using humour. They state that "many meetings are punctuated by bursts of humour, which tend to occur at strategic points" (Holmes \& Stubbe, 2015, p. 109).

In the context of workplace meetings in non-English speaking countries, the use of humour promotes solidarity. Mohd Omar and Mohd Jan (2013) examined the use of humour in building asymmetrical and symmetrical relationships in an academic institution in Malaysia. The study applied Hay's (1995) theoretical framework, which categorises the functions of humour in strengthening solidarity into sharing, capitalising on shared meaning, classifying and maintaining boundaries, and teasing. Four meetings were video-recorded, with a total of 382 minutes length. The findings showed that humour was found in all meetings and was used to build solidarity through teasing $(42.15 \%)$, clarifying boundaries (25\%), capitalising on shared meaning $(16.7 \%)$, and sharing $(10.4 \%)$. The study confirms that the functions of humour in the study are similar to those in the Western contexts in terms of building and improving solidarity in the workplace.

According to Murata (2014), most research on workplace humour is about humour in English-speaking contexts. Murata (2014) conducted a contrastive analysis study of humour in seven business meetings in Japanese in a Japanese company and nine business meetings in English in a New Zealand company. These meetings were video-and/or audio recorded. The study took both a social constructionist approach and used interactional sociolinguistics as analytical frameworks, because humour was not only seen as a relational strategy among interactants but also related to cross-cultural communication. Findings show that the biggest difference between the two companies is the individuals who contributed to 
humour. In the New Zealand company, all people were free to contribute equally to humour. In the Japanese company, people who were in authority like the chairperson initiated the humour and others responded to it. The study also suggests that the use of humour might be a result of cultural differences between the two countries.

As described in the introduction chapter of this thesis, Vietnam is becoming a potential employment market for highly qualified foreign employees. This employment requires and fosters the use of English as a language of communication in the workplace. However, the literature search reveals no research to date about the use of humour in English communication in the workplace in Vietnam in general use or in workplace meetings.

\subsubsection{Power relationships}

Research into the power of language in the workplace has been the focus of many studies including Bourdieu (1991), Brown and Levinson (1987), Fairclough (1989), Holmes and Meyerhoff (1999), Holmes and Stubbe (2015), Marschan-Piekkari, Welch, and Welch (1999), Vine (2004), Westwood and Rhodes (2013), and Yaoharee (2013). Power is considered "a relative concept which includes both the ability to control others and the ability to accomplish one's goals" (Holmes \& Stubbe, 2015, p. 3). It is often studied in relation to gender, humour and politeness. A review of studies on power shows that Brown and Levinson's (1987) model of politeness has inspired much research into power, gender and humour, as well as solidarity, and these are often examined in terms of discourse. It is clear that language is a very important means of enacting power (Holmes \& Stubbe, 2015).

\subsubsection{Discourse strategies as a means of 'doing power'}

According to Vine (2004), an examination of workplace data can reveal the concept of power because "power relationships exist between people employed at different levels within an organisation" (p. 1). Vine (2004) explored the issue of power among people from different job levels in a New Zealand workplace using both quantitative and qualitative methods. She reviewed two types of power, namely 'legitimate' power and 'expert' power. The former refers to the power that is based on the positions of the participants in terms of hierarchy, such as the manager and staff. The latter refers to power due to a particular skill or a strength of the participant. The study focused on examining directives, requests and advice used by the manager in terms of a speech act approach. The results showed that the managers used different forms of control acts, such as directives, requests and advice in interactions with their subordinates at different levels, including senior staff, executive assistants and administration staff. A control act is "an attempt to get someone to do something" (Vine, 2004, p. 27), while a head act is "the minimal unit which can realize a 
request; it is the core of the request sequence" (Blum-Kulka, House, \& Kasper, 1989, p. 275). Vine's study identified 364 control acts which had 439 head acts in total. Of these, directives constituted $73 \%$, equal to 265 control acts and 319 head acts, requests constituted $14 \%$ and advice constituted $13 \%$. These head acts were then classified into 276 explicit head acts and 163 implicit head acts. Again, directives constituted the largest number of both explicit and implicit head acts at 226 (equal to 71\%) and 93 (equal to 29\%) respectively. Explicit head acts consisted of imperatives, interrogatives and declaratives. Findings showed 87 control acts of directives, of which 73 were 'the base form of verb' (84\%), six 'you + imperative' control acts, six 'let's + imperative' control acts, and two 'embedded' control acts. It is clear that the base form imperatives and 'you + imperatives' were very forceful forms while 'let's' and 'embedded imperatives' were less forceful.

Together with imperatives, the use of interrogatives and declaratives were also reported in the findings of Vine's (2004) study. The former consisted of modal interrogatives, which took the form 'modal + you + verb' (for example, “can you just write up a bit neater" (p.77)) and non-modal interrogatives, such as questions. These interrogatives were used more with requests (30\%) than directives (11\%). The latter included modal declaratives such as 'pronoun + modal + main verb', marginal-auxiliary declaratives (for example: “you need to just check the travel booking”), if clauses and simple declaratives (for example: "you're talking to Mary"), and embedded declaratives such as "I wonder if" (p. 80).

The managers in this study also used mitigation to be less forceful in communication with their staff. For example, they asked their subordinates how they wished to do something. They had their staff involved in the decision-making process. Instead of exerting power differences between them and their staff, the managers were found to minimise their power and care for the face needs of the subordinates. The study claims that in order to understand power relationships in the workplace it is important to use a conversation analysis approach, which can be used to examine context at different levels.

Holmes, Stubbe, and Vine (1999) examined how language was used to construct professional identity in a government policy unit in New Zealand. The study applied discourse analysis, pragmatics and conversation analysis to explore the dynamic aspects of workplace interactions, which are believed to display the participants' identities. The authors state that "workplace interactions are seldom neutral in terms of power" (p. 354). They further claim that the analysis of professional identity closely relates to "the ways in which power and solidarity are enacted through discourse" (p. 354). Speech functions, discourse 
strategy and actual linguistic forms were the three levels of analysis employed in this research. The study also took into account the social and pragmatic factors of the participants, such as the status and social distance. Findings showed that managers exercised power in a wide range of ways. They used explicit discourse strategies which showed their role of authority, for example, "I intend to deal with this problem immediately" (p. 357). Also, the managers used speech acts to exercise power and show their controlling role in the meeting, as the workplace meeting is a good opportunity for people to enact their role and power. They managed the meeting by using explicit kinds of speech acts such as "setting the agenda, summarising decisions, and closing the meeting" (p. 358). An example of setting the agenda in a meeting is "what I would like to do is..." This was made clear at the beginning of the meeting. Summarising the main points of the meeting and making decisions on these points were reported as a strategy used by the manager. It was also the manager's responsibility to close an interaction. The managers were reported to issue directives (e.g. check the flight time), express approvals (e.g. it's really good, it's come out really well), and issue challenges (e.g. asking questions) to their subordinates to do power directly.

The managers used discourse strategies and specific forms of linguistics such as "meta-discoursal comments and meta-pragmatic expressions and illocutionary force" (Holmes et al., 1999, p. 362) to express their professional identity and relative power in workplace interactions. They used direct strategies in making requests or giving feedback. These included statements of agreement such as "yes, that's right" and expressions of approvals such as "good" and "fine", while the subordinates often used neutral responses such as "mm" and "yes" (p. 362).

Different choices of linguistic forms used by the managers with their subordinates could also help the subordinates signal the relationships between them. That is to say, the use of discourse in workplace interactions can reveal not only the relationships of the participants involved in terms of social distance and power, but also reflect the goals of these interactions.

In their recent work, Holmes and Stubbe (2015) further studied the issue of power in the New Zealand workplace. This was a part of the Language in the Workplace Project (LWP) which aimed to "identify the characteristics of effective communication in New Zealand workplaces, to identify the causes of miscommunication, and to disseminate the results of the analysis for the benefit of workplace practitioners" (p. 12). According to Holmes and Stubbe (2015), power in the light of sociology is "a relative concept which includes both the ability to control others and the ability to accomplish one's goals" (p. 3). They explored the power of the participants based not only on their authoritative positions 
but also on the linguistic manifestation used in workplace interactions. The authoritative position enabled the participant to 'do power' by issuing the rules that other people had to follow. The linguistic manifestation included expressions of directives such as imperatives, interrogatives and declaratives. Of these, imperatives were used more often than other linguistic forms, which showed power relationships directly and explicitly. Some examples of imperatives were "go right through this", "give them back to us", "get rid of them now", and "get him to make the changes" (p. 31). Other explicit forms of directives such as 'need' and 'want' were reported as being used by the managers. Stronger and more intense linguistic forms of directives such as 'very', 'definitely', 'must' and 'have to' were the strategies used by the leaders, which showed their authority over the subordinates.

The manager was reported to "draw on a variety of linguistic and pragmatic devices to decrease or attenuate the force of directives" (Holmes \& Stubbe, 2015, p. 36), such as modal verbs (may, can), justifications (for example: "I mean", “I just think", “otherwise we'll we'll we'll dart a bit”), and hesitation (for example: “we've we've”) (p. 32). These devices also included the use of praises, positive reinforcements, tag questions, hedges and rising intonation. Holmes and Stubbe emphasise that the use of the above linguistic forms closely relates to the discourse context. They could be interpreted differently when they were put out of the context, meaning that the participants might not feel offended by the manager's direct imperatives. However, these imperatives could cause offence to those of equal status when they were used out of the appropriate context.

It should be noted that the above-reviewed studies were conducted in the New Zealand context where English is the first language. This fact explains why most of the participants could use different discourse strategies and linguistic forms in different situations. Their choices of language uses could help them to enact their power directly or indirectly. The power explored in the studies seemed to be legitimate power or position power as it was enacted by the manager or the superior with their staff or subordinate. Few studies have focused on examining expert power (the power that is derived from a particular skill or strength of the participant), especially in non-English speaking contexts.

\subsubsection{Language as a source of "expert power"}

When workers are fluent in the language that is in high demand in their workplace they can be empowered in those organisations. This is an example of expert power. Marschan-Piekkari et al. (1999) conducted an exploratory, qualitative case study at Kone Elevators, a Finnish multinational cooperation, to examine the impact of language on the company's communication. In total, 25 units located in 10 different countries in Europe, Mexico and South-East Asia were selected for the study. Data were collected from 
interviews with 110 participants and from observation field notes. Findings reported in the study reveal that limited language skills seem to affect the development of relationships between participants.

Conversely, language could function as a facilitator in the company's inter-unit communication. Those who had better English skills had more contacts and networks, and perhaps had a higher profile in the company. This study is of particular interest in highlighting the role of language as a source of power. For example, English was used in communication across units in the company, and contacts between units were channelled to those who were able to use this language. This made the communication become personbound and also created dependencies in workplace communication networks. It was language that helped individuals have more power than their actual position indicated. Thanks to their language ability, individuals might gain more powerful and influential positions in the company. Being limited in language skills appeared to prevent subsidiary staff from building and maintaining horizontal relationships not only with other units in the company but also with the headquarters in the Kone context.

Notably, the study discovered a shadow hierarchy or hidden structure brought about by differing contributing language backgrounds in the Finnish company. There was in effect a shadow language-based power structure operating in terms of language groups in the company. Marschan-Piekkari et al's (1999) research opens the topic of how important language is for power relations in the company. In the case of Kone, the operational structure was based on language rather than geographical location. While in 1994 the formal organisation chart of the company was based on geographical regions, by 1996 it had changed to be based on language. The regions identified in the company structure in 1994 were Northern Europe, Central Europe, Southern Europe, North America and Asia/Pacific. The company structure based on languages starts with headquarters using English and Finnish, then Finnish (Finland and Finns as expatriates), English (USA, UK, Australia and South East Asia), Scandinaviska ${ }^{1}$ (Denmark, Norway and Sweden), German (Germany and Austria), and Spanish (Spain, Mexico and Italy). This new structure was called "a 'shadow' structure, lying behind the formal organisation chart" (Marschan-Piekkari et al., 1999, p. 433). This was because language skills helped to connect the company's units together. Within the shadow structure, the language distance showed the closeness or remoteness between the headquarters and subsidiaries.

\footnotetext{
${ }^{1}$ Scandinaviska: This is the original word used in the research, which means 'Scandinavian'.
} 
For example, those who were fluent in Finnish and English were closer to the headquarters than others. Scandinaviska languages were reported to be closer to the headquarters than Spanish. This was because the participants from Scandinavian countries tended to be able to use English and the Finnish managers were competent in Swedish and therefore could understand Scandinaviska as well.

English was described as a source of power for Japanese employees with proficient English ability by SanAntonio (1987). SanAntonio examined the implications of the English language only policy of an American firm in Japan using an ethnographical approach. The study found that "language use is a marker which can be manipulated situationally by an employee" (p. 194). The two main situations or communicative events were meetings and interactions with visiting foreigners. English was spoken at meetings, and it was required to be spoken in the presence of a foreigner. However, the study also found that Japanese employees spoke Japanese in meetings in the absence of the foreigners, and that they were animated and talkative. The foreigners conducted the meetings in a very formal, quiet and controlling style. They focused on turn-taking and brief answers. In these meetings, one employee, with good English ability and cultural knowledge of the foreign managers, dominated the meeting and spoke directly to the foreign managers as a language mediator. This was because the American managers would become angry if Japanese employees could not answer the questions quickly and clearly. English ability helped Japanese employees with good English language ability to construct their identity. They were aware of saving face for their Japanese colleagues by not helping them overtly in the meeting because that would show their poor English ability. These employees were assigned to accompany the visiting foreigners as interpreters. In this case they were empowered and involved in higher level meetings than their normal position. Thus, proficient English ability brought Japanese employees opportunities for promotion and training as well as admiration and respect from other Japanese colleagues.

Tange and Lauring (2009) examined the communicative practices within 14 multilingual Danish organisations and claim that the employees' behaviour should be explained in relation to languages skills and theories on social identity and power. The study found that the implementation of English as a corporate language leads to communicative practices of language clustering and makes the communication become thin. This results in a disruption in transferring information. Employees who master this language could access the communication patterns and information flow as well as engage in social relationships in the organisation, which is similar to the findings of Marschan-Piekkari et al. (1999). Those 
who lack this language were isolated from information networks in the company (MarschanPiekkari et al., 1999; Tange \& Lauring, 2009).

However, a lack of English language proficiency can be a great barrier in communication, which causes misunderstandings in the company. In the context of Kone, 92\% of the employees were foreigners. This fact increased the risk of problems in communication. Since the company language was English, all the company's reports and documents were in English. At a result, employees who did not speak or read English encountered problems with the company documents. The drawback as a barrier caused by limited English ability was indicated by $57 \%$ of the interviewees, especially at the lower levels of the company organisation. Therefore, language ability was an important component of the subsidiaries in terms of relative power. Marschan-Piekkari et al. (1999) argue that language issues need to be sorted out and included in the company's strategic plans. They recommend employing language training as an important solution to help reduce the problem of miscommunication. The next section discusses international studies of miscommunication in the workplace.

\subsubsection{Miscommunication}

Communication is considered a key to understanding how an organisation works (Huhta et al., 2013). Problems with clear and accurate communication have been studied in terms of both causes and effects on individuals and organisations. They are known as miscommunication. Miscommunication, especially miscommunication in the workplace, has been the concern and research interest of many scholars worldwide, including Coupland, Wiemann, and Giles (1991a), Stubbe (2010), Tzanne (2000) and Verdonik (2010). Kell, Marra, Holmes, and Vine (2007) describe miscommunication as "a major source of problems among members of work teams and organisations" (p. 41). Miscommunication is "an interesting and slippery concept" involving "any sort of problem that might arise interactionally, and typically to local processes of misunderstanding" (Coupland et al., 1991a, p. 1). In their view, miscommunication is not only labelled as "communication breakdown, communication failure, and indeed miscommunication itself", but it "may be a matter of transient annoyance, or it can inhibit life-satisfaction, health, and healing" (Coupland, Wiemann, \& Giles, 1991b, p. 3). Since miscommunication reflects the richness and complexity of human interaction, we can study it from different perspectives and use differing analytical methods (Coupland et al., 1991b; Holmes \& Stubbe, 2015; Stubbe, 2010). 
Coupland et al. (1991a) propose an integrative model of levels of analysis of miscommunication, and Stubbe (2010) argues that this model is still the best starting point for studying its complexities. The model consists of six levels of analysis which represent a range of classifications of miscommunication, "increasing in complexity and contextualization from 1 to 6" (Kasper, 2004, p. 2) and "synthesising social psychological and discourse-analytical perspectives" (House, Kasper, \& Ross, 2003, p. 8). At level 1, miscommunication is seen as prevalent and participants are unaware of a communication problem, so they have no concern for repair. Miscommunication becomes more complex and problematic at level 6 of the model, which requires an ideological analysis. Miscommunication at this level "disadvantages the targeted social groups" (Kasper, 2004, p. 2). Miscommunication in the context of mechanical engineers' communication can be analysed at different levels but seems to fit most accurately with level 3 and level 6. At level 3, miscommunication "takes on implications of personal inadequacy and therefore, perhaps, blame" (Coupland et al., 1991b, p. 13). The blame here could be because of "poor communication skills, unwillingness to communicate, bad temper, personality problems or some other individual difference" (pp. 13-14). Since miscommunication here is mostly because of individuals' lack of skills, they can be repaired by training.

The review has identified 11 causes of miscommunication including occasions when: the message or the content was not accurately transferred, the complexity of language and interaction in the workplace caused the miscommunication (Stubbe, 2010), important information was not transferred from one person to another, mistakes were made with document packing codes, and when single person did not hear the explanation or instruction (Holmes \& Stubbe, 2015), and other problems with language involving the level of English, pronunciation, connotations, technology and the ability to express key points (Brewer, 2010). Miscommunication is positively related to task conflict in culturally diverse work groups and miscommunication is positively related to process conflict in culturally diverse work groups (Korovyakovskaya \& Chong, 2015) and to the inability to understand what another person means in cross-cultural settings. Differences in semantics, accents, and dialects can be obstacles (Govindarajan \& Gupta, 2001), as well as engineers' poor pronunciation (Le et al. (2016).

In her Ph.D. research about miscommunication and problematic talk at work in a variety of New Zealand workplaces, Stubbe (2010) provides a descriptive analysis of the issues that arise in workplace communication and the discursive strategies that are used to deal with miscommunication and problematic talk. The thesis was developed as a part of the Wellington Language in the Workplace Project (LWP) and examined miscommunication 
and problematic talk through participant observations. In total, 31 factory staff participated in the study and about 800 interactions were examined. Stubbe proposes a model for "analysing miscommunication and problematic discourse in workplace interaction which is based on a flexible multi-layered theoretical and methodological framework" (p. vii). This uses a social constructionist paradigm which frames communication as "an interactive, collaborative process of meaning making" (p. 76). The analytic methodology includes interactional sociolinguistics, conversational analysis, pragmatics and critical analysis. The findings reveal that a wide variety of communicative actions can be qualified as problematic in different ways. For example, the study found that miscommunication occurs when the message or the content was not accurately transferred. The data show cases of problematic talk which involves relational and power issues. Miscommunication and problematic talk were confirmed "to be ubiquitous aspects of the communication process" (p. 208) and that there is always a potential for problems to occur due to the complexity of language and interaction in the workplace. Because of this potential the study claims that people are always managing this risk at different linguistic or discursive levels through, for example, the use of pragmatic devices to mitigate face threats. In single interactions, people tend to use hedges, attenuators, boosters and various kinds of intensifiers to mitigate face threats. They also use such discourse strategies as supportive feedback and humour in their communication for the same purpose. At a more macro-level, people use discursive resources. They use acts that avoid face threats and use different kinds of turn. They employ different strategies to manage roles and identities. Stubbe argues a range needs to be applied to workplace miscommunication. She states that the analysis of miscommunication and problematic discourse "relies heavily on contextual information and ethnographic knowledge at a number of different levels and must always be seen in the light of wider societal discourses" (Stubbe, 2010, p. 209).

Breakdowns in communication are a common feature of workplace communication, including the communication of non-native speakers of English. According to Coupland et al. (1991b), "language use and miscommunication are in fact pervasively and intrinsically flawed, partial, and problematic" (p. 3). In a book chapter reporting on their project "Language in the Workplace" in the New Zealand context, Holmes and Stubbe (2015) investigate instances of miscommunication where ineffective or problematic communication results in negative outcomes not only for individuals but also for organisations as a whole. They identify miscommunication as "a key contributing factor in the escalation of workplace disputes" in New Zealand (p. 138). This chapter, "Miscommunication and problematic talk at work", presents four different examples of miscommunication in the workplace. The first 
example is about Jan, a branch manager, and Heke, a policy manager, who were engaged in a meeting in Heke's office in a government organisation. They were talking about a meeting that Jan attended unexpectedly. Jan was embarrassed when she met with another organisation representative instead of Marama, who was scheduled to be in charge. She did not have the information she needed and could not be very involved in the meeting. It could be inferred that important information was not transferred from one person to another and Jan was not informed about the meeting. This resulted in inadequate communication between her organisation and their business partner.

Holmes and Stubbe (2015) provide a second example of misunderstanding similar to the first one, but with an extended analysis. It describes a regular meeting in the morning between the team leader Ginette and the packers. She told the packers there were mistakes with document packing codes. That is, the product did not have the correct pack codes on and the packers did not check carefully what they were packing. Ginette was both direct and directive in her communication. The way she managed this serious misunderstanding shows the effect of the dimensions of power and politeness at work. She showed her role as a team leader and as a tough boss with direct and explicit strategies. For example, she showed directness when she identified the problem very clearly, as illustrated in line 5, "the checks aren't done properly", and line 2, "line two was put on hold because the pack code was wrong". She indicated her supervisory role when using the pronoun "I" in line 11, "when I went over to check the line three check list". She also showed concern for the face needs of the team members by not blaming the mistake on any single member. That is, when she used the pronoun "we" in lines 8 and 9, "we did the same thing we did exactly the same as the other two shifts".

Holmes and Stubbe (2015) describe two other examples which provide insight into the way workplace miscommunication can be managed, and these examples reinforce the important role of power and politeness in analysing misunderstandings at the workplace. Example 3 is a conversation between the packers Lesia and Sam on the packing line. This example shows that miscommunication can easily occur if a single person does not hear the explanation or instruction. They were discussing Ginette's instructions about the packing codes. Lesia identified the problems with the packing codes that their team leader outlined in the meeting. The packers tried to take out the zero number in the codes, which caused serious delays in shipping the products. Sam said that they could take the number zero out because it meant nothing. This was because Sam did not attend the meeting with Ginette that morning and did not get her explanation about the code numbers. When Sesia mentioned Ginette's explanation, she said, “oh, I wasn't over here”. 
Example 4 in Holmes and Stubbe's (2015) research is a conversation on the packing line between the team leader Ginette and a team member named Sam. They were talking about the packing codes. Ginette used facilitative coaching strategies to help Sam see his mistakes in packing codes (line 6: "no er well yeah I did know I was my-that was my mistake"). She got him to see the importance of paying attention to detail and doing the checks (line 14: "if you go by the book you can't go wrong"). She gave positive feedback about Sam's job (line 9: "no the way you did it this morning is good that's what we're supposed") and acknowledged his contributions (line 15: “That's right...just remember that when you're doing the check list"). This example shows the different strategies Ginette used to deal with each situation on the factory floor.

These above examples illustrate miscommunication in the workplace where people are working together on a site and speaking face to face. Miscommunication is also reported to occur in international virtual workplaces where people often work online across national and cultural boundaries. Brewer (2010) conducted a qualitative workplace multi-case study of 22 staff from three organisations. The participants came from seven different countries, namely Sweden, the US, France, the Philippines, Singapore, Canada and Australia. The study aimed to examine the factors that cause miscommunication in international virtual workplaces. In total, the author conducted 99 interviews, collected sample texts from the participants and carried out an online focus group interview. The findings identified 11 factors that cause miscommunications, namely language, information sharing, technology, culture, tone, undiagnosed challenges, time, haste, etiquette, delivering criticism, and other. Of these, language emerged as the most significant and frequent factor leading to miscommunication in international virtual workplaces. The language here refers to English, which was the language of communication or the lingua franca among the three organisations. The problems with language identified in the study were the level of English, pronunciation, connotations, technology and the ability to express key points. These problems were reported to account for $18 \%$ of the problems of 14 out of 22 participants who experienced miscommunication in the context of their work. These 14 participants came from Sweden, the Philippines, the US, Singapore and France. The differences in pronunciation were described as a frequent factor of miscommunication in web conferences. This was due to the participants' inability to understand the dialect of English used by different people across the nations. In addition to this, misinterpretation of the meaning of the words could cause significant misunderstanding. For example, the sentence "it must be done" was spoken by a manager in Sweden who interprets 'must' as mandatory, but people from other language backgrounds may interpret 'must' differently, and she found it hard to 
make others understand what she meant. Connotations also made it difficult to communicate effectively, as people might have different definitions or understanding of the implications or associations of certain words or phrases, and this caused miscommunication too. Technology here included missing emails and having problems with phone lines. The former could be sending emails with an attachment but the attachment did not reach the receiver or emails went in the junk mail folder and the receiver did not notice it. The latter referred to phone line quality, the inability to hear multiple conversations which took place at the same time or having difficulty in hearing and understanding accents. In terms of English proficiency, the study found that a low level of English proficiency meant that speakers lacked detail in their communication. People with better English ability seemed to provide greater detail. The study recommended that participants in international virtual workplaces should be facilitated with metacommunication in order to make it easy for them to communicate and they should be encouraged to discuss the issues of miscommunication as communication preferences. Finally, they should also "check back on communications of importance" (Brewer, 2010, p. 343) to identify the missing information or any misinterpreted information.

Culturally diverse workplaces increase the complexity of interactions among employees, which can result in miscommunication. Korovyakovskaya and Chong (2015) conducted a survey questionnaire with 222 individuals who were working in culturally diverse organisations throughout the United States to examine the relationship between verbal miscommunication and different types of conflict, namely 'task', 'process' and 'relationship'. Miscommunication in this study is defined as the "failure of sender(s) and receiver(s) from different cultures and different languages to communicate clearly and properly between/among themselves, that is when the said receiver(s) of the information do(es) not decode it as intended by the sender(s)" (p. 44). The study assessed the verbal miscommunication which took place in the work settings in relation to work-related issues at peer level and supervisor level. The three hypotheses that miscommunication is positively related to task conflict, process conflict and relationship conflict in culturally diverse work groups were tested with canonical correlation analysis. The findings show that miscommunication at the peer level is more positive and influential than that at the supervisor level. The correlation coefficients were close between two levels which indicate that miscommunication at these levels is significant. Of the three conflicts, task and process were positively significant while the correlation coefficients of the relationship were positive but not significant. These findings support the first and second hypotheses, that is, miscommunication is positively related to task conflict in culturally diverse work groups and 
miscommunication is positively related to process conflict in culturally diverse work groups. However, they do not support the third hypothesis, which states that miscommunication is positively related to relationship conflict in culturally diverse work groups. In summary, the study found that miscommunication is more likely to occur in the task and process types of conflict among not only peer members but also between supervisor and subordinates in culturally diverse work groups. The study recommends that "effective conflict management strategies need to be in place to mitigate the effects of task and/or process conflicts on work outcomes" (Korovyakovskaya \& Chong, 2015, p. 50). Also, those who supervise culturally diverse work groups have to take active steps to avoid miscommunication. Finally, the administration should provide training on cross-cultural communication and ways to resolve conflicts.

Language barriers at multinational companies have been the research focus of some previous researchers, such as Freely and Harzing (2003), Harzing and Freely (2008), and Harzing, Köster, and Magner (2011). Language barriers are defined as "the inability to understand what another person is saying is always a potential barrier to communication in cross-cultural settings" (Govindarajan \& Gupta, 2001, p. 64). Harzing and Freely (2008) claim that the "simplistic definition of the language barrier as a problem of 'miscommunication' becomes replaced by a cycle of effects that explain not only how the miscommunication occurs but also how it can escalate." (p. 56). Multinational companies often have to find a way to deal with the problem of language barriers when they set up branches in other countries that do not share the same language (Harzing et al., 2011), especially in the case of the headquarters and its subsidiaries. Harzing et al. (2011) conducted a qualitative study to examine the language barrier and its solutions at eight German and Japanese multinational companies in the relationship with their subsidiaries. The study found that a language barrier was present in the interaction between the managers of the corporate headquarters and its subsidiaries. This barrier was the cause of slowed work productivity and increased costs of decision-making. In terms of solutions, the study suggests "informal day-to-day changes in communication patterns, structural solutions at organisational level and bridge individuals" (Harzing et al., 2011, p. 282). Of these, the communication patterns involved what could be named as adaptive communication strategies, such as building redundancy, adjusting the mode of communication and code-switching. Building redundancy consists of such simple methods as asking someone to repeat the information several times and providing examples for illustration. The mode of communication could be talking on the phone or email communication, depending on the participants' language ability. For example, Japanese managers are often better at written language so they 
preferred email communication (Harzing et al., 2011). Code-switching was reported when local employees reverted to talking with each other in their native language. Though codeswitching was often considered to irritating and uncomfortable for others, it was perceived as a good solution to language barrier. Tange and Lauring (2009) found that people "prefer to consult someone from their own speech community rather than approach an expert belonging to another language group" (p. 225) when they encounter work-related problems.

Govindarajan and Gupta (2001) surveyed the effectiveness of 70 global business teams and found that only 18 percent rated themselves as "highly successful" while " $82 \%$ fell short of their intended goals" (p. 63). Notably, one-third of the teams rated themselves as completely unsuccessful. Their survey of 58 senior executives of the US and European multinational organisations showed that overcoming communication barriers ranked second in the importance of tasks after cultivating trust among team members. The study also revealed language as one of the three hindrances to communication, together with geography and culture. In a team where people all spoke different languages, they would require interpreters who might fail in capturing the richness of the communication. Even when people in the team spoke the same language, "differences in semantics, accents, tone, pitch and dialects can be impediments" (Govindarajan \& Gupta, 2001, p. 65). One of the executives in the study Goran Lindahl, the former CEO of ABB Group, a Swedish-Swiss multinational corporation, described his company's official language as "poor English" and that no one should be embarrassed in expressing ideas because of their imperfection in English. Govindarajan and Gupta suggested investing more in language and cross-cultural training to overcome communication barriers.

Poor pronunciation is one of the causes for miscommunication reported in the context of Vietnam. Le et al. (2016) examined how 14 Vietnamese information technology engineers communicated in English at the workplace in relation to what they had learnt at university. The study reveals a gap between the English communication needs required by these engineers and the English education provided by their university. That is, the English language competence that these engineers had developed at work was due to work requirements and necessity, but was not taught at the university, especially communication with other varieties of English in the lingua franca context. Thus, the study reported that engineers' poor pronunciation often caused breakdowns in conversations. This poor pronunciation involved the mispronunciation of key words, the indistinctness of vowels or the omission of final sounds. The difficulty in distinguishing between 'can' and 'can't' in the engineers' speech was one typical example in the participants' pronunciation. This caused a lack of confidence and reluctance to communicate with foreign colleagues. 


\subsection{Plurilingual and Pluricultural Competence}

As has been addressed in the introduction to the study, plurilingual and pluricultural competence plays a crucial role in communication in today's world of integration, internationalisation, and globalisation. This competence is described in the CEFR (Council of Europe, 2001) and has been acknowledged in a number of studies (Beacco, 2005; Coste et al., 2009; Council of Europe, 2006; Jasone \& Durk, 2013; Piccardo, 2013).

In a study about the specificity of plurilingualism as an individual characteristic, Piccardo (2013) uses plurilingualism as a lens to examine the present linguistic landscape and its implications for language education because it allows more dynamic interaction and mutual influence of languages. Using this lens, the study distinguishes plurilingualism from multilingualism which "stresses the separate, advanced mastery of each language a person speaks" (p. 601). In the light of plurilingualism, languages interrelate and interconnect at the level of the individual. The process of acquiring and using a language is dynamic. The development of plurilingualism inspired pedagogy involves the understanding that language teaching and learning "should be seen in conjunction with the overall objective of promoting plurilingualism and linguistic diversity" (Piccardo, 2013).

Jasone and Durk (2013) claim that the traditional teaching of English as a second or foreign language often encourages "the isolation of English from the other languages in the students' repertoire and in the school curriculum" (p. 591) and this is a kind of hard boundary in language learning. They, therefore, propose an innovative plurilingual approach that can soften the boundaries between English and other languages. This is because plurilingual speakers can combine elements from different languages such as from their first language. This means that students can take advantage of their own resources and the language teaching can be more effective by using the resources that learners have. Jasone and Durk (2013) conclude that the plurilingual approach "allows for maximum exposure to the target language and for work on communicative and academic skills in English, but at the same time plurilingual teaching practices draw on learners' metalinguistic awareness and experiences as plurilingual speakers enabling them to learn English in a more effective way" (p. 596).

In summary, preparing plurilingual and pluricultural competence for language learners is essential because "we are all plurilingual" (Piccardo, 2013, p. 604). This is because every day we use different registers with different kinds of people and in different contexts. There is a tendency for people to use common foreign language words without translating them into their first language. They even use specific technical terms in various places even when this use is incomplete or imperfect. 


\subsection{Chapter Summary and the Research Gap}

This chapter has reviewed a number of needs analysis studies that investigated workplace uses of language as well as studies conducted in the university situation. This review has revealed a gap in the literature of the needs analysis field, showing that very little research has studied the issue of miscommunication due to lack of English and how people cope with this issue in the workplaces of mechanical engineers. The English communication needs reported in these studies were mostly about linguistic needs such as English language skills and communicative events. Even at this level, none of the reviewed studies focused on investigating the English communication needs of mechanical engineers in Vietnamese workplaces where English is one of the foreign languages.

The review of recent research in the workplace has shown the complexity of language use, that is, social dimensions such as humour, solidarity and power relationships which could be seen when breakdowns or other issues in communication happen. These issues can also be explored in a needs analysis study to see what real English communication needs are.

In order to capture a full picture of the English communication needs of mechanical engineers in the workplace, a pragmatic mixed methods needs analysis study is employed. This needs analysis study interacts with the workplace culture and plurilingual and pluricultural competence (as can be seen in Figure 5 below) in order to discover the realworld complex use of English.

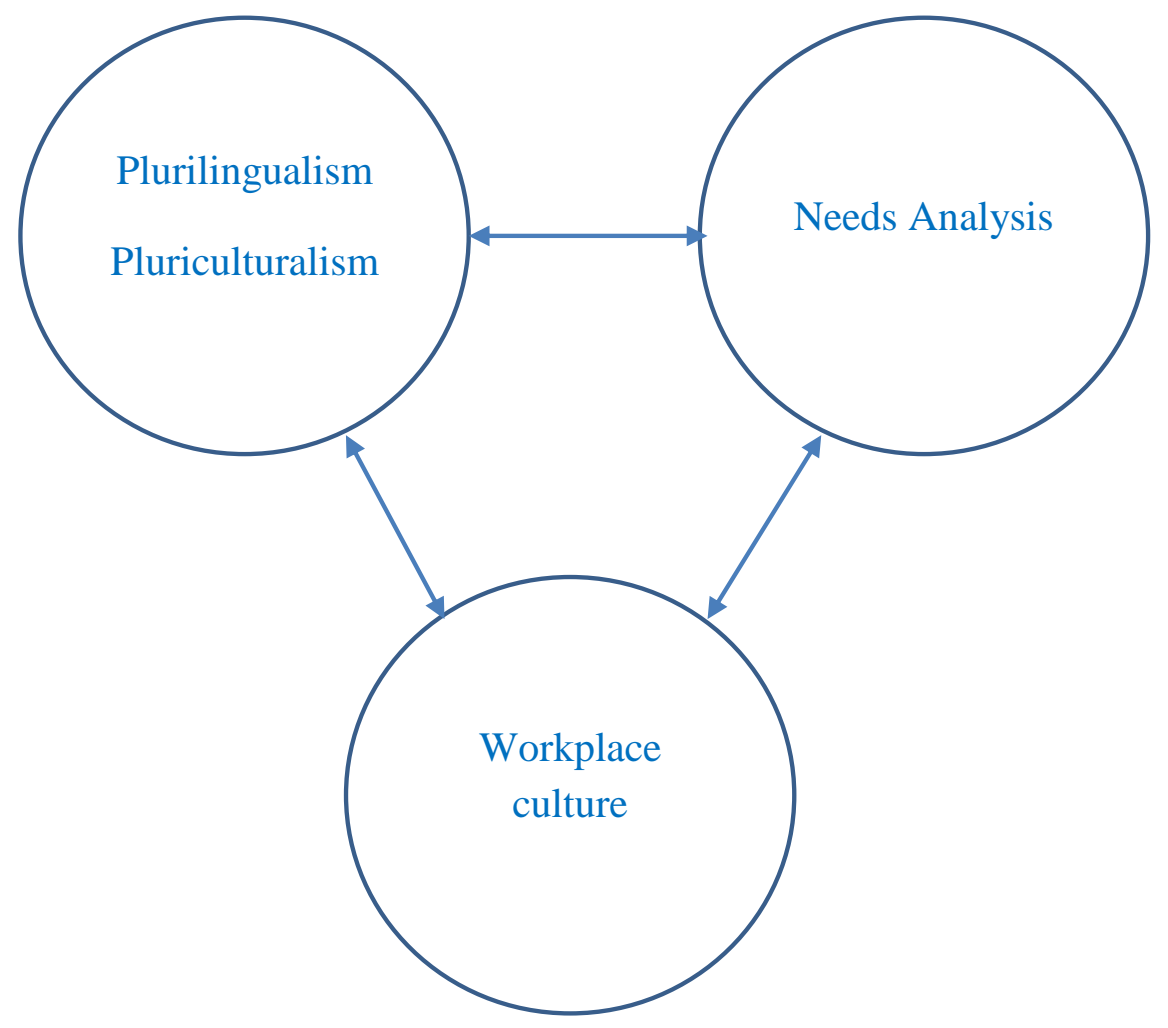

Figure 5: Scope of needs analysis 


\section{CHAPTER FOUR: RESEARCH METHODOLOGY}

This chapter describes the research paradigm and the research design of the study. It specifies the methods and the procedures throughout the study, including mixed methods approach, ethical considerations, methods of data collection, data analysis, and evaluation. Finally, the validity of the research is discussed and a summary of this chapter is given.

\subsection{Research Questions}

This pragmatic mixed methods needs analysis study aimed to answer the main research question: What are the English communication needs of mechanical engineers in the Vietnamese context? and the following sub-questions:

1. What kinds of real-world English skills are required by Vietnamese mechanical engineers to function effectively in the workplace?

2. What social factors and social dimensions affect the English skills that mechanical engineers use in their workplace and how do these affect this use of English?

3. Where and when do breakdowns or other issues in communication occur and what are the effects of these issues?

\subsection{Research Paradigm}

A paradigm is "a way of looking at the world. It is composed of certain philosophical assumptions that guide and direct thinking and action" (Mertens, 2010, p. 7), or "a basic set of beliefs that guides action" (Guba, 1990, p. 17).

According to Guba (1990), a research paradigm can be characterised through its ontology, epistemology and methodology. Ontology examines the nature of reality and the nature of human being in the world. Epistemology examines the relationship between the enquirer and the known or how we know something. Methodology examines the process of research or how we go about finding something out (Creswell, 2007; Denzin \& Lincoln, 2000; Guba, 1990).

This study employed a pragmatic paradigm which is "typically associated with mixed methods research" (Creswell \& Plano Clark, 2011, p. 41). Pragmatists claim that knowledge is built on pragmatic grounds (Creswell, 2003). Knowledge, in their view, is always "about relationships between actions and consequences" (Biesta, 2010, p. 112) and about "what works in practice" (Johnson \& Christensen, 2008, p. 33). The study began with a research problem. I will outline the process of developing the research problem. 
My own experience as a lecturer of English at a University of Technology Education had led me to conclude that the English language of some mechanical engineers beginning work in Vietnam was insufficient for the needs of the workplace. This belief was reinforced by the literature on needs analysis for non- English language speakers in a variety of workplaces internationally. Hence it was important to find out what sorts of English language were actually required by engineers working in multilingual environments. The study had three phases: a survey of engineers and their managers, interviews with engineers and their managers, and observations of engineers in their workplace.

In this case, the ontology behind the investigation is a positivist one that particular types of English language use exist and can be examined. This led to the questionnaire design based on Munby (1978) and a deductive and content approach to the data analysis, quantifying participant responses and minimising threats to reliability and external validity through the number of participants.

A positivist approach was also involved in gathering data from the interviews with the engineers and their managers to capture lists of communicative events that might be helpful for pedagogical purposes. This approach is reflected in the nature of research questions which ask the 'what' of what sorts of skills are required.

Thematic analysis was used in the analysis of the qualitative data from the open questionnaires, the interviews with mechanical engineers and their managers, and observations of mechanical engineers and their managers in the workplace.

Sub-research questions two and three sought to probe the nature of the social interactions in the workplace in order to understand why particular sorts of English language might need to be used at particular times and why difficulties might emerge when knowledge of the English language was insufficient. In this part of the study the underlying ontology remains that there is a reality that can be examined, but the analysis may also have to take into account that there may be differing perspectives on the nature of that reality. For this reason the ontology of pragmatism is appropriate for this study. That is to say that I was concerned to capture and understand the reality of a problem and perspectives on this problem could undergo change.

When the same issue emerged for many or most of the participants this was taken into account, but some issues which were described by one or just a few of the participants might also be considered of importance. For this reason the approach taken with the interviews is thematic analysis. Thematic analysis is more inductive in approach because it seeks to use the data to probe the nature of the phenomenon under examination. A more inductive approach was particularly needed for the second and third research questions in 
order to attempt to understand how the social contexts of language use affected the language required. The need to probe the social contexts of language use is reflected in the 'how' of the part of question two which asks 'how social factors and the social dimensions of language use affect this use of English' and the 'why' of why difficulties might emerge in English language use for English language uses without high proficiency in English.

Through the thematic analysis of the data some wider social implications of language use emerged including the ways that language proficiency is involved in the power relationships of the structures of companies. Any discussion of power relationships involves a different ontological and epistemological perspective, one which tends to see reality as socially constructed. The parallels drawn with this study and the Wellington Language in the Workplace study involve a degree of social constructivism. In this study however the focus is on the implications of language use for pedagogical purposes and so the emphasis remains on the 'how' of the effects of power relationships on language use rather than the 'why' and in this sense the study remains primarily pragmatic in its approach, assuming that there is a reality that can be examined through processes of negotiation, discussion and interpretation and that knowledge about this reality can be captured through the mixed methods approaches of survey, interview and observation.

A pragmatic approach seems most appropriate to examine the reality of the communication needs of mechanical engineers. It is based on an assumption that mechanical engineers' English ability may affect their work productivity and that what they learn from the university may be different from their actual uses of English in the workplace. In terms of philosophy, pragmatism is considered "a worldview [that] arises out of actions, situations, and consequences rather than antecedent conditions (as in postpositivism)" (Creswell, 2014 b, p. 10). The methodology employed in this study is a mixed methods approach. In this methodological approach "the researcher mixes both quantitative data and qualitative data" (Creswell \& Plano Clark, 2011, p. 43) and so "may combine deductive and inductive thinking" because "quantitative and qualitative methods are compatible within the pragmatic paradigm" (Mertens, 2010, p. 38). In this paradigm, the researcher chooses the most appropriate approaches, variables and units of analysis to answer their research questions (Teddlie \& Tashakkori, 2003). Using this paradigm, I examined the real-world use of English of mechanical engineers, how the English learnt at university was used in practice and how social factors and social dimensions affected the English use. This paradigm enabled me to explore the main research question using multiple methods for collecting data from a triangulation of sources including adapted questionnaires, semi-structured interview 
questions, and, especially, observations to capture more holistically the real-world English communication needs.

\subsection{Mixed Methods Approach}

This study used mixed methods design to examine and understand the English communication needs of professional mechanical engineers in which quantitative and qualitative research approaches are combined or integrated into a single research study (Creswell, 2014b; Johnson \& Christensen, 2008). Patton (1990) argues that "using a combination of data types increases validity as the strengths of one approach can compensate for the weaknesses of another approach" (p. 224). Thus, questionnaires were used to gain a wider sample of the perceptions of employers and managers of mechanical engineers, and mechanical engineers themselves about the English skills required by mechanical engineers in the workplace and how these English skills were used in relation to social factors and social dimensions. In order to more deeply answer the research question, detailed rich descriptions and explanations from the participants were gathered by using a qualitative approach. According to Denzin and Lincoln (2000), qualitative research consists of a set of interpretive, material practices that make the world visible. It uses the inductive exploratory or 'bottom up' method. It is used for the purpose of describing, explaining and gaining an understanding of how participants think and experience their lives. Since qualitative data are descriptive (Bogdan \& Biklen, 1992), "thick and rich" and "can tell a story" (Patton, 2002, p. 47), this data allowed me to gain an in-depth understanding about the English communication needs of mechanical engineers in their real-world workplace context. The purpose of employing mixed methods design in this study was to "provide strengths that offset the weaknesses of both quantitative and qualitative research" (Creswell \& Plano Clark, 2011, p. 12) and to neutralize the weakness of either quantitative or qualitative data (Creswell, 2014b). In their earlier edition, Creswell (2007), claims that the combination of both quantitative and qualitative methods can provide "better understanding of research problems than either approach alone" (p.5).

There are three criteria for choosing a mixed methods design study: implementation, priority and integration (Creswell, 2003). Implementation means the time of collecting data, that is, data can be collected at the same time (concurrently) or in phases (sequentially). Data for this study were collected sequentially (quantitative data were collected first, and then qualitative data). Priority stresses the weight of the study, whether the weight is given to a quantitative or qualitative approach. My study gave more priority to qualitative research, which generally is given more weight in studies that use sociolinguistic theory. The study 
collected rich and in-depth data from open-ended questions in the questionnaires, 12 open individual semi-structured interviews with participants, and eight observations of real-world English uses in the workplace. Open questions gave the participants opportunities to express their opinions about what they lacked and needed. They could talk more about the topic and I was able to ask follow-up questions to collect as much information as possible to answer the research questions. Field notes from observations of mechanical engineers' real-world English uses in their work allowed me to compare the information provided by the participants in the questionnaires and interviews. Observations enabled me to capture a direct source of data of the real-world uses of English. Creswell and Plano Clark (2007) claim that the researcher can give priority to either quantitative data or qualitative data, or to both in his/her single study or in multiple phases research. Integration refers to the phase in the research process where the researcher mixes the data.

This study employed explanatory sequential mixed methods design, that is, quantitative data were collected and an initial analysis was done. This choice of research design has been discussed in a personal communication with Professor John Creswell. The initial findings of the questionnaire were then explained and deepened in more detail with qualitative data (Creswell, 2014b; Creswell \& Plano Clark, 2011). The mixed sampling design used for this study was identical sequential (Creswell, J., personal communication, December 7, 2015. ${ }^{2}$ ), which means that "the same people participate in both the quantitative and qualitative phases of the investigation" (Johnson \& Christensen, 2008, p. 246).

That is, participants for interviewees were invited from those who participated in the questionnaires. Detail of this mixed methods sequential explanatory design can be found in the research diagram in Figure 6 below.

\footnotetext{
${ }^{2}$ I had the opportunity to join a Mixed Methods Research Workshop which was hosted by NZCER and Massey University in December 2015. The workshop was conducted by Professor John Creswell and Professor Burke Johnson. At first I was concerned about the type of research design of this study as the semi-structured interviews and observations were carried out right after a quick initial analysis of the questionnaire with the purpose to choose the participants for the interview and the findings that needed more in-depth information. However, when I raised my concern in the workshop, Professor John Creswell confirmed that my study was an explanatory sequential mixed methods design. This confirmation helped me feel confident to continue the analysis of the data.
} 


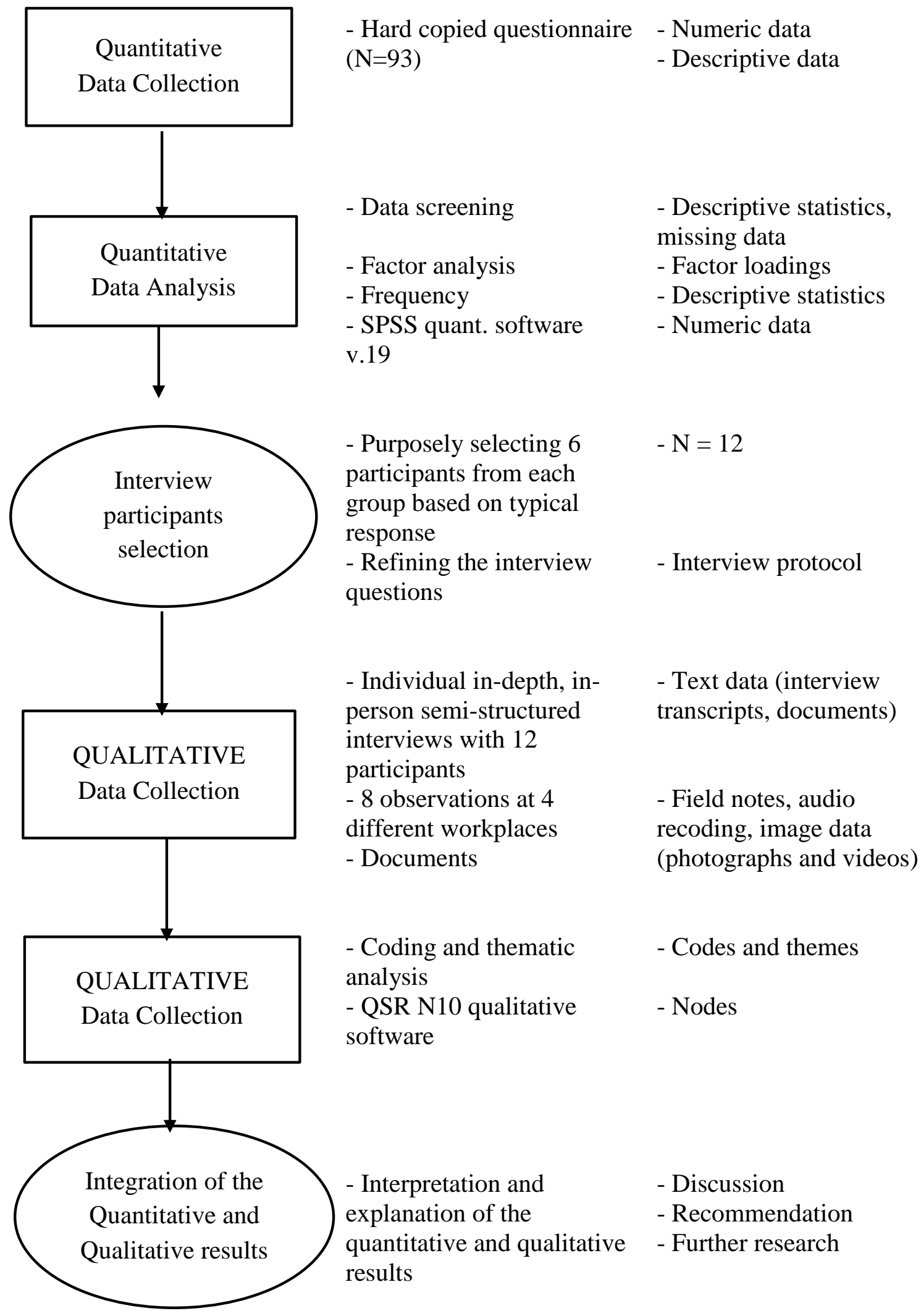

Figure 6: Mixed methods sequential explanatory design procedures (adapted from Ivankova and Stick (2007)) 


\subsection{Ethical Considerations}

This research was conducted following the guidelines of the New Zealand Association for Research in Education (NZARE). The ethics of this research have also been approved by the Victoria University of Wellington Faculty of Education Ethics Committee, approval number SEPP/2013/49 RM20017.

As a cultural issue in Vietnam, one cannot conduct research in a company or factory without the director's consent or permission. All the appointments to meet or talk to the director also have to be arranged by the administrative office of that company. I first contacted the administrative office of each company by telephone, specifically the personnel manager of the company, to explain that the intention of my research was to find useful information about mechanical engineers' English uses that would ultimately be beneficial to companies such as this. I then invited the company to participate. When the personnel manager agreed I sent all the documents in both English and Vietnamese (letter of invitation, information sheet, and consent form) to the personnel manager, who reported my research to the director of the company. The Vietnamese versions were enclosed to make sure that all the Vietnamese managers and participants understood the research and its purpose. After gaining permission from the director, I then contacted the personnel department to ask them to introduce me to the department managers and mechanical engineers in the company.

Regarding the participant recruitment, I found the contacts of the managers and some mechanical engineers in the company's staff list and contacted them to invite them to participate in my study. Again, I explained the intention of my research. I told them that I was a lecturer of English at a technical university and that the research was intended to investigate whether the English courses that we taught our students met or mismatched the requirements of English in the workplace. I told them that I wanted to examine the actual uses and requirements of English of mechanical engineers in real-world contexts so that universities like mine could help students to better prepare their English language skills for the workplace. I explained that they would play a very important role in the study, as they had the voice of the insiders in the research. I told them that their participation was voluntary and that I would not feel offended if they said they did not want to participate. I also asked them to introduce me to their colleagues. Again, all the research documents were sent to them. When they gave me their consent, I came to their department to see them. I brought some small token gifts (New Zealand pens and key chains, candy and fruit) to their office. We all shared the candy and fruit and talked. They asked me about my study and my life in New Zealand as well as New Zealand as a country. This was a way to gain their trust and build rapport. I gave them the questionnaires (Appendices A and B). The needs analysis questionnaire for employers and managers of mechanical engineers (Appendix A) was given 
to those who were managers. The needs analysis questionnaire for mechanical engineers (Appendix B) was given to those who were mechanical engineers. Then I explained in detail to help them fully understand the purposes of the questionnaire and every single question in the survey. I also sought their consent to participate in the follow-up semi-structured interviews (Appendix J: Interview consent form for employers and managers of mechanical engineers and mechanical engineers). There were two interview schedules (Appendices $C$ and D). I also sought their consent for me to conduct observations of their working days (Appendix K: Observation consent form for managers of mechanical engineers and mechanical engineers). ${ }^{3}$

The interviews were conducted in different contexts which were private except for the cafés. One manager was interviewed at a hotel when he was on a business trip to another city. Five other managers were interviewed in their private office. Two mechanical engineers were interviewed at the cafés with some other people sitting at other tables. We sat in a corner of the café so we kept a distance between us and a few people in the café in order to be quite private. Four other mechanical engineers were interviewed at their department office while no one else was present. Before starting the interview, I asked the interviewees for their permission to audio record the interview. I explained that they could ask to listen to their recording and request to read the transcription again after the interview, and could request to change or delete any unnecessary information. I asked them to express their thoughts and opinions informally and naturally. In these interviews, I used the 'tôi' (I) pronoun and called them 'Anh' (you). This way of addressing is seen as neutral in communication in Vietnamese culture. Before interviewing them, I usually had an informal talk with them to get to know them more and to create a relaxed atmosphere. We asked about career and family as well as English language learning. Such informal talk is typical in Vietnamese culture. It helped us understand more about each other and brought us closer so that the interviews were conducted informally and naturally.

All interviews with Vietnamese participants were conducted in Vietnamese (the participants' mother tongue), which were then transcribed and translated into English. The transcriptions and translations were checked by two Vietnamese lecturers of English. Interviews with the foreign interviewees were conducted in English, which were then transcribed. These two lecturers were asked to sign a confidentiality agreement (Appendix L) to make sure that they understood the importance of the ethical issues of this research and to seek their consent to keep all the research information confidential.

\footnotetext{
${ }^{3}$ Please note: The title of this thesis was originally named "Needs analysis of English for mechanical engineering students in the Vietnamese context". This title was changed to "Needs analysis of English for mechanical engineers in the Vietnamese context" once learning needs were not considered as part of the thesis. However, the earlier title appears in the documents in the appendices.
} 
All the participants were given the opportunity to check the accuracy of the transcriptions, but none of them requested this checking. This opportunity was mentioned in the information sheet and explained in person to them before their consent to participate in the research.

I was aware that because I was observing workers in the presence of their managers, both groups may have behaved differently due to my presence (a possible Hawthorne effect). The Hawthorne effect is "an experimenter effect whereby participants in any human-centred study, may exhibit a typically high level of performance simply because they are aware that they are being studied" (Macefield, 2007, p. 145). I tried to reduce this effect as much as I could by making myself inconspicuous and acknowledging it as I interpreted the data.

Finally, all information about the participants and the companies was kept confidential. To protect the companies' and participants' identities, I used pseudonyms to name the companies as well as the participants (see more detail in Section 4.5.1 and Section 4.5.4). All the proper names (people and places) that appeared in the study were either written as X, XX or XYZ. The home countries of the foreign participants were also written in pseudonyms. The companies and participants were also informed that all the data would be kept secure for a period of up to five years to protect their identity and the data would be used for the research purposes only.

\subsection{Data Collection}

Data for this study were collected from August to December in 2013. I had invited a total of seven companies to participate in my research. Of these, four companies gave me permission to conduct the study in their workplace. These included two companies in a central north province and two companies in two provinces in the north of Vietnam. These companies differed in terms of size, types of ownership and business. The procedure was as follows:

First, general information about the companies' business and size was searched on the internet.

Second, I contacted the company's personnel manager by telephone to explain the aims of my research and invite their company to take part in the project.

Third, if the personnel manager agreed to report to his/her director, I waited for their feedback. I then emailed them all the documents about the study, such as the invitation letter, information sheet and consent form. These documents were translated into Vietnamese to make sure that the participants understood the study and its purpose as well as their roles in the study clearly. For foreign participants, English versions were distributed.

Finally, after seeking the permission from directors of the research sites, I visited each site to meet the participants and invite them to participate in my study. Each time, I 
came to the personnel manager first to seek general information about the company, such as names of departments or the place (worksite) where I could meet the managers of mechanical engineers and mechanical engineers themselves. After that, I came to see them, talked to them, explained the reason why I was there, explained the purpose of conducting the research, and invited them to take part in the study.

\subsubsection{Research Sites}

The differences in the location, size, business type and ownership type of the companies in this study help to provide a full picture of the use of English in the workplace. Table 4 below shows these differences and information about the research sites, such as employees from English speaking and non-English speaking countries and whether they held management positions, and information about the customers and suppliers of these companies. These companies have been given pseudonyms for the reason of confidentiality.

Table 4: General information about the selected companies

\begin{tabular}{|l|c|c|c|c|}
\hline \multicolumn{1}{|c|}{ Company } & $\begin{array}{c}\text { The food } \\
\text { producing } \\
\text { company } \\
\text { information }\end{array}$ & $\begin{array}{c}\text { The dairy } \\
\text { company } \\
\text { (C1) }\end{array}$ & $\begin{array}{c}\text { The } \\
\text { motorbike } \\
\text { company } \\
\text { (C3) }\end{array}$ & $\begin{array}{c}\text { The building } \\
\text { construction } \\
\text { company } \\
\text { (C4) }\end{array}$ \\
\hline Ownership & Joint venture & $\begin{array}{c}\text { Privately } \\
\text { owned }\end{array}$ & Foreign owned & State owned \\
\hline Number of employees & 450 & 1500 & 1000 & 50 \\
\hline $\begin{array}{l}\text { Number of mechanical } \\
\text { engineers }\end{array}$ & 20 & 40 & 50 & 35 \\
\hline $\begin{array}{l}\text { Employees from } \\
\text { English speaking and } \\
\text { foreign countries }\end{array}$ & Yes & Yes & Yes & No \\
\hline $\begin{array}{l}\text { Employees from } \\
\text { English speaking and } \\
\text { foreign countries in } \\
\text { management positions }\end{array}$ & Yes & Yes & Yes & No \\
\hline Foreign customers & Yes & Yes & Yes & Yes \\
\hline Foreign suppliers & Yes & Yes & Yes & Yes \\
\hline
\end{tabular}

\subsubsection{The food producing company:}

This is a joint venture food producing company. It employs about 450 people, including both national and international employees. Of these, about 20 of them are mechanical engineers. The foreign employees come from different English speaking and non-English speaking countries. Some of them hold management positions and some are technical experts and engineers. The company has both local and international customers and suppliers. There is a technical department, which is in charge of all technical and engineering issues. Because of these above features, the English language is used together with Vietnamese. 


\subsubsection{The dairy company:}

This is a privately owned dairy company with a total of about 1500 employees. It has different departments with more than 40 mechanical engineers. The two departments which employ the most mechanical engineers are the garage and maintenance. This company employs a considerable number of foreign employees and most of them hold management positions. Its products are supplied to both local and international customers. The company also has both local and international suppliers. Thus, English language is necessary and important in the company.

\subsubsection{The motorbike company:}

This is a foreign invested motorbike company. The company employs about 1000 people both nationally and internationally. Of these, about 50 are mechanical engineers. Their products serve not only local customers but also foreign markets. They are customers of both local and international suppliers. Since this is $100 \%$ foreign invested company with many foreign managers and experts, the English language is a must for people who are working here, especially engineers.

\subsubsection{The building construction company:}

This last research site is a state-owned building construction company. There are 35 mechanical engineers out of 50 official employees in total. Since this company is carrying out different projects in different places, they employ hundreds of local workers depending on the requirements of each project. These temporary workers usually work in the construction sites managed by the company's manager and supervised by the company's mechanical engineers. Most of the company's projects are large ones run by foreign contractors. Thus, the company has both local and international customers and suppliers and the English language is required to work with them and the head contractor as well as the sub-contractors.

\subsubsection{Participants}

There were two sets of research participants in this study: the managers of mechanical engineers and mechanical engineers themselves. As the study aimed to inform the tertiary students about the types of English and English language skills they need to prepare for workplace use, these participants could provide objective information or the target situation for these students. They varied in terms of working experience, position and gender, which relate to demographics and sociocultural features.

The following table details the number of questionnaire and interview participants from each company. 
Table 5: Number of participants from each research site

\begin{tabular}{|c|c|c|c|c|c|c|c|c|}
\hline \multicolumn{2}{|c|}{ Participants } & C1 & C2 & C3 & C4 & Male & Female & Total \\
\hline \multirow{2}{*}{ Managers } & Questionnaire & 5 & 6 & 8 & 3 & 20 & 2 & 22 \\
\cline { 2 - 9 } & Interview & 1 & 3 & 1 & 1 & 6 & 0 & 6 \\
\hline \multirow{2}{*}{$\begin{array}{c}\text { Mechanical } \\
\text { engineers }\end{array}$} & Questionnaire & 16 & 19 & 16 & 20 & 67 & 4 & 71 \\
\cline { 2 - 9 } & Interview & 2 & 1 & 2 & 1 & 6 & 0 & 6 \\
\hline
\end{tabular}

\subsubsection{Questionnaire participants}

Purposive sampling was used to select managers of mechanical engineers and mechanical engineers. I specified the characteristics of the participants of interest for my study (Johnson \& Christensen, 2008).

\subsection{Managers of mechanical engineers}

The term 'manager' here referred to the management positions. They were invited to complete the questionnaire based on the following selection criteria:

- (i) They were director, vice-director, personnel manager, department manager or deputy manager, and

- (ii) They took part in the recruitment process, managed and worked with mechanical engineers.

These managers were from four selected companies in the central north and north provinces of Vietnam. Their ages ranged from 20 to 50. In total, 22 participants completed the questionnaires: six from the food producing company, five from the dairy company, eight from the motorbike company and three from the building construction company. They held different positions, ranging from deputy manager to manager and department director. Among these participants, there were two females and 20 males. Nine out of 22 had 6-10 years' work experience.

As stated in the beginning of the section, permission was sought from the director of each research site before conducting the study. Then I made an appointment to meet the personnel manager and other appointments with the managers of different departments to inform them of the research. Each manager was given an information sheet (Appendix $\mathrm{H}$ ), a questionnaire consent form (Appendix I), and a questionnaire (Appendix A). Later on, an interview consent form (Appendix $\mathbf{J}$ ) and an observation consent form (Appendix K) were given to those who agreed to participate in the interview and observation.

\subsection{Mechanical engineers}

These were professional mechanical engineers who were working in the four selected companies. They were invited to complete the questionnaire based on the following selection criteria: 
- (i) They had graduated from tertiary institutions; and

- (ii) They had at least one year's work experience as a mechanical engineer.

These selection criteria were expected to provide rich information (should relate to the research question and the theoretical framework). There were 71 mechanical engineers in this set of participants. Of these, 67 out of 71 were male and four were female. Notably, 53 of them were aged from 20 to 30 .

Figures 7 and 8 below show the age range and years of work experience of managers and mechanical engineers.

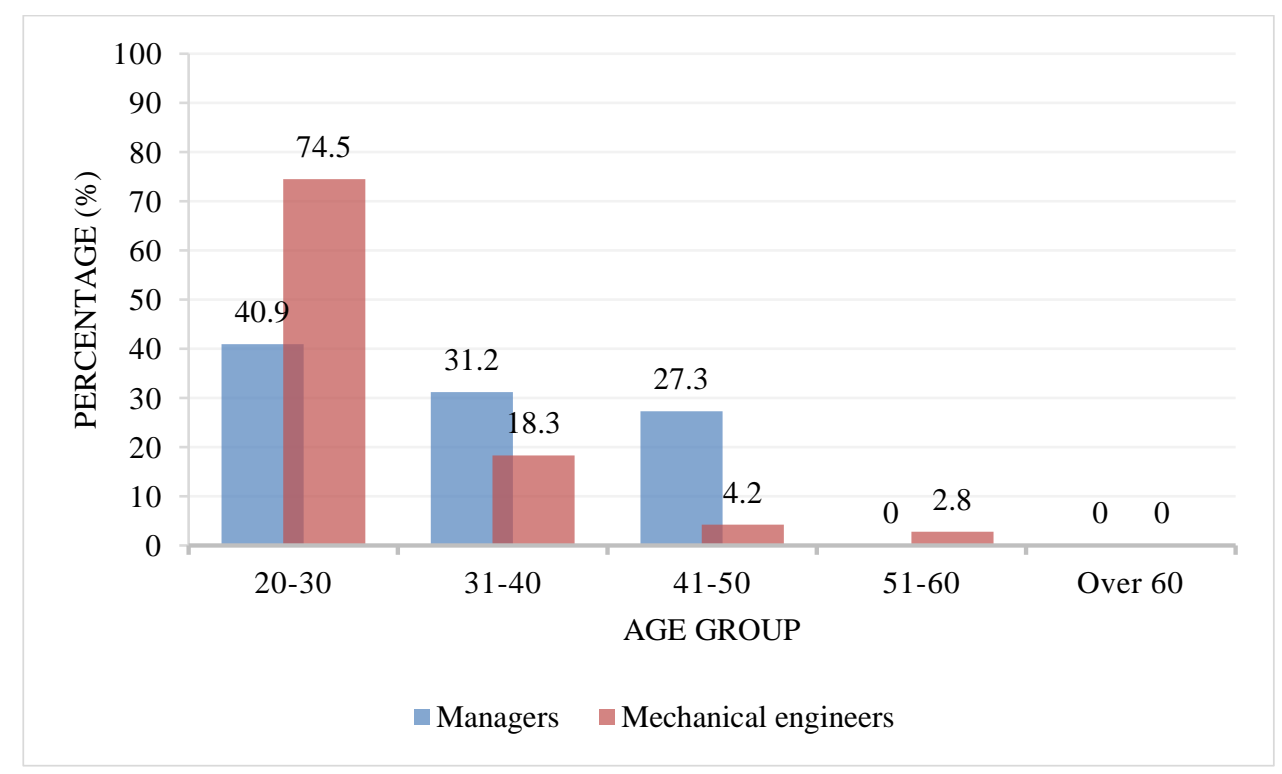

Figure 7: Age range of managers and mechanical engineers

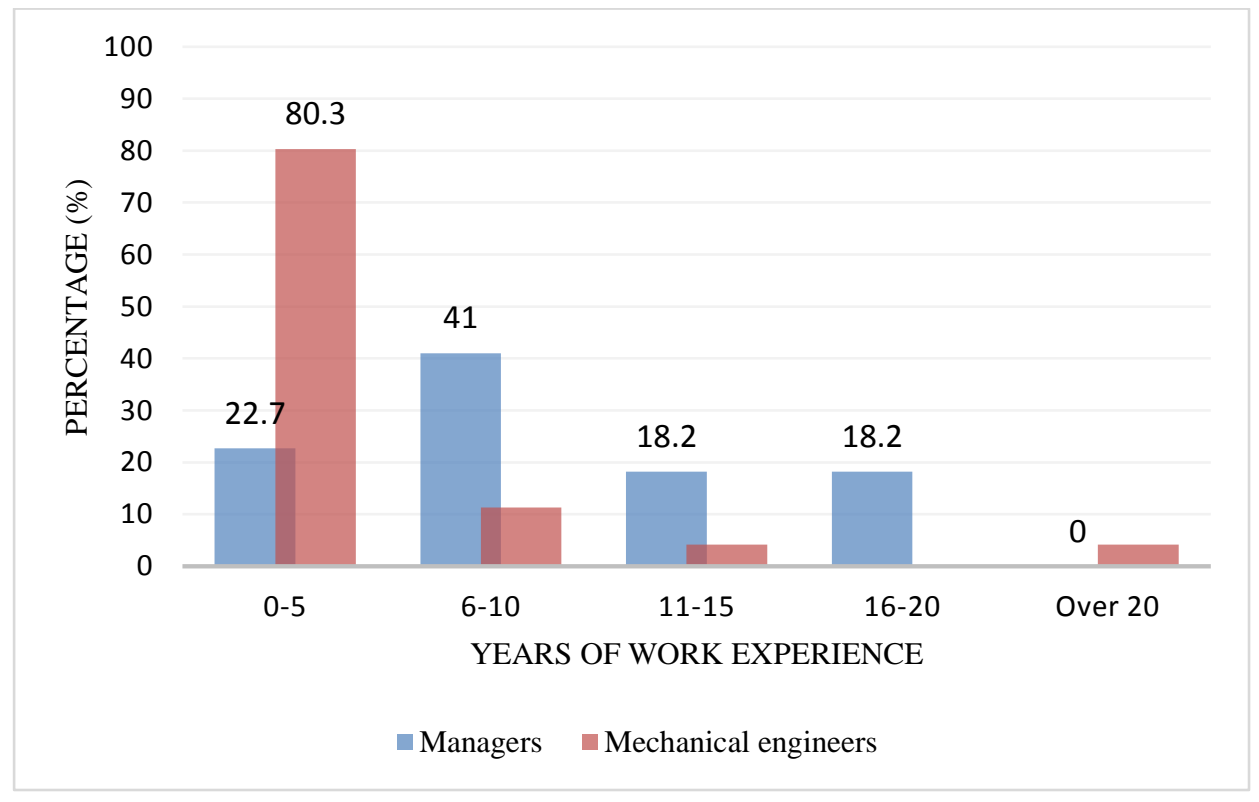

Figure 8: Work experience of managers and mechanical engineers 
After gaining permission to conduct my research from the directors of the companies, I visited these research sites to contact and meet the mechanical engineers. During my visits to their departments to meet their managers, I met and talked to some of them. Some others were contacted when they were having group meetings or working in their offices or at the worksites. For the remaining participants, I met them individually in different situations in the company. When meeting and talking with them, I explained the purpose of my research and how important their voices would be in contributing to this study. The information sheet, questionnaire consent form and the questionnaire were given to them before they completed the questionnaire to make sure that they fully understood the research purpose and to ensure their consent to participate in the study. I also gave them opportunities to ask any questions about the study.

Many participants in the study agreed enthusiastically to participate because they were so concerned with the issue and wanted to contribute to helping with the solution.

\subsubsection{Semi-structured interview participants}

To invite participants for semi-structured interviews, purposive sampling was used. I based the selection criteria on work position, work experience and information provided in the questionnaires. After an initial analysis of the questionnaire, I found that gender was unequal and did not consider it as a criterion for selection because most of my participants were male. Questionnaire participants were asked if they were willing to take part in an interview with me. None of the female participants agreed and therefore all the interviewees were male. These interviewees held different positions in their companies. In addition, the priority went to those who had more years of work experience as a mechanical engineer in the field. More importantly, I examined the information that participants provided in their questionnaires to select those whose answers could represent as close as possible the whole range of information given by other participants. In total, 12 participants participated in the interview schedule (six managers and six mechanical engineers).

\subsubsection{Observation participants}

As stated in the information sheet and consent form, participants were asked for permission to observe their working day and during the interviews permission was sought to conduct my observations. The participants for this method of data collection included five managers of mechanical engineers (one at $\mathrm{C} 1$, two at $\mathrm{C} 2$, one at $\mathrm{C} 3$ and one at $\mathrm{C} 4$ ) and different numbers of mechanical engineers at different companies. 


\subsubsection{The researcher as an 'insider'}

Throughout the research process, I, the researcher, functioned both as an 'outsider' to the participant group and an 'insider' in their group. According to Miles, Huberman, and Saldaña (2014), “outsiders to a group influence insiders, and vice versa” (p. 296).

Sharing the same language with the participants (except for some foreigners), I was considered an 'insider' in the study (Irvine, Roberts, \& Bradbury-Jones, 2008). As an insider I was able to give attention to cultural issues which might affect the researcher's ability to collect and interpret data effectively (Irvine et al., 2008). As a Vietnamese, I had a certain understanding about the Vietnamese culture, which made me an 'insider' to the study (Shklarov, 2007). I was also aware of the possibility of "a loss of objectivity and the consequent disregard to particular nuances" (Irvine et al., 2008, p. 37) as a result of the cultural familiarity and therefore tried to adopt a reflexive stance based on my particular identity as a researcher and background to shape the collected data.

\subsubsection{Data collection methods and process}

In order to collect various data and participants' experience, four different company ownerships were selected. They were purposely invited because the study aimed to explore the diversity of the use of English language in various workplace settings and ownerships. Three different methods of data collection were employed, namely questionnaire, semistructured interview and observation. These instruments were framed in relation to the CNP model proposed by Munby (1978) to study communication needs in a sociolinguistic lens, and one question in the questionnaire used a similar form of the questionnaire used by Kaewpet (2008) with some adaptation. Though they were designed prior to a recently published model of needs analysis, namely the Common European Framework (CEF) Professional Profile introduced by Huhta et al. (2013), they could reflect and describe the categories in this new model. Therefore this new CEF model was employed to guide the analysis of data in this study. The reasons for using these methods of data collection have been explained in Sections 4.2 and 4.3.

\subsubsection{Questionnaire}

A questionnaire was employed in this study to collect both quantitative and qualitative data. According to Johnson and Christensen (2008), a questionnaire is "a selfreport data collection instrument that each participant fills out as part of a research study" (p. 170). It was used in this study because it allowed me to collect data from a large population (Mertens, 2005) and measure many different kinds of participants' characteristics (Johnson \& Christensen, 2008). The advantage of a larger sample is that it provides the 
ability to generalise the results. The questionnaire data were mostly quantitative and were primarily used for description and explanation.

I used the questionnaire to ask for participants' views about the real-world use of the English language by mechanical engineers and the types of English they used and needed in the workplace. I had designed two forms of questionnaire for two sets of participants, based on the purpose of the study and the selected needs analysis model (the Communication Needs Processor). Through using the survey questionnaire, I could design questions that cover various sociolinguistic aspects of the English communication needs as described in the CNP model. Some questions were also designed based on the reviewed workplace communication studies to address the context of the study. Such questions could provide a general view about the real-world needs of mechanical engineers such as the frequency of English use, their satisfaction as well as their perceptions about the importance of English language skills, the types of English they used and especially the communicative events that they engaged in. In these questionnaires, Question 16 was adapted from Kaewpet's (2008) study. This question was about the various communicative events which are central to the current study.

The first questionnaire was for the managers of mechanical engineers (Appendix A) and the second questionnaire was for the mechanical engineers (Appendix B). The former had two versions: English and Vietnamese. The English version was for the foreign participants. The Vietnamese translation version was for Vietnamese managers. The second form was translated into Vietnamese so that all mechanical engineers could fully understand and complete it, as this was their mother tongue. These questionnaire forms were trialled to make sure that they were fit for the research purpose and could provide answers to the research questions.

Trialling the questionnaire for managers of mechanical engineers: This questionnaire was trialled once and four managers in a thermal power plant company in the central north of Vietnam completed it. All of them were male and aged 30-50. They worked directly with mechanical engineers. It took them 25 to 30 minutes to complete the questionnaire. They were asked to express their thoughts while completing it and they asked for clarification of some words such as 'colloquial' and 'informal'. They also asked if they could number two English language skills in questions 27 and 28 at the same frequency and lack. For example, they ranked listening and speaking as the most frequent or as number 1. I explained to them to help them understand the meaning of these terms and that they could rank more than one skill in one of the frequency measurements. I thought these issues were not significant problems and decided not to change them. The trialled data were input into 
SPSS software to check the reliability of the questions by using Cronbach's Alpha as described in Field (2009).

Trialling the questionnaire for mechanical engineers: Nine mechanical engineers who were working in the same thermal power plant company were invited to complete the questionnaire. One of them was female. They all had more than two years' work experience. They spent 20 to 30 minutes filling in the questionnaire. Four of them were asked to speak their thoughts. Besides asking the author to clarify the same words (colloquial and informal), they said that gender should not have been considered, as most of mechanical engineers were male. They also said that the setting of the communicative events in Question 16 were mainly in the workplace. I took these thoughts into consideration and then decided not to leave the gender variable and the setting variable out. This was because the participants were able to follow the questionnaire and filled in correctly what the questions asked. They could leave these variables blank if they wished. This was also because gender could help me describe the demographic information of my participants. The setting of the communicative events could provide me actual information about the types of English language and its skills that had been prepared or not prepared for mechanical engineering students at tertiary institutions. Again, the trialled data were input into SPSS software to check the reliability of the questions by using Cronbach's Alpha as described in Field (2009).

Using the questionnaire: 30 questionnaires for managers of mechanical engineers were distributed and 22 completed ones were returned. The percentage of response was $73 \%$. A response of $71 \%$ was obtained when 100 questionnaires for mechanical engineers were distributed to mechanical engineers and 71 completed ones were collected. These questionnaires consisted of both closed and open-ended questions. The questionnaire for managers of mechanical engineers had three parts. Part 1 aimed to collect information about the managers' personal backgrounds and about the company, such as the type of ownership, the number of mechanical engineers, the production market and main suppliers.

Part 1 sought information about participants' personal backgrounds. I also aimed to collect information about the company, such as the type of ownership, the number of mechanical engineers, the production market and main suppliers in the questionnaire for managers of mechanical engineers. This part in the mechanical engineers' questionnaire consisted of 12 questions out of 31 in total, whereas this part in the second form had eight questions asking about participants' gender, age, company, position, working experience, responsibility, the kind of work they do and their English training history. In short, this part aimed to collect participants' demographic information and basic information about the company. Part 2 asked participants questions about their perceptions of English 
communication needs. Part 3 asked for their suggestions to improve the English course for mechanical engineering students at tertiary institutions based on their experiences from the workplace. To make it easier for the data analysis and data presentation, the questions in parts 2 and 3 of the two forms of the questionnaire were labelled in the same order (from question 13 to 31$)$.

All the items input into SPSS software were checked for reliability by using Cronbach's Alpha. The zero component variables were removed from the analysis because they cannot be computed. As a result, the overall Cronbach's Alpha based on standardised items in the questionnaire completed by 22 managers of mechanical engineers was .839 as illustrated in Table 6 below:

Table 6: Reliability statistics of the questionnaire for managers

\begin{tabular}{|c|c|c|}
\hline \multicolumn{3}{|c|}{ Reliability Statistics } \\
\hline & $\begin{array}{c}\text { Cronbach's } \\
\text { Alpha Based } \\
\text { on } \\
\text { Cronbach's } \\
\text { Alpha }\end{array}$ & \\
\hline .865 & $\begin{array}{c}\text { Standardized } \\
\text { Items }\end{array}$ & \\
\hline & N of Items \\
\hline
\end{tabular}

The overall $\alpha$ of the questionnaire completed by 71 mechanical engineers was .897 as can be seen in Table 7 below:

Table 7: Reliability statistics of the questionnaire for mechanical engineers

\begin{tabular}{|c|c|c|}
\hline \multicolumn{3}{|c|}{ Reliability Statistics } \\
\hline & $\begin{array}{c}\text { Cronbach's } \\
\text { Alpha Based } \\
\text { on } \\
\text { Cronbach's } \\
\text { Alpha }\end{array}$ & \\
\hline .816 & $\begin{array}{c}\text { Standardized } \\
\text { Items }\end{array}$ & \multirow{2}{*}{ N of Items } \\
\hline
\end{tabular}

These overall $\alpha$ was excellent because it was above .8 which indicates good reliability (Field, 2009).

Closed questions aimed to gather general and numeric data, whereas open-ended questions helped me gain more authentic and deep qualitative data (Dickie, 2008). The participants had opportunities to provide their comments in questions 18 to 22 . In this 
questionnaire, the participants were asked if they would be willing to participate in an individual interview with the researcher.

\subsubsection{Semi-structured interview}

Using semi-structured qualitative interviews in this study, I had an opportunity to generate rich data and considered interviewees' language to be essential to get an insight into their perceptions and experiences of their needs of English use and the types of English language that they use. According to Long (2005a), interviews are more direct ways of finding out what people think or do by asking them. Its scope can be the understanding of an individual or a group perspective (Fontana \& Frey, 2000). It is a key tool of gathering data in many social science branches such as linguistics.

There were two interview schedules to generate data about communication needs. The interview questions were designed based on the adaptation of the Communication Needs Processor introduced by Munby (1978) and the Learning Needs model by Hutchinson and Waters (1987). The first schedule was for the managers of mechanical engineers (Appendix C) and the second schedule was for mechanical engineers (Appendix D). These interviews lasted from 30 to 45 minutes. Interviews with Vietnamese managers and mechanical engineers were conducted in their first language. Twinn (1998) argues that to "maximize the quality of data interviews and analysis should be undertaken in the first language of the informants" (p. 660). This was also because I shared the same language with the participants, which could enhance the rigour of the research (Irvine et al., 2008) because this could limit the chance of misunderstanding.

Employing this method of data collection, I was able to get more information by having asked them semi-structured questions. In these interviews, I asked a number of supplementary questions and guided the interviewees to provide insight on the themes of the study. Some of the interview questions were based on the participants' answers in the questionnaires, which allowed me to explore more in-depth information to best answer the research questions.

In the information sheet given to them prior to the interview, they were informed that they could check the interview transcript to ensure accuracy and could make any amendment if they wished, but none of them required this checking.

\subsubsection{Observations}

Since the main purpose of this study was to delve into mechanical engineers' realworld uses of English in the workplace, observation was the most important and distinct data collection instrument from other studies. It enabled me to capture the active use of English 
through an insider view. Observation is defined as "the watching of behavioural patterns of people in certain situations to obtain information about the phenomenon of interest" (Johnson \& Christensen, 2008, p. 211). Observation helps to "record information that occurs in a setting, to study actual behavior, and to study individuals who have difficulty verbalizing their ideas" (Creswell, 2014a, pp. 235-236). In this study, I used qualitative observation, which "allows direct, in-depth, contextualised study of participants' actions" (Huhta et al., 2013, p. 19) and "involves observing all relevant phenomena and taking extensive field notes" (Johnson \& Christensen, 2008, p. 212). This way of collecting information about people is often used in studies that use a sociolinguistic approach. Before conducting the observations, permission from the managers and mechanical engineers themselves was sought. I spent two days at each company to observe mechanical engineers working. In total, I conducted eight observations. I was being an insider in this case. The observations revealed examples of the mechanical engineers' real uses of English in the various workplace contexts and therefore were very important for my study because participants did not always do what they said they did in the questionnaire or interview. I took very full hand written field notes. Since all the mechanical engineer participants were Vietnamese, I am used to with their English accents and pronunciation. Also, they spoke very slowly due to their English ability and this helped me to record detail of their communication. I have worked as an interpreter for many years which took place at the universities, factories, hospitals, and farmers' farms. Thus, I could record very quickly the detail of the conversations as well as instructions. I used many abbreviations in recording filed notes to save time and to closely follow the conversation. I combined field notes and checklists to record these observations (Appendix E). During the break in the observation and especially after each observation, I refined the field notes by adding more detail as quickly as possible while my memory was fresh. Using hand written field notes, I could record actual language behaviours, the time duration and frequency of each event. I could tick in the checklist of the common communicative events. For example, during my observations, I could listen to my participants' speaking English or communicating with their manager. I could take notes on the genres of English language skills and how they were used in real contexts, the accents and technical words that they used. I could see contexts or situations they were involved in and the way they used English to support their work. I could see what was actually happening and triangulate this with what the participants reported to me. These interactions included the participants' choice of English vocabulary and technical terms, intonation, pausing, and accents which helped the analysis into the key themes in the study such as degree of formality, humour, solidarity and power relationships. Thus, it is the findings from observations that make this study differ 
from studies which have been reviewed in the literature. Observations enabled me to gain an in-depth insight into the language needs of mechanical engineers' professional working context (Huhta et al., 2013). During the observations, I carefully noted down all the technical words that the participants used, both in their spoken communication and written communication (in work schedules, notices, tasks written on the whiteboards, technical manuals, and technical drawings).

In short, this method of data collection allowed better understanding of the context of my study and provided me the kinds of data which were not fully obtained from the questionnaire and interview.

\subsubsection{Identification in the data}

As explained to the participants in the information sheet and consent form, the research sites and participants' identity were kept confidential. They are identified in the study as follows:

Research sites: four companies were named C1, C2, C3 and C4.

The two sets of participants: The abbreviation "M" was used to refer to managers of mechanical engineers and "ME" was used to refer to mechanical engineers.

Semi-structured interviews: There were six interviews with managers of mechanical engineers and six interviews with mechanical engineers. Each participant was given a pseudonym in Vietnamese.

Table 8: Identification of participants in the study

\begin{tabular}{|ll|l|c|}
\hline \multicolumn{2}{|c|}{ Pseudonyms } & \multirow{2}{*}{ Company } \\
\hline \multicolumn{2}{|c|}{ Managers } & \multicolumn{2}{c|}{ Mechanical engineers } \\
\hline Chuot & & Suu Dan & $\mathrm{C} 1$ \\
James & Thin Ty & Ngo & C2 \\
Mike & & Than Dau & C3 \\
Tuat & & Hoi & C4 \\
\hline
\end{tabular}

The identification was coded in the following way to identify each set of data in the analysis:

Participant pseudonym - Manager - Company

Participant pseudonym - Mechanical engineer - Company

For example: Ty-M-C1, Suu-ME-C1 


\subsection{Data Analysis}

As there were different methods of data collection, different methods of data analysis were applied. Details of linguistics in sociolinguistics such as the types of English use and English language skills were explained using the questionnaire data as well as relevant data from individual semi-structured interviews and field notes. The lens shifted to a sociological perspective to workplace communication provided in the CEF model and the Language in the Workplace Project (LWP). Thus, the explanation and presentation of data were deepened to discuss the adequacy of language for need, the social dynamics and dimensions of the language use, and the match and mismatch of the language preparation thanks to the rich qualitative data. The data about communicative events were analysed and presented in comparison with the CNP model by Munby (1978) and CEF model by Huhta et al. (2013). Snapshots were presented at the end of the findings Chapter Six with the purpose of showing a full picture of the uses of English in the workplace by mechanical engineers before shifting to the last chapter of findings (Chapter Seven) about the social dimensions of the use of English in the workplace. The data about the social aspects of the use of English in this Chapter Seven were analysed using thematic analysis and presented in the style of the LWP.

Different instruments for data analysis were employed. The Statistical Package for the Social Sciences (SPSS) version 19 and Microsoft Excel were used to analyse the quantitative data and make bar graphs. The qualitative data, including open questions in the questionnaire, interviews and observations, were analysed inductively using thematic analysis with the help of the Nvivo software version number 10 . The process of the qualitative data analysis was done based on Braun and Clarke's (2006, p. 87) thematic analysis model as follows:

1. Familiarizing yourself with the data: Transcribing data, reading and re-reading the data, noting down initial ideas.

2. Generating initial codes: Coding interesting features of the data in a systematic fashion across the entire data set, collating data relevant to each code.

3. Searching for themes: Collating codes into potential themes, gathering all data relevant to each potential theme.

4. Reviewing themes: Checking if the themes work in relation to the coded extracts (level 1) and the entire data set (Level 2), generating a thematic 'map' of the analysis.

5. Defining and naming themes: Ongoing analysis to refine the specifics of each theme, and the overall story the analysis tells, generating clear definitions and names for each theme.

6. Producing the report: The final opportunity for analysis. Selection of vivid, compelling extracts, relating back of the analysis to the examples, final analysis of selected 
extracts, relating back of the analysis to the research question and literature, producing a scholarly report of the analysis.

Thematic analysis of the qualitative data was centrally concerned with communicative events identified in the study. Communicative events are situations in which the participants use English to communicate (Kaewpet, 2008; Munby, 1978). These communicative events may involve listening and speaking or reading and writing within group settings or by individual participants.

Also, different sources of qualitative data were named in Nvivo, such as managers' interviews, mechanical engineers' interviews, open questions in the questionnaire, and field notes.

\subsubsection{Analysis of questionnaire}

The SPSS software was used to analyse the participant questionnaire data. All frequency responses were calculated and presented in tables, bar graphs, and charts. The use of frequency helped me to compare the results between managers of mechanical engineers and mechanical engineers. It also showed the most common communicative events that mechanical engineers were engaged in to function in their work effectively. The open responses were analysed using thematic analysis as described above. The long responses were read through carefully and significant points were noted. As a result, a list of main points was made (Burton \& Bartlett, 2005).

The frequency of managers' responses in Part 1 was analysed to find out their age range, years of working experience, the kind of company ownership, and the company customers and suppliers. Their frequency responses in Part 2 were calculated to find out their perception about English communication needs, including their satisfaction about mechanical engineers' English ability, the frequency of English use, the frequency of the English communicative events that mechanical engineers performed, the setting of these events, and the importance of adapting the workplace use of English for someone of higher or lower status. This part of the questionnaire also asked multiple response questions to find out the kind of people with whom mechanical engineers communicated and the types of English communication that they used when they communicated with different kinds of people.

The frequency of mechanical engineers responses were analysed to find out their age range, years of working experience, company, the kind of work they were involved in and the English courses they had taken. The frequency responses in Part 2 were calculated to find out their perception about English communicative needs, including their satisfaction with their English ability, the frequency of their use of English in general and that of the 
communicative events in which they were involved, the setting of these events, and the importance of adapting their use of English for someone of higher or lower status. The multiple response questions were analysed to find out the percentage per cases of their answer.

The percentage of participants who had suggestions to improve the ESP courses for mechanical engineering students and agreed to participate in the interview sections were calculated in Part 3 of both forms of questionnaire.

When importing questionnaire data into SPSS, I also imported the open comments and information from open questions. This helped me store and manage data, which were then imported into word files. The qualitative data from these files were read through and coded into categories and themes.

\subsubsection{Analysis of individual semi-structured interviews}

In total, 12 interviews were conducted. I transcribed and translated six of them into English. The other six interviews were transcribed and translated by two lecturers of English at tertiary institutions in Vietnam. One of them holds a Ph.D. in education and the other holds a Masters degree in Teaching English as a Second Language (TESOL). They were experienced in translating from English into Vietnamese and vice versa. Each interview lasted about 30 minutes. The main category covered the English language use in the workplace (including participants' personal information, English communication needs and English learning needs, and their suggestions for better English preparation for mechanical engineering students at tertiary institutions). The translations were checked by two of my colleagues who hold Masters Degrees in English linguistics and TESOL. Both had signed a confidentiality agreement.

These translations were printed out and read through many times to get a general sense of the overall information, to enable me to note down initial ideas and generate initial codes (Braun \& Clarke, 2006). All the information provided by the interviewees were read carefully and sub-coded. The sub-codes were then coded into codes. All the codes were grouped into sub-categories, and then categories before the themes were made. The main themes are presented in the findings Chapter Six and Chapter Seven.

At first, the hard copies of the translations were read and the main nodes were noted on the margins. I numbered these nodes in cardinal order. By doing this, I could figure out the number of times they were mentioned by the interviewees and collate data relevant to each code. This was also to make sure that the coding process was done throughout the entire data analysis (Braun \& Clarke, 2006). These codes were then collated into potential themes. The translated interviews were carefully read again to gather data relevant to the potential 
themes. These themes were reviewed to see if they worked with the coded extracts as well as the entire data set. The themes were then defined and named before the final report was produced. I used Nvivo 10 software program as a tool to manage the data. All translated interviews were imported into Nvivo. Nodes of the main and sub-themes highlighted in the printed versions were then made in Nvivo. When making these nodes, I used pseudonyms for participants to keep their confidentiality. Foreign names were used for foreign participants and Vietnamese names were used for Vietnamese participants. Quotes are presented in the findings chapters.

\subsubsection{Analysis of observations}

Hand written field notes and checklists used in the observations were analysed using thematic analysis (see the sample of this coding process in Appendix M). The full field notes had more detail added right after each observation. I did this because I did not want to miss any detail that I saw and heard in my observations, as they were fresh in my memory. Based on the descriptive field notes including the kinds of work and purposes, forms and levels of English used and reflective notes, initial codes were generated before the themes were found, reviewed, and defined and named. Then the report of findings was produced. Although checklists were used in the observation, it was difficult to quantify exactly the frequency of the communicative events used by the participants, because the observation time was not long enough to collect this kind of information and this kind of quantification is not appropriate to thematic analysis.

Technical vocabulary was observed to be of crucial importance and used frequently by the participants. Technical words were listed under company headings because some of this vocabulary was specific to the manufacturing purposes of the company. Understanding the nature of technical vocabulary is important for recommendations for course design. Since some academic words were observed to be used by the participants, an online vocabulary search tool namely AWL tag cloud \& gapfill was used to search for the common academic words used in the research sites. Then a list which groups the identified academic words from level 1 to level 10 in the AWL proposed by Coxhead (1998) was reported and can be seen in Chapter Six, Section 6.3.5.

\subsection{Research Validity}

Validity is considered the most important aspect of a research project (Creswell \& Plano Clark, 2011; Tashakkori \& Teddilie, 2003). It refers to the degree of accuracy that a study reflects or assesses the specific concept or any construct that the researcher is 
measuring (Thorndike, 2005). In order to acknowledge that both quantitative and qualitative methods must have strong validity in mixed methods research (Johnson \& Christensen, 2008), potential threats to validity and trustworthiness of this study were addressed, and mitigation of the threats was taken into account. The tables below summarise the threats as well as the mitigation applied in the study.

Table 9: Threats to the validity of the quantitative data and mitigation of these threats

\begin{tabular}{|c|c|c|}
\hline & Threats to the validity & Mitigation \\
\hline \multirow[t]{3}{*}{$\begin{array}{l}\text { Quantitative } \\
\text { validity }\end{array}$} & $\begin{array}{l}\text { The selection of participants } \\
\text { for the quantitative and } \\
\text { qualitative data collection, the } \\
\text { sample size, not choosing } \\
\text { participants for the follow-up } \\
\text { qualitative phase and not } \\
\text { designing an appropriate } \\
\text { instrument. }\end{array}$ & $\begin{array}{l}\text { The same individuals were selected in both } \\
\text { phases, a large quantitative sample size } \\
\text { and small qualitative sample size were } \\
\text { used, and the questionnaire instrument was } \\
\text { designed based on the research questions } \\
\text { and Munby's (1978) CNP needs analysis } \\
\text { model. }\end{array}$ \\
\hline & & $\begin{array}{l}\text { The questionnaires were translated into } \\
\text { Vietnamese and checked by two } \\
\text { Vietnamese lecturers of English } \\
\text { The questionnaires were piloted before } \\
\text { being delivered. } \\
\text { Cronbach's Alpha was also used to } \\
\text { measure the reliability of the survey } \\
\text { questions. }\end{array}$ \\
\hline & Managing data & $\begin{array}{l}\text { As the total of } 93 \text { participants, the } \\
\text { quantitative data were big and could cause } \\
\text { mistakes while recording, storing and } \\
\text { analysing, so the data were input into SPSS } \\
\text { software version 19. Microsoft Excel was } \\
\text { also used to produce bar charts. }\end{array}$ \\
\hline & $\begin{array}{l}\text { With regard to issues of data } \\
\text { analysis, the potential threats } \\
\text { could be choosing weak } \\
\text { quantitative results for the } \\
\text { follow-up qualitative approach, } \\
\text { or not addressing validity } \\
\text { issues. }\end{array}$ & $\begin{array}{l}\text { To minimize these threats, significant } \\
\text { results were chosen, such as major themes, } \\
\text { and the study addressed both quantitative } \\
\text { and qualitative validity. }\end{array}$ \\
\hline
\end{tabular}


To mitigate the threats to the trustworthiness of the qualitative data, six out of nine strategies for validation in qualitative research introduced by Creswell and Poth (2018) were applied. Details are shown as follows:

Table 10: Threats to the validity of the qualitative data and mitigation of these threats (adapted from Creswell, 2018)

\begin{tabular}{|c|c|c|}
\hline $\begin{array}{l}\text { Threats to the } \\
\text { trustworthiness } \\
\text { qualitative data }\end{array}$ & & Mitigation \\
\hline Insufficient data & Triangulation & $\begin{array}{l}\text { The combination of different types of data could } \\
\text { increase validity because they can compensate for the } \\
\text { threats to validity of each type (Patton, 1990, p. 224). } \\
\text { The combination of questionnaire, semi-structured } \\
\text { interviews and observations helped to strengthen and } \\
\text { deepen the examination of real-world use of English } \\
\text { in the workplace by mechanical engineers. I was } \\
\text { interested to confirm that the types of English } \\
\text { language skills reported through the survey data were } \\
\text { also discussed in the interviews and seen in the } \\
\text { observation as a form of triangulation of that data. }\end{array}$ \\
\hline Mistranslation & $\begin{array}{l}\text { Member } \\
\text { checking }\end{array}$ & $\begin{array}{l}\text { The transcripts of the interviews were emailed to the } \\
\text { participants to ensure the accuracy and credibility of } \\
\text { the account (Creswell, 2014a). The translations were } \\
\text { checked by two lecturers of English who held Masters } \\
\text { Degrees in English Linguistics. I also contacted some } \\
\text { participants to clarify the data for accuracy during the } \\
\text { process of analysing and interpreting the data. }\end{array}$ \\
\hline $\begin{array}{l}\text { Misunderstanding } \\
\text { of the research } \\
\text { context }\end{array}$ & $\begin{array}{l}\text { Rich and thick } \\
\text { description }\end{array}$ & $\begin{array}{l}\text { The research setting and the data were described in } \\
\text { detail. The comprehensive description of the research } \\
\text { context, participants, and research methodology helps } \\
\text { readers decide whether the findings and implications } \\
\text { of the study can be transferred to other settings. }\end{array}$ \\
\hline \multirow[t]{2}{*}{ Bias } & $\begin{array}{l}\text { Bias } \\
\text { clarification }\end{array}$ & $\begin{array}{l}\text { I commented on past experiences, biases, prejudices, } \\
\text { and orientations that shaped the interpretation and } \\
\text { approach to the study by writing field notes and } \\
\text { discussing the research with my supervisors. }\end{array}$ \\
\hline & $\begin{array}{l}\text { Peer } \\
\text { debriefing }\end{array}$ & $\begin{array}{l}\text { The whole research process was supervised and } \\
\text { reviewed by two supervisors so that mistakes or } \\
\text { irrelevant information were minimised. }\end{array}$ \\
\hline Managing data & \multicolumn{2}{|c|}{$\begin{array}{l}\text { Nvivo software version } 10 \text { were used to store the qualitative data } \\
\text { systematically and undertake the coding process. }\end{array}$} \\
\hline
\end{tabular}


In general, in a mixed methods study, potential threats to validity may arise not only in the data collection process, but also in data analysis (Creswell \& Plano Clark, 2007). Throughout the research, I took as many steps as possible to minimise the threats to validity as well as to ensure the validity of the study as suggested by Cohen (2011) in relation to the research design, data collection, data analysis, and data presentation. As described and explained in this chapter, the selection of a sequential explanatory mixed method design to answer the research questions was appropriate for this study. The data collection instruments and sampling methods were also appropriate for my study. When analysing data, I ensured the validity by using respondent validation, which means the interviewees were sent the transcription of their interviews in Vietnamese to check for clarification and accuracy. Moreover, I read the transcriptions and translations of the data carefully and thematic analysis was used to code and analyse the qualitative data. I minimised the threats to validity in the stage of reporting data by avoiding presenting inaccurate data or reporting them very selectively and unrepresentatively. Much of contextual information was described to help the readers understand the research context to see if the results could be transferred. Additionally, I ensured that the research questions were answered using the most significant data so that claimed could be made (Cohen, 2011). In addition, the triangulation of data was purposely utilised to improve the internal validity.

\subsection{Chapter Summary}

In summary, this chapter has presented information about the methodology employed in this study. It has explained the choice of pragmatism as the research paradigm as well as the reasons for choosing the mixed methods research design with three methods of data collection, namely questionnaire, individual semi-structured interview and observation.

The chapter has also described information about the four research sites and the procedure with which I approached these worksites. Information about the participants has been provided. A total of 93 participants completed the questionnaire and 12 participants were invited to participate in follow-up to the semi-structured interview, and eight observations were conducted. The chapter has presented in detail the ethical considerations that this study had taken into account.

The chapter has described the detail of the data analysis process in which SPSS software was used to manage and analyse the quantitative data and Nvivo software, and thematic analysis approach to manage and analyse the qualitative data. Finally, this chapter 
has discussed the validity of the study by using a triangulation of methods of data collection, trialling of data collection instruments and integration of data analysis.

The next Chapters Five, Six and Seven present the findings of this study, which aim to answer the main research question "What are the English communication needs of mechanical engineers in the Vietnamese context?" Chapter Five provides findings from the questionnaire to answer the first sub-research question about the real-world English skills required by Vietnamese mechanical engineers to function effectively in the workplace, and to partly answer sub-research question 2 about the social factors and social dimensions of the use of English in the workplace. Chapter Six and Chapter Seven address the second subresearch question and third sub-research question about breakdowns in communication and their effects.

Depending on each sub-question, the appropriateness, authenticity and thickness of data, the presentation of findings prioritises the source of data collection which best answers that question.

Findings from the questionnaires (see appendices A \& B) are presented in a single chapter (Chapter Five) because these were the initial findings of this sequential explanatory research design. Also, this was because the survey questionnaire provided a wider overview from a reasonably large sample of 93 participants which were then deepened in more depth in the follow-up semi-structured interviews and real-world observations. 


\section{CHAPTER FIVE: QUESTIONNAIRE FINDINGS OF REAL- WORLD ENGLISH SKILLS REQUIRED BY VIETNAMESE MECHANICAL ENGINEERS}

\subsection{Introduction}

The current chapter is the first of three findings chapters of the study. The chapter presents the quantitative data from the survey questionnaire to give a broad overview of the perceptions of the participants about the English communication needs first. A part of these findings has been presented at the 6th International Conference on Responding to Challenges of Teaching English for Communication ${ }^{4}$. Then the findings of Chapter Six and Chapter Seven focus more on insider voice with thick description provided by the interviews and observations to give more detailed explanation of the English communication needs required by Vietnamese mechanical engineers.

Findings from the survey questionnaires for both managers and mechanical engineers in the study provide answers to the first sub-research question about the real-world English language skills required by mechanical engineers in the workplace. Information about the degree of formality that was perceived as important by the participants was also given in the survey.

English listening and speaking skills were reported in the questionnaires as the most important skills for mechanical engineers to function effectively in the workplaces, followed by reading and writing skills. These are also the skills which were perceived as the most important in the interviews and were naturally the most common skills seen in the observations. It is useful to indicate the strong consonance between all the data sources at this point.

The questionnaire results allow me to see if what I learned from observation and interview was confirmed by larger samples of manager and mechanical engineers. This proved to be the case. These broader findings contribute to the discussion points of the study in relation to pedagogical implications for curriculum design and for teachers and students.

${ }^{4}$ This International conference was held at SEAMEO Regional Training Center, August 13-15, 2015 in Ho Chi Minh City, Vietnam. All the papers presented at the conference have been made available online at http://www.vnseameo.org/TESOLConference2015/Materials/Fullpaper 
In total, 93 participants answered the questionnaire including 22 managers and 71 mechanical engineers. The two forms of the questionnaire were framed in relation to the CNP model proposed by Munby (1978) and Kaewpet (2008), with the majority of questions being identical, except for Part 1 about personal information. The number of participants from each research site is shown in Table 11 below.

Table 11: Number of questionnaire participants from each research site

\begin{tabular}{|c|c|c|c|c|c|c|c|}
\hline Participants & C1 & C2 & C3 & C4 & Male & Female & Total \\
\hline Managers & 5 & 6 & 8 & 3 & 20 & 2 & 22 \\
\hline Mechanical engineers & 16 & 19 & 16 & 20 & 67 & 4 & 71 \\
\hline
\end{tabular}

(C1 is the food producing company; $C 2$ is the dairy company; $C 3$ is the motorbike company; and $C 4$ is the building construction company)

\subsection{The Frequency of English Use}

In the questionnaire, both managers and mechanical engineers were asked to describe their perceptions of the frequency of mechanical engineers' use of English in Question 14. There were six categories ranging from daily (many times in a day), frequently (several times in a week), sometimes (more than five times in a month), occasionally (less than five times in a month), rarely (less than five times in a year) and never. As can be seen from Figure 9 below, there was a considerable difference in the two groups of participants' perception about the frequency of English use of mechanical engineers in the workplace. That is, $77.3 \%$ of the managers' responses said that their mechanical engineers used English daily, while $43.7 \%$ of the mechanical engineers' responses said that they used English daily. Nearly onefifth of the mechanical engineers responded that they frequently used English and more than one-fifth responded that they sometimes used English in the context of their job. Notably, only $1.4 \%$ of the mechanical engineer participants and none of the manager participants indicated the last choice (Never) in the survey. 


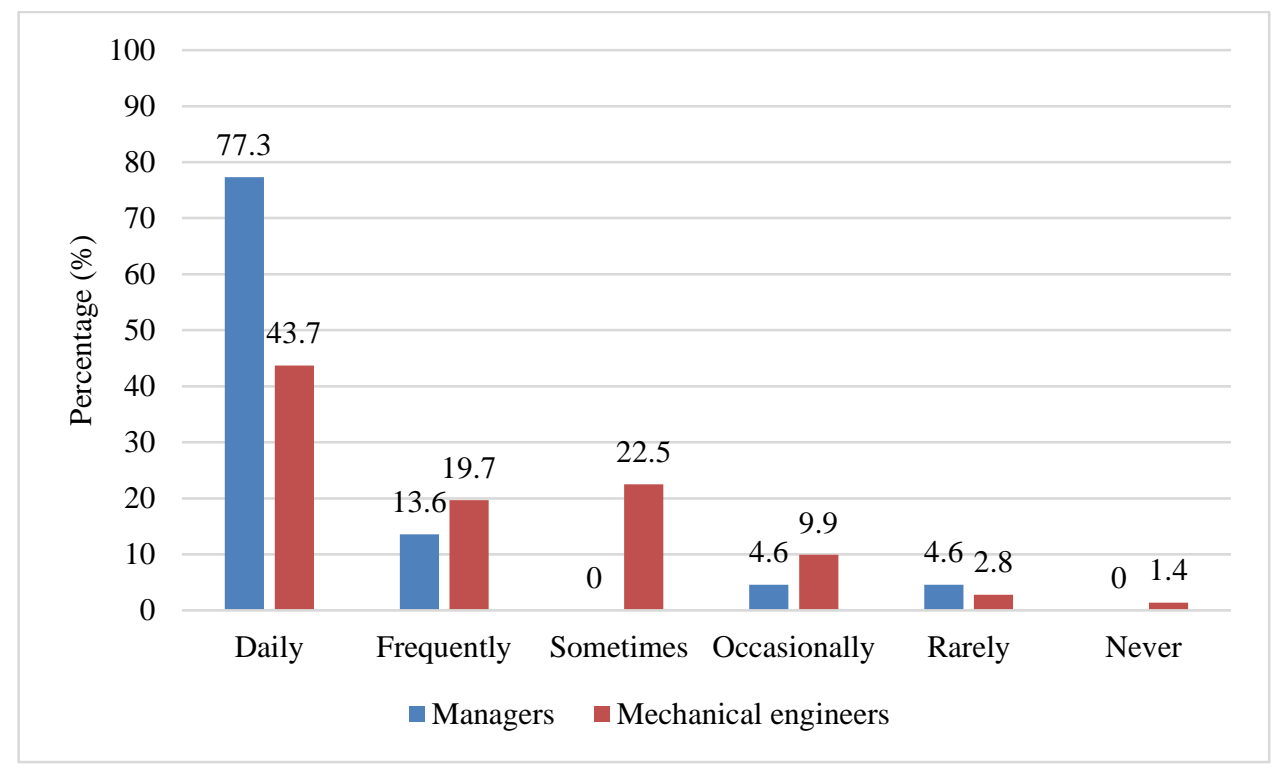

Figure 9: Participants' perception of the frequency of English use of mechanical engineers

Figure 9 shows that English was frequently or daily used by over $63 \%$ of mechanical engineers as reported in the survey.

In contrast to the high frequency of English use required by mechanical engineers, the findings of Question 13 about the degree of satisfactory English ability in the questionnaire revealed that almost half of the mechanical engineer participants' responses $(49.3 \%)$ and nearly half of the manager participants' responses (45.5\%) showed a lack of satisfaction with mechanical engineers' English ability at work. This dissatisfaction also emerges in the interview and observation data.

\subsection{The Contexts for English Uses in the Workplace}

As will be described in Section 6.2.1 of the Chapter Six, context information is not only about the location, but also about the persons and communication situations (Huhta et al., 2013). The questionnaires revealed information about the mechanical engineers' everyday English communication and the communicative events of the workplace.

The questionnaire data indicates the importance of English language skills to communicate with foreign managers, something which also emerged from both the observation and interview data. In response to Question 10 about foreign employees in their company, $68.2 \%$ of the managers' responses indicated that their company employed workers from English-speaking countries and other foreign countries, and that $75 \%$ of these foreign employees held management positions. While $4.6 \%$ of the manager participants' responses said that their company's customers were locals, the remaining participants stated that their company's customers were both local and international. All four companies had both local and international suppliers. 
In response to Question 17 about the people with whom mechanical engineers communicated in English, the survey completed by 22 managers indicated that mechanical engineers often communicated in English with their managers (33.3\%), suppliers (19\%), supervisors $(16.7 \%)$, colleagues $(14.3 \%)$ and clients $(11.9 \%)$. This finding was strongly consonant with the observation data, which showed that mechanical engineers mostly communicated in English with their foreign managers and supervisors.

In a slight contrast to the questionnaire for managers, Question 17 in the questionnaire completed by 71 mechanical engineers found that mechanical engineers often communicated in English with their colleagues (27.2\%), managers (21.9\%), supervisors (21.9\%), suppliers (14\%) and clients (7.9\%). Notably, while the manager participants did not give any response to choice ' $F$ ' (Others), 7\% of mechanical engineers responses selected this choice.

The open question number 29 in both forms of questionnaires about the language expertise and skill sets that employers look for in mechanical engineers also revealed information about the people with whom mechanical engineers communicated in English. Similarly, both managers and mechanical engineers talked about communication with the foreign managers, supervisors and experts, and foreign business partners and clients. These findings will be reported (below).

\subsection{Communicative Events}

Communicative events are situations in which the participants use English to communicate (Kaewpet, 2008; Munby, 1978). These communicative events may involve listening and speaking or reading and writing within group settings or by individual participants. Question 16 in both forms of the questionnaire, which was adapted from Kaewpet (2008), was designed to seek information about the 20 most common communicative events and settings that mechanical engineers are likely to engage in. Most of these communicative events were consistent with those reported in the interviews and seen in the observations, except for reading textbooks, writing technical papers and writing research papers, which were not described in the interview or observed.

The frequency of the communicative events was calculated by the SPSS software and detail can be found in Table 12 below. 
Table 12: The frequency of communicative events adapted from Kaewpet (2008) as perceived by managers and mechanical engineers

\begin{tabular}{|c|c|c|c|c|c|c|c|c|c|c|c|c|c|c|}
\hline \multicolumn{15}{|c|}{ The average percentage (\%) of the frequency of MEs' communicative events as perceived by managers (Man.) and mechanical engineers (ME) } \\
\hline \multirow[t]{2}{*}{ Communicative events } & \multicolumn{2}{|c|}{$\begin{array}{c}1 \\
\text { Never }\end{array}$} & \multicolumn{2}{|c|}{$\begin{array}{c}2 \\
\text { Rarely }\end{array}$} & \multicolumn{2}{|c|}{$\begin{array}{c}3 \\
\text { Occasionally }\end{array}$} & \multicolumn{2}{|c|}{$\begin{array}{c}4 \\
\text { Sometimes }\end{array}$} & \multicolumn{2}{|c|}{$\begin{array}{c}5 \\
\text { Frequently }\end{array}$} & \multicolumn{2}{|c|}{$\begin{array}{c}6 \\
\text { Daily }\end{array}$} & \multicolumn{2}{|c|}{ Missing } \\
\hline & Man. & ME & Man. & ME & Man. & ME & Man. & ME & Man. & ME & Man. & ME & Man. & ME \\
\hline 1. Listening to English-speaking boss's instructions & 13.6 & 9.9 & 9.1 & 18.3 & 0.0 & 9.9 & 13.6 & 25.4 & 36.4 & 18.3 & 27.0 & 7.0 & 0.0 & 11.3 \\
\hline $\begin{array}{l}\text { 2. Listening to presentations and discussions in a } \\
\text { meeting, seminar or conference }\end{array}$ & 4.5 & 4.2 & 9.1 & 19.7 & 22.7 & 12.7 & 36.4 & 39.4 & 22.7 & 5.6 & 4.5 & 5.6 & 0.0 & 12.7 \\
\hline 3. Delivering oral presentations on projects & 4.5 & 22.1 & 13.6 & 19.7 & 18.2 & 25.4 & 50.0 & 14.1 & 13.6 & 5.6 & 0.0 & 2.8 & 0.0 & 11.3 \\
\hline 4. Making telephone conversations & 4.5 & 14.1 & 9.1 & 21.1 & 9.1 & 15.5 & 40.1 & 26.8 & 13.6 & 5.6 & 18.2 & 4.2 & 4.5 & 12.7 \\
\hline 5. Group meetings & 0 & 18.3 & 9.1 & 14.1 & 18.2 & 14.1 & 27.3 & 19.7 & 31.8 & 16.9 & 9.1 & 5.6 & 0.0 & 11.3 \\
\hline 6. Public speaking & 9.1 & 21.1 & 13.6 & 18.3 & 40.9 & 12.7 & 27.3 & 31 & 9.1 & 0 & 0 & 1.4 & 0.0 & 15.5 \\
\hline $\begin{array}{l}\text { 7. Engaging in professional conversations (this } \\
\text { includes elements of informal, casual, and/or business } \\
\text { conversations) }\end{array}$ & 0 & 19.7 & 13.6 & 11.3 & 22.7 & 11.3 & 36.4 & 35.2 & 22.7 & 11.3 & 4.5 & 1.4 & 0.0 & 9.9 \\
\hline 8. Talking about everyday tasks and duties & 0 & 8.5 & 9.1 & 11.3 & 9.1 & 9.9 & 13.6 & 23.9 & 31.8 & 23.9 & 36.4 & 11.3 & 0.0 & 11.3 \\
\hline 9. Reading product specifications/ descriptions & 0 & 1.4 & 9.1 & 7 & 4.5 & 9.9 & 27.3 & 19.7 & 36.4 & 36.6 & 22.7 & 16.9 & 0.0 & 8.5 \\
\hline 10. Reading textbooks & 4.5 & 11.3 & 18.2 & 21.1 & 27.3 & 5.6 & 40.9 & 29.6 & 9.1 & 16.9 & 0 & 2.8 & 0.0 & 12.7 \\
\hline $\begin{array}{l}\text { 11. Reading professional texts, e.g. rules of practice, } \\
\text { contracts }\end{array}$ & 0 & 8.5 & 18.2 & 14.1 & 36.4 & 11.3 & 13.6 & 42.3 & 27.3 & 12.7 & 4.5 & 1.4 & 0.0 & 9.9 \\
\hline 12. Reading technical papers & 4.5 & 18.3 & 18.2 & 18.3 & 22.7 & 8.5 & 31.8 & 28.2 & 22.7 & 12.7 & 0 & 2.8 & 0.0 & 11.3 \\
\hline 13. Reading online manuals & 4.5 & 4.2 & 0 & 14.1 & 22.7 & 15.5 & 40.9 & 23.9 & 31.8 & 31 & 0 & 2.8 & 0.0 & 8.5 \\
\hline 14. Writing proposals/ design projects & 4.5 & 36.6 & 27.3 & 14.1 & 22.7 & 7 & 36.4 & 29.6 & 9.1 & 2.8 & 0 & 0 & 0.0 & 9.9 \\
\hline 15. Writing technical reports & 0 & 26.8 & 18.2 & 7 & 18.2 & 8.5 & 31.8 & 22.5 & 22.7 & 15.5 & 9.1 & 9.9 & 0.0 & 9.9 \\
\hline 16. Writing business letters, faxes, and memos & 4.5 & 28.2 & 13.6 & 9.9 & 36.4 & 11.3 & 9.1 & 25.4 & 27.3 & 11.3 & 9.1 & 1.4 & 0.0 & 12.7 \\
\hline 17. Writing technical papers & 22.7 & 49.3 & 45.5 & 8.5 & 22.7 & 12.7 & 4.5 & 11.3 & 4.5 & 7 & 0 & 0 & 0.0 & 11.3 \\
\hline 18. Writing research papers & 31.8 & 49.3 & 45.5 & 15.5 & 18.2 & 12.7 & 0 & 8.5 & 4.5 & 1.4 & 0 & 1.4 & 0.0 & 11.3 \\
\hline 19. Communicating through emails & 0 & 9.9 & 0 & 5.6 & 22.7 & 12.7 & 13.6 & 18.3 & 27.3 & 23.9 & 36.4 & 21.1 & 0.0 & 8.5 \\
\hline 20. Accessing information through the internet & 0 & 4.2 & 0 & 8.5 & 4.5 & 12.7 & 36.4 & 22.5 & 50 & 25.4 & 9.1 & 18.3 & 0 & 8.5 \\
\hline
\end{tabular}


As can be seen in Table 12, above, the perceptions of both managers and mechanical engineers about the communicative events required by mechanical engineers in the worksite in the study were listed in one table so that the comparison could be easily identified. The frequency was from level 1 (never) to level 6 (daily). The last column in the table shows the percentage of the unanswered questionnaires. The comparison is interesting because it gives views from two different groups of participants. The view of the managers of these engineers were at one remove from the views of the mechanical engineers themselves. The managers were directly working with their engineers and could, to some extent, assess the English ability of these engineers and were perhaps more indirectly, aware of the communicative events that their engineers had to engage in. As some of these managers had been exmechanical engineers themselves this also gave them a basis from which to provide useful insights into this question. Some minor differences in the perceptions of managers and mechanical engineers do emerge in the findings (see below). Generally, both managers and mechanical engineers perceived communicative event number 8 (talking about everyday tasks and duties), communicative event number 19 (communicating through emails), communicative event number 9 (reading product specifications/descriptions), and communicative event number 20 (accessing information through the internet) as the most frequently used communicative events by mechanical engineers. These communicative events were seen in the observations.

\subsubsection{Managers' perceptions of their mechanical engineers' communicative events}

The frequency of communicative events that mechanical engineers were likely to engage in, as perceived by the managers, was calculated using SPSS software. The numbers represent the continuum scale of 'never' to 'daily'. Table 13, below, illustrates this frequency in terms of mean score and the communicative events are put in order of the most frequent to the least. 
Table 13: Managers' perceptions about the frequency of communicative events that their mechanical engineers were likely to be engaged in

\begin{tabular}{|l|c|c|c|c|}
\hline Communicative events & Valid N & Missing & Mean & Median \\
\hline 8. Talking about everyday tasks and duties & 22 & 0 & $\mathbf{4 . 7 7}$ & 5.00 \\
\hline 19. Communicating through emails & 22 & 0 & $\mathbf{4 . 7 7}$ & 5.00 \\
\hline 20. Accessing information through the internet & 22 & 0 & $\mathbf{4 . 6 4}$ & 5.00 \\
\hline 9. Reading product specifications/ descriptions & 22 & 0 & $\mathbf{4 . 5 9}$ & 5.00 \\
\hline 1. Listening to English-speaking boss's instructions & 22 & 0 & $\mathbf{4 . 3 2}$ & 5.00 \\
\hline 5. Group meetings & 21 & 1 & $\mathbf{4 . 1 4}$ & 4.00 \\
\hline 4. Making telephone conversations & 21 & 1 & $\mathbf{4 . 1 0}$ & 4.00 \\
\hline 13. Reading online manuals & 22 & 0 & $\mathbf{3 . 9 5}$ & 4.00 \\
\hline 15. Writing technical reports & 22 & 0 & $\mathbf{3 . 8 6}$ & 4.00 \\
\hline $\begin{array}{l}\text { 7. Engaging in professional conversations (this includes } \\
\text { elements of informal, casual, and/or business } \\
\text { conversations) }\end{array}$ & 22 & 0 & $\mathbf{3 . 8 2}$ & 4.00 \\
\hline $\begin{array}{l}\text { 2. Listening to presentations and discussions in } \\
\text { meeting, seminar or conference }\end{array}$ & 22 & 0 & & \\
\hline 16. Writing business letters, faxes, and memos & 22 & 0 & $\mathbf{3 . 7 7}$ & 4.00 \\
\hline $\begin{array}{l}\text { 11. Reading professional texts, e.g. rules of practice, } \\
\text { contracts }\end{array}$ & 22 & 0 & $\mathbf{3 . 6 4}$ & 3.00 \\
\hline 3. Delivering oral presentations on projects & 22 & 0 & $\mathbf{3 . 5 5}$ & 4.00 \\
\hline 12. Reading technical papers & 22 & 0 & $\mathbf{3 . 5 0}$ & 4.00 \\
\hline 10. Reading textbooks & 22 & 0 & $\mathbf{3 . 3 2}$ & 3.50 \\
\hline 14. Writing proposals/ design projects & 22 & 0 & $\mathbf{3 . 1 8}$ & 3.00 \\
\hline 6. Public speaking & 22 & 0 & $\mathbf{3 . 1 4}$ & 3.00 \\
\hline 17. Writing technical papers & 22 & 0 & $\mathbf{2 . 2 3}$ & 2.00 \\
\hline 18. Writing research papers & $\mathbf{2 . 0 0}$ & 2.00 \\
\hline
\end{tabular}

According to the manager participants, the most frequent communicative events using English were talking about everyday tasks and duties, communicating through emails and accessing information through the internet. These communicative events were followed by reading product specifications and descriptions, listening to the English speaking boss's instructions, group meetings, making telephone conversations, reading online manuals and writing technical reports.

Still important but less frequent were engaging in professional conversations (this includes elements of informal, casual, and/or business conversations); listening to presentations and discussions in a meeting, seminar or conference; writing business letters, faxes and memos; reading professional texts; delivering oral presentations on projects; reading technical papers; reading textbooks; and writing proposals/design projects.

Less frequent again were public speaking, writing technical papers and writing research papers.

In terms of frequency, the data reveal that talking about everyday tasks and duties were reported to occur very frequently, as did communication through email and accessing 
information through the internet. This is consistent with the observation findings, which revealed the high-frequency listening and speaking skills used in the context of the mechanical engineers' job. Although for Question 27 (see Table 15) and Question 28 (see Table 16) of the questionnaire, mechanical engineers wrote that listening and speaking were the two skills they used most and they also lacked most, it appears that reading and writing skills were of a high frequency of use too. Communicating through email requires both reading and writing skills, while accessing information through the internet requires skill in reading.

\subsubsection{Mechanical engineers' perceptions about their communicative events}

The surveys filled in by 71 mechanical engineers revealed the frequency of the communicative events that they were likely to engage in to function effectively in their jobs. Table 14 below shows these communicative events in order of frequency, from the most frequent to the least frequent.

Table 14: Mechanical engineers' perceptions about the frequency of communicative events that they were likely to be engaged in

\begin{tabular}{|l|c|c|c|c|}
\hline Communicative events & Valid N & Missing & Mean & Median \\
\hline 9. Reading product specifications/ descriptions & 65 & 6 & $\mathbf{4 . 4 6}$ & 5.00 \\
\hline 20. Accessing information through the internet & 65 & 6 & $\mathbf{4 . 2 2}$ & 4.00 \\
\hline 19. Communicating through emails & 65 & 6 & $\mathbf{4 . 1 4}$ & 4.00 \\
\hline 8. Talking about everyday tasks and duties & 63 & 8 & $\mathbf{3 . 8 7}$ & 4.00 \\
\hline 13. Reading online manuals & 65 & 6 & $\mathbf{3 . 7 8}$ & 4.00 \\
\hline 1. Listening to English-speaking boss's instructions & 63 & 8 & $\mathbf{3 . 5 1}$ & 4.00 \\
\hline $\begin{array}{l}\text { 2. Listening to presentations and discussions in a } \\
\text { meeting, seminar or conference }\end{array}$ & 62 & 9 & $\mathbf{3 . 4 5}$ & 4.00 \\
\hline $\begin{array}{l}\text { 11. Reading professional texts, e.g. rules of practice, } \\
\text { contracts }\end{array}$ & 64 & 7 & $\mathbf{3 . 4 5}$ & 4.00 \\
\hline 10. Reading textbooks & 62 & 9 & $\mathbf{3 . 3 2}$ & 4.00 \\
\hline 15. Writing technical reports & 64 & 7 & $\mathbf{3 . 2 5}$ & 4.00 \\
\hline 5. Group meetings & 63 & 8 & $\mathbf{3 . 2 2}$ & 3.00 \\
\hline $\begin{array}{l}\text { 7. Engaging in professional conversations (this includes } \\
\text { elements of informal, casual, and/or business } \\
\text { conversations) }\end{array}$ & 64 & 7 & $\mathbf{3 . 1 3}$ & 4.00 \\
\hline 12. Reading technical papers & & & & \\
\hline 4. Making telephone conversations & 63 & 8 & $\mathbf{3 . 0 8}$ & 3.00 \\
\hline 16. Writing business letters, faxes, and memos & 62 & 9 & $\mathbf{2 . 8 4}$ & 3.00 \\
\hline 6. Public speaking & 60 & 11 & $\mathbf{2 . 7 0}$ & 3.00 \\
\hline 3. Delivering oral presentations on projects & 63 & 8 & $\mathbf{2 . 6 8}$ & 3.00 \\
\hline 14. Writing proposals/ design projects & 64 & 7 & $\mathbf{2 . 4 2}$ & 2.00 \\
\hline 17. Writing technical papers & 63 & 8 & $\mathbf{2 . 0 8}$ & 1.00 \\
\hline 18. Writing research papers & 63 & 8 & $\mathbf{1 . 8 9}$ & 1.00 \\
\hline
\end{tabular}

Based on the mean score, mechanical engineers themselves perceived that reading product specifications, accessing information through the Internet and communicating 
through emails were the most frequent communicative events. These reading events were followed in frequency by talking about everyday tasks and duties, reading online manuals and listening to an English-speaking boss's instructions, listening to presentations and discussions in a meeting seminar or conference, and reading professional texts.

Still significant but less frequent were reading textbooks, writing technical reports, group meetings, engaging in professional conversations, reading technical papers and communicating on the telephone.

Less frequent again were writing business letters, faxes and memos, public speaking, delivering oral presentations on projects, writing proposals/ design projects, writing technical papers and writing research papers.

In terms of frequency, the questionnaire data revealed that reading product specifications occurs very often and so do reading on the internet (the interviews suggested this reading includes looking for product instructions and specifications) and communicating in writing through email. According to the questionnaire responses, once the technical information has been accessed then this information and daily tasks need to be discussed, reference made to manuals and manager's instructions listened to. Presentation of and discussion of relevant ideas in meetings is also an important communicative activity, followed by the reading of professional texts. This order is slightly different from that in the managers' perceptions, which indicate talking about everyday tasks and duties as the most frequently used communicative event, followed by communicating through emails and accessing information through the internet.

These results from the questionnaire are consistent with the snapshot of the mechanical engineer's day (see Section 6.3.6 in the findings of Chapter Six), which initially prioritised reading and responding to emails, informal discussion about the day's requirements, reading reports, and then drawing, writing reports, assessing equipment in the field so that reports could be written about them.

Language skills are required to realise communicative events or activities (Munby, 1978) to take place in the factories where this study was conducted. The next section provides information about the work-related English language skills which were reported in the questionnaire data. 


\subsection{Work Related English Language Skills Reported in the Questionnaire}

\subsubsection{Numeric data}

Regarding the English language skills, Questions 23 to 26 in the questionnaires asked about the importance of listening, speaking, reading and writing skills; Question 27 asked about the most frequent skills of use; and Question 28 sought information about the skills of mechanical engineers that were most lacking.

In terms of importance, the six categories scale (strongly agree, agree, slightly agree, slightly disagree, disagree, and strongly disagree) was used and nearly $100 \%$ of the participants' responses (including managers and mechanical engineers) claimed that all the macro skills (listening, speaking, reading and writing) were important for mechanical engineers to perform effectively in their jobs. The percentages for frequency varied considerably. It should be noted that listening and speaking were again perceived as the most important skills, with $63.6 \%$ of the managers' and $59.2 \%$ of the mechanical engineers' responses strongly agreeing on listening skills, and $41 \%$ of the managers' and $55 \%$ of the mechanical engineers' responses strongly agreeing on speaking skills. The percentages of the managers' responses strongly agreeing on reading and writing skills were $45 \%$ and $31.8 \%$, and those of mechanical engineers were $47.9 \%$ and $40.1 \%$, respectively. This importance and its order again matched with findings from the interviews and observations.

Only a small percentage of $4.6 \%$ of the managers' and $2.8 \%$ of the mechanical engineers' responses slightly disagreed about the importance of writing skills in the job performance of the mechanical engineers. While none of the managers' responses disagreed on the importance of listening and speaking skills, $1.4 \%$ of the mechanical engineers slightly disagreed, and $1.4 \%$ of them disagreed.

Question 27 of the questionnaire asks about the English language skills mechanical engineers use most, and the participants were invited to number from 1 (the most frequently used) to 4 (the least frequently used). Both managers' and mechanical engineers' responses stated that listening and speaking were either most frequently or frequently used by mechanical engineers in the context of their job and they indicated that listening was more important. $63.6 \%$ of the managers' and $54.9 \%$ of the mechanical engineers' responses specified listening skills as the most frequently used, followed by speaking skills. This indicates an expectation that listening also involves understanding, as languages skills are interrelated. These findings were mostly in line with results from the interviews and observations, except for reading skills which were observed as being required by the 
mechanical engineers in the worksites in the study. Writing skills, on the contrary, were perceived as the least frequently used skills by $59.1 \%$ of the managers' and $54.9 \%$ of the mechanical engineers' responses, followed by reading skills. Detail of this frequency can be found in Table 15 below:

Table 15: Question 27 - The frequency of the English language skills perceived by the managers and mechanical engineers

\begin{tabular}{|c|c|c|c|c|c|c|c|c|c|}
\hline \multirow{2}{*}{$\begin{array}{c}\text { Scales } \\
\text { Skills }\end{array}$} & \multicolumn{2}{|c|}{$\begin{array}{c}\text { Most } \\
\text { frequently }\end{array}$} & \multicolumn{2}{|c|}{ Frequently } & \multicolumn{2}{|c|}{$\begin{array}{c}\text { Less } \\
\text { frequently }\end{array}$} & \multicolumn{2}{|c|}{$\begin{array}{c}\text { Least } \\
\text { frequently }\end{array}$} & \multirow{2}{*}{ Total \% } \\
\hline & M & $\mathrm{ME}$ & M & ME & M & ME & M & ME & \\
\hline Listening skills & 63.6 & 54.9 & 28.2 & 38.0 & 4.6 & 12.7 & 4.6 & 4.2 & 100 \\
\hline Speaking skills & 18.2 & 22.5 & 52.1 & 35.2 & 22.7 & 18.3 & 9.1 & 7.0 & 100 \\
\hline Reading skills & 9.1 & 19.7 & 8.5 & 15.5 & 41 & 39.4 & 27.3 & 32.4 & 100 \\
\hline Writing skills & 9.1 & 9.9 & 8.5 & 8.5 & 31.8 & 26.8 & 59.1 & 54.9 & 100 \\
\hline
\end{tabular}

When they were asked about the most lacking skills of mechanical engineers in Question 28 of the questionnaire, both groups of the participants indicated listening and speaking skills (see Table 16 below). This finding was later confirmed in the observations as the main causes leading to breakdowns in communication.

Table 16: Question 28 - The most lacking English language skills perceived by the managers and mechanical engineers

\begin{tabular}{|l|l|c|c|c|c|c|c|c|c|}
\hline Scale & \multicolumn{2}{|c|}{$\begin{array}{c}\text { Most } \\
\text { lacking }\end{array}$} & \multicolumn{2}{c|}{ Lacking } & \multicolumn{2}{c|}{$\begin{array}{c}\text { Less } \\
\text { lacking }\end{array}$} & \multicolumn{2}{c|}{ Least lacking } & \multirow{2}{*}{ Total \% } \\
\cline { 1 - 9 } \begin{tabular}{|l} 
Skills \\
Participants
\end{tabular} & $\mathrm{M}$ & $\mathrm{ME}$ & $\mathrm{M}$ & $\mathrm{ME}$ & $\mathrm{M}$ & $\mathrm{ME}$ & $\mathrm{M}$ & $\mathrm{ME}$ & \\
\hline Listening skills & 31.8 & 40.8 & 41 & 38.0 & 13.6 & 14.1 & 13.6 & 7.0 & 100 \\
\hline Speaking skills & 31.8 & 39.4 & 45.5 & 35.2 & 18.2 & 19.7 & 4.6 & 5.6 & 100 \\
\hline Reading skills & 9.1 & 8.5 & 0 & 15.5 & 45.5 & 29.6 & 45.5 & 46.5 & 100 \\
\hline Writing skills & 27.3 & 19.7 & 13.6 & 8.5 & 27.3 & 33.8 & 31.8 & 38.0 & 100 \\
\hline
\end{tabular}

As Table 16 illustrates, $31.8 \%$ of the managers' and $40.8 \%$ of the mechanical engineers' responses stated that listening was the most lacking skill of the mechanical engineers and nearly the same proportion of each group agreed on the lack of speaking skills of the mechanical engineers.

If writing skills were stated to be the least frequently used skills (see Table 15), it is clear from Table 16 that reading skills were the least lacking skills, as perceived by $45.5 \%$ 
of the managers' and $46.5 \%$ of mechanical engineers' response, followed by writing skills as claimed by $31.8 \%$ of the managers' and $38 \%$ of the mechanical engineers' responses.

\subsubsection{Qualitative data from open questions in the questionnaire}

In response to Question 29 about the English language expertise and skill sets that employers are looking for from mechanical engineers, all 22 manager participants and 59 out of 71 mechanical engineer participants provided responses, which are divided into the following themes:

\subsubsection{The requirements of all macro English language skills}

In the questionnaire, four out of 22 managers and 13 out of 59 mechanical engineers who provided the written comments emphasised the importance of all macro English language skills. Mechanical engineers required these skills to perform effectively in their jobs, especially to work with foreign managers and experts.

- All skills because they help mechanical engineers perform their work effectively and also help them better in communication as well as update information.

- Be fluent in all skills: listening, speaking, reading and writing, as they are essential needs in this integrated world.

One manager participant noted that his mechanical engineers had very basic English and that they must know English in order to perform their work. He commented:

Engineers must know how to read, write and understand mechanical English, mechanical terms, of course these should come after learning basic English. Most of [the] engineers working in our company don't have basic English. It is very important for the engineers' future because to become a manager in the company one must have good English ability.

\subsubsection{The importance of listening and speaking skills}

Many manager and mechanical engineer participants described English listening and speaking skills as the most important required by mechanical engineers to communicate with foreign managers, supervisors and colleagues, as well as clients and suppliers. Listening and speaking were interrelated, as listening came with understanding and giving feedback.

Listening and speaking skills, because in a joint venture company mechanical engineers usually work with foreign experts and colleagues. Also, the company will integrate and open its market to the world market.

Listening and speaking skills. Mechanical engineers can complete their work well through the experts' instructions and direct discussions with foreign experts.

Notably, listening was perceived as the English language skill that the employers wanted most from prospective mechanical engineers. This was because they were required 
to understand requests and instructions from foreign managers and experts, as commented by some mechanical engineer participants.

Listening and speaking skills. Listening is very important to perform the work effectively.

Listening skills to understand requests and instructions. Speaking skills to talk about the work progress, results and to report work progress.

Many managers described the importance of the listening skills or their engineers from their perspectives as managers. One followed up the importance of listening skills with the importance of daily communication and the ability to read technical documents.

Listening skills to understand the manager's instructions and communication. Daily communication with colleagues and clients. Technical English, able to understand technical documents.

Listening skill because it is the worst skill they have.

These skills were also seen in the observations.

\subsubsection{General English for communication and English for technical communication}

In the responses, some participants said that the employers wanted their mechanical engineers to have good communication skills and English for technical communication, especially English for mechanical engineering. Being able to communicate and understand international standards about the field of mechanical engineering was perceived to be important.

- English for communication and English for mechanical engineering. Understand international standards about mechanical engineering.

- English for mechanical engineering and English for mechanical designing and construction execution because the company specialises in designing, installing steel houses and buildings.

These responses might indicate that in the context of the mechanical engineers' job, they had to communicate with foreign people using both general English for communication and English for technical communication in their field. The other comments were about the importance of technical English and technical drawings in the context of the mechanical engineers' jobs.

Specific technical drawing is the engineer's language.

It seemed that in the workplace communication, technical English was in high demand. In one case there was a comment that mechanical engineers were required to use English all the time and English was the language in which they communicated with the world. 
Mechanical engineers MUST use technical English all the time. All communications with the world are in English.

These findings were perceived in the interviews and seen in the observation.

\subsubsection{Combination of listening, speaking and reading or writing}

In their comments, some mechanical engineer participants perceived that employers wanted to look for engineers who possessed listening, speaking and reading skills for different tasks in different contexts.

Listening, speaking and reading skills. Listening and speaking skills are needed to communicate with foreign experts. Reading skills are used for reading documents.

Writing skills were also of importance for report writing

- Speaking and writing in order to communicate when working and to write reports.

- Reading and writing skills to read documents and write reports.

Some manager participants also stressed in their responses that the employers required their mechanical engineers to have reading and writing skills to function in their job effectively.

- Listening, speaking and reading skills because they are daily and essential needs. Writing skills are less frequently used. Only some staff use writing skills for email communication with foreign business partners, suppliers or clients.

- Writing emails to the suppliers and able to explain the equipment such as trouble shooting, calibration and tolerance which are frequently repeated problems.

\subsubsection{Overview of the findings from Question 29}

In summary, both groups of participants claimed that the employers were looking for those who had good English communication skills, which included all four macro skills namely listening, speaking, reading and writing. If English listening and speaking skills were required for communication with foreign managers, experts, business partners and clients; English reading skills were required for reading and understanding documents; and English writing skills were used for writing reports and email communication. Besides these skills, mechanical engineers were also required to have technical English, especially English for mechanical engineering.

\subsection{Questionnaire Findings about the Formality of English Use in the Workplace}

In both forms of the questionnaires, participants were asked about the kind of English they used in the presence of different groups of people, such as managers (question 18), colleagues (Question 19) and clients and business partners (Question 20). Below each question, they were asked to give their comments if they wished. They were also asked to 
express their opinion about the importance of mechanical engineers' adapting the workplace use of English for someone of higher status (Question 21) or lower status (Question 22) than them.

\subsubsection{Managers' responses about the types of English used by their mechanical engineers}

Figure 10 shows the managers' response rates over the types of English mechanical engineers communicated with the 'boss' (Question 18), colleagues (Question 19) and clients and business partners (Question 20).

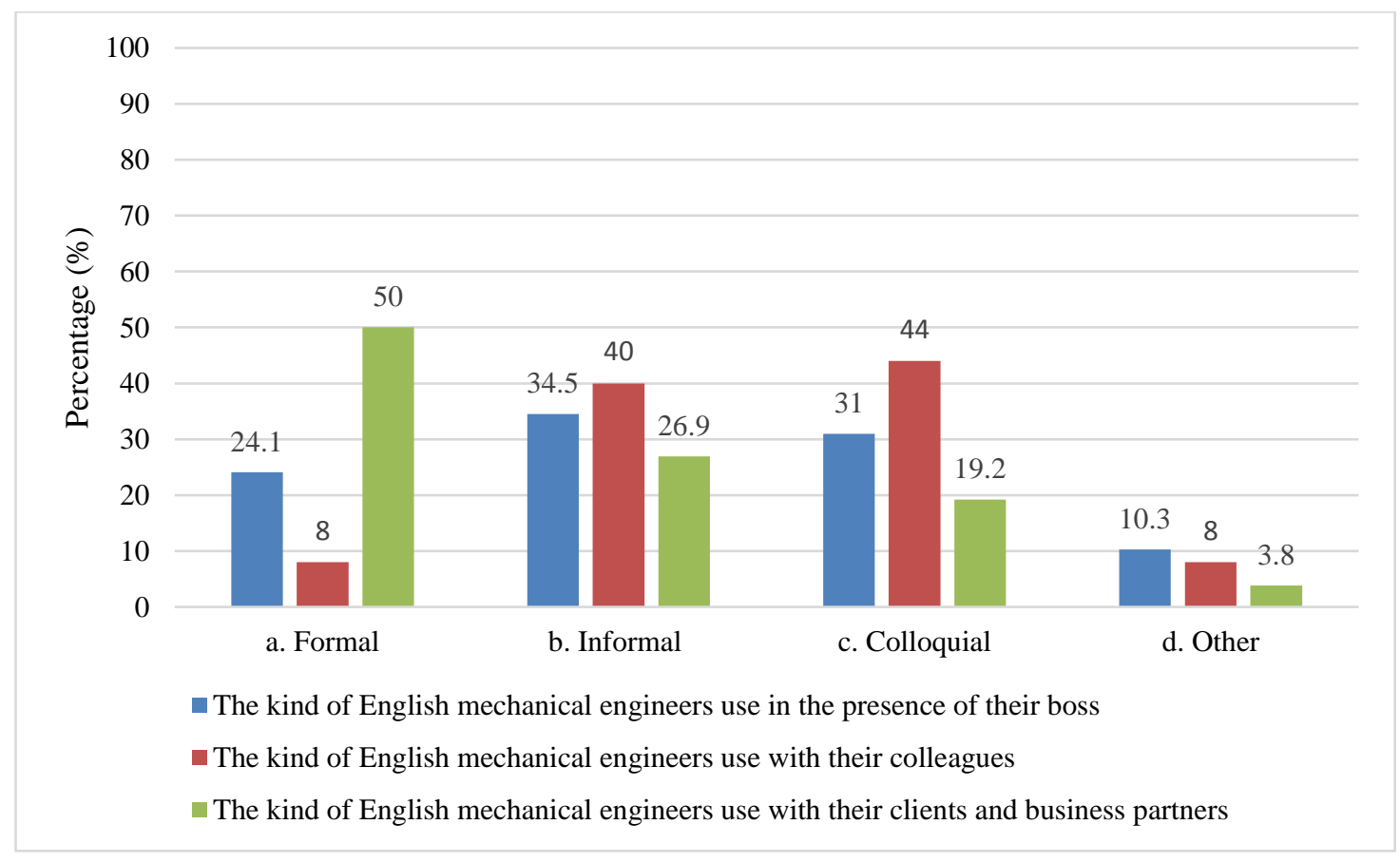

Figure 10: Managers' perceptions about the kind of English their mechanical engineers communicated with them (the 'boss'), their colleagues, and clients and business partners

It is clear from the graph that mechanical engineers were perceived to use more informal and colloquial English than formal English and any other kinds. However, it seemed that they were aware of the importance of using more formal or polite English for someone of higher authority, such as managers and business partners. Specifically, more than $24 \%$ of the managers' responses said that mechanical engineers used formal English to communicate with their managers and especially $50 \%$ of their responses indicated that mechanical engineers used formal English in communication with the clients and business partners.

More informal English (40\%) and colloquial English (44\%) were used when the mechanical engineers communicated with their colleagues and they had their reasons to do so. Notably, about one-third of the managers' responses said that mechanical engineers used 
these types of English with the managers and clients and business partners. Below are the managers' comments about their perceptions.

\subsubsection{Managers' comments about the types of English used by their mechanical engineers}

In the questionnaire, some manager participants provided their comments for their answers after each question. Of these, three of them mentioned that mechanical engineers used formal English to communicate with their managers because they wanted to show politeness and respect in communication.

As can be seen from the graph in Figure 10, formal English was the most common type of English used by mechanical engineers to communicate with their company's clients and business partners. According to two manager participants' explanations, this was because the mechanical engineers wanted to show respect and cooperation and make an impression on the listeners. One manager further said that formal English should be used when suppliers and customers are attending the same discussion or meeting. In this instance with the use of formal English, they were not only showing politeness and formality for individuals, they were also enhancing the company's reputation.

The data labels in the graph in Figure 10 show that mechanical engineers used informal English and colloquial English, not only with colleagues but also with the foreign clients and business partners as perceived by their managers. One of the most common reasons given in the written responses by three managers for using these types of English was that most of the engineers used a very low level of English without following the more formal uses of English they had learnt from English textbooks. Some of these responses were:

- They have no choice because of their poor English ability.

- Most of the engineers are using very poor and basic English.

This explanation was further claimed by the participants in the interviews, which is presented in the findings of Chapter Six.

In the questionnaire, five manager participants commented that their mechanical engineers used informal, colloquial English when communicating with their colleagues to make the communication short and easy to understand and also to show friendliness:

- Be short and easy to be understood.

- Showing the closeness and cooperation among colleagues.

One participant even commented that his mechanical engineers used their local language (Vietnamese) almost all the time.

99\% of the time they communicate in Vietnamese. 
Some manager participants said in the questionnaire that they themselves and their mechanical engineers as well did not focus much on the grammatical rules as in formal English textbooks, even though the use of English was quite complex, as seen in an example below.

No rules, just for the effectiveness of the work. They have to talk about problems and problem analysis and solving, new problems that are forecasting based on experience.

These manager participants claimed that they and the mechanical engineers cared more about the effectiveness of the work, the solidarity and the friendliness at work, which can be interpreted from the comment of one manager participant below.

To develop the solidarity in working in groups.

This probably explains why mechanical engineers used little formal English compared with informal and colloquial English.

\subsubsection{Mechanical engineers' responses about the type of English they use}

The mechanical engineer participants' responses showed a slight difference in the types of English they used to communicate with the 'boss', colleagues and clients and business partners. This difference can be seen in Figure 11 below.

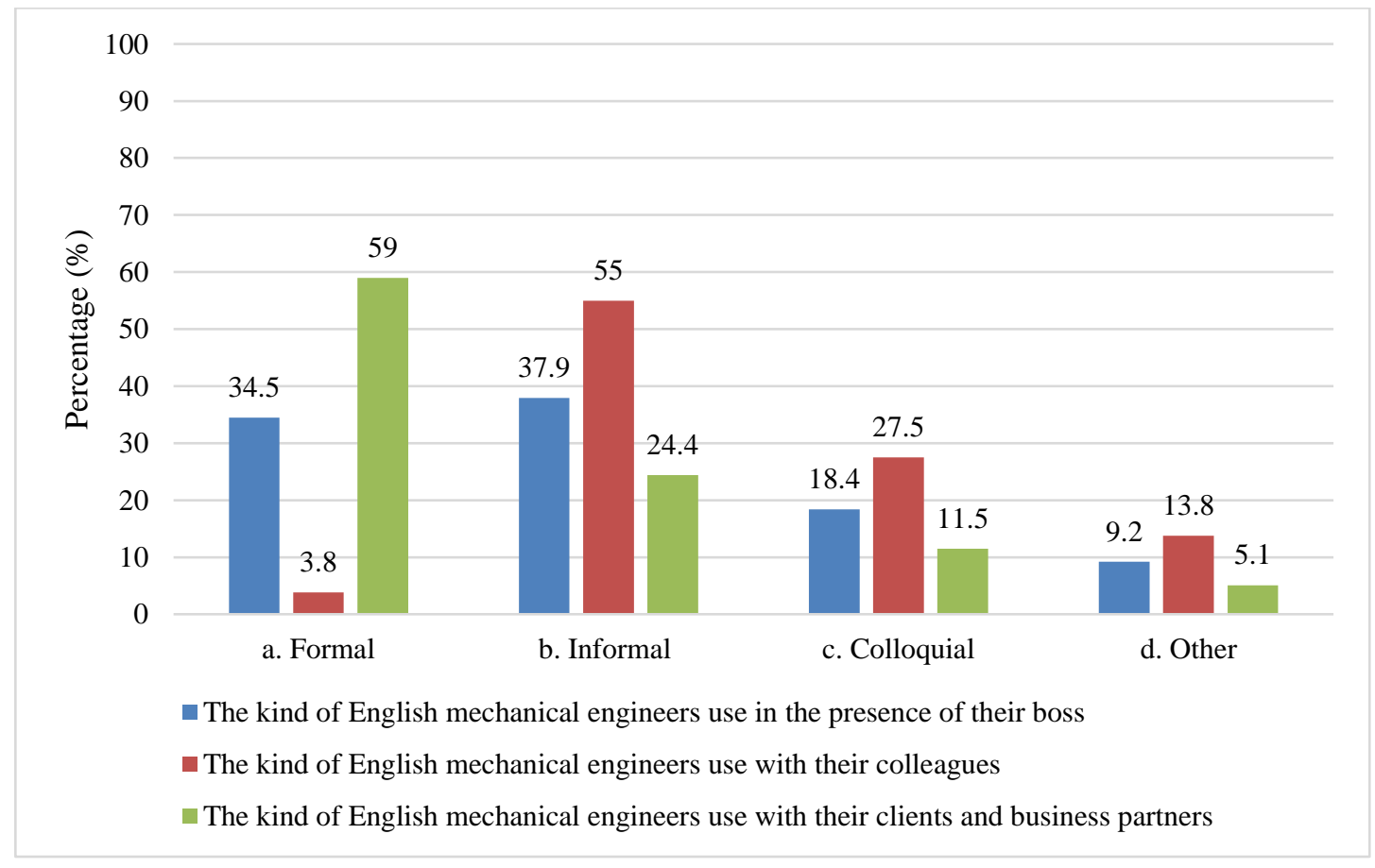

Figure 11: Mechanical engineers' perceptions about the type of English they used with their 'boss', colleagues, and clients and business partners 
The figure shows differences in mechanical engineers' response rates about the type of English they used to communicate with different kinds of people. If formal English (34.5\%) and informal English (37.9\%) were the two main types of English they used with their managers, informal English (55\%) and colloquial English (27.5\%) were the main types of English they communicated with their colleagues. Little formal English was perceived to be used by the mechanical engineers in communication with their colleagues. Notably, 59\% of the mechanical engineer participants' responses said that they used formal English to communicate with the company's clients and business partners, followed by informal English at $24.4 \%$ of the response rates and colloquial English which yielded $11.5 \%$ of their responses.

\subsubsection{Mechanical engineers' comments about the type of English they used}

Along with their answers to Questions 18, 19 and 20, as illustrated in Figure 11 above, 19 mechanical engineer participants commented on their choices of the type of English they used in the presence of their boss, and 14 out of 71 respondents commented on their use of English with colleagues and client and business partners.

As described in Section 5.6.3 above, 37.9\% of their responses were informal English. Further to this choice, 13 respondents commented about the type of English they used. Most of these comments were due to their English ability as well as the purpose of being understood. Because of their poor English ability, these mechanical engineers chose to use informal and colloquial as well as body language. Some participants commented that they also used body language and key technical English vocabulary and guessed the meaning based on the keywords. Below are some of these comments:

- Combine speaking and using gestures and actions.

- Mainly use word by word English. Use key words to express ideas and do not follow grammar structures.

- Poor English. Just know some words and therefore listen to the key words and guess the meaning.

- Easy to use and understand. Be funny.

- Should speak clearly and easy to be understood.

Also, one participant said that he used informal English with the boss because he wanted to be close to him, especially in greetings.

- Greeting the boss informally to show the friendliness and closeness.

- To form a friendly environment to get to know each other in order to perform the work effectively.

In the contexts in which informal, colloquial and other types of English were used, again, the main reasons were because of the need to be brief and make it easy to understand each other, to show solidarity, flexibility and create a friendly working environment. 
Mechanical engineers mostly used these types of English in communication with their colleagues, especially informal English, which constituted 55\% of their responses as described in Section 5.6.3 above. Notably, some participants commented that they had no other choice because of their limited English ability. According to some of the mechanical engineer participants in the questionnaire, they only used English in compulsory situations, and they mostly used word-by-word communication; otherwise, they used Vietnamese.

- Do not use English if it is not in a compulsory situation.

- Often use Vietnamese. English is used in meetings.

- Rarely use English with Vietnamese colleagues because they are Vietnamese and we don't know much about English. We are shy when communicating in English.

According to a few remarks, formal English was used to communicate with their managers because they wanted to show respect and be polite in communication as well as to make a good impression on the managers.

- Formal English to respect the listeners. Informal English to show the closeness and friendliness.

- It is necessary to show the respect and informality with the management level.

- Using formal English to show respect to the boss.

As has been shown in Figure 11 above, the majority of the mechanical engineer respondents said that they used formal English when working with the foreign managers, supervisors, suppliers and customers. The reasons for this use of English were explained by ten mechanical engineer participants. They wanted to be formal, polite and respectful.

- Be formal and polite when contacting with local and international suppliers.

- Because clients and business partners are important to the company.

- Using formal English to show respect to the clients and business partners.

These mechanical engineers were aware that clients and business partners were crucial to their company and they wanted to enhance the cooperation relationship and the company's reputation.

- To show the politeness and also closeness so that both parties can understand each other and have a long-term cooperation.

- To be polite and make [a good] impression.

Regarding politeness and formality, it is clear that the more formal English mechanical engineers was used in the workplace, a lower degree of formality was used in their communication. Vice versa, the more informal and colloquial English was used, a higher degree of formality was used in their communication. This explained why many questionnaire participants commented that they used informal and colloquial English to show closeness and friendliness with the interlocutors. 
In summary, both manager and mechanical engineer participants agreed that mechanical engineers used different types of English with different groups of people. It is obvious that though the majority of mechanical engineers had minimal English ability, they tried hard to adapt their use of English to the right persons and contexts. If formal English was mostly used in communication with the managers or the boss and clients and business partners, mechanical engineers used more informal and colloquial English with their colleagues.

\subsection{Social Status}

Strong evidence of the degree of formality was found when the questionnaire participants perceived the importance for mechanical engineers to adapt their workplace use of English for someone of higher status (Question 21) or lower status (Question 22). This is one of the social aspects of using English in the workplace which is described in more detail in Chapter Seven.

\subsubsection{Managers' responses}

Figure 12 shows and compares findings from Question 21 and Question 22 about social status in the questionnaire for manager participants.

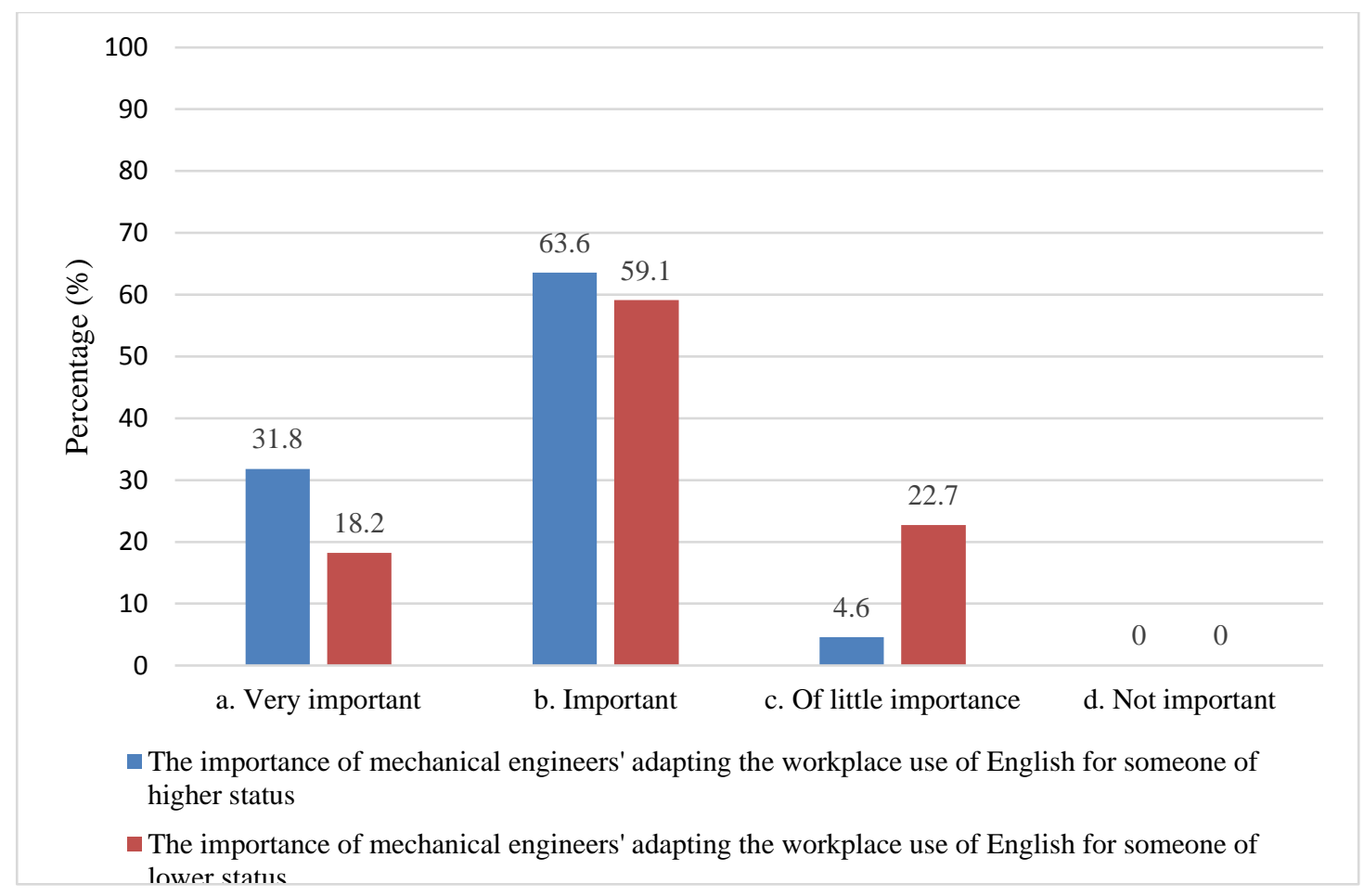

Figure 12: Managers' perception about the importance for mechanical engineers to adapt the workplace use of English for someone of higher/lower status 
It is clear from the graph that most manager participants said that it was 'important' to 'very important' for mechanical engineers to adapt the workplace use of English for someone of higher and lower status. Of these, manager participants thought that mechanical engineers considered it was more important to adapt their use of English for someone of higher status. While $31.8 \%$ of the managers' responses said that it was 'very important' for mechanical engineers to adapt their workplace use of English for someone of higher status, the response rate for someone of lower status was $18.2 \%$. Though the managers' overall response rates to question 22 were lower than those to question 21 , they still showed the importance for mechanical engineers to adapt their workplace use of English. If 'Of little importance' received only $4.6 \%$ of the managers' response rates in question 21 , this figure for question 22 was much higher at $22.7 \%$. This revealed a level of understanding of the need for varying degrees of formality in workplace communication.

\subsubsection{Managers' view of language and social status}

Though only four manager participants provided comments about the importance for mechanical engineers to adapt their workplace use of English for someone of higher status, two of them said that this was to show respect to authority.

Show respect [to] the management level.

This kind of cultural issue has been reported in another study in Vietnam by Weng (2015).

In regard to Question 22, some manager participants commented that mechanical engineers adapted their workplace use of English to show solidarity and closeness with the staff so that they could perform their work more effectively.

Showing closeness with staff so that work can be completed effectively.

The importance of adapting the use of English was considered as part of the communication culture in the company, something commented on by one of the manager participants in the questionnaire.

The lower status people are often simple workers and the communication with them can be in Vietnamese for them to understand what they need to do.

The above example may indicate that social status does have effect on the language used in the workplace. The findings revealed that both managers and mechanical engineers had to take the issue of social status into consideration in their work communication. 


\subsubsection{Mechanical engineers' responses}

Sharing the same view with the manager questionnaire participants, in the questionnaire $35.2 \%$ of the mechanical engineer participants' responses said that it was 'very important' to adapt their use of English for someone of higher status (Question 21) compared with $14.7 \%$ for someone of lower status in Question 22. The majority of the mechanical engineers' response rates indicated that it was 'important' for them to adapt the workplace use of English for people of higher and lower status than them, as can be seen in Figure 13 below.

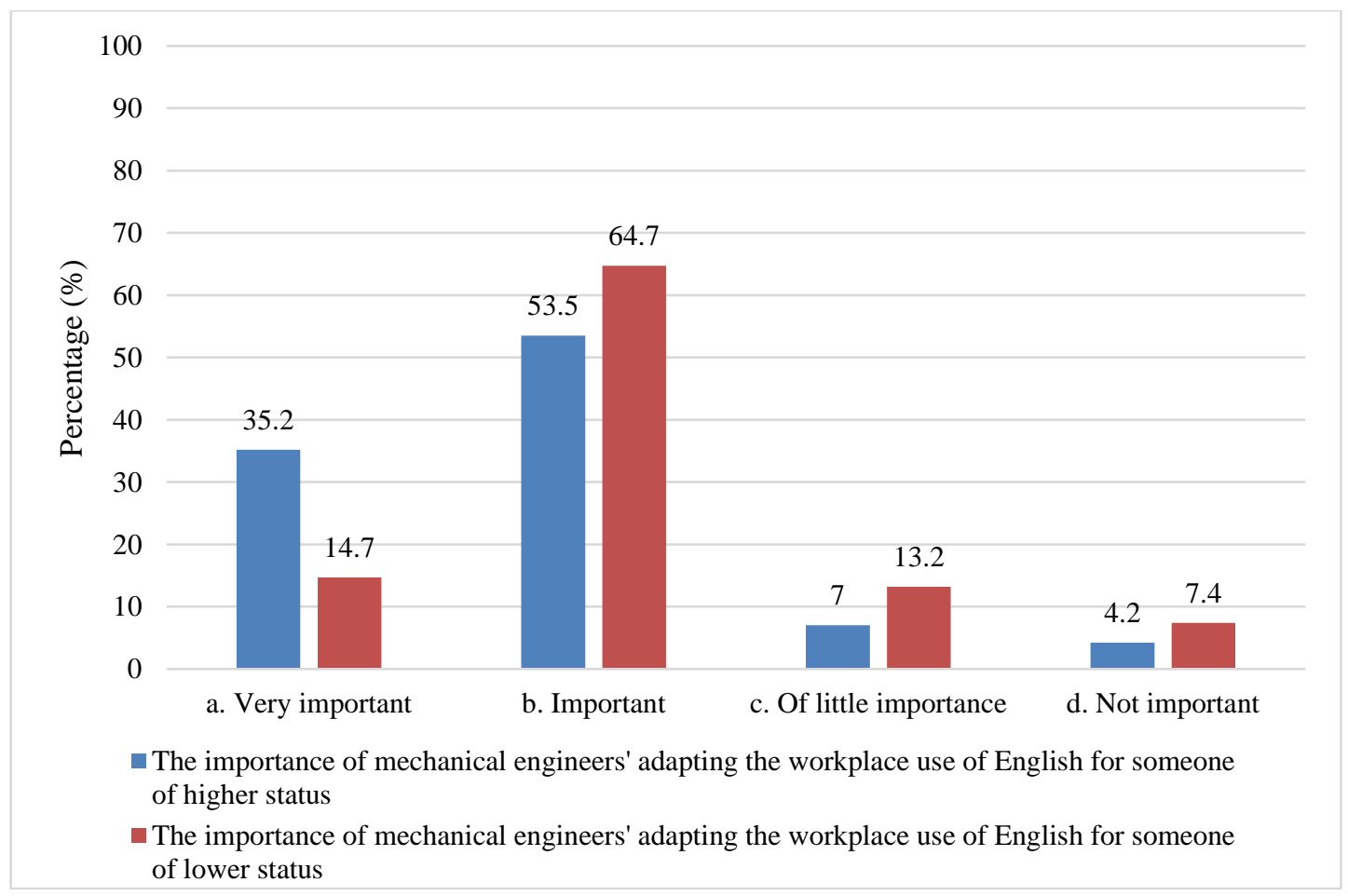

Figure 13: Mechanical engineers' perception about the importance of adapting their workplace use of English for someone of higher/lower status

Mechanical engineers seemed to be aware of the importance of adapting their workplace use of English to match with each group of people and each context. Few of their responses said it was 'Of little importance' and 'not important'. This can be said to be their great effort, as we know that nearly half of them were not satisfied with their English ability.

5.7.4 Mechanical engineers' comments about the importance of adapting the workplace use of English

In the questionnaire, some mechanical engineer participants commented on their answers to Question 21 and Question 22 about social status. According to these participants, 
they adapted their workplace use of English for different reasons. Of these, nine mechanical engineers said that they adapted their use of English for people of higher status to show respect and admiration. Using formal English was not only to be polite and respectful to people of higher authority but also to prove one's English ability, as commented by one of the mechanical engineers in the questionnaire.

- Because the management in the company are foreigner[s], it is polite to use formal English.

- Showing that you always respect and want to learn from them.

- The management will have a good impression [of] those who can understand and speak English well.

- With those who have important positions such as the General Director, we need to use the kind of English that shows their important status. We try to show our ability, too.

Being aware of who they were communicating with means mechanical engineers were respecting the interlocutors and showing formality and being polite in communication. In addition to this, they were enhancing their face and making a good impression on the listeners, especially their managers. This finding is consistent with that from the interviews.

It is important to know who you are talking to so that you understand them easier. This is also to show friendliness and your communication skills. This helps you improve your English ability and communicative competence.

The participants seemed to have a positive view about workplace use of English. Some of their comments said that adapting the use of English was a good way for them to practise and improve their English ability.

Both manager and mechanical engineer participants set a target to form an English speaking environment in the company along with the aim of showing friendliness and closeness among employees. This is consistent with the findings from the interviews, which will be presented later on in this chapter. Thus, nearly $77 \%$ of the managers' responses said that it was important for mechanical engineers to adapt their English in different contexts. It was also important for the managers themselves to adapt their use of English and some of them said that there should have been a target to develop spoken communication skills for employees, especially engineers. Sharing the same view with the manager participants, $79 \%$ of mechanical engineers' responses perceived the importance of adapting the workplace use of English. They were aware of adapting their English to the people they communicated with and to the context of the communication. They considered using English in an optimistic way, that is, the more they used English, the more English they could learn and the more confident they were in communication. 
In regard to the workplace use of English for people of lower status, adapting and simplifying the workplace English use did not mean that mechanical engineers had to lower themselves, but meant they respected people of lower status and this could motivate these people to work harder and more effectively. Also, it showed that they understood and sympathised with the people they were communicating with.

- To show respect to the lower status [people] so that they will try their best to complete the work.

- To show the understanding and knowledge about figures and instructions to help them understand what to do.

Adapting the use of English did not only help them to form a good English language environment but also brought people close to each other.

- This helps us to practise English and form an English-speaking environment at work.

- To form professional working habits and to learn from other people.

- To show the friendliness and closeness when communicating with other without showing your position.

The above comments show that adapting the use of English relates to the change in the degree of formality and solidarity, so more informality was reported as contributing to higher solidarity.

According to some of the mechanical engineer participants in the questionnaire, using formal English was not only to show respect and be polite, but also to impress the management and show their ability, including communication skills. Further analysis of the comments made by the participants showed that the mechanical engineers were aware of the importance of knowing who they were communicating with so that they could use the most appropriate type of English in that context to the best of their ability.

\subsection{Chapter Summary}

This chapter has presented findings from the survey questionnaire about the English communication needs required by mechanical engineers to perform their work effectively in the workplace. These needs not only consisted of the English language skills and the numerous communicative events that required specific language skills, but also the understanding of the social aspect of the use of English in the workplace. If the requirements of English speaking and listening skills were perceived as more important compared with English reading and writing skills, the ability to understand the social contexts and adapt their use of English to match with these contexts were also perceived as important by both manager and mechanical engineer participants, something to be taken into consideration in curriculum design.. 


\section{CHAPTER SIX: QUALITATIVE FINDINGS OF REAL-WORLD ENGLISH LANGUAGE SKILLS REQUIRED BY MECHANICAL ENGINEERS}

\subsection{Introduction}

The previous chapter presented the findings from the questionnaire, which provided a general overview about the English communication needs of mechanical engineers from 22 manager participants and 71 mechanical engineer participants. These general findings are deepened by those provided by the 12 semi-structured interviews with 12 participants and those of the observations about the real-world English language skills required by mechanical engineers. Of these, observation data gave the most authentic, thickest and richest details. Findings from semi-structured interviews did provide rich and deep data, but these were from the participants' perspective.

The presentation starts with findings from the interviews about the contextual information, communicative events and specific English language skills as well as various purposes, forms and levels of English used by the participants (Section 6.2). The presentation continues with a description of the contexts for English uses, communicative events, and work-related English language skills observed being used by the mechanical engineers. Finally, this section presents successful interactive uses of English and adaptive communicative activities observed mostly in meetings. Detail of these findings are presented in Section 6.3.

Both sources of findings indicated that all four companies had an international and plurilingual working environment and English was the language of communication when Vietnamese management and employees worked with foreign employees and foreign business partners. According to Hoi (one of the mechanical engineers at the building construction company), English would bring many advantages to the company, not only in bidding for projects but also in implementing the projects with other foreign sub-contractors, so he and his colleagues were motivated to learn this language to support their jobs. Pseudonyms are used in this chapter.

At the moment our company really needs English because we are having big projects with foreign contractors, so English is very important. It is a key to success of a company. This is the main incentive that I and other people in the company learn English in order to perform our work effectively (Hoi-ME-C4). 
In the interviews, English was perceived as very important, because it related to the work productivity, effectiveness and success. Thus, mechanical engineers needed English to function effectively in their jobs.

According to Thin, one of the Vietnamese managers at the dairy company, his mechanical engineers were motivated to learn English as it helped them to work more effectively. He said,

The effectiveness of the job motivates the mechanical engineers to learn and use English. (Thin-M-C2)

Sharing the same view as his colleague, Ty, another Vietnamese manager at this company stated the importance of English in helping him and his mechanical engineers to perform their job better and faster.

The work effectiveness will be improved because if the mechanical engineers' English ability is good, they can read and understand documents faster, can communicate and discuss with the foreign experts easier and therefore can process the work faster (Ty-M-C2).

The interviews revealed that mechanical engineers considered English as being very important in their everyday work. They claimed that being able to use English was an important demand of the job. When Ngo was asked in the first question of the interview what he required English for, he said English helped him perform the work well because he was a supervisor who often worked with foreign experts, received job requests and reported the work progress of his team to the general foreign manager.

It seemed useful to provide the snapshots in the style proposed by Huhta et al. (2013), but using in this case data from actual cases, describe an overview of the day for the manager and the mechanical engineer, followed by a description of the setting and communicative events required by the mechanical engineers. The snapshots aimed to provide a holistic picture of the context of English uses in the worksites for pedagogical purposes. The first snapshot views a manager's working day, but also serves the useful purpose of showing the work relation between the manager and mechanical engineers which in turn illustrates the mechanical engineers' uses of English. The second snapshot described a typical working day of a mechanical engineer who has to involve in numerous communicative events and use English frequently to function his/her job effectively. 


\subsection{Interview Data}

In total, 12 participants (six managers of mechanical engineers and six mechanical engineers) were interviewed, using a semi-structured set of questions. The detail about the number of participants from each research site can be found in Table 17 below:

Table 17: Number of interview participants from each research site

\begin{tabular}{|c|c|c|c|c|c|c|c|}
\hline Participants & C1 & C2 & C3 & C4 & Male & Female & Total \\
\hline Managers & 1 & 3 & 1 & 1 & 6 & 0 & 6 \\
\hline Mechanical engineers & 2 & 1 & 2 & 1 & 6 & 0 & 6 \\
\hline
\end{tabular}

(C1 is the food producing company; $C 2$ is the dairy company; $C 3$ is the motorbike company; and $C 4$ is the building construction company)

There were two schedules of semi-structured interviews for the managers and mechanical engineers (see Appendices C \& D). The former consisted of nine questions and the latter had ten questions with most of the questions being identical for each set of participants. Most of the interview questions were framed in relation to the questionnaire, with the aim of seeking more in-depth information to answer the research questions.

All the interviews were analysed using thematic analysis (Braun \& Clarke, 2006). Findings from the interviews are consistent with the observations which highlighted the importance of the English language. Besides the important role of English in the workplace, findings from interviews and observations revealed information about the mechanical engineers' English communication needs, the context of English uses, the communicative events that mechanical engineers were engaged in, the English language skills, and the importance of technical English and vocabulary. These are presented separately in terms of interview data and observation data, as follows.

\subsubsection{The contexts for English uses in the workplace}

The setting parameter proposed by Munby (1978) refers to both physical setting (workplace and study settings) and psychological setting (various environments in which the target language is used). In their recent research, Huhta et al. (2013) use the term 'context information', which is classified into location, person, communication situations, and textand discourse-type in a needs analysis study. The contexts for workplace English identified in the interviews were not only about the locations but also about the communication situations and the persons involved in these communication situations. 


\subsubsection{Locations}

Location refers to the settings in which communication takes place and the physical characteristics of these settings (Huhta et al., 2013). The location was not discussed very often in each interview, but together the interview participants identified the following contexts in which mechanical engineers required English to function effectively:

- Office

- Workshop

- Maintenance department

- Garage department

- Farm and cluster

- Factory

- Project construction site

- Different work sites in the company

- Contract (project) bidding ceremony

- Production zone

- Outside the company: English clubs, travelling

Though mechanical engineers were engaged in a wide variety of work contexts, only those who worked at the building construction company were reported to take part in a contract (project) bidding ceremony. This is described in more detail in Section 6.2.2 as one of the new communicative events required by the mechanical engineers.

\subsubsection{Using English to communicate with foreigners}

The interviews revealed the need to use English to communicate with foreign directors and managers, foreign experts and consultants, supervisors, suppliers and customers. Mechanical engineers were also required to attend company meetings and group meetings in the presence of people who were not Vietnamese, something also found in Kaewpet (2009a) and Zaid and Kamarudin (2011).

The participants in the interviews stressed how essential English was for mechanical engineers in Vietnam because of the need to communicate to solve real life problems. According to Chuot, one of the managers at the food producing company, English was essential for work communication at his company.

English is used for communication between foreign experts and mechanical engineers or between the managers and mechanical engineers (Chuot-M-C1)

One of the managers at the dairy company described this as a frequent need. 
Moreover, in their work they have to communicate with foreign experts so they need English in order to work and communicate daily with these people. The general manager of our department is a foreigner (Ty-M-C2).

In this manager's company, mechanical engineers worked in different departments which were managed by the foreign managers. They also worked with the foreign experts from different countries, who were employed to work for the company or invited to the company for consulting and training for staff.

Mike, one of the foreign managers at the motorbike company, not only discussed English as the daily language of communication for him and his staff, but also described the diversity of the foreigners who needed to be communicated with in English.

Mechanical engineers in my department need English language to understand my orders, my requests, and to understand my colleagues who are also foreigners from different countries. We are a multinational company. We have companies in China, Italy, Vietnam ... and we have colleagues from all around the world, so it is necessary to speak English, understand English because we have to communicate with other colleagues who come from other countries (Mike -M-C3).

Than described using English on production lines, and noted that English was only used when there were foreigners present.

In meetings, talks and discussions with foreign colleagues and managers about quality or new models that we install on production lines. If Vietnamese together, we use Vietnamese (Than-ME-C3).

Hoi described the use of English on the construction site as an obligation.

Normally we have to communicate directly with safety managers from Japan, Malaysia, India, and Philippines. They are experienced experts who use English for work communication so English is a MUST in our company (Hoi-ME-C4)

Since Hoi's company took part in this project as a sub-contractor, he and his colleagues had to work with the head contractor, which was a foreign company, and many other Vietnamese and foreign sub-contractors. This explained why there were hundreds of foreign employees from different countries working in the project and English became the common language among them. All the sub-contractors had to attend a daily meeting held by the head contractor. They had to present their company's work schedule for that day and give feedback to any questions from the head contractor and other sub-contractors.

\subsubsection{Communicative events}

In the interviews participants identified communicative events occurring in the context of mechanical engineers' work in various worksites. They are listed in terms of the main English language skills as below: 


\section{Listening skills}

Listening to the foreign boss's instructions, requests and orders

Listening to presentations and discussions in a meeting, seminar or conference

Listening to different English accents (international English)

Listening to the foreign managers and experts' technical explanations

Listening to safety instructions

Speaking skills

Delivering proposal presentations

Communicating via the telephone

Attending meetings (company and department meetings, group meetings)

Bidding for contract

Presenting work schedules in meetings

Talking about everyday tasks and duties

Interpreting English into Vietnamese and vice versa

Communicating with the suppliers and customers

Communicating with foreign directors, managers and experts

Greetings

Addressing the attendees' questions in meetings

Reporting technical problems or errors

Reading skills

Reading product specifications and instructions

Looking for the correct spare parts

Reading professional texts

Reading online manuals

Reading technical documents

Accessing information through the Internet

Interpreting technical drawings

Reading the catalogues

Writing skills

Writing proposal

Writing technical reports

Writing work plans

Writing daily reports

Ordering spare parts

Communicating through emails

Reporting technical faults to the manufacturers and suppliers

Collecting technical faults

Other occasions

Deciding the spare part suppliers

Joining English training courses provided by the company

Communicative events are the situations in which the participants use English to communicate or they refer to the tasks that the participants have to do which can be receptive or productive (Kaewpet, 2008; Munby, 1978). 
Huhta et al. (2013) describes communicative events in a wider view as "an interaction involving a combination of verbal and non-verbal interaction between participants in a specific setting" (p. 196). This view is consistent with the observations and interviews. The interviewed participants said that mechanical engineers had to do their best to understand and be understood including both verbal and non-verbal English.

The reported communicative events in the interviews largely confirm what were seen in the observations (see Section 6.3.1), except for the following communicative events:

Delivering proposal presentations

Communicating via the telephone

Bidding for contracts

Addressing the attendees' questions in meetings

Reporting technical problems or errors

Reading professional texts

Joining English training courses provided by the company

Of these exceptions, bidding for projects seemed to be an important communicative event required by mechanical engineers in the growing Vietnamese work market. Though this event was identified in one company, I was told by the director of this company that it was an essential requirement in today's competitive market. The more developed the economy of Vietnam is, the more competitive enterprises encountered. To be engaged in a contract (project) bidding ceremony, not only does the quality of the bidding application need to be well-prepared but the persons who represent the company to present the bidding proposal need to be proficient in English in order to deliver the presentation.

The frequency of use and the importance of the communicative events were perceived differently by the participants.

Almost all the participants perceived communicating through emails, talking about everyday tasks and duties, reading product' specifications and instructions, communicating with foreign directors, managers and experts, and participating in group meetings as important to mechanical engineers. These events are again consonant with both with the questionnaire data and the snapshot of the day in the life of the mechanical engineer I observed, which prioritised reporting the electric motors in use and checking email.

Some participants identified communicating via the telephone, interpreting English into Vietnamese and vice versa, accessing information through the internet, reading online manuals, listening to the foreign boss's instructions and writing technical reports as 
significant in the context of the mechanical engineers' job. For example, according to Thin, telephone communication is used for urgent situations which require the presence of mechanical engineers.

The manager will call mechanical engineers to ask them to come to the worksite or anywhere to check the machines' problems and fix them (Thin-M-C2).

The interview participants also reported other communicative events, which included communicating with the suppliers and customers, interpreting technical drawings, reading professional texts, listening to presentations, discussions in a meeting, seminar or conference and the rest left in the list.

English was the language of communication between the foreign suppliers and mechanical engineers. Mechanical engineers were required to be able to describe exactly the things they wanted to order, discuss all contract details as well as negotiate prices.

Mechanical engineers who work in the spare part[s] section need to send orders to the suppliers and exchange information when they need to discuss about technical issues or to verify the information, the details of the spare parts, etc. via emails and telephone (Ty-MC2).

According to Munby (1978), communication needs can be interpreted in terms of specific language skills. These skills are required to realise the communicative events or activities which have been identified in this study, thanks to the CNP model. Details of the specific English language skills are presented in the following section.

\subsubsection{Work related English language skills that emerged from the interview data}

\subsubsection{Listening skills}

A key finding of the interviews is that both managers of mechanical engineers and mechanical engineers said that listening and speaking were the most important skills that were required in order to function effectively in the workplace. Most of the mechanical engineer participants claimed that they were required to listen to and understand what their managers or supervisors asked, requested or instructed. They were then expected to give feedback to these questions, requests or instructions.

Some managers also stated that their mechanical engineers needed English to understand their orders, requests and instructions, and also to understand their colleagues who came from many different countries around the world. 
Dialect, international English and the difficulty of listening

A real-world skill in mechanical engineers' workplaces was identified as listening and communicating with different English accents. These accents align with Munby's category of dialects in 'Communicative syllabus design' (Munby, 1978).

Dialect refers to regional English (Munby, 1978), which can be local or international (Kaewpet, 2008). In the interviews, the participants identified international dialects of English in the context of mechanical engineers' jobs. The ability to understand and use international English was seen in my observations of the working days of mechanical engineers and discussed in the interviews with the participants. There are many different dialects of English used in engineering across the world (Kaewpet, 2008) and in Vietnam. Dialect is "a geographically based language variety with distinct syntactic forms and vocabulary items" (Finch, 2005, p. 211). Though accent refers merely to features of pronunciation, it is included in dialect (Finch, 2005). Hoi described the challenges for graduates when they started to work in his company due to their limitation in English listening skills. This was because of the diversity of different English accents of foreign employees that mechanical engineers had to communicate with, as his company employed people from Asia, Europe and Africa, and these employees spoke using different English accents, which made it difficult for the Vietnamese employees to understand what they meant in communication. Therefore, some argued that there is a need of a better preparation of international English for mechanical engineering students at university or graduates to enter the professional mechanical engineering field. Hoi stated:

Most of graduates are weak at listening skills so they have a lot of difficulties when they start working. They should prepare basic communications skills and get used to different accents such as Indian, Malaysian, Japanese, Indian and Indonesian. If so, they will not [be] shock[ed]. Today we work in an international environment because our business partners are from all parts of the world. In short, we should know and use international English (Hoi-ME-C4).

\subsubsection{Speaking skills}

Though it is clear that listening and speaking are interrelated (Liyong, 2006), speaking was perceived by the interviewed participants as the more important skill. Many of the interviewed participants talked about speaking skills. Speaking skills here included communicating with the foreign managers, supervisors, customers and suppliers, communicating via telephone, talking about everyday tasks and duties, and participating in group meetings. Their claims were consistent with what I had observed. In the context of their work, mechanical engineers had to communicate with their foreign managers and supervisors in English. This communication took place in the company meetings and department 
meetings. Some meetings were held by their managers. In some cases their foreign managers and supervisors attended the meeting as observers or watchers. Their communication might also be about daily life such as family or holiday plans.

Chuot said that his mechanical engineers had to present their ideas in meetings with foreign managers and experts. This could be about work solutions, working schedules, and feedback from the customers and the suppliers. He said:

In meetings held by the foreign experts or managers, the mechanical engineers have to present their ideas/opinions (Chuot-M-C1).

Since listening and speaking are reciprocal, mechanical engineers need speaking skills to give feedback to any requests and questions. Ty, one of the managers of the dairy company (C2), said that his mechanical engineers had to report their work progress and explain what they were doing when being asked by him. This was mainly at the construction sites and in the workshop when he visited these places.

Speaking mainly helps them to feedback information, to present their ideas, explain their ideas, and tell them what they are doing and why they are doing so (Ty-M-C2).

As for Thin, another manager of $\mathrm{C} 2$, oral communication was important for his mechanical engineers, as they had to report their work to him. He only used English, so his employees had to communicate in English, too.

But the most important is conversation (oral communication). Mechanical engineers have to report their work/progress to the manager (Thin-M-C2).

\subsubsection{Reading skills}

The interviews revealed that after listening and speaking, the next most valued skills were reading and writing. These were seen by the mechanical engineers and managers as being essential English skills for the workplace. The reading skills consist of reading technical documents, reading manuals, instructions, and specifications, reading for information on the internet and interpreting technical drawings. The following quotes from the interviewed participants illustrate the importance of reading English in the workplace for these mechanical engineers. According to Ty, mechanical engineers were required to have at least a minimum level of English in order to understand technical documents such as operating manuals, instructions or even to use technical software.

All documents about machinery are in English, including operating manuals, repairing technology, software, etc., which require mechanical engineers to know English at least to read and understand documents (Ty-M-C2)

The need for reading skills seems to be higher than both managers and mechanical engineers' claims about its frequency. This need matches what I had been told in the 
observations and the mechanical engineers' claim in Question 16 of the questionnaires about the communicative events that mechanical engineers were likely to be engaged in. They claimed reading product specifications/descriptions and accessing information through the internet were the most frequent communicative events they were likely to be engaged in. Though this claim was inconsistent with their claim about the most frequent English language skills used by themselves, it is explainable as they were talking about reading skills in general, not a specific communicative event, as in Question 16 of the questionnaire.

The mechanical engineers' explanations for the needs to use reading skills are illustrated in the following examples:

- We need English to read technical documents and technical drawings (Dan-ME-C3).

- I use English to order new machines or spare parts. If they are new equipment and machines that I do not fully understand, I must read the documents in English and the detailed parts of machine through manual instructions in English (Suu-ME-C1).

Documents in English:

The interview participants emphasised the importance of English in their workplaces because of the fact that almost all documents to support the companies' business were in this language. Mechanical engineers were required to read technical documents in English and work with the foreign experts and foreign managers. When working in this environment, English is the language of communication (Kaewpet, 2008; Parveen \& Asim, 2013; Venkatraman \& Prema, 2007). If they can communicate clearly in English for work, it is likely that they can do their work faster, more easily and more effectively.

These documents included memos, notices, work schedules, email, reports, manual instructions, online instructions, catalogues, and online technical information and documents.

According to Chuot, one of the managers at the food producing company, mechanical engineers and other employees required English to read and understand documents and work in an international working environment like his company.

English is the language of technology as all documents, websites, and catalogues are in English so they have to try their best to learn English, especially in a working environment like our company (Chuot-M-C1).

Chuot told me that his mechanical engineers had to use English every day, not only with the foreign managers and experts, but also for email communication and information updates. He said the company prioritised improving the English ability of its staff by providing them with free English training courses.

Sharing the same view, Tuat, the director of the construction building company said 
that English was required in every aspect of his mechanical engineers and staff's work. This could be working with imported machinery or foreign technical designs and drawings, and bidding for contracts.

All designs of the factory are from foreign countries so they are all in English. Therefore we have to prepare bidding documents in English, construction buildings are in English, make check-up documents in English (Tuat-M-C4)

Since his company took part in big projects managed by the foreign head contractors, his mechanical engineers and staff were required to be able to communicate in English. In order to win any contract (project) bidding, they had to prepare a bidding profile and proposal. Tuat told me that his mechanical engineers of the engineering department and the staff of the planning department had to prepare these documents, then present their proposal to win the bidding.

Similar to the views of their managers, mechanical engineers highlighted the necessity of English in terms of reading and understanding documents in the context of their job. One of them noted,

For the mechanical engineers, all documents are in English, so if they want to perform their work effectively, they should have English. If they have English ability, they can process their work faster (Dan-ME-C1).

Dan and his colleagues needed English due to the requirements of their job.

The drive of the use of English is the work requirements. In our working environment, all documents, all forms, and all reports are in English (Dan-ME-C3).

Beside the needs to read and understand all the forms and documents in English, mechanical engineers had to read and write technical reports in English, too.

As for Suu, English was a high demand in his company and mechanical engineers required English to read and understand product specifications and instructions. He said:

There are a lot of products, machinery parts with detailed specifications and descriptions to help us understand them. They are all in English so we need English to read and understand them (Suu-ME-C1).

Beside the high demand for reading skills, English writing skills were perceived to be of importance too.

\subsubsection{Writing skills}

The interview participants identified writing emails, reports and work schedules as writing skills required by the mechanical engineers. Of these, writing emails was perceived as the most frequently used skill.

According to Mike, one of the foreign managers at the motorbike company, email 
communication was a frequent means of communication in his company and his mechanical engineers required this skill at a standard level. He said:

Communicating through emails is quite standard because our reports speak for us (Mike -MC3).

In addition, he explained that his mechanical engineers often reported their work via email and that reports were important to them as they could convey more information than their speaking.

As for Tuat, from the building construction company, email communication was in high demand as a daily activity of his mechanical engineers. This was because the company had a lot of foreign business partners.

Communicating through emails is a daily activity which is in English because most of our partners are foreign companies (Tuat-M-C4).

Mechanical engineers also claimed the importance and frequency of email communication in the interviews as follows:

- I communicate via email to report work to my manager, to exchange information and to do communication with our business partners, and to make any complaints about the products for example (Ngo-ME-C2)

- Writing activities consist of reports and emails. Reports are written in prepared forms. The other main activity is writing email (Than-ME-C3)

As has been reported in Section 5.4 of Chapter Five, writing skills were required due to different positions of the mechanical engineers. According to Ty, one of the Vietnamese managers at the dairy company, email communication was one of the requirements of the mechanical engineers' job. He said:

All are due to the work requirements. For example, mechanical engineers who work in the spare part[s] section need to send orders to the suppliers and exchange information when they need to discuss about technical issues or to verify the information, the details of the spare parts, etc. via email and telephone (Ty-M-C2).

For mechanical engineers who mainly worked in the office, writing skills were required more frequently than other skills due to the nature of their job responsibilities. These mechanical engineers had to look for the correct spare parts, decide on the suppliers and then order the correct spare parts, machines and machinery devices. They told me that they had to collect errors and report them to the suppliers, and discuss any technical issues with the suppliers. Most of these activities were done via email communication.

To sum up, though mechanical engineers were required to use all four English 
language skills, listening and speaking were perceived as the most important ones. In the dynamic lingua franca workplace, these engineers had to communicate in both oral English and written English with their foreign managers, supervisors, clients and suppliers. Reading skills were of frequent use because they had to understand documents in English as well as reports and emails.

\subsubsection{The purposes, forms and levels of English used in the workplace}

In the interviews the participants identified the following purposes, forms and levels of English being used by the mechanical engineers. They were English for technical communication, varying forms (body language, spoken and written English) and genres of English such as formal and standard written English. More formal types of English were used in communication with the management, and more informal and colloquial types of English were used in communication with colleagues and foreign experts. The participants also discussed low levels of English for communication in their workplaces such as wordby-word free communication.

\subsubsection{English for technical communication}

Among the types of English required by mechanical engineers, technical English was perceived as the most important. In the interviews both managers and mechanical engineers emphasised the importance of technical English, especially technical vocabulary in the context of the mechanical engineers' job (See Section 6.3.5). This is strongly consistent with the observation findings about the use of technical vocabulary and the comments of the participants in the questionnaire. Thus, Tuat, one of the Vietnamese managers, said in the interview that English in general and technical English in particular would make 50\% of the success of an engineer.

According to Mike, one of the foreign managers at the motorbike company, using key technical terms in their communication was an easy way for understanding. He said,

We have English as a common language. If we use key technical words, it will be easier for people to understand and this will reduce troubles (Mike-M-C3).

Mike said that what he wanted was his engineers to speak very good technical English at a high level and that if they could use formal English, it would be better. He told me that English was a communication barrier (McKenzie \& Qazi, 1983) when he first came to work in this company and he and his engineers had to try to find out the way to understand each other. He explained that using the correct technical word was one of the best ways to achieve clear workplace communication. 
James is also one of the foreign managers at the dairy company, who stated that only about $20 \%$ of his mechanical engineers could communicate with him in English. He said technical English was important for engineers in general and mechanical engineers at his department in particular, and that having employees with good technical English ability is one of his goals in employment.

If you can find someone who can speak technical English, can read the catalogues, read the specification which is 20 pages in English and can understand it, this would be wonderful. This is the goal and we are looking for them (James-M-C2).

James said that if someone knew technical English, he could communicate with them and they could understand what he meant. His claim matched what the mechanical engineers said about technical English in the interviews and observations.

In the interviews, the mechanical engineers reported that though their English ability was not good, they could communicate with their foreign directors, managers, supervisors and experts to some extent thanks to technical vocabulary. This is strongly consistent with what I observed and what they told me during my observations. Their limited English ability prevented them from communicating fluently with the foreign managers and they had to use Basic English and key technical words. Sometimes they had to guess what the foreign managers meant by listening to the key technical words. Thus learning and memorising the technical vocabulary was one of the ways they learnt their English and used it for work communication as had been stated by Ngo, one of the mechanical engineers at the dairy company:

Regarding English language skills, we only focus on improving technical words to support our job (Ngo-ME-C2).

Once they knew the technical words for the things they wanted to talk about, the mechanical engineers could communicate with their foreign managers to a certain extent. This was because they had been working together for a certain period of time and could understand each other. This was also because they used the same technical words every day and these words were familiar to both parties.

As for Dan, one of the mechanical engineers at the motorbike company, technical words were important in workplace communication. Being an engineer, he was required to know the names of the spare parts, machinery devices and technical details. Dan's explanation showed how he considered English for workplace communication differed from English for everyday communication outside the workplace. He noted: 
English for communication in the workplace is different from English for communication outside the company because English in the workplace is combined with English for specific purposes. As for ESP, engineers should know the names of spare parts, devices and technical details which require a wide range of technical words (Dan-ME-C3).

He further explained that this was because the English language used in the workplace was a combination of General English (GE) and English for specific purposes (ESP) which was technical English in his field. According to Hutchinson \& Waters (1987), the difference between GE and ESP is that GE refers to contexts such as school where needs are not specified, while ESP specifies detailed and selective goals and that GE provides a broad foundation.

Sharing the same view with Dan, Suu, one of the mechanical engineers at the food producing company, said that it would be very difficult to apply General English for communication in a specialised field like mechanical engineering which requires technical English. Suu further explained that in dealing with a technical problem of a machine, the mechanical engineer had to talk about many different machinery parts which were hard to name in English if he did not know equivalent English technical vocabulary.

\subsubsection{Varying forms of English uses}

Together with the technical English, mechanical engineers were reported to use Basic English for communication, broken English (Linderman, 2005), word-by-word free communication and body language. These forms and types of English were related to their adaptive communicative activities. Basic English here is similar to the A1 level in the CEFR which described in the glossary at the beginning of the thesis. According to Council of Europe (2001), Level A1 is for Basic User who "can understand and use familiar everyday expressions and very basic phrases aimed at the satisfaction of needs of a concrete type. Can introduce him/herself and others and can ask and answer questions about personal details such as where he/she lives, people he/she knows and things he/she has. Can interact in a simple way provided the other person talks slowly and clearly and is prepared to help" ( $p$. 24). Mike, one of the managers, claimed that using simple English meant it was more readily understood and there would be fewer mistakes and misunderstandings in the workplace. He said:

What I am looking for from my guys who are working with me is easy, not formal, but understandable, reduce misunderstanding as little as possible, reduce mistakes and errors. The simpler the communication is, the better [the] result is because you have less possibility to make mistakes (Mike-M-C3). 
Mechanical engineers used Basic English due to their limited English ability. Despite having learnt English from high school to tertiary level, they could only communicate in very Basic English for beginners as illustrated in the quote below:

They graduated from universities, however they could only understand Basic English like hello, how are you? How are you doing?. When I ask more questions, they could not answer (Thin-M-C2).

As for James, a person who could use Basic English was someone who could ask simple questions in the daily life. He would be happy if all of his engineers could speak this Basic English. He told me that only about $20 \%$ of his mechanical engineers could communicate in English with him. He stated,

It doesn't matter what you are going to learn, everybody must learn basic English so that they can communicate such as asking about the time (what is the time now?), greeting (how are you?), where do you live? You are hungry? You want to eat? How do I get to the bus station? These are Basic English (James-M-C2).

James' claim was consistent with what Ngo, one of his mechanical engineers, shared in the interview, that the company provided English for communication courses for its employees to be able to understand and communicate in basic English to function in their jobs effectively.

The company usually provides English for communication courses for technical workers, Basic English so that they can understand (Ngo-ME-C2).

If the mechanical engineers and other technical workers had Basic English, they could understand and communicate with their foreign managers to some extent and therefore could perform the required job.

Having very basic English also meant that mechanical engineers had to struggle to understand and be understood. Broken English, word-by-word communication, body language and actions were their adaptive communicative activities. According to Linderman (2005), broken English refers to anything from speech with frequent pauses to incomprehensible or very low-proficiency speech. Ngo, a mechanical engineer at the dairy company said that he and his colleagues often used broken, word-by-word and unstructured English, which did not follow grammatical rules they may have learnt in formal textbooks at schools.

Sharing the same view with Ngo, Ty further explained that his mechanical engineers had to try everything to understand and be understood, including using body language because of their limited English ability. 
They use anything that they can in order to help others to understand them. They use wordby-word communication, body language, and actions (Ty-M-C2).

It is clear from Ty's quote that the types of English that mechanical engineers used in their communication were various. They did everything they could do to communicate with their foreign managers and experts. They were flexible in their communication.

\subsection{Observation Data}

As has been introduced in Section 6.1, this chapter has presented findings from the interviews about the real-world English language skills required by mechanical engineers. Section 6.2 has provided various contexts and communicative events in which mechanical engineers used English to function effectively in their job. These identified contexts and communicative events required them to have different specific English language skills and types of English.

This section presents observed data which not only aim to deepen findings from the interviews but add in new details which can only be seen in day-to-day observations. These new details include the two snapshots describing the working days of a manager and a mechanical engineer as well. The section also provides observed interactive uses of English and adaptive communicative events which were successfully used by the mechanical engineers in the study. Finally, the section lists the technical words, including academic words observed being used by the participants.

\subsubsection{Setting and communicative events}

The analysis of the observation data which employed the thematic analysis approach reveals the importance of setting and communicative events. These are the two variables in the CNP needs analysis model proposed by Munby (1978). Huhta et al. (2013) use the term 'context information' instead of 'setting' which gives more detail in describing the context. The 'communicative events' variable is similar to "the most frequent situations and the most demanding situations" proposed by Huhta et al. (2013, p. 31).

From my observations, mechanical engineers worked in two main settings inside the office and outside the office. Outside the office settings include the production factory, production line and construction site. Mechanical engineers in different workplace settings were observed to be engaged in a wide variety of communicative events. 


\subsubsection{In the office}

The mechanical engineers whom I observed working in the office (including temporary offices at the construction sites), communicated in English with foreign managers. They mostly sat and worked with their computers. They listened to the manager's questions, requests and instructions. They told me that their tasks included receiving job requests to order spare parts, looking for the right spare parts by reading the catalogues, reading online product specifications and descriptions, contacting the suppliers via emails, deciding the suppliers and ordering spare parts, and reading technical reports. So in this context, unlike most of the other sites to be discussed in this study, the mechanical engineers were using more reading and writing skills than listening and speaking skills. The process was that after ordering products, the office mechanical engineers had to check incoming products, collect errors, classify errors and divide them into categories, then report them to the manager and suppliers via emails. These skills, important to the smooth functioning of the worksite, included writing reports and email communication with the management and suppliers and manufacturers, which required a level of formal English language.

\subsubsection{In the workshop and garage, on the production line and construction site.}

Communicating in English with the foreign managers and supervisors, responding to the managers' questions, reporting on work progress, and listening to the managers' questions and requests were observed to be the common communicative events required by mechanical engineers who worked in the workshop, garage, production line and construction site. I was told that the foreign managers and supervisors often came to check their employees' work once in the morning and once in the afternoon and this was a regular pattern. In the food production company and the dairy company, foreign managers were seen visiting all workshops and worksites in the factory to check their staff's work, especially in the morning staff meeting. The foreign managers wanted to know what had been discussed in this meeting, the work plan for the day and any issues the engineers had. The mechanical engineers had to respond to the manager's questions and report their work progress. The building construction company was involved in an extensive project which required their mechanical engineers to work with foreign site managers and supervisors of the head contractor and other sub-contractors. These managers and supervisors came from different countries in the world, especially from Asia. Since the mechanical engineers worked in the construction site, they were observed being supervised and checked by these foreign managers and supervisors at least twice a day. They responded to the questions of the foreign 
managers, and listened to their requests and instructions, as well as reported their work progress.

\subsubsection{Daily supervision tasks}

Most of the observed mechanical engineers were supervisors and leaders of specified groups. Their observed daily tasks consisted of managing a group of workers and engineers, holding the morning meeting, organising daily manpower, having the foreign manager come to their worksite, following the manager's visit and check, and listening to the manager's questions, requests and instructions. During the manager's visit, they reported, discussed and explained any technical issues to the manager. They needed to meet the manager in person to report work progress and to receive job requests.

It cannot be denied that Vietnam is experiencing huge and fairly recent economic growth and is opening up to the world. It is attracting many foreigners to its large work market, most of whom work as managers, supervisors and experts. Three out of four workplaces under investigation employed foreign employees from different countries in the world including India, Australia, Thailand, China, Israel, New Zealand, America, Malaysia, Japan, the Philippines and Italy. Many of these foreign employees held management positions. The remaining company took part in projects which were governed by foreign companies. As a result, all the worksites in the study involved the dynamics of foreign employees, which required and promoted the use of English in these workplaces. The dynamics of international managers and engineers and Vietnamese mechanical engineers was a key feature of every workplace observed. The dynamics of international uses of English in these workplaces will be reported in the next chapter that answers sub-research question two.

Findings from the observations revealed a list of communicative events that mechanical engineers were engaged in, listed under the relevant English language skills as below:

Listening skills

Listening to the foreign manager's questions, requests and instructions

Listening to presentations and discussions in meetings

Listening to different English accents of foreign managers, colleagues, supervisors and experts

Listening to the foreign site managers and supervisors' requests, questions and instructions

Listening to safety instructions

Speaking skills 
Presenting the work plan of the day

Discussing with and explaining technical problems to the manager

Attending meetings (morning meeting, group meeting, daily meeting)

Having to respond when the foreign manager came to check their work every day

Discussing production plans, results, technical issues, and quality issues

Talking about safety requirements

Interpreting English into Vietnamese and vice versa

Communicating with the foreign managers and supervisors at least twice a day

Greeting the foreign managers

Responding to the managers' questions

Reporting work progress

Working with the foreign site managers and supervisors on the construction site Reading skills

Reading online products' specifications and descriptions

Looking for the right spare parts in manuals and online

Reading technical reports

Reading online manuals

Reading documents in English

Updating information

Interpreting technical drawings

Reading the catalogues

Writing skills

Making technical drawings

Writing reports

Writing work plans/work schedules

Taking notes of the meeting

Ordering spare parts

Email communication with the management, manufacturers and suppliers

Reporting the spare parts errors to the manager and suppliers via email

Analysing errors of spare parts

Contacting the suppliers via email

Classifying errors and dividing them into categories

Checking incoming spare parts

Using auto CAD software

Other communicative events

Deciding on/choosing the suppliers

Working with the PC in the office

Managing a group of workers

Holding morning meetings

Organising daily manpower

Following the manager's visit to their worksite

Using body language in communication

Copying and saving data

Real-world observations identified that mechanical engineers were involved in more communicative events than those that the participants reported in the interviews. Of the communicative events listed above, mechanical engineers were observed to have been 
required to have additional speaking and writing skills to engage in various situations in the context of their jobs. The key new events were: Listening to the foreign manager's questions, requests and instructions, listening to presentations and discussions in meetings, listening to safety instructions, discussing with and explaining technical problems to the manager, attending meetings (morning meeting, group meeting, daily meeting), interpreting English into Vietnamese and vice versa, reading online products' specifications and descriptions, reading technical reports, interpreting technical drawings, making technical drawings, writing reports, and email communication.

On the other hand although fewer communicative events were observed requiring listening skills, listening to the foreign manager's questions, requests and instructions, listening to presentations and discussions in meetings, listening to different English accents of foreign managers, colleagues, supervisors and experts, listening to the foreign site managers and supervisors' requests, questions and instructions, and listening to safety instructions were crucial communicative events because they directly affected the performance of particular jobs. Apart from these additional communicative events almost all the communicative events observed were consistent with those listed in the questionnaire and reported in the interviews. More detail about these communicative events described and analysed in the following sections about the English language skills being observed.

6.3.2 Work related English language skills observed being used by the managers and supervisors

This section is included in this chapter because managers and supervisors (mechanical engineers functioned as supervisors) were observed to have better English than ordinary mechanical engineers. The former included foreign managers and some Vietnamese deputy managers. The latter were mostly Vietnamese mechanical engineers and some foreign site supervisors of the head contractor. They were seen to use English more frequently than their engineers and workers.

Supervisors were those who worked closely with their foreign managers. They were observed during their daily communications with their managers. The observed responsibilities included managing their teams or groups, holding morning meetings and group meetings, organising daily manpower, receiving job requests from the manager, instructing their workers to execute the job, and attending regular meetings with the manager and the company.

The observations in the four factories offered a glimpse into the everyday work lives of managers and employees and revealed the importance of oral skills in English. 


\subsubsection{Work related English language listening and speaking skills}

As might be expected in an observation situation, listening and speaking skills were observed being used by managers and supervisors more often than reading and writing skills. Listening skills emerged as very important in this context because of the requirement to listen to the foreign manager's requests, questions and instructions, and to listen to presentations and discussions in meetings or seminars. Clear speaking skills were also important. The supervisors of the food producing company and the dairy company were seen reporting their teams' work progress to their foreign managers. The supervisors of the production area in the motorbike company were observed reporting the production plan, as well as technical issues such as oil and water inside the tank and high consumption of oil. Those who worked for the building construction company were seen listening to the foreign site supervisor's requests and instructions. These managers and supervisors not only used expressive language to give instructions but also listened carefully to employees' reports and explanations.

\subsubsection{Work related English reading and writing skills}

Reading skills observed being required by managers and supervisors were reading emails and reading reports (technical reports, production reports, and incoming spare part reports). I was told that these were their daily communicative events. Emails were from the suppliers, manufacturers, customers, staff and the higher management level. As for managers, reports were from their office staff and supervisors.

As for supervisors, they received reports from their mechanical engineers which were often written on prepared forms. They told me that they had to read through these reports and classify them before reporting to their manager.

Parallel with reading skills, managers were observed using writing skills for emails. I was told that they had to read and reply to many emails every day. These emails were mostly about professional issues and the remaining were with the management. One of the foreign managers of the motorbike company was observed writing the agenda items of the meeting on the white board in his office.

Supervisors were seen using writing skills for writing emails, writing work plans and writing reports. While observing a morning meeting at the motorbike company, I noticed the foreign manager talked about his staff's proposals for research and development. He required the key mechanical engineers who functioned as supervisors to update their proposals with attached documents for reference. The supervisors who worked at the food producing company and the dairy company told me that they were required to write production 
proposals, maintenance proposals, and proposals for ordering spare parts about four times in a year.

Together with managers and supervisors, it was clear from the observations of the mechanical engineers that proficiency in English language skills was an essential part of their work too. These skills are presented in Section 6.3.3 below.

\subsubsection{Work related English language skills observed being used by the mechanical engineers}

As has been reported in the findings of Chapter Five (Section 5.5) and Section 6.2.3 of this chapter, listening and speaking skills were revealed in the questionnaire and interview data as the most important skills, and the observations allowed me to see many occasions where listening and speaking skills occurred and how they occurred. Observations also gave me some information which I was told rather than when I observed. During the observations some of the participants offered more information when they spontaneously spoke to me and when they answered my questions. Through observations, I was able to see some reading and writing activities, though the contexts did not allow me to see much.

Mechanical engineers were observed using different work-related English language skills to perform their work, namely English language listening, speaking, reading and writing skills. Of these, listening and speaking skills were observed being used more often than reading and writing. As has been discussed earlier, the kinds of English language skills used by mechanical engineers differed in terms of workplace setting and their position in the company. Though the skills are interlinked, the next sections will describe them in turn.

\subsubsection{Work related English language listening and speaking skills}

Mechanical engineers were observed communicating in English mostly with their foreign managers and supervisors, which required both listening and speaking skills. The observations revealed the following communicative events.

\subsection{Listening to the manager's requests, questions and instructions}

Mechanical engineers, especially those who worked at workshops, garages, production areas and construction sites were engaged in this event daily. This was because at least twice a day the managers of the food producing company, the dairy company and the building construction company were seen visiting all their work areas in the company to check the work progress of their staff and update the work plan, as well as to give more job requests if necessary. The short conversation below between a south Asian manager and a mechanical engineer is an example: 
Example 6.4

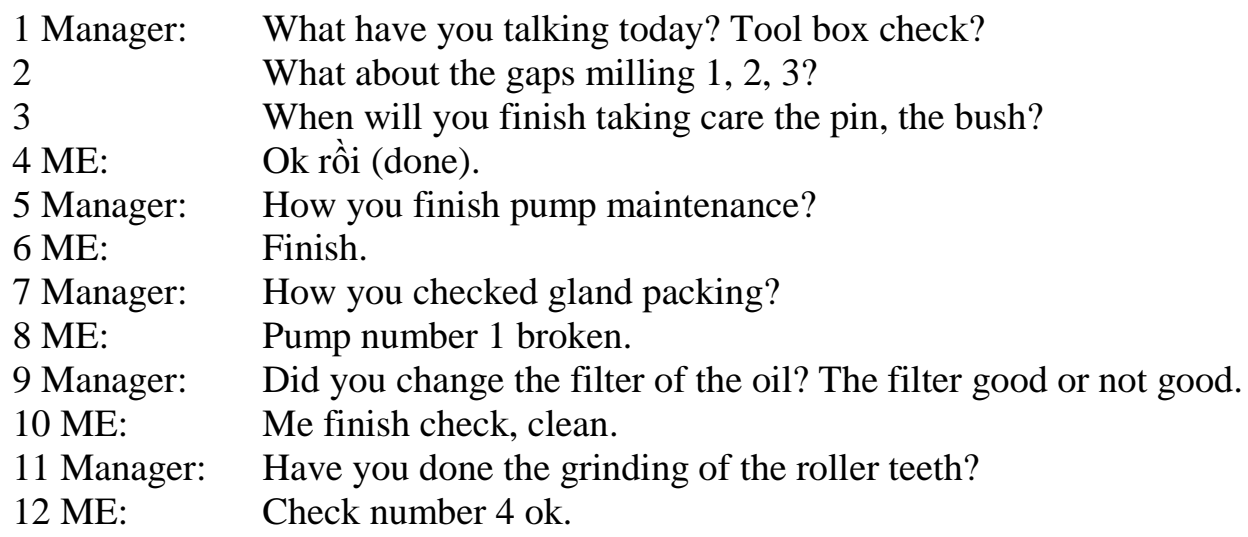

The conversation took place in the morning when the foreign manager visited the production area of the food producing factory. The manager asked questions about his staff's morning meeting and their tasks such as the reported gaps in milling 1, 2, 3 (line 2) and the pin and bush in the milling (line 3). He also asked the mechanical engineer about the maintenance of the pump (line 5), the gland packing (line 7), the oil filter (line 9) and the grinding of the roller teeth (line 11).

Another example is at the dairy factory between the Middle Eastern manager and his mechanical engineer:

Example 6.5

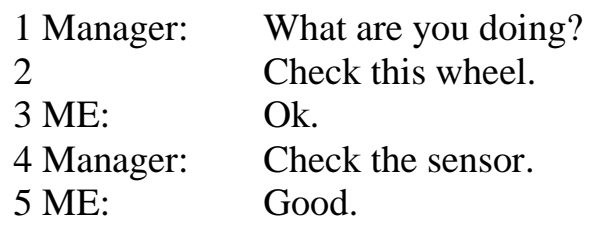

This short conversation took place in a workshop of the dairy company. When the foreign manager came to check his staff's work, he saw a mechanical engineer standing next to a tractor. He asked this mechanical engineer to check the wheel (line 2) and the sensor (line 4) of the tractor. Then he continued visiting around the workshop and kept checking and asking about his staff's work. The manager used directives. He used the imperative "check" to request the mechanical engineer carry out the tasks. The mechanical engineer could understand this request and in turn used "ok" and "good" to answer the manager's questions.

\subsection{Listening to presentations and discussions in meetings}

As can be seen from previous examples, one of the key communicative events where English was required was meetings. The observed meetings were morning meetings (in the office and at the worksite), daily meetings, meetings with the head contractor and group 
meetings. Mechanical engineers not only presented their ideas, work plans or proposals at these meetings, but also listened to presentations and discussions of other mechanical engineers and the foreign managers.

Mechanical engineers working at the food producing company were managed by a southern Asian manager who often attended their morning meetings to update information. This manager said that those with better English ability were assigned to be supervisors and team leaders. These supervisors or team leaders managed different groups of engineers and workers. Every day they held a morning meeting to organise daily manpower, to talk about work safety requirements and assign tasks to each staff. They used English in the presence of the foreign manager and Vietnamese in the absence of the foreign manager. A similar finding was reported by SanAntonio (1987) in the study of Japanese employees in an American firm in Japan. The Southern Asian manager told me that he and his mechanical engineers had to attend a regular meeting with the company every three months to update information. In this meeting they reported their department plans and proposals. They listened to presentations of other departments and the board of directors. These presentations were concerned with matters such as the production plan, the business market and the company's mission.

Worksite mechanical engineers of the dairy company were observed to have a short morning meeting with the foreign manager to receive job requests and report work progress. This was because most of the mechanical engineers in this company were team leaders. They had frequent contact with the general foreign manager. I was told that they often had this kind of meeting early on a working day. Then they came back to their team and held a morning meeting for their team members to carry out the work plan. Again, they used English in the presence of their foreign manager and Vietnamese in his absence. I was told that other mechanical engineers sometimes attended group meetings with the foreign manager to discuss technical issues. One of the foreign managers in this company said that whenever there were new technical issues that his mechanical engineers were not familiar with, he took this chance to instruct them about how to deal with it. He presented the procedures to reinstall or to fix the issues. He was very happy because his staff was eager to learn new knowledge.

For mechanical engineers at the motorbike company, attending meetings was one of their daily activities. They had scheduled morning meetings, unscheduled meetings and regular meetings with their foreign manager. 


\section{Morning meeting}

Below is an example of the manager's presentation in their morning meeting:

The manager said, "the item is the description of the critical point. The reference documentation explains how we find this problem. What is the reference documentation about the investigation of this?" He continued, "In the action section, you describe all the actions such as the corrective action, or the name of the documents relates to the action".

Throughout the meeting, the manager presented different issues which could be questions and answers and instructions to update the proposal. The following is a record of the morning meeting in the motorbike factory based on field notes taken during my observation.

The meeting started at $8.30 \mathrm{am}$. The setting of the meeting was their department office. It took place in the corner of the office which was divided into different work stations for the manager and his mechanical engineers. The meeting place was not insulated. It was very noisy with different kinds of sounds from other departments. These were the sounds from machines, hammers and other instruments and the ringing melody of the cell phones. The mechanical engineers did not turn off their cell phones or set on silent and a phone rang loudly. The Southern European manager conducted the meeting. He and five mechanical engineers sat around an oval table put in the bottom right corner of their office. There was a sample motorbike engine, a laptop and a projector on the table. They sat facing a white wall which was also used as the projector screen. The mechanical engineers put on the white uniform of the company with the company's logo on their chest, but the manager did not. The manager sat at the top of the table facing the projector screen with his laptop connected to the projector. Three mechanical engineers sat on the right hand side of the manager and two others sat on the left, next to the white boards. Each of them had a little diary book to take notes and a cell phone on the table. They used their cell phones in the meeting. Two of them answered the phone when it rang. One of them used his smart phone to record the meeting.

There were two white boards on their left hand side. The first board was full of notes written in English which were the department monthly working plans. Half of the second board presented tasks to be closed soon, written in English and presented in headings and key technical terms. The remaining half was blank which was used by the manager later on to specify key tasks to be done. There was no formal agenda that was shared at the start. The meeting was divided into three parts.

Part 1 of the meeting:

In this part, the manager talked about his mechanical engineers' unfinished tasks. For example, he asked them if they had remembered to back up their computer but they had not 
done it. He said, "I tell you many times but you don't do it and now the information technology server died, we can't get access to our information". One of the mechanical engineers said they copied the information but when the server updated, they could not follow it every day. The manager said, "every time I told you that you must buy a register, extend a register and copy all the materials". The mechanical engineer then told his colleagues in Vietnamese that he could not copy and copy every day. The manager seemed to understand this and said in a louder voice, "every time you speak the same, hah". The mechanical engineers then discussed the copying in Vietnamese. They said that the server was updated every day and they could not follow this update. The manager said that they had a spare computer so they could copy data into that computer. If they did not do it, he could do it. But he stated that he was the manager of the department and every one had a computer and had to keep an additional copy and information in it. Otherwise, if the server died, they would lose the data. The other mechanical engineer said in English that the situation was temporary and they would be able to get access to the server soon.

Example 6.6

1 Manager:

$2 \mathrm{ME}$ :

3 Manager:

$4 \mathrm{ME}$ :
Ok, alo. So what you say?

The server is out temporary.

But we have broadcast the solution of the problem? Yes.

Broadcasting the situation and the solution here (line 4) meant that the server had the possibility of being disconnected and the solution was they had to copy the data into their register or personal computer every day.

There were different kinds of English used in this first part of the meeting. The manager went directly to the issues of the meeting. He spoke fluent English with a strong Southern European accent. He lengthened sounds, especially the last sound of the word. He spoke most of the meeting time. He used a considerable number of directives (for example, "you must buy a register"), rising intonations at the end of the sentences (for example, "but we have broadcast the solution of the problem?"). The mechanical engineers talked very little. They mostly said yes or no and used short sentences. I could see two mechanical engineers could speak more English than the others. Most of them used a great deal of Vietnamese with each other and I thought the manager could not understand this use of codeswitching. They discussed what the manager had presented in Vietnamese. They talked quite freely, even when the manager was talking in English. During the meeting, the manager had to remind them twice about their use of Vietnamese. He wanted them to talk in English. This might be because of my presence as an observer. The manager usually looked at his mechanical engineers when talking, but his engineers did not make much eye contact in the 
meeting. In one occasion in this part of the meeting the manager was angry with his employees.

Part 2 of the meeting:

In this second part, the manager stood up and went to the white board to write the priority to complete first on the board. First he mentioned the issues. He talked about each issue and then he wrote on the board the key words. That was the new motorbike quality plan. He said, "We have been discussing about this project. Alo, what we have to do? We have to..." He wrote:

- update the plan with critical issues

- update list of top ten troubles

- update list of checking

During this time, he kept talking and writing on the board and the mechanical engineers listened to him and took notes in their diaries.

He then told them to present in the presentation of the proposal item by item, be simple and explain in the presentation by attaching a file for reference. He drew a sample table on the white board as follows:

\begin{tabular}{|l|l|l|}
\hline Item & $\begin{array}{l}\text { Reference } \\
\text { documentation }\end{array}$ & Action \\
\hline$\cdots$ & $\cdots$ & $\ldots$ \\
\hline
\end{tabular}

After drawing the above table, he explained each column. He said, "the item is the description of the critical point. The reference documentation explains how we find this problem. What is the reference documentation about the investigation of this?" $\mathrm{He}$ continued, "In the action section, you describe all the actions such as the corrective action, or the name of the documents relates to the action."

He also told his engineers to make the draft and show him that draft for discussion. He would help them to amend the draft.

In this part of the meeting, the mechanical engineers only listened and took notes of the key points that the manager presented on the white board. He used many key technical words and some of them were academic words. He used imperatives to highlight the key issues that their department had to accomplish. Also, he instructed the employees what they needed to do by drawing a table on the board to illustrate the job requirements as well as his instructions. 
Part 3 of the meeting:

In this third part, the foreign manager talked about the pending issues to be closed. He said, "Alo, we have some activities which is long time pending, ok". For each issue, he asked one of the mechanical engineers who was assigned to finish the update. They talked about the report of Cylinder Head from a South East Asian country, the camshaft, the proposal for $R \& D$, the gear noise status, trouble report of rocker arm, and the piston circle distance. After talking about each pending issue, he wrote it on the board and finally they had a list of pending issues on the board.

Example 6.7

$\begin{array}{ll}\text { 1 Manager: } & \text { Cylinder head. } \\ \text { 2 ME: } & \text { Finished. } \\ \text { 3 Manager: } & \text { Not finish. } \\ \text { 4 Manager: } & \text { First of all I want to close the cylinder head from XYZ. } \\ 5 & \text { X, did you update the result of the material checking the file? } \\ \text { 6 X: } & \text { I will take a picture. } \\ \text { 7 Manager: } & \text { Ok, so we can close. } \\ 8 & \text { Camshaft, the situation we have to update information. } \\ \text { 9. ME: } & \text { I update already but now we must wait for... } \\ \text { 10 Manager: } & \text { Also a pending issue, ok? } \\ 11 & \text { Ok, the R\&D (research and development) } \\ 12 \text { ME: } & \text { Now I am updating. } \\ 13 \text { Manager: } & \text { You are updating zero point, zero per cent? } \\ 14 & \text { Ok, done. If we don't update the file, this proposal not go. } \\ 15 & \text { The noise is close, not a pending issue any more. } \\ 16 \text { ME: } & \text { The gear. } \\ 17 \text { Manager: } & \text { Noise from the gear is another problem } \\ 18 & \text { Keep updating information and feedback from the supplier. } \\ 19 & \text { The Trouble report Rocker Arm. This a sensitive issue. }\end{array}$

When he asked his engineers about this, they asked each other in Vietnamese and kept discussing this issue in Vietnamese. He again reminded them to speak in English. He continued the presentation by asking one of the mechanical engineers:

Example 6.8

1 Manager: Is there any pending issues? You remember or not remember?

2 ME: $\quad$ The piston which allows clearance and now need assembly line.

3 Manager: $\quad$ Yes, Piston Circle Distance.

4 ME: $\quad$ Because actually when check in this position we have to cut by our

5 equipment. We can not selection $100 \%$ the piston.

When the manager was talking, the phone of one mechanical engineer rang loudly and he answered the phone at his seat. The manager did not pay attention to this and he kept presenting. Sometimes, mechanical engineers took diary notes. The meeting lasted 30 minutes. After presenting all the priorities and pending issues, the manager required his mechanical engineers to update and complete the proposals for the priorities and issues that 
they had discussed. He then asked one of the key mechanical engineers to have an individual meeting with him to discuss his proposal.

In this meeting, mechanical engineers not only listened to the manager's presentations but also their colleagues' proposal presentations. Then they discussed with each other. They answered the manager's questions and asked questions too.

I was told that listening to presentations and discussions in meetings was also a regular communicative event of mechanical engineers at the building construction company. As for the key mechanical engineers, they had to represent the company to attend daily meetings with the foreign head contractor and other sub-contractors.

During my observations at the worksites, one formal meeting was observed at the building construction company.

\section{The formal meeting}

This meeting was held by the foreign head contractor between them and the subcontractors who took part in the project.

This formal meeting took place at the meeting room of the head contractor's office. Though the meeting place was in a container office, the tables and chairs were put in a rectangle shape where the chairman sat in the front and attendees sat on both sides. There was a big whiteboard behind the chairman and a projector. The room was equipped with two air conditioners. The setting was, in other words, itself more formal than any other meetings that I had observed in the other three worksites in this study. The chairman was from an Asian country and represented the head contractor. Attendees in this meeting were about 20 representatives of all the subcontractors. Some subcontractors sent two representatives and some sent only one. The building construction company sent two people, one manager and one mechanical engineer, who could communicate well in English. English was the main language used in the meeting. When everyone was present, the chairman started chairing the meeting. He assigned attendees to report their working schedules. Each subcontractor had prepared a working schedule describing the work plan of the day of their company.

The chairman assigned people to report their company's work schedules and asked them to comment if they wished by using a kind of imperatives and directives such as "Any comments?" and "All done?" In their presentations, the representatives also used many key technical words such as "manpower", "direct manpower", "indirect manpower", "instrument" and "construction point".

The mechanical engineer who represented his company in this case had to be able to communicate well in English in order to report the company's work schedule to the head 
contractor and other subcontractors in the meeting. He had to listen to and understand the chairman's requests and questions as well as presentations or reports and comments from the representatives of other subcontractors, many of whom were foreigners from different nonEnglish speaking countries (for example Japan, the Philippines, Malaysia and India). He reported his company work plan for that afternoon and the next day. The chairman asked him about Gate 4 in the project and that when they would start to build the fence in that area. He said they would do it on Monday. The type of English he used was formal spoken English. He also used key technical words when reporting the detail of the work plan.

In this formal meeting, the chairperson was Eastern Asian and the attendees were both Vietnamese and foreigners who were representatives of other sub-contractors. The representative of each sub-contractor presented their work schedules and discussed any comments from the meeting members. Below is a short extract from the meeting:

Example 6.9

1 Chairman: Excuse me everyone. Can we start now? C4 from Vietnam please.

$2 \mathrm{ME}: \quad \quad \quad \quad \quad \quad$ would like to report work plan of $\mathrm{C} 4$ Vietnam for today

3 backfilling point G. Direct workers 5; Indirect workers 7; Position point G;

$4 \quad$ Equipment; and Quantity. That's all. Thank you.

5 Chairman: Any more questions? Comment $[\mathrm{s}]$ ?...

$6 \quad$ (and the meeting continued with reports from other sub-contractors)

The attendees had to listen to presentations from all sub-contractors and asked questions if they wished. They used quite formal English: "I would like" (line 2), "thank you" (line 4). They also used short and key specialised words in their field, such as "backfilling", "point”, “direct worker", "indirect worker", "equipment" and "quantity" (lines 3 and 4). The chairman used formal English, such as "excuse me" and "please" (line 1) and directive English such as "any more question?" and "comment[s]" (line 5).

The above meeting and other meetings that I observed again reveal information about the setting, communicative events, English language skills, types of English, technical vocabulary and social dimensions that may affect the mechanical engineers' English uses. In the formal meeting there was a high degree of formality in the relationship between the chairman and the attendees. The chairman exercised his power via the language he used and the manner of directing the meeting. Some of the information about social dimensions is presented in this chapter and some is introduced briefly here and explained in more depth in the findings of Chapter Seven. 


\subsubsection{Other work related communicative events that required English speaking skills}

Parallel with listening skills, speaking skills were required for communication. Mechanical engineers were observed using speaking skills quite often in their job, especially those who worked outside the office. The details of the skills are presented as follows:

\subsection{Safety talks}

Talks about safety were required and were observed in all four factory sites, especially by mechanical engineers who worked in the workshops, production areas, garages and construction sites. The foreign managers kept reminding their staff to meet the safety requirements. Mechanical engineers had to check if engineers and workers in their group met the safety requirements such as helmets, safety boots and goggles. I was told that this was often the first thing discussed in the morning meeting. If the foreign manager was not attending the meeting, he would come and check later in the day. For mechanical engineers who worked at the construction site of the project, the safety talk was one of the most important issues in their work plan for the day. Safety requirements were checked by foreign site managers and supervisors daily.

\subsection{Talking about everyday tasks and duties}

The observations showed that mechanical engineers were engaged in talking about everyday tasks and duties in English daily, especially those who worked outside the office settings. This communicative event consisted of other skills, such as discussing the morning meeting, reviewing work done the previous day, presenting the work plan for the current day, reporting the work progress to the foreign manager, and addressing any questions about work from the manager. The following short conversation between a southern European manager and a mechanical engineer is an example:

Example 6.10

$\begin{array}{ll}\text { 1 Manager: } & \text { Have we got the spare parts? } \\ \text { 2 ME: } & \text { Yes, yesterday. } \\ \text { 3 Manager: } & \text { Correct number? } \\ \text { 4 ME: } & \text { Uhm, not sure. I check again. }\end{array}$

The mechanical engineer then talked about his work plan for that day:

I will check all spare parts today because I will go to XX (a province in the centre north of Vietnam) tomorrow.

I was told that this was their daily event, because at least twice a day mechanical engineers were observed being checked and asked by their foreign manager. They had to address any questions, and receive job requests or instructions from the manager. 
While they were working, if there were any technical issues, mechanical engineers had to report them to the manager. They told me that if this was urgent and their English was good enough to talk on the phone, they would report via telephone. If not, they would come to see the manager in person to report. This was because then they could use body language and other communication strategies to be understood as well as to understand the foreign manager's questions, requests and instructions.

\subsection{Other communicative events that required speaking skills}

Other communicative events observed being used by mechanical engineers were reporting the status of spare parts, greeting foreign managers and supervisors to the office or worksite, reporting technical problems such as broken motors, reporting the proposed time to deal with technical problems, explaining technical troubles or situations to the manager, and reporting manpower and equipment for the day.

Mechanical engineers were seen attending meetings, presenting work plans and proposals in different meetings, discussing work plans in meetings and having daily conversations with their foreign manager and colleagues.

Mechanical engineers who had better English ability also functioned as interpreters for the foreign manager, engineers and workers to communicate with each other. When other engineers and workers did not understand what the foreign manager asked, requested and instructed, they interpreted from English into Vietnamese for them to understand. As well they interpreted engineers and workers' answers in Vietnamese into English for the manager to understand.

\subsubsection{Work related English language reading and writing skills}

As has been discussed earlier, reading and writing skills are required by mechanical engineers in general and those who work in the office in particular. There were various subskills or communicative events observed being used by them, as follows:

\subsection{Reading memos, notices and work schedules on the notice board}

This communicative event was observed being required by mechanical engineers. Memos, notices and work schedules were seen in all companies and offices. They were written in English and Vietnamese, and some were bilingual. The notice boards and the white boards in offices were places where mechanical engineers could update general information about the company, work plans or any social affairs for staff such as holiday break and sports activities. 
In some workplaces, urgent work memos such as corrective actions, operation watch schedule, and job requests were placed on the notice boards. This was to remind the mechanical engineers of the tasks that needed to be completed soon. Of these, job requests from different departments in the factory were sent to the technical department where office mechanical engineers had to collect them, classify them and give them to the right person. If the job requests were about faults of spare parts, they classified and divided them into categories and then reported the errors to the manager and the suppliers. These job requests were written in pre-prepared forms and they had to read through all of them in order to classify the errors.

\subsection{Reading product specifications and descriptions}

This was observed as a frequent communicative event of mechanical engineers, especially those who worked in the office. For mechanical engineers whose job was to look for the right spare parts and order them from the suppliers, this reading activity consisted of reading the catalogues, and reading online manuals and product descriptions on the manufacturer's website. Office mechanical engineers were observed to have some catalogues from suppliers to introduce their products on their work desks. When they received job requests from the production factory or other departments, such as the workshop and garage, they needed to order the right parts in terms of function and specific details of diameter, figures and measures. Thus, they needed to look up in the catalogues and then search online for more information and choices. They needed to compare prices among suppliers and choose the supplier to order from.

Mechanical engineers who worked in workshops, garages and other places were also required to understand product specifications and descriptions in order to install or uninstall them. Some of them were observed bringing their laptops to the worksite to look for information they needed. They told me that they did so to make sure they did the right things. If they did not know or were not familiar with any technical problems, they could search online instructions. Some others also used their smart phone to update information.

\subsection{Other communicative events requiring reading skills}

Reading emails, technical reports, work schedules, technical documents in English, names of spare parts and operating buttons on machines, and proposals were observed communicative events of mechanical engineers.

Office mechanical engineers were seen to check their email every day. This was one of their first activities at the start of their working day. They read through all the emails they 
had in their inbox and replied to the urgent ones. They said that they replied to the less important emails later in the day. I was told that these emails were mostly from the management, colleagues and suppliers. Their foreign manager often discussed work, gave job requests or kept giving reminders about work via email. They sometimes received job requests from other departments via email. They communicated with the suppliers via email to discuss orders and prices, as well as errors of spare parts.

When arriving at the office to start their working day, mechanical engineers looked at their work schedules to update their work plan for the day. They also read work schedules when attending meetings. Construction site mechanical engineers were seen holding work schedules in their hand. Work schedules were used not only for managing their workers but also reporting to the foreign site manager and supervisors when they visited the work site.

Office mechanical engineers had to read technical documents online to understand more about the machines or spare parts they were looking to order. Construction site mechanical engineers also needed to read technical documents to update information. Some of them were observed searching and reading technical documents on the laptops they had brought to the workshop and garage.

Reading technical drawings was one of the most frequent communicative events of mechanical engineers. They were required to interpret the details or figures and notes in technical drawings. According to the foreign manager of the engineering department of the food producing company, technical drawing was the most effective means of communication, because the visual clues supported the explanation. He said:

The most effective way of communication in my workplace is drawing. This means you should be able to use the AutoCAD, but it is not easy to draw everything. You have to save everything in a safe place. I usually use my camera and take every snap of drawings, pictures and problems to show my guys what I mean, what I want them to do.

Besides reading technical drawings, mechanical engineers were also required to read PowerPoint presentations and Excel files on projector screens in meetings. Sometimes, their foreign manager presented the key issues of the meeting on the white board and they had to read and take notes in their diaries. These were technical symbols, abbreviations and headings, which mostly used technical terminology.

Together with the demand to use reading skills, writing skills were observed to be of crucial importance in mechanical engineers' work performances. 


\subsection{Writing technical reports}

Mechanical engineers in each factory were observed writing different kinds of reports. Within each factory, the observations showed that mechanical engineers with different positions were required to do different tasks. There were different kinds of technical reports.

Office mechanical engineers of the food producing company were seen writing daily production reports and condition monitoring reports. When I looked at the reports, I could see they were quite simple. Daily production reports showed quantity figures whereas condition monitoring reports included photos describing the condition of machines for illustration. Below is an example of the condition monitoring report:

\section{Condition monitoring report}

Date ....

Machine ID: PP183

Description: Injection pump

Area: Ash and Pray Pond

Location: Level 1

\section{Content of report}

Injection pump observation

Conclusion: Description of errors with photos attached

Mechanical engineers who worked in the factory often followed the work schedules and reported their work progress orally to the foreign manager when he visited the worksite to check their work. No written reports were observed being written by these mechanical engineers.

Since most of the mechanical engineers of the dairy factory were team leaders, they often reported their work via email or in person when they came to see the foreign manager when they were required. They reported their work by filling in a prepared form in bilingual English and Vietnamese, namely "working confirmed", which included details of area, equipment name, machine ID, work order, receipt number, date, working hour and duration, and other details. There were signatures of persons in charge at the end of the report.

Mechanical engineers of the motorbike company were observed writing incoming inspection reports, corrective action reports, trouble reports and non-conformity reports. They also needed to synthesise all technical issues to report to the manager before meetings. Office mechanical engineers at the construction site of the building construction company were observed writing daily work plan reports to send to their site manager and the head contractor, as well as other sub-contractors in the project. It was named the "daily manpower/ construction equipment report" and consisted of job name, job code, date, name of the contractor, prepared by, and approved by. The main content of the report was about 
manpower, such as management staff (site manager, supervisor, and safety staff), direct workers and indirect workers, work locations and work hours. Following the section on manpower was information on the equipment required to complete the job.

\subsection{Email communication}

This was an observed common communicative event of mechanical engineers, especially those who worked in the office. They often checked their email right after starting their working day. Email was a frequent means of communication in the observed factories. The observed participants told me that most of their emails were in English because their director and manager were foreigners and all the factories did business with foreign business partners. As seen in the snapshots for a working day for the manager and mechanical engineer (above), email communication can be a starting activity of the professionals in the domain.

Mechanical engineers communicated via email with the management and colleagues. They discussed work issues, and reported any technical issues to the manager and other people in charge. The manager also sent the job requests to his staff via email. Work schedules and company notices were sent via email, too.

For those whose job was to work with the supplier or customer, email was their main communicative event and an effective way of communication. They discussed orders, contracts and business matters and negotiated prices via email. They reported technical problems and troubles with incoming spare parts to the management and suppliers.

\subsection{Other communicative events requiring writing skills}

Some mechanical engineers were observed writing work plans and proposals, and taking notes. Those who worked in the building construction company were seen writing work plans in their temporary office at the construction site. They had to update their work plan every day to report to the site manager, the head contractor and other sub-contractors in the daily meeting. These work plans were then sent to the site mechanical engineers for execution.

Writing proposals was not seen as a frequent activity of the observed mechanical engineers. The deputy manager of the technical department of the dairy company said that most of his mechanical engineers were team leaders and they had to write work proposals three to five times in a year. As for those who worked in the motorbike company, this was seen as a communicative event. They were observed revising their proposals before meeting 
with the foreign manager. They had to present their proposals in the meeting. The manager and colleagues gave comments and they needed to update the proposal after the meeting. In conclusion, mechanical engineers were observed using English frequently with different sorts of skills. Some skills were used successfully and some were not in their daily work communication. The following section presents the successful and less successful interactive uses of English which were observed by myself.

\subsubsection{Successful interactive uses of English observed and adaptive communicative events}

What I observed and what mechanical engineers and their managers told me about their English uses in the workplace revealed various levels of English ability among mechanical engineers. I was told that only some mechanical engineers had good enough English for work while the majority of them had average English and low level of English ability. Because of their weakness in using English, they faced many challenges in performing their work effectively in the workplace. To overcome these challenges, mechanical engineers employed different strategies, which were observed to be successful or have the potential to slow the communication down, as follows:

\subsubsection{Successful interactive uses of English observed}

Mechanical engineers were observed using informal spoken English which was not always correct in terms of standard English that they learned at school. This included using sentences which were not framed as questions but became questions through intonation and using short, informal broken English that could be understood. Mechanical engineers were also observed using sentences which did not follow correct grammar structures. The extract below from a conversation between the foreign manager and mechanical engineer at the food producing company is an example:

Example 6.11

1 Manager: Did you change the filter of the oil? The filter good or not good.

2 ME: $\quad$ Me finish check, clean.

3 Manager: Have you done the grinding of the roller teeth?

$4 \mathrm{ME}: \quad$ Check number 4 ok.

The mechanical engineer said "me finish check, clean" (line 2). This answer was not correct in terms of a standard English grammatical structure. Instead of giving a yes/no answer, he uttered a sentence which could be understood by the manager. He meant he checked the oil filter and it was clean. The correct sentence could be "Yes, I checked it and it was clean". His answer to the second question was similar. He used word-by-word English and again the manager could understand what he meant. This was consonant with what the 
manager of the motorbike company told me about their uses of English at work. He said they did not care about the form but cared about understanding.

The majority of mechanical engineers at the food producing company, the dairy factory and the building construction company were observed using short broken English and informal, simple and technical English in communication with the foreign managers. They were seen communicating with the foreign manager every day when the manager visited their worksites for regular checks. The following conversation between the foreign manager and his mechanical engineer took place in the garage of the dairy company. This is a kind of one-to-one interaction as described in Vine (2009). The foreign manager visited this place to check his staff at work. They were standing next to a tractor and the manager used directives to ask his mechanical engineer to tighten the water hoses and the wheels.

Example 6.12

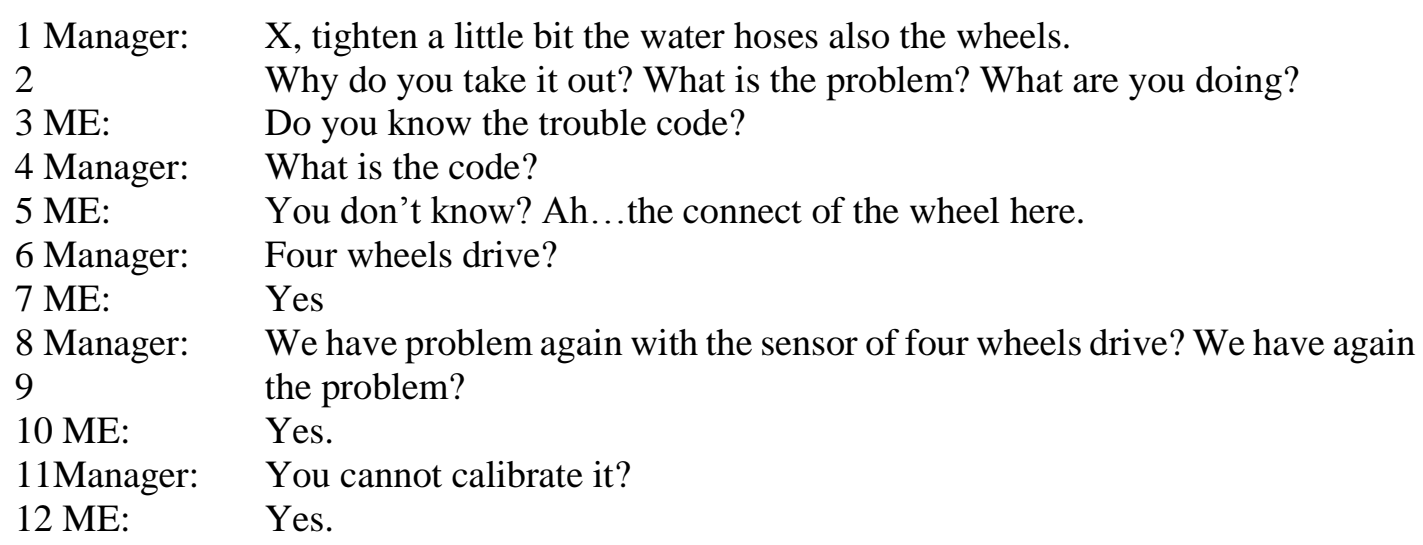

The language used in the conversation was simple and technical. The mechanical engineer mostly used very short answers like "yes" (lines 7, 10, 12). He understood the questions and the technical problems and just said "yes" to all questions. He even used a sentence which was not framed as a question, but became a question through rising intonation at the end of the sentence to ask his manager: "you don't know?" (line 5). The manager used an imperative to assign a task to the mechanical engineer " $\mathrm{X}$, tighten a little bit the water holes also the wheels" (line 1) and some interrogatives such as "we have problem again with the sensor of four wheels drive? We have again the problem?" (lines 8 \& 9) and "you cannot calibrate it?" (line 11) to clarify the information. The use of interrogatives was less direct and more polite than the use of imperatives. These are the various forms of directives that the managers used to get employees to carry out the tasks. According to Vine (2009), "imperatives are a direct way of issuing a directive, while the use of an interrogative form, especially model interrogatives using can or could, are much more indirect and forceful" (pp. 1395-1396). Sharing the same view, Koester (2010) argues that 
directives can be the uses of imperatives, modals of obligation as have to and need to, and more indirect request using would and could.

Technical drawings could be used by engineers to communicate quite complex meanings without the need to use oral or written English. According to Mike, one of the foreign managers at the motorbike company, technical drawings supported their work communication. Mechanical engineers who worked in the food producing company and the dairy company were observed using technical drawings to communicate with their foreign managers. They reported their work progress by showing the technical drawings with little oral communication, just pointing at the place where they wanted to report on the progress of their execution.

Another interaction which was observed being used successfully by mechanical engineers and their foreign managers was having someone who was proficient in English function as an interpreter. The foreign manager at the food producing company and the dairy company knew the varying English ability of their mechanical engineers and just talked to those who could understand English. In case they wanted to talk about something important or new, they asked their personal assistant or the deputy Vietnamese manager to interpret for them. When observing mechanical engineers at the milling area of the food producing company, I saw the mechanical engineer and other employees in this section help each other to understand the manager's questions. They spoke out freely when they understood the questions and knew the answers.

Besides these successful interactive uses of English, mechanical engineers also used adaptive communicative activities, which were observed as having the potential to slow communication down more than the above-discussed strategies.

\subsubsection{Adaptive communicative activities}

Due to their weakness in using English, a majority of mechanical engineers were observed struggling in communicating with the foreign managers and foreign site managers and supervisors.

Mechanical engineers at the food producing company were seen struggling to understand and be understood using both English and Vietnamese in their daily communication. They used a mixture of English and Vietnamese to answer the manager's questions as well as to report their work progress. They used key technical words and some Vietnamese words in their sentences. The following short conversations between the foreign 
manager and his mechanical engineers at the food producing company are some examples to illustrate their strategy of combining the two languages:

Example 6.13

1 Manager:

2 Engineers and workers:
When will you finish taking care the pin, the bush?

Ok rồi $(=$ done $)$

Example 6.14

1 Manager: Can I know/may I know what you talk in the tool box check in the morning?

2 ME: $\quad$ Tool box?

$3 \quad$ Kiểm tra an toàn ah? Xong rồi (Tool box checking? Done)

Example 6.15

1 Manager: The rubber replacing, complete?

2 ME: $\quad$ Yes.

3 Manager: $\quad$ Have you checked ID (induced draft)?

4 ME: $\quad$ Quạt ID ah? Quạt ID là phải Clean pipes xong, sau đó vận tốc tua bin,

5 sau đó đấu lắp lại chạy quạt mới cân bằng (I $\mathrm{D}$ fan? ID is to finish cleaning

6 pipes, then the speed of the turbine, the reconnect for the fan to operate)

7 Manager: Uhm, good.

In the above examples, the mechanical engineer understood the questions and could address them. He did not give a full answer like 'I have finished taking care of them/they have been done' and 'we talked about safety requirements, work plans for the day'. Instead, he used code-switching and used the Vietnamese word "ok rồi" (example 6.13, line 2) which means "done" in English.

Mechanical engineers at the maintenance department of the dairy company were observed trying to communicate with their foreign manager. They were seen coming to the manager's office to report their team work progress and receive new job requests from the manager. The manager told me that his mechanical engineers had to come to his office every morning because their poor English ability prevented them from reporting their work on the phone or via email. This was also because the manager himself could not fully understand their English. When they met in person, it was easier for them to understand each other because they could use their body language, actions, photos and even some Vietnamese to explain what they wanted to talk about. They used simple English including key technical words in their field to communicate with their manager. One of them was seen using a pen and a piece of paper to draw what he wanted to talk about to his manager. The following example is an extract in the conversation between the supervisor of the water treatment system and his foreign manager. 
Example 6.16

1 Manager: How is the pipe system? Specify the position of the pump?

2 Engineer: We have four pumps (he opened a drawing to show his manager).

The supervisor had prepared the technical drawing of the water treatment system and he showed it to the manager to explain what he wanted to report. They both looked at the drawing. The mechanical engineer pointed at the drawing to show the manager the positions of the pumps, the pipe system and the water level.

When observing their morning meeting with the foreign manager, mechanical engineers of the quality engine department at the motorbike company were seen discussing the foreign manager's questions in Vietnamese together before giving the answers to the manager. This activity was repeated four times in the meeting and the manager had to remind them to speak in English instead of Vietnamese. They were also observed using body language and real objects when talking with their manager about technical issues. Their manager, who came from a southern European country, told me that though his employees' English ability was not very good, they could find a way to work together. On one hand, he had to simplify his use of English to help his staff understand what he meant. On the other hand, they mostly spoke using technical words. I was told that using the right technical terminology was very important in their work communication.

The building construction company took part in a big project at the time of my observation, and their mechanical engineers were required to work with the foreign head contractor and other Vietnamese and foreign subcontractors. Except the key mechanical engineer, whose English was good enough for daily meetings with the head contractor and work communication, other mechanical engineers had to struggle to communicate in English. They were observed using Vietnamese in their group meeting without the presence of the foreign site manager or site supervisors. I was told that they used English in the presence of the head contractor representative. In this case, they used simple and technical English such as today manpower, direct men and indirect men, number of equipment required, and position of execution. When they worked at the construction site, they were seen communicating with the foreign site supervisors of the head contractor. They used simple English as in the example below, which took place in the construction site. The mechanical engineer was supervising his team to build the fence when a foreign site supervisor came to check their work. 
Example 6.17

1 Supervisor: Hello.

2 ME: $\quad$ Hello

3 Supervisor: How is it going?

4 ME: $\quad$ Ok

5 Supervisor: Any issues?

6 ME: $\quad$ No, thank you.

They greeted each other. Then the site supervisor asked if they had any problems in executing the work. Though the English they used was simple, it showed a level of formality which will be discussed in more depth in the next chapter. This mechanical engineer told me that he could only understand simple questions and used single key words to report to the supervisor when being asked. He said that the foreign site manager and supervisors also knew his and the other staff's English ability and therefore used simple English too. They used instructional English such as "strengthen the foundation" and "narrow this gap".

Throughout eight observations conducted at four workplaces, English vocabulary was observed being used by mechanical engineers, frequently including technical words and academic words in their field and general words. The following section presents the list of technical words and academic words.

\subsubsection{List of technical words, technical word phrases and academic words observed being used by mechanical engineers}

It seems to be that much of the communication in the observed work contexts took place based on a knowledge of the key technical vocabulary and, especially for reading and writing, some key academic words. Since the observations were conducted at four different companies with different business majors, the list of the observed technical vocabulary at each workplace is presented separately as below:

\subsubsection{The food producing company}

The common language of mechanical engineers at this company related to the safety talk, safety requirements, helmets, safety boots, goggles, and technical drawing. The safety talk is the first thing that happens to mechanical engineers and workers every day. Technical words used in the evaporator area: bush, bearing, welding, alignment, worn out knife, hard facing, and pin.

Technical words used in pan area: hard facing, setting comb, pump maintenance, gland packing, oil filter, roller teeth, welding, grinding, pin, bush, and lubrication. 
Technical words used in milling area: cutting, alignment, aerator, assembling, rubber, sulphur furnace, lubrication, bush, sharp, assembling, coupling, belt conveyor, splicing, elevator, gear box, slat conveyor, chain, and runner plate.

Technical words used in boiler area: test, boiler, pipe, chimney, water pressure, hydraulic, hydraulic testing, legal statutory requirement, boiler design pressure, operation pressure, steam pressure, pressure at the top valve, induce draft fan, force draft fan, efficiency of the boiler \& optimization of the boiler, water chemistry, $\mathrm{pH}$ (potential Hydrogen), alkalinity, TDS (Total Dissolved Solids), sensor, level sensor, temperature sensor, graphics, separator (plain end, drive end), engineering unit (temperature, pressure, RPM (revolution per minute)), torque, actuator, valve, butterfly valve (big dish), globe valve, and screw conveyor.

Technical words used in control room: calibration, graphics, sensor, $\mathrm{pH}$ sensor, conductivity sensor, level sensor, temperature sensor, Process and Instrument Diagram (PID), and Engineering Flow Diagram (EFD)

\subsubsection{The dairy company}

Technical words used in the garage and workshop are: air filter, engine oil filter, hydraulic oil filter, strainer, cab air filter, nipple, hydraulic hose, brake, axle, wheel, tyre, bolt, nut, washer, pin, bushing, piston, cylinder, seal, O-ring, gasket, belt, pulley, knife, fan, radiator, fuel pump, hydraulic pump, engine, injector, connector, terminal, battery, charger, starter, alternator, A/C, sensor, solenoid, hydraulic schematic, electric schematic, light, bulb, fuse, relay, pressure, ampere, and voltage.

Technical words used in the maintenance department are: maintain, maintenance, fix, repair, replace, bucket, rubber, John deer (tractor), CAT 91 (tractor), water treatment system, pump, pump installation, technical drawing, water pressure, water depth, water level, hammer, electricity system, electricity connecting point, rope, parachute, pipe, pipe break, clean, tool, and voltage.

\subsubsection{The motorbike company}

Technical words used in the quality engine department are: manpower, spare-part, report, error, online system, incoming spare-part inspection, investigation, analysis, analysis of error, electrical starter, quality plan, item, update, list of checking, cylinder head, proposal for research and development, gear noise status, reference document, machining, procedure, work instruction, according, database, system, folder, general overview, file, status, link, schedule of action, statistical, process, sampling, statistical analysis, drift of process, trouble 
shooting, back-up system, update, re-test, proposal of improvement, camshaft, material checking, piston circle distance, thread gauge, corrective action, reject indicator, objective, defect, verify, reject, warranty, cooperation, market claim, ranking, target, assembly, gasket, component, fuel injector, blue dot mark, identification, functionality, feedback, plastic, production date, submit, attachment, replacement, and deduct payment.

Technical words used in the engine plan department are: production line, production plan, production result, technical issue, quality issue, project, tank, oil and water in the tank, consumption of oil, exhaustion, install, LCD screen, light signal (green, yellow, red), graphic, WH (ware house), assembly line, machining line, engine code, error, categories,

supplier, technical report, online work, input equipment, stud, vehicle model, description of component, initial occurrence, place of occurrence, date of occurrence, repeated occurrence, occurrence reported by, trouble report, trouble - shooting request, and confirm.

\subsubsection{The building construction company}

Technical words used in the building construction company are:

Construction, manpower, direct staff, indirect staff, supervisory staff, safety staff, security staff, equipment, processing, safety, occupational safety, work category, work location, installing posts, excavation, concrete, net fence, welding, construction equipment, survey equipment, crane, folk lift, transporting container, illustration, safety analysis, operating process, speed of truck, allowed speed, loading, unloading, position of unloading, risk of loosing occupational safety, hoisting cable, slipping cable, twisting cable, bumping component, implement, safety requirement, safety belt, protection gloves, protection glasses, protection clothes, protection helmet, safety boots, scaffold,

Technical words used in waste management are:

Industrial waste: concrete debris, rebar, cement bag, machine oil waste

General waste: portable toilet, burnable waste (paper, cigarette butts, bamboo), unburnable waste (plastic pet bottle, glass bottle, synthetic resins)

Waste storage, waste treatment, environmental sanitation company, foundation, garbage, garbage can, bucket, landfill, dispose, disposal area

These technical words were collected not only from the conversations between the mechanical engineers with their foreign managers but also from the notices on the notice boards in their office, work schedules and reported in the meetings that I attended during the 
observations. These words are presented separately because they were observed and collected at different worksites with different business fields. This separation aims to help the readers understand the various work situations that mechanical engineers were likely to be engaged in. Also, this technical word list demonstrates the importance of English for technical communication.

A key finding from observations is that mechanical engineers were required to use a considerable number of academic words to function effectively in their jobs. According to Coxhead (2000), "an academic word list plays a crucial role in setting vocabulary goals for language courses" (p.214), which is challenging for vocabulary learning and teaching. With the aim to find out if mechanical engineers required academic words, all the above-observed words are put together in one text. I used an online vocabulary search tool on eapfoundation.com website to find the academic words as described in the methodology chapter. That is, all the technical words above were copy and pasted into a tool named 'AWL tag cloud \& gapfill'. After running the tool, a list of AWL was found and presented in terms of levels as follows:

Level 1 analysis / area / environmental / identification / indicator / issue / legal / occurrence / procedure / process / processing / requirement / requirements / research Level 2 categories / category / construction / consumption / design / item / maintain / maintenance / potential / security / survey

Level 3 component / document / illustration / initial / link / location / schematic / technical

Level 4 code / error / implement / investigation / occupational / project / statistical / status

Level $5 \mathrm{draft} /$ objective / reject / target

Level 6 attachment / input / instruction / transporting

Level 7 confirm / coupling / disposal / dispose / equipment / file / foundation / globe / submit

Level 8 induce / inspection / schedule / terminal / vehicle

Level 9 revolution

Level 10 assembling / assembly

These academic words picked up from different technical word lists of different companies were presented together in one table to give an overview of the importance of academic words in the workplace. I did not observe the use of as many of academic words as technical words, but it remains significant that any professional mechanical engineer might be required to know some academic words to function effectively in their jobs. 


\subsubsection{Snapshots}

Snapshots are also used as an additional way to present the findings from the observations. They provide a 'day-in-the-life' narrative, which describes the context and interaction of the professionals in the domain (Huhta et al., 2013). The snapshot is one of the six categories in the CEF Professional Profile model and it is used to provide inside into the routine situations of a normal working day that mechanical engineering English language learners may encounter in their future jobs in the field. Huhta et al. (2013) argue that snapshots are valuable "to give the course designer an inside into the personal experience of a professional" (p. 63). The use of snapshots in this study provides a pedagogical tool which can inform course designers to develop learning tasks that are relevant to the learners. A task is seen as a primary unit in the CEF needs analysis model, and it is integral to the work context of a professional such as mechanical engineers. Munby's CNP model has been criticised for its complexity (Ha, 2005; West, 1994), but much of this complexity can be more effectively captured through observation. Using both the CNP model and CEF model, the study's goal was to examine workplace communication needs in a more holistic view because it takes account of the individual and how this individual interacts in a given context of his/her field of action (Huhta et al., 2013). The English communication needs are not only about the linguistic needs such as the types of English language required, the communicative events, and the English language skills required, different English accents or the English for technical communication but also include the social dimensions hidden behind this use such as solidarity and power relationships. The CEF in general and the snapshot, in particular, can also inform ESP teachers and students about the complex communication needs in mechanical engineers' professional contexts which should be included in the course book by the course designers.

As described in the methodology chapter, the analysis of the qualitative data was primarily concerned with communicative events. A working day of one engineer and one manager is presented. Each presentation starts with a table. Then the snapshot is presented in a narrative form, followed by another table to provide information of the degree of formality of the language, the people with whom the participants communicate in English and indicators of the relationship between them. These tables are finally followed by a commentary on the types of communicative events involved in the day for both the manager and the mechanical engineer.

Since the mechanical engineers were observed using English mostly with their foreign manager, an overview of the working day of a manager is presented first. This 
overview is of one of five of managers I observed. This manager was chosen to include in the snapshot because he was one of the foreign managers who had been working in Vietnam for more than two years. He knew some Vietnamese words. Of all these observations that I conducted with the managers, the one with James closely matched most of the data that managers reported about their daily activities in the interviews. I understand that one observation of a manager or a mechanical engineer seen through my eyes bounded by time and place cannot be generalised, especially it may have had the Hawthorne effect because of my presence. However, it is a part of the findings of the thesis which can inform course designers as a result of a needs analysis research.

\subsubsection{A working day of a manager}

A working day of a manager is firstly described in Table 18 below to give an overview of the communicative events and the English language skills that the participant needs to carry out the communicative events for that day.

Table 18: Observed and reported communicative events and the required English language skills in a working day of a manager of mechanical engineers

\begin{tabular}{|c|c|c|c|}
\hline \multicolumn{2}{|c|}{ Communicative events of the day } & \multirow{2}{*}{ Purposes of the events } & \multirow{2}{*}{$\begin{array}{c}\text { English language } \\
\text { macro skills }\end{array}$} \\
\hline Observed & Reported & & \\
\hline Greeting employees & & $\begin{array}{l}\text { To say hello to the employees to } \\
\text { start the working as well as to let } \\
\text { them know that he is at work. }\end{array}$ & $\begin{array}{l}\text { Speaking and } \\
\text { listening }\end{array}$ \\
\hline \multirow[t]{2}{*}{ Checking email } & Reading email & $\begin{array}{l}\text { To see if there are any job requests } \\
\text { from the manager, any reply or } \\
\text { information from the suppliers. }\end{array}$ & Reading \\
\hline & $\begin{array}{l}\text { Replying to } \\
\text { emails }\end{array}$ & To deal with work issues. & Writing \\
\hline $\begin{array}{l}\text { Having a conversation } \\
\text { with the Vietnamese } \\
\text { deputy manager }\end{array}$ & & $\begin{array}{l}\text { To confirm a meeting with a local } \\
\text { commune chairman. To get } \\
\text { directions to the location of the } \\
\text { meeting. }\end{array}$ & $\begin{array}{l}\text { Speaking and } \\
\text { listening }\end{array}$ \\
\hline $\begin{array}{l}\text { Meeting } r \text { the } \\
\text { mechanical engineer } \\
\text { in charge of the } \\
\text { workshop }\end{array}$ & & $\begin{array}{l}\text { To update the progress of work To } \\
\text { allocate the tasks of the day. }\end{array}$ & $\begin{array}{l}\text { Speaking and } \\
\text { listening }\end{array}$ \\
\hline $\begin{array}{l}\text { Meeting the } \\
\text { mechanical engineer } \\
\text { in charge of the water } \\
\text { treatment system }\end{array}$ & & $\begin{array}{l}\text { To update the work progress To } \\
\text { allocate the tasks for the day. }\end{array}$ & $\begin{array}{l}\text { Speaking and } \\
\text { listening }\end{array}$ \\
\hline $\begin{array}{l}\text { Supervising the } \\
\text { workshop by walking } \\
\text { around and talking } \\
\text { with the employees }\end{array}$ & & $\begin{array}{l}\text { To check the employees' work } \\
\text { progress and give them } \\
\text { instruction if necessary. }\end{array}$ & $\begin{array}{l}\text { Speaking and } \\
\text { listening }\end{array}$ \\
\hline $\begin{array}{l}\text { Giving instructions at } \\
\text { the workshop }\end{array}$ & & $\begin{array}{l}\text { To instruct the employees about } \\
\text { how to do the right job. }\end{array}$ & Speaking \\
\hline $\begin{array}{l}\text { Meeting with the } \\
\text { board of directors }\end{array}$ & & $\begin{array}{l}\text { To report and discuss professional } \\
\text { issues. }\end{array}$ & $\begin{array}{l}\text { Speaking and } \\
\text { listening }\end{array}$ \\
\hline
\end{tabular}




\subsubsection{Snapshot: Overview of the day for the manager}

James is a manager from the Middle East in the maintenance department at the dairy company (C2). He is 43 years old. He went to an engineering school in his home country. He has worked in Africa, too. He has been working in the company for more than two years. James arrived at work between 7.30 and $7.45 \mathrm{am}$. First, he walked into the workshop, which was in front of the department office, to greet his employees. He said hello in both English and Vietnamese. He said, "hello/ Xin chào, how are you?" He then went into his office and looked around as if he wanted to check something. The office of this department was made from a container which was divided into three workstations: one for James, one for the deputy manager and one for the personal assistant. After surveying his office, he sat down at his workstation and logged into his laptop to check emails. He told me that on average he had from 30 to 80 emails per day. He said that $70 \%$ of these emails related to professional issues and 30\% belonged to management issues. The first group of emails were with his Vietnamese deputy manager, personal assistant, supervisors, engineers, and many of these emails were with the suppliers. The second group of emails were with the company management. Some of these were urgent and he had to reply to them. While he was working with his laptop, the personal assistant asked him if he would like a cup of coffee. He said yes and she made a cup of coffee for him.

Second, James talked with his Deputy Manager (DM) who was sitting and working in the same office. The interaction was about a meeting with the vice chairman of the local commune next Monday. The deputy was going on a business trip on that day, and the manager wanted to know how to get to the meeting location. The manager asked the deputy the way to get to the vice chairman's office. The deputy manager described the way and also said that his personal assistant who knew the address would accompany him next Monday. Below is an extract from their conversation:

Example 6.1

$\begin{array}{ll}\text { 1 James: } & \text { You are not here on Monday? } \\ 2 \text { DM: } & \text { Yeah. Mr. X - one of the mechanical engineers will be in charge with you } \\ 3 & \text { and the secretary ok. } \\ 4 & \text { Because I will talk to X and make him understand all things } \\ 5 \text { James: } & \text { Ah, X know and the secretary know. Their office is near [XXX] } \\ \text { 6 James: } & \text { Near [XXX] office? } \\ 7 \text { DM: } & \text { Near the local commit [he means committee] office. } \\ \text { 8 James: } & \text { Ah, I know I know. In the junction you turn right... on the right side. } \\ 9 \text { DM: } & \text { Yes. Everyone will know }\end{array}$


Third, one of his mechanical engineers came to receive a work request from him. He assigned the work request orally. The meeting lasted five minutes. He asked the mechanical engineer to manage his team to fix the stairs on the John Deere 02 tractor. He told him to weld the stairs tightly. Then he told the mechanical engineer to change the rubber of the bucket for Cat 91 (a kind of tractor in the company farm).

Fourth, he had a short meeting with another mechanical engineer who was in charge of the water treatment system. The engineer reported the progress of the pump installation. He showed the manager a drawing, and they both looked at this drawing. The manager asked him to specify the positions of the four pumps. He asked the engineer about the water pressure, water depth, and level.

Fifth, he visited the worksite. He walked around the workshop which was in front of his office to check what the mechanical engineers and workers were doing. Here he said hello in English to his people and talked to the mechanical engineer who was the supervisor. At that time, the workers were hammering and grinding a part of the tractor. He pointed at the inside of that part and was not pleased with what they had done. He asked the supervisor to open the part that was being worked on up and look inside.

Example 6.2

$\begin{array}{ll}\text { 1 Manager: } & \text { Every time you need open and look inside. } \\ \text { 2 Supervisor: } & \text { I will ask them again. Sometimes I talk about... } \\ 3 \text { Manager: } & \text { Not sometimes, all the times. I talk to you all the time. } \\ 4 & \text { I talk same same all the times. Check check check. } \\ 5 & \text { You talk same same your guys all the times. Check check check. }\end{array}$

He also asked the supervisor why there were so many people there. The supervisor said they were waiting for the car to take them to the farm to fix one of the tractors. There was not an interpreter at the time, and it seemed that the mechanical engineer could understand what he said. He did not interpret the manager's words into Vietnamese at that time. The workers kept silent.

Sixth, he drove to the head office to attend a meeting of the board of directors. The meeting was confidential, so I could not accompany him.

Finally, he went home from the head office without returning to his office. He told me that he was having a meeting with the board of directors that afternoon too and would not come back to his office.

The table below presents the type of English and the working relationship between the participants being observed. 
Table 19: Observed and reported communicative events, formality and relationship in a working day of the manager of mechanical engineers

\begin{tabular}{|c|c|c|c|c|}
\hline \multicolumn{2}{|c|}{$\begin{array}{c}\text { Sequence of communicative } \\
\text { events }\end{array}$} & \multirow{2}{*}{ Purposes of the events } & \multirow{2}{*}{$\begin{array}{l}\text { Degree of } \\
\text { formality }\end{array}$} & \multirow{2}{*}{ Relationship } \\
\hline Observed & Reported & & & \\
\hline Greeting employees & & $\begin{array}{l}\text { To say hello to the } \\
\text { employees. }\end{array}$ & $\begin{array}{c}\text { Low } \\
\text { formality }\end{array}$ & $\begin{array}{l}\text { Manager to } \\
\text { employees }\end{array}$ \\
\hline \multirow[t]{2}{*}{ Checking email } & $\begin{array}{l}\text { Checking } \\
\text { email }\end{array}$ & To update information. & N/A & Manager \\
\hline & $\begin{array}{l}\text { Replying } \\
\text { email }\end{array}$ & To deal with work issues. & $\begin{array}{l}\text { High and } \\
\text { low } \\
\text { formality }\end{array}$ & $\begin{array}{l}\text { Manager to } \\
\text { engineers, } \\
\text { suppliers, and } \\
\text { colleagues } \\
\end{array}$ \\
\hline $\begin{array}{l}\text { Having a } \\
\text { conversation with the } \\
\text { Vietnamese deputy } \\
\text { manager }\end{array}$ & & $\begin{array}{l}\text { To confirm a meeting } \\
\text { with a local commune } \\
\text { chairman. To get } \\
\text { directions to the location } \\
\text { of the meeting. }\end{array}$ & $\begin{array}{l}\text { Low } \\
\text { formality }\end{array}$ & $\begin{array}{c}\text { Manager to } \\
\text { deputy manager }\end{array}$ \\
\hline $\begin{array}{l}\text { Meeting the } \\
\text { mechanical engineer } \\
\text { in charge of the } \\
\text { workshop }\end{array}$ & & $\begin{array}{l}\text { To update the work } \\
\text { progress To allocate the } \\
\text { tasks of the day. }\end{array}$ & $\begin{array}{l}\text { Low } \\
\text { formality }\end{array}$ & $\begin{array}{l}\text { Manager to } \\
\text { mechanical } \\
\text { engineer }\end{array}$ \\
\hline $\begin{array}{l}\text { Meeting the } \\
\text { mechanical engineer } \\
\text { in charge of the water } \\
\text { treatment system }\end{array}$ & & $\begin{array}{l}\text { To update the work } \\
\text { progress To allocate the } \\
\text { tasks of the day. }\end{array}$ & $\begin{array}{l}\text { Low } \\
\text { formality }\end{array}$ & $\begin{array}{l}\text { Manager to } \\
\text { mechanical } \\
\text { engineer }\end{array}$ \\
\hline $\begin{array}{l}\text { Supervising the } \\
\text { workshop }\end{array}$ & & $\begin{array}{l}\text { To check the employees' } \\
\text { work progress. }\end{array}$ & $\begin{array}{c}\text { Low } \\
\text { formality }\end{array}$ & $\begin{array}{l}\text { Manager to } \\
\text { employees }\end{array}$ \\
\hline $\begin{array}{l}\text { Giving instructions } \\
\text { at the workshop }\end{array}$ & & $\begin{array}{l}\text { To instruct the } \\
\text { employees about how to } \\
\text { do the right job. }\end{array}$ & $\begin{array}{l}\text { Low } \\
\text { formality }\end{array}$ & $\begin{array}{l}\text { Manager to } \\
\text { mechanical } \\
\text { engineer and } \\
\text { workers }\end{array}$ \\
\hline $\begin{array}{l}\text { Meeting with the } \\
\text { board of directors }\end{array}$ & & $\begin{array}{l}\text { To report and discuss } \\
\text { professional issues. }\end{array}$ & $\begin{array}{c}\text { High } \\
\text { formality }\end{array}$ & $\begin{array}{l}\text { Manager to board } \\
\text { of directors }\end{array}$ \\
\hline
\end{tabular}

\subsubsection{Commentary on the snapshots}

The manager is engaged in different communicative events during the day that require the English language. Although the manager in the snapshot is not a native speaker of English, English is the language he uses to communicate with the engineers, workers, suppliers and the company's board of directors. Many of the workers could not understand English, so the mechanical engineers often interpret from English into Vietnamese for them. The manager knows some simple Vietnamese words only and he uses these to build and maintain social relationships with his workers, for example, greeting them in Vietnamese in the morning. He uses all four macro English language skills, but listening and speaking are used more frequently because meetings are one of his most frequent communicative events. 
He has meetings with the deputy manager, mechanical engineers, and technical workers. He visits the workshop and construction site to supervise the work progress and make sure that the allocated tasks are done properly by the employees. He also attends the meeting with the board of director. Another key communicative event in his working day is email communication. Most of these emails are about professional issues and communicates with foreign and local suppliers, the deputy manager and engineers. The remaining of the emails relate to management issues. So within the day the manager is communicating in English with different kinds of people for different purposes and using different types of English including informal, formal and English for technical communication. The tasks ranged from communication needs supported by visible items such as fixing the stairs of the tractor to more abstract and complex situations such as such as communicating with suppliers by email.

From the observation of his use of English, I can see that he uses English both to build solidarity with his employees and to use his power as a manager in the context of his job. A high degree of solidarity can be seen as he held many informal meetings with the engineers in a day. The working relationship between him and the deputy manager, the personal assistant and the key engineers who come to his office to report the work progress and receive new tasks for the day was an indication of solidarity and the ability to sustain effective relationships with each other at work. However, he sometimes showed his power as the manager when he was displeased with the employees' work. Then he shows he was angry in part by using directives, a high pitched voice, and repeating words for additional emphasis. The manager told me that that the tasks were not done properly due to the mechanical engineer's lack of English proficiency. The engineer misunderstood his requests and then asked the workers to do something else. The engineer did not perform the requested task himself. He assigned the workers to do it, and he supervised their performance. The manager's use of English and behaviour showed the power of his role to some extent. The engineer wanted to explain, but the manager continued saying that he had told him many times that he had to be careful and make sure that he understood the request.

\subsubsection{A working day of a mechanical engineer}

Suu, a mechanical engineer at the food producing company $(\mathrm{C} 1)$, worked as a supervisor of mechanical devices and assistant for the foreign engineering manager. In a normal working day, Suu had to use English frequently to function his job effectively. $\mathrm{He}$ was chosen to be included in the snapshot as he was one of the key mechanical engineers in 
the factory. He worked directly with the foreign manager, assist the manager to work with other engineers and workers in the factory. Suu's normal day of work closely matched with what other mechanical engineers reported in the interviews in terms of communicative events and English language skills required to carry out these events. His normal working day is tabulated in Table 20 below, followed by a snapshot described in a narrative form:

Table 20: Observed and reported communicative events and the required English language skills in a working day of the mechanical engineer

\begin{tabular}{|c|c|c|c|}
\hline \multicolumn{2}{|c|}{ Communicative events of the day } & \multirow{2}{*}{ Purposes of events } & \multirow{2}{*}{$\begin{array}{c}\text { English language } \\
\text { skills }\end{array}$} \\
\hline Observed & Reported & & \\
\hline $\begin{array}{l}\text { Greeting the } \\
\text { manager and } \\
\text { colleagues }\end{array}$ & & $\begin{array}{l}\text { To say hello to start the working } \\
\text { day. }\end{array}$ & Speaking \\
\hline $\begin{array}{l}\text { Having a short } \\
\text { meeting with the } \\
\text { foreign manager }\end{array}$ & $\begin{array}{l}\text { Having a short } \\
\text { meeting with the } \\
\text { foreign manager }\end{array}$ & $\begin{array}{l}\text { To report the pending issue(s) } \\
\text { (the problem of the motors) and } \\
\text { important arising issues to the } \\
\text { foreign manager. }\end{array}$ & $\begin{array}{l}\text { Speaking and } \\
\text { listening }\end{array}$ \\
\hline Checking email & Checking email & $\begin{array}{l}\text { To see if there are any urgent } \\
\text { tasks to be completed. }\end{array}$ & Reading \\
\hline $\begin{array}{l}\text { Writing an email } \\
\text { to the manager } \\
\text { and key staff in } \\
\text { the department }\end{array}$ & & $\begin{array}{l}\text { To inform the manager and staff } \\
\text { about the plan for testing the } \\
\text { machines. }\end{array}$ & Writing \\
\hline $\begin{array}{l}\text { Checking new } \\
\text { incoming email }\end{array}$ & $\begin{array}{l}\text { Receiving a task } \\
\text { from the manager } \\
\text { through email }\end{array}$ & $\begin{array}{l}\text { To follow up the pending issue, } \\
\text { schedule the time and inform } \\
\text { related people. }\end{array}$ & Reading \\
\hline $\begin{array}{l}\text { Reading daily } \\
\text { production reports }\end{array}$ & $\begin{array}{l}\text { Reading daily } \\
\text { production reports }\end{array}$ & $\begin{array}{l}\text { To understand the production } \\
\text { matters of the day. }\end{array}$ & Reading \\
\hline \multirow[t]{2}{*}{$\begin{array}{l}\text { Checking the } \\
\text { status of the } \\
\text { mechanical } \\
\text { devices and } \\
\text { reporting their } \\
\text { status to the } \\
\text { foreign manager } \\
\text { orally }\end{array}$} & & $\begin{array}{l}\text { To update the work progress and } \\
\text { give tasks of the day. }\end{array}$ & $\begin{array}{l}\text { Reading } \\
\text { Speaking }\end{array}$ \\
\hline & $\begin{array}{l}\text { Reporting the } \\
\text { status of the } \\
\text { working machines } \\
\text { to the foreign } \\
\text { manager via email }\end{array}$ & $\begin{array}{l}\text { To report the status of the } \\
\text { machines and machinery } \\
\text { devices. }\end{array}$ & Speaking \\
\hline \multirow[t]{2}{*}{$\begin{array}{l}\text { Making the plan } \\
\text { for testing the } \\
\text { machines and } \\
\text { emailing it to the } \\
\text { manager and } \\
\text { assigned staff }\end{array}$} & $\begin{array}{l}\text { Making the plan } \\
\text { for testing the } \\
\text { machines and } \\
\text { emailing it to the } \\
\text { manager and } \\
\text { assigned staff }\end{array}$ & $\begin{array}{l}\text { To send working plans to the } \\
\text { people in charge of } \\
\text { implementing those plans. }\end{array}$ & Writing \\
\hline & $\begin{array}{l}\text { Making technical } \\
\text { drawings }\end{array}$ & $\begin{array}{l}\text { To visually communicate how } \\
\text { something functions or is } \\
\text { constructed. }\end{array}$ & Writing \\
\hline
\end{tabular}




\begin{tabular}{|l|l|l|c|}
\hline & $\begin{array}{l}\text { Making proposals } \\
\text { for expenses }\end{array}$ & $\begin{array}{l}\text { To report to the manager for } \\
\text { approval. }\end{array}$ & Writing \\
\hline & $\begin{array}{l}\text { Translating } \\
\text { technical } \\
\text { documents from } \\
\begin{array}{l}\text { English } \\
\text { Vietnamese }\end{array}\end{array}$ & $\begin{array}{l}\text { To help engineers and workers } \\
\text { who lacked English to } \\
\text { understand the documents. }\end{array}$ & $\begin{array}{l}\text { Reading and } \\
\text { writing }\end{array}$ \\
\hline $\begin{array}{l}\text { Monitoring the } \\
\text { conditions of the } \\
\text { mechanical } \\
\text { devices }\end{array}$ & $\begin{array}{l}\text { Reporting to the } \\
\text { manager and other } \\
\text { departments orally } \\
\text { or in short written } \\
\text { technical reports } \\
\text { about the } \\
\text { problems with the } \\
\text { machines or } \\
\text { devices }\end{array}$ & $\begin{array}{l}\text { To keep the manager update of } \\
\text { the situation and discuss the } \\
\text { arising issues if there are. }\end{array}$ & Reading \\
\hline
\end{tabular}

\subsubsection{Snapshot: Overview of the day for the mechanical engineer as a narrative}

Suu graduated from a university of technology in the north of Vietnam, having majored in manufacturing engineering. At university, he learned general English only. $\mathrm{He}$ did not take the ESP course in mechanical engineering. He said that this was a disadvantage for him when he started working in the company. He told me that he had to learn technical English himself. He has been working in this company for more than six years, and for four years as the engineering manager's assistant. He was required to use English in his work as his department manager was a foreigner, and all documents in the company were mostly in English.

Suu arrived at his office at $7.30 \mathrm{am}$. The office was big and was divided into ten work stations. The manager and other engineers worked in the same office with him. The manager's work station was in the left corner of the office which was behind Suu's. When he came, the manager was working at his desk, and two other engineers were working at their work stations, too. He said hello to his colleagues and the foreign engineering manager in English. His colleagues and the manager said hello to him as an exchange.

When he saw me there, he said "chào anh" (hello) to me. The manager also said "hello" to Suu and introduced me to him using a mixture of English and Vietnamese, "This is anh Tinh" (This is Mr. Tinh). I said "nice to meet you" to him and shook his hand. The way they exchanged the greeting was friendly and informal. Right after that, they started their working day in an informal way. The manager sat down at his work station and asked 
Suu about the motors. This was not a scheduled meeting but a short report in the morning for five minutes. Suu told me that every day he came to the office first and if he had anything to report to the manager, he did it first. Vice versa, if the manager wanted to ask something, he asked Suu, because Suu was his assistant. The conversation took place at their work stations.

The problem of the motor had been a recurring one for several days that affected the department work progress and needed to be dealt with as soon as possible before the production season begun in October. Suu stood up by his work station and had the conversation with his manager. The manager thought they had seven motors, but Suu reported that they had six at the moment because one was broken. He told the manager that of these six motors, four were working well and the other two could not operate and needed repairing. He reported the time it took to repair, and the manager told him to buy new ones if necessary. The factory was in a maintenance period and the production season was coming soon. The manager told Suu that all the electric motors needed to be ready for work. Below is an extract from their conversation:

Example 6.3

1 Manager: We have total seven motors?

2 Suu: $\quad$ Not seven, now only six.

3 Manager: One already broken, so you only have six motors

$4 \quad$ and you already sent one motor for repair?

5 Suu: $\quad$ Uhm. Because now we have four good motors, two cannot operate

6 so we have to send to repair.

7 Manager: Uhm. So you have one motor broken, two need repair.

$8 \quad$ You repair or buy new motors?

$9 \quad$ Keep an eye on this and if we need we buy new motors.

10 Suu: I not have enough time because it takes two weeks.

11Manager: To buy or repair?

12 Suu: To repair.

13 Manager: Why it took long time to repair?

$14 \quad$ But last time you go to XXX, you have checked with them?

15 Suu: $\quad$ No, because it far from XXX and we have no car.

16 Manager: Uhm. So what we will do to replace?

17 Suu: We make already.

18 Manager: Make a motor request to buy a new one.

19 Suu: $\quad$ Buying a new motor is more than three millions (Vietnamese Dong).

20 Manager: Ok. So you give me the feedback who you want to nominate

21 and I will send to the factory.

22 Suu: $\quad$ Ok.

The manager came to the conclusion that because it took so long to repair the old motors, they would buy new ones instead. He asked the mechanical engineer to nominate the supplier, and he would report to the factory for approval. 
After reporting the status of the motors to the manager, Suu sat down at his work station and logged on to his computer to check emails. There was a PC, a printer, and several document files on his working desk. He told me that he needed to check emails to know if there were any urgent tasks to be completed. First, he emailed the key staff in the department and carbon copied to the manager about the plan for testing the Tippler and Spotter machines with all the bins (Tippler is a machine used to unload goods and Spotter is used to push the wagon). Ten minutes later, he received the reply from the manager about the problems with the Tippler and Spotter. He was asked to follow-up this issue and set the date and time, and informed others to do the work. All the recipients of the emails were asked to nominate the person-in-charge to complete the job. Suu told me that he read and checked about ten emails per day and most of these were in English. He communicated via email with his foreign manager, other departments in the company, and business partners to discuss the technical issues. Most of the time, the recipients included the foreign manager, so English was used.

Next, Suu read the daily production reports to know the production matters of that day. The report presented information about particulars (items), the number of products of the current season compared with last season, the time account and the product analyses. It also had a section for remarks.

After reading these reports, he left the office for the production department, as he wanted to know the status of the mechanical devices in progress to report to his foreign engineering manager. When he came back to the office, he met the manager and reported orally to him that all machines were working well. He told me that sometimes he had to report via emails. Then, he sat down at his work station to do the paper work to assist the manager. He made the plan for testing the Tippler and Spotter on Friday and then emailed the plan to the assigned staff and carbon copied to the manager. He told me that his work as an assistant consisted of making technical drawings, making proposals of expenses, translating technical documents from English into Vietnamese to support their work, especially for the workers to read and understand the instructions and function of the machines and machinery parts, and assisting other departments to deal with any problems that arose.

After that, Suu joined the technical team to monitor the condition of all the mechanical devices. He and two other engineers visited the factory to check the machinery system. They used a measuring and testing instrument to collect the data. He told me that they collected the data in a week and then analysed them to assess the status of the machines. 
If the machines or any machinery parts broke down, they had to report to the manager and other departments orally or by short written technical reports in English.

Finally, he returned to his office, tidying up his work station and checking out to finish his working day.

From the above narrative snapshot, it is clear that in engaging the communicative events of a normal working day, Suu used different types of English language to communicate with different kinds people as presented in the following table, followed by a brief commentary on the snapshot:

Table 21: Observed and reported communicative events, formality and code sharing in a working day of the mechanical engineer

\begin{tabular}{|c|c|c|c|c|}
\hline \multicolumn{2}{|c|}{ Communicative events of the day } & \multirow[t]{2}{*}{ Purposes of the events } & \multirow{2}{*}{$\begin{array}{l}\text { Degree of } \\
\text { formality }\end{array}$} & \multirow[t]{2}{*}{ Relationship } \\
\hline Observed & Reported & & & \\
\hline $\begin{array}{lr}\text { Greeting } & \text { the } \\
\text { manager } & \text { and } \\
\text { colleagues } & \end{array}$ & & $\begin{array}{l}\text { To say hello to start the } \\
\text { working day. }\end{array}$ & Low formality & $\begin{array}{l}\text { Colleague to } \\
\text { colleague }\end{array}$ \\
\hline $\begin{array}{l}\text { Having a short } \\
\text { meeting with the } \\
\text { foreign manager }\end{array}$ & $\begin{array}{l}\text { Having a short } \\
\text { meeting with the } \\
\text { foreign manager }\end{array}$ & $\begin{array}{l}\text { To report the pending } \\
\text { issue(s) (the problem of } \\
\text { the motors) and } \\
\text { important arising issues } \\
\text { to the foreign manager. }\end{array}$ & Low formality & $\begin{array}{l}\text { Engineer to } \\
\text { manager }\end{array}$ \\
\hline Checking email & Checking email & $\begin{array}{l}\text { To see if there are any } \\
\text { urgent tasks to be } \\
\text { completed. }\end{array}$ & N/A & Engineer \\
\hline $\begin{array}{l}\text { Writing an email } \\
\text { to the manager } \\
\text { and key staff in } \\
\text { the department }\end{array}$ & & $\begin{array}{l}\text { To inform the manager } \\
\text { and staff about the plan } \\
\text { for testing the } \\
\text { machines. }\end{array}$ & High formality & $\begin{array}{l}\text { Engineer to } \\
\text { manager and } \\
\text { colleagues }\end{array}$ \\
\hline $\begin{array}{l}\text { Checking new } \\
\text { incoming email }\end{array}$ & $\begin{array}{l}\text { Receiving a task } \\
\text { from the } \\
\text { manager through } \\
\text { email }\end{array}$ & $\begin{array}{l}\text { To follow up the } \\
\text { pending issue, schedule } \\
\text { the time and inform } \\
\text { related people. }\end{array}$ & $\begin{array}{l}\text { High and low } \\
\text { formality }\end{array}$ & $\begin{array}{l}\text { Manager to } \\
\text { engineer }\end{array}$ \\
\hline $\begin{array}{l}\text { Reading daily } \\
\text { production } \\
\text { reports }\end{array}$ & $\begin{array}{l}\text { Reading daily } \\
\text { production } \\
\text { reports }\end{array}$ & $\begin{array}{l}\text { To understand the } \\
\text { production matters of } \\
\text { the day. }\end{array}$ & High formality & Engineer \\
\hline \multirow{2}{*}{$\begin{array}{l}\text { Checking the } \\
\text { status of the } \\
\text { machinery } \\
\text { devices and } \\
\text { reporting their } \\
\text { status to the } \\
\text { foreign manager } \\
\text { orally }\end{array}$} & & $\begin{array}{l}\text { To update the work } \\
\text { progress and give tasks } \\
\text { of the day. }\end{array}$ & & $\begin{array}{l}\text { Engineer to } \\
\text { manager }\end{array}$ \\
\hline & $\begin{array}{l}\text { Reporting the } \\
\text { status of the } \\
\text { working } \\
\text { machines to the } \\
\text { foreign manager } \\
\text { via email }\end{array}$ & $\begin{array}{l}\text { To report the status of } \\
\text { the machines and } \\
\text { machinery devices. }\end{array}$ & High formality & $\begin{array}{l}\text { Engineer to } \\
\text { manager }\end{array}$ \\
\hline
\end{tabular}




\begin{tabular}{|c|c|c|c|c|}
\hline \multirow[t]{4}{*}{$\begin{array}{l}\text { Making the plan } \\
\text { for testing the } \\
\text { machines and } \\
\text { emailing it to the } \\
\text { manager and } \\
\text { assigned staff }\end{array}$} & $\begin{array}{l}\text { Making the plan } \\
\text { for testing the } \\
\text { machines and } \\
\text { emailing it to the } \\
\text { manager and } \\
\text { assigned staff }\end{array}$ & $\begin{array}{l}\text { To send working plans } \\
\text { to the people in charge } \\
\text { of implementing those } \\
\text { plans. }\end{array}$ & High formality & $\begin{array}{l}\text { Engineer to } \\
\text { manager and } \\
\text { colleagues }\end{array}$ \\
\hline & $\begin{array}{l}\text { Making technical } \\
\text { drawings }\end{array}$ & $\begin{array}{l}\text { To visually } \\
\text { communicate how } \\
\text { something functions or } \\
\text { is constructed. }\end{array}$ & $\begin{array}{l}\text { High and low } \\
\text { formality }\end{array}$ & engineer \\
\hline & $\begin{array}{l}\text { Making } \\
\text { proposals for } \\
\text { expenses }\end{array}$ & $\begin{array}{l}\text { To report to the } \\
\text { manager for approval. }\end{array}$ & $\begin{array}{l}\text { High and low } \\
\text { formality }\end{array}$ & $\begin{array}{l}\text { Engineer to } \\
\text { manager }\end{array}$ \\
\hline & $\begin{array}{l}\text { Translating } \\
\text { technical } \\
\text { documents from } \\
\text { English to } \\
\text { Vietnamese }\end{array}$ & $\begin{array}{l}\text { To help engineers and } \\
\text { workers who lacked } \\
\text { English to understand } \\
\text { the documents. }\end{array}$ & $\begin{array}{l}\text { High and low } \\
\text { formality }\end{array}$ & $\begin{array}{l}\text { Engineer to } \\
\text { colleagues } \\
\text { and workers }\end{array}$ \\
\hline \multirow[t]{2}{*}{$\begin{array}{l}\text { Monitoring the } \\
\text { conditions of the } \\
\text { mechanical } \\
\text { devices }\end{array}$} & & $\begin{array}{l}\text { To collect data by using } \\
\text { an instrument to } \\
\text { measure and test the } \\
\text { devices. }\end{array}$ & N/A & Engineer \\
\hline & $\begin{array}{l}\text { Reporting to the } \\
\text { manager and } \\
\text { other } \\
\text { departments } \\
\text { orally or in short } \\
\text { written technical } \\
\text { reports about the } \\
\text { problems with } \\
\text { the machines or } \\
\text { devices }\end{array}$ & $\begin{array}{l}\text { To keep the manager } \\
\text { update of the situation } \\
\text { and discuss the arising } \\
\text { issues if there are. }\end{array}$ & Low formality & $\begin{array}{l}\text { Engineer to } \\
\text { manager }\end{array}$ \\
\hline
\end{tabular}

\subsubsection{Commentary on the snapshot}

The working day of this mechanical engineer required him to engage in several communicative events that required both spoken and written English language skills. $\mathrm{He}$ worked directly with the foreign manager and other key mechanical engineers. He has to use all the four macro English language skills: listening, speaking, reading and writing. Of these speaking and reading skills are used more frequently. Speaking and listening skills were required in his daily work communication, listening to understand the foreign manager's requests and instructions and speaking skills to report work progress as well as discuss workrelated issues with the foreign manager. Reading skills were required for such communicative events such as reading emails, technical reports, and documents. In face to face spoken communication, he seemed to use more informal English, and this was consistent with findings from the survey questionnaire, semi-structured interview, and observation of other mechanical engineers' working days. The use of more informal English 
could be an indication of a low degree of formality which can be built after a long period working together. There was obvious evidence of high solidarity between the mechanical engineer and his foreign manager shown in the way they talked and behaved. The mechanical engineer's use of English became more sophisticated when he was engaged in email communication as this communicative event that required more formal written English. The switch between informal and formal English, spoken and written communication showed the complex communication needs in the context of this mechanical engineer's work.

\subsubsection{Summary of the snapshots}

From both the tables and the narratives of the working days of the manager and the mechanical engineer, it becomes clear that the English language requirements in the working day of each are complex. Both the manager and the mechanical engineer had to switch between formality and informality many times in a day for different purposes and sometimes they required more colloquial English for communication between different sorts of people at different times and places. It should be noted that all the observed speakers were not native speakers of English but came from different countries and cultures and that their knowledge of the power relationship and hierarchy in a Vietnamese workplace might be different.

Although the snapshots have limitations as they described only one observation of each participant, they show some pictures of English use in the workplace to some extent. They give an insight into the English communication needs of a mechanical engineer professional. As for the manager, the communicative events require more speaking and listening because he often works face-to-face with the employees. He can communicate in English with some engineers on his own and seek help from his personal assistant or engineers who have good English ability. Thus, mechanical engineers sometimes function as an interpreter to interpret English into Vietnamese for other people to understand the foreign manager's requests and instructions and vice versa. This is consistent with the managers' report in the interview that they often meet in person with their mechanical engineers and workers to assign tasks and discuss work issues as well as to listen to their report of the work progress. The mechanical engineer, besides the use of listening and speaking skills to communicate face-to-face with the foreign manager, need to use reading and speaking frequently to fulfil the tasks of the working day such as reporting work progress or outcomes via emails, writing technical reports, reading emails and technical reports, and reading and translating technical documents from English into Vietnamese. These findings are consistent with the questionnaire and interview. More careful and detailed analysis of 
the notes from the observations reveals the key facts of real-world uses of English required by the mechanical engineers have been presented earlier in the chapter and are also presented in Chapter Seven in relation to the social dimensions of the use of English. They give insight into what it means in practice to work in a plurilingual and pluricultural workplace.

\subsection{Chapter Summary}

This second findings chapter answers the first sub question, which asks what kinds of real-world English skills are required by Vietnamese mechanical engineers to function effectively in the workplace. These include the various contexts for English uses in numerous communicative events required by mechanical engineers. English listening and speaking were the most frequently used skills, followed by reading and writing skills. The findings then include some detail of the communicative events that required specific English language skills so that mechanical engineers could function effectively in their work context. The chapter aims to show the general overview of the English communication needs of mechanical engineers in different workplaces in Vietnam. The questionnaire findings were deepened by results from the semi-structured interviews about the real-world English skills required by the mechanical engineers in the workplaces under investigation. It started with the contexts for English uses in the workplace, then presented the list of communicative events identified in the interviews in compared with those in the observations. The section on the interview findings continued to describe the work-related English language skills and the types of English required by mechanical engineers to function effectively in their jobs.

Finally, the chapter has presented the most authentic data from the observations which show a detailed picture of the English communication needs of mechanical engineers in the context of their workplace. This included the information about the workplace setting, the communicative events that the mechanical engineers were engaged in, the work related English language skills, the interactive uses of English and adaptive communicative activities, and the English vocabulary in use. The snapshots were presented at the end of the chapter to give an insight into a 'day-in-the-life' of the professionals in the domain. This was also aimed as a bridge to link to the following chapter about the social dimensions of the English uses in the workplace. 


\section{CHAPTER SEVEN: SOCIAL DIMENSIONS OF THE USE OF ENGLISH IN THE WORKPLACE}

\subsection{Introduction}

This chapter provides answers to sub-question 2: "What social factors and social dimensions affect mechanical engineers' use of English in their workplace and how do these affect this use of English?" and sub-question 3: "Where and when do breakdowns or other issues in communication occur and what are the effects of these issues?"

\subsection{Social Factors and Social Dimensions}

This section examines social factors and dimensions that could affect mechanical engineers' language use in the workplaces in which the study was conducted. Social dimensions such as politeness strategies and formality, humour and power relationships were considered to see how they affected mechanical engineers' uses of English in the Vietnamese workplace context.

As the analysis of the data proceeded it became clear how important the analysis of typical patterns of workplace discourses emerging in the observations would be to understanding the language required of mechanical engineers. According to Koester (2010), workplace discourses consist of interactions occurring across a wide range of occupational settings such as factories, offices, hospitals, governments, the private sector and non-profit organisations. In the context of my study, these interactions include company meetings, group meetings, office talk, construction site communication and contract (project) bidding ceremonies. There are different approaches to studying workplace discourse because it is situated in sociology, anthropology and linguistics, and various methods which have been employed in investigating workplace discourse, such as ethnography, conversation analysis, genre analysis, interactional sociolinguistics and critical discourse analysis (Koester, 2010). Based on what emerged in the data from the thematic analysis it became clear that the social dimensions which are realised in the workplace discourse would need to be considered to at least a certain extent from a sociological perspective where social relationships and social interactions are examined (Calhoun, 2002).

The chapter presents findings from each source of data collection to answer the two sub-questions. A summary of the questionnaire data presented in Chapter Five is first presented, then the findings from the semi-structured interviews and more details from 
observations of four meetings. The main events in three of these meetings have already been presented in Chapter Six. In this chapter the focus is on the key themes emerged in the data analysis including politeness strategies, formality and informality, use of humour and use of language to 'do power' from the style provided by the Language in the Workplace Project (LWP). Two of these examples involve observed issues or problems in communication and provide an opportunity to consider the language used when communication issues occur. In other words, the findings to these two questions sometimes intersect and are interesting to consider in relationship to each other. Issues or problems in communication and managers' responses to them tended to reveal underlying power relationships in sometimes stronger ways than formality and informality.

The analysis of data in the LWP provides one model for the analysis in this chapter. This approach enables a consideration of the social context of the interactions of the mechanical engineers and their managers as well as the direct use of language. A key difference in this study in comparison with the LWP is that this study takes place in a lingua franca, plurilingual and pluricultural environment and English is not the first language for any of the participants, Vietnamese workers and foreign managers alike. Some of the normal patterns of rules of politeness strategies apply differently in a context where minimal knowledge of English is required in order to 'get things done'.

\subsubsection{Summary of the questionnaire data}

Some strong findings about formality and informality and breakdowns in communication emerged from the survey data, particularly the written responses in the questionnaire data.

Mechanical engineers and their managers were strongly aware of the need to use more formal English with managers and foreign company representatives, and this might have been expected. What was less expected was that both engineers and their managers described being strategic about using less formal language with and among workers in the worksites in order to build workplace solidarity. Informality in language use also emerged as a strategy to avoid communication issues. These are among key findings of this study.

\subsubsection{Degrees of formality reported in the semi-structured interviews}

The issue of formality and informality did not emerge very strongly in the interviews. When it did emerge it was sometimes related to the potential for communication issues or avoiding such issues. The following themes emerged: 


\subsubsection{The use of formal and standard written English}

In the interviews, some managers said that their mechanical engineers who had good enough English ability were able to use both formal and informal English in communication with the management and business partners. They had more choices in using English depending on the situation. For mechanical engineers who had better English ability, especially those who had to use more writing skills, formal English was required. The mechanical engineers' writing skills needed to follow standard English such as that taught in textbooks more closely. Below is a quote from Ty's interview:

The need for writing skills depends on each position. If mechanical engineers who only work in the workshop, they do not need writing skills. For those who are in charge of spare parts a lot of written English was used in email communication with the suppliers (Ty-M-C2).

According to Than, one of the mechanical engineers at the motorbike company, their choice of the type of English depended on the purpose and context of communication. In face-to-face communication, they used informal English, but formal English was used in writing such as emails and reports. He stated:

We usually use informal English when speaking and formal English when writing (ThanME-C3).

It can be explained that in face-to-face communication, mechanical engineers could understand and make themselves understood by using other paralinguistic features such as body language, gestures and facial expressions. Also, the foreign managers were aware of their engineers' English ability and tended to accept the impoliteness in the engineers' uses of English. In his explanation of the use of English writing skills, Hoi said that the writing should follow writing rules, such as format and style as well as the use of grammar structures and vocabulary. This was because of the importance of the writing contents such as ordering spare parts, negotiating prices, and querying about technical issues. It was also because of the people who received or read the written communication were foreign managers, business partners or clients. Thus, Hoi raised the importance of preparing different writing styles to support the students' future jobs. He insisted that being accurate in writing meant fewer possibilities of making mistakes and causing misunderstandings. He said:

Writing should be accurate to avoid misunderstandings. Students should prepare different writing styles such as report writing, email writing, etc. (Hoi-ME-C4).

There are more examples explaining the reasons for using formal written English in the interviews. This refers to social status and power relationships, which are presented in Section 6.3 of the observation data and in more depth later in this chapter. 


\subsubsection{Simplifying the use of English}

As also seen in the written answers to the survey, in the interviews, some managers said that they had to simplify their English to make it easier for the staff to understand. They further stressed that it was important to know who they were talking to and how much English that person could understand.

When you are in a workshop, you cannot use a very difficult language that only [a] few people can understand. It is not worth to speaking formal English but no one can understand you (M-Mui-C3).

Mui's perception showed that he understood his employees and was aware of their English ability. It also indicated that the purpose of understanding communication was very important in the workplace. It seemed that the managers had a good understanding about their engineers. They were aware of who the engineers were, what English level they had and knew what to speak to be understood. This result revealed a good relationship between the managers and their employees, and the low degree of formality lead to a higher degree of solidarity in the company's work relationships.

\subsubsection{Showing politeness, formality and informality}

In the interviews, participants, especially the mechanical engineers, perceived the importance of showing politeness to foreign managers, supervisors and suppliers. As there were different settings and communicative events identified in the interviews (see Sections 5.3 and 5.4), depending on each situation, mechanical engineers described requiring different types of English, such as formal, informal, and colloquial English, English for technical communication and a combination of English and Vietnamese.

The need for a high degree of formality was shown in a description of the type of English used by Dan, one of the mechanical engineers at the motorbike company. He was aware of the necessity of using more formal English when communicating with people of a higher status than him.

When I communicate with someone who has a higher position than me, I have to use the kinds of English that show my respect, such as formal English (sir/madam; I would like to report an issue...) (Dan-ME-C3).

Such words like "sir", "madam" and the structure "would like" are indications of a high degree of formality in the workplace communication. Though these words are simple and can be used easily, they convey the speakers' awareness of showing respect to the listener and their confidence in communication. 
Some of the mechanical engineers were conscious that they could only adapt their use of English to match the context when their English ability allowed them to do so. Those who had good enough English ability had more choices in their use of English and so had more power in communication, the kind of expert power which will be described in more detail later in the chapter. For example, according to Chuot, one of the Vietnamese managers at the food producing company, mechanical engineers used formal English not only to show respect to their managers but also to get the managers' attention. They had the opportunity to show their ability and make a strong impression on the managers because the findings showed that these engineers had a better voice in their workplace compared with those who lacked English proficiency.

When they communicate with their management such as the General Director, they will try to be more polite and formal. They want to show respect and be nice in the eye of their boss (Chuot-M-C1).

Being able to use formal English means that they could show the managers their English ability and could be promoted to a better position such as supervisor. I was told that English was not only the requirement but also an important condition to gain a better salary and promotion which are great incentives for employees.

Skills from the domain of pragmatics such as the ability to make 'small talk' also improved communication and so increased workplace solidarity.

I am much closer to the supervisors who speak English than those who don't. It is easier for me to have small talk (how are you? How is your wife, children?) (Mike-M-C2).

From Mike's observation, it could be inferred that English was a bridge to connect the foreign managers and local engineers. It was English language that brought them closer with each other not only inside but also outside the workplace. Communication in English in general and formal English in particular brought an advantage to the local engineers, that is, it is a way of learning and practising their English as reported by some mechanical engineer participants.

I mostly use English with our managers, kind of formal English. I would like to improve my English to support my work progress and promotion (Ngo-ME-C2).

From Ngo's point of view, using English including formal English to communicate with the managers could help him learn English better. Once his English was better, he would be able to perform his work more effectively and more importantly he would have the opportunity of being promoted. 
However, because of limited English ability, most of the mechanical engineers said they did not care about the issue of formality in communication. They just tried their best to convey the meaning of their speech by using any English words that they had. Some participants said that they did not have another choice due to their English ability.

We usually use polite and formal language in writing. When speaking, we use informal English. In short, these factors do affect but not much to change of the kind of English that we use because of our English ability (Than-ME-C3).

In this case, it is the English ability that affected the degrees of politeness and formality in their communication. Once they used such forms of English as informal and colloquial English, word-by-word communication and body language, they were lowering the degree of formality in their communication.

Social status was reported to affect the degrees of politeness and formality in the type of English mechanical engineers used with colleagues or staff of the same position.

There is a difference in the use of English when we communicate with people of higher position. We usually use formal English. However, with colleagues and staff of the same position, we use informal English which is more flexible (Suu-ME-C1).

Instead of using formal English, Suu said that he and his colleagues used informal English to communicate with each other. This aligns with the survey data on the strategic use of informal language. The reason for this was because the mechanical engineers wanted their communication to be flexible, non-distant and more comfortable. This made their working environment friendlier and everyone had a closer relationship. In this case there was a low degree of formality among them.

Mechanical engineers sometimes strategically used informal English with foreign experts because they just wanted to be understood easily. They did not care much about politeness and formality. They cared more about understanding and time-saving.

When they communicate with the experts in their section or other sections, they still use informal and colloquial English to save time and to make it easier to be understood (Ty-M$\mathrm{C} 2)$.

As described in the previous chapter most of the mechanical engineers had to struggle to communicate in English, so using informal English and very Basic English were their strategies. They had to struggle to understand and be understood. They wanted to be proficient in English to support their work but, because of their limited English ability, they had to use every English word that they knew to express what they wanted to say. This is a reason why one of the foreign managers stated that his engineers had to try hard to 
communicate with him.

They use every English word that they know to talk with me (Mao-M-C2).

Based on what he said, it seemed that there was no power distance between him and the employees. They both cared about understanding each other to support the company's work.

\subsubsection{The potential for misunderstanding caused by limited English}

This section reports data from the interviews about the potential for misunderstanding caused by limited English. This theme will be returned to more strongly in relation to the observation data (in 7.3. below). A strong theme that emerged from the interviews was that a limited ability to use English listening and speaking skills brought about the potential of misunderstandings in communication and communication issues similar to those described by Kaewpet (2009a) and McKenzie and Qazi (1983). According to Tuat, the director of the construction building company, his mechanical engineers needed English to join bidding projects. They were required to listen to and understand the proposals from other companies, to be able to present their proposal fluently and their presentation had to be clearly understood by others. They had to address any questions or concerns from the project owner or investor. Even when they were working on the construction site, if they had any ideas, they were required to be able to present their ideas and explain in detail to persuade their business partner's site manager or supervisor to approve the ideas. Tuat explained the importance of these communication skills in his interview:

And when you want to communicate with your partner but you cannot make it clear, cannot explain to them to help them understand, they will not approve your solution to carry out the work. Therefore listening and speaking are the two most important skills (Tuat-M-C4).

Tuat claimed that in business communication, poor English speaking skills might result in the failure of bidding for contracts, trading or daily work at the construction site. If the mechanical engineers could not prove their solution to be the best choice to the foreign site manager or supervisor, their team would not be approved to conduct the work. Thus they were required to have sufficient listening and speaking skills to perform their work effectively.

Mike, one of the foreign managers at the dairy company, said that he had to do most of the communication with the business partners and suppliers himself because he wanted to make sure that the company could buy the correct spare parts that they needed. He said: 
Today I am doing it myself because I am not sure for $100 \%$ that I can get the correct spare parts after paying thousands of dollars for them. This doesn't mean that my men don't know. This is because of misunderstanding between two parties.

He further stated that his mechanical engineers not only made mistakes in speaking but also in writing, especially writing emails.

Even when they send me emails in English, sometimes they write in English with so many mistakes that I don't understand the meaning of the main points.

Buying the wrong spare part was described as a disaster because of its consequences, such as time consumption and financial loss due to a pause in production. One of the reasons leading to this mistake was because of poor English for technical communication. Mike said that his mechanical engineers had to communicate with the suppliers to ask for a quote of the price and delivery time, for example. In return the supplier would ask them questions about the cause of the problem leading to the breakage of a specific spare part, what they should do to prevent that problem next time, and how to check it. These seemed to be very simple questions, but for his mechanical engineers he said it was like they were speaking "German". He used speaking "German" as a metaphor to mean that something very difficult or impossible. He further reported that when his engineers did not understand the questions, they used Google translation, which was not always correct. This led to misunderstanding and became a problem.

These technical questions are in technical English and they don't understand. They don't know how to answer. They start to[get] confuse[d] and put this line into that line and use Google to translate. The problem is that Google doesn't always translate the same and they don't understand the suppliers. This will be a big mess and a disaster for me to buy the wrong spare part (Mike-M-C2).

A low level of English skill could negatively affect mechanical engineers' ability in understanding instructions from foreign managers and supervisors, as well as the ability to present their ideas or respond to any questions.

If their listening and speaking skills are poor, they will not understand the foreign experts' instructions or present their ideas (Ty-M-C2).

The participants described the frequency of their use of English listening and speaking skills as daily, and particularly in daily meetings.

According to Hoi, one of the mechanical engineers of $\mathrm{C} 4$, listening was the most important skill as it helped him and his colleagues understand other people's messages in communication so that they could avoid making mistakes. The managers gave very precise 
instructions or directions and it was essential that these were understood by the engineers in order for the engineers to function effectively.

To perform your work effectively, you need all four skills. However, I think listening is the most important because if you can listen and understand what other people say, you can record them so that you know what to do, what they want and can avoid making mistakes (Hoi-ME-C4).

It can be inferred that the better English speaking and listening skills the participant possessed, the fewer mistakes they probably made. All the points emerging from the questionnaires and interviews become more vivid when seen in the observation data.

\subsubsection{Degrees of formality reported in observations}

In the observations, a certain degree of formality was observed in one of the regular morning meetings of the motorbike company, while a high degree of formality was observed in the formal meeting between the foreign head contractor and the representatives of the building construction company which joined the project as one of the sub-contractors.

\subsubsection{High degree of formality}

A mixture of formality and informality was observed in the long meeting described in Section 6.3.3 of Chapter Six. The meeting was about key issues of the department. The manager's use of English was both formal and informal. It was formal because of the manager's and engineers' preparation from the meeting place to the meeting contents and equipment needed, such as a laptop and projector. There was a degree of formality in the dress codes. It was easy to identify who the manager or leader was based on the way they dressed. If mechanical engineers had to wear white uniforms at work, their manager dressed casually. Formality was also seen in the arrangements for seating. The manager sat up in front and the mechanical engineers sat along the two sides of the table. Throughout the meeting, the manager used both formal and informal English. It was formal when he said "I would like you to follow these priorities in a circle", "please follow the item[s] one by one" and "we have been discussing about this project". Since he was the chairman of the meeting, he directed everything. He talked a great deal and this showed his role as the manager. He used many key technical words, including some academic words (issue, research, assembly). He used directives ("we have to update information", "keep updating information and feedback from the supplier"), which showed his status as the manager and the person who chaired the meeting. This resulted in a high level of formality between him and the employees.

The higher degree of formality was particularly observed in the formal meeting (see 
Section 6.3.3) in terms of physical setting as well as the language used in the meeting.

The setting of this meeting itself revealed the degree of formality. The meeting room was very bright with many electric bulbs and was cooled by two air conditioners. The tables and chairs were new and set out in a rectangle shape. The chairman sat in the front where he could observe everyone easily. There was a whiteboard behind the chairman so that he could illustrate and write down the key issues of the meeting. All the attendees had to wear the uniforms of the construction site with helmets and boots, even with the company's name printed on their uniforms. Also, the atmosphere of the meeting was different from those in my previous observations of other meetings. When the chairman started the meeting, people stopped their small talk and discussions. No mobile phones rang during the meeting. The degree of formality was more obvious in the kind of English that was used in the meeting. The chairman used formal English such as "Excuse me, can we start now?", "Can I have the report from XYZ, please?". In response to the chairman's speech, the representatives of the subcontractors used quite formal English in their reports too, such as "I would like to report our company today and tomorrow work plan", "We will start executing at Gate 4, Point G" and "Thank you".

\subsubsection{Low degree of formality}

But there was also significant evidence of a low degree of formality observed throughout some meetings too. Evidence of this informality included using the cell phones in the meeting, and the workers discussing the problems in Vietnamese (see the description of the morning meeting in Section 6.3.3 of Chapter Six).

In the morning meeting, the foreign manager also used linguistic and pragmatic devices such as modal verbs (for example, "so we can close") or rising intonation (for example, "You remember or not remember?") to mitigate the directness of his speech. This seemed to show a low degree of formality related to a higher solidarity relationship.

There was a strong indication of a low degree of formality observed in mechanical engineers' working days, especially those who worked in the food producing company and the dairy company. Most of the mechanical engineers were observed communicating in English with their managers in an informal way because of their limited English ability. They spoke in any style that they could do to avoid communication issues. This can be seen as a kind of unintended impoliteness (Holmes et al., 2008). A majority struggled to communicate and used adaptive communicative activities, as has been presented in Section 6.3.4 of Chapter Six. 


\subsubsection{Humour in the workplace, informality and high solidarity}

Humour is reported here, thanks to data from workplace observations. It emerged in the findings of this study unexpectedly but showed its important role in language use in the workplace. It was found not only in workplace interactions among Vietnamese mechanical engineers, but also between them and the foreign managers, especially in workplace meetings.

\subsubsection{Humour promotes hilarity and harmony}

In the observed morning meeting at the motorbike company, humour was recorded happening at least twice throughout the meeting from both the foreign manager and Vietnamese mechanical engineers. The manager made a joke about the proposed time to finish the department priorities.

\section{Example 7.1}

1 The manager:

You can finish tomorrow.

2 Mechanical engineers:

3 The manager:

[laugh loudly].

4 Mechanical engineers: [laugh even louder].

5 Another mechanical engineer: Today we can't finish.

6 The manager: $\quad$ You are right, tomorrow is too much time.

7

It is a joke, hey.

(The conversation was extracted from the meeting between the Southern European manager with Vietnamese mechanical engineers at the motorbike company)

Regarding a proposed time to finish the task, everyone laughed loudly and they seemed to be relaxed. Presumably he said that because he wanted to make it explicit in case there were misunderstanding from the Vietnamese engineers but it seemed to me that the employees knew that he was making a joke. Probably they were used to the manager's sense of humour. The Vietnamese engineers also made jokes about their manager's strange behaviour, as well as his tone of speech in the meeting. They said in Vietnamese that the manager looked happier and more motivated to show off because of my presence. They meant that the manager talked more that day than usual. Then when I asked him if I could copy what he wrote on the board, he was very happy and smiled at me. His staff said to each other in Vietnamese that their manager was very agreeable about being observed and they all laughed. The manager's performance in this situation could be understood in relation to the Hawthorne effect. According to Macefield (2007), the Hawthorne effect is "an experimenter effect whereby participants in any human-centred study, may exhibit atypically high levels of performance simply because they are aware that they are being studied" (p. 145). But taking into account the Hawthorne effect what was observed was that the 
Vietnamese workers felt relaxed enough to laugh at their boss in this way demonstrated an existing high solidarity relationship between the manager and the mechanical engineers. The use of humour in this meeting is typical of the findings of Holmes and Stubbe (2015) finding that "many meetings are punctuated by bursts of humour, which tend to occur at strategic points" (p. 109). Holmes and Stubbe further note that workplace humour is obviously context bound, which generates hilarity among workmates. Once laughter happened, the gap in the power relationship between the foreign manager and the employees seemed closer and they were more motivated to be involved in the meeting. There was high solidarity between them.

Another example of humour was seen in the morning meeting between the foreign manager and his staff in the welding area in the factory of the food producing company and again involved the researcher. When the manager introduced me (the researcher) to his staff, he said "this is doctor Tinh. Bác sỹ Tinh comes to check how I and you use English everyday" (he meant a medical doctor). This was because I told him that I was a doctoral student and would like to conduct a study exploring the English communication needs of his mechanical engineers. He translated the word "doctor" into "Bác sỹ" in Vietnamese and spoke both Vietnamese and English which made his staff laugh a lot. His staff said "not bác sỹ" (not medical doctor) and everyone laughed. The atmosphere was very happy and the manager seemed to be very friendly, sociable and close to his workers. The use of humour revealed the harmonious relationship between them. Humour plays an important role in constructing participants as equals and managing power relationships in the workplace in terms of playing down power differences (Holmes \& Stubbe, 2015).

\subsubsection{Understanding each other well results in low formality and high solidarity}

A significant finding was that both foreign managers and local employees seemed to understand each other very well despite the lack of appropriate formality. The foreign managers were aware of the mechanical engineers' English ability and could adapt to this. They accepted this fact and even accepted people's impoliteness in communication as a result of limited English ability. Below is an example in which the mechanical engineer asked his manager a question using rising intonation. The conversation took place when the manager came to a workshop to check his employees' work progress.

Example 7.2

1 FM: $\quad X$ (a mechanical engineer), tight a little bit the water hoses also the wheels.

2 FM: $\quad$ Why do you take it out? What is the problem? What are you doing?

$3 \mathrm{X}$ : $\quad$ Do you know the trouble code?

4 FM: $\quad$ What is the code?

$5 \mathrm{X}$ : $\quad$ You don't know? Ah... The connect of the wheel here 


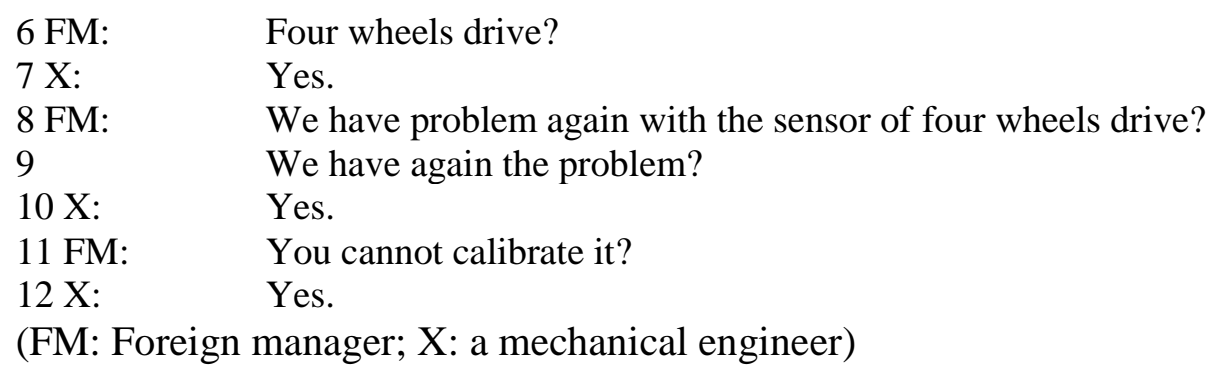

I was following and observing both the manager and his mechanical engineer's work at the time but I did not see any displeased facial expressions on the manager's face. The mechanical engineer' words were not formal and polite when he asked "Do you know the trouble code?", "You don't know?" Also, the mechanical engineer was quite blunt in his speech by answering "Yes".

It seemed that they did not care much about formality. Instead, they took more care about understanding and work effectiveness. There seemed to be a high solidarity in their work relationship.

In the workplace where there is an issue of high solidarity, people are open and close to each other. They find it easier to cooperate and help each other. They are motivated to work, share and learn from each other. From the above example, it is clear that the engineer had no fear of communicating with the foreign manager, though his English was not good enough to fully interpret and understand what the manager's question was. But although from my observation he did not feel an issue of power from his manager, he still found himself embarrassed because of his English ability, as this affected his face.

The participants also employed adaptive communicative activities to communicate with the employees. However, despite trying hard, they sometimes failed and issues in communication occurred. These issues caused minor to serious problems for individuals and organisations (finance loss and face loss). Once issues in communication occurred, as will be presented in Section 7.3 below, the work relationship was affected, which could affect the solidarity at the workplace. The foreign managers or the management became angry and used more directives, which showed the underlying power relationships between them, as presented in detail in Section 7.3.2.

\subsubsection{Power relationships}

As described in the introduction chapter and also in the literature review chapter, the popularity and importance of the English language is increasing in Vietnam. The findings of this study confirm this importance, as English has a high status in Vietnamese workplaces. This can be reflected in the fact that people who do not have sufficient English ability may 
be excluded from positions which may lead them to power (Hoang, 2010). The kind of power relationships that develop based on skills in English found and analysed in this research can be called 'expert power', something which has been described in Chapter Three (literature review)

The overarching finding was that possessing good English language skills not only helps people to work more effectively and gain promotions, but it also affects their level of empowerment. Those who had better English ability might have more power than their official positions in the company and this was the kind of 'expert power'. Findings from the interviews and observations revealed that mechanical engineers who had power thanks to their good English language ability were promoted to become deputy managers, supervisors and team leaders in all four worksites in this research. Among supervisors in a company, for example, those who had better English language skills than other supervisors often had a stronger voice in the company. These supervisors or managers often impressed their foreign managers and were the ones the foreign managers often spoke to.

Something that became apparent through observation was the English language ability of the subcontractor representatives. They could communicate well in English, they understood the chairman's requests and other members in the meeting could understand their presentations. This was seen in particular in the formal meeting described above. Although he was only a Vietnamese mechanical engineer and not the manager, he accompanied his manager to the meeting and reported on the company's work schedule to all members in the project. Although nearly half of the representatives in this meeting were foreign engineers who came from different countries (such as China, Thailand, the Philippines and South Korea), this Vietnamese mechanical engineer representing the building construction company could understand their various English accents. Because he had sufficient English, this Vietnamese mechanical engineer could show his status in the meeting, save his face and the company's face as well. He could show his status in the meeting.

The foreign chairman's presentation in the formal meeting, as described in Section 6.3.3 of Chapter Six and Section 7.2.2 of this chapter, demonstrated the issue of power relationships between him and the representatives of the subcontractors in the project. The chairman did not smile when chairing the meeting. The meeting atmosphere seemed to be serious; there was no private talking or discussions during the meeting. Throughout the meeting, the chairman's manner of delivery showed his status. This was illustrated by the kind of directives he used. When they finished the meeting, the chairman said "Ok, no more comments", "All finished". The way he ended the meeting showed his power to some extent. 
The context and the atmosphere of the meeting as well as the type of English they used showed a high degree of formality in their work relationship, which reflected the power relationships and low solidarity between this manager and other people in the meeting.

Even when there appeared to be high solidarity relationships in meetings the reality of the underlying power relationships could emerge. An example was seen in the morning meeting described in Section 6.3.3, when at one point the foreign manager was not happy and became angry with a response by one mechanical engineer. His anger showed in his rising intonation as a question in his reply (“you are updating zero point, zero per cent?"). This moment of anger probably affected the level of solidarity in the relationships in the meeting and showed the underlying power relationships between them because the local engineers were observed keeping silent. In the next few minutes of the meeting, they did not smile or make jokes. Some even looked at their notebooks instead of looking at the manager.

A business-like relationship based on low formality and high solidarity was also seen. This was in a conversation between the foreign manager and his mechanical engineer at the food producing company (see Example 7.3), which is described in Section 7.3.2. There was frequent code-switching and the free and friendly way of communication and the types of language they used could showed a high level of solidarity between them. There was no strong evidence of formality between the 'boss' and the staff.

In the conversation, no formal greeting was made, nor was a formal invitation for a cup of tea made by the mechanical engineer as is often seen in the Vietnamese culture, but the foreign manager was still happy. In this case, we can see the relationship was of low formality and high solidarity. It might also indicate that these people had been working together for a long time. What was observed in this study was that when the participants communicated in a formal and polite way, solidarity was low. When they communicated with each other in an informal way, they seemed to have a good relationship, which was a signal of a high degree of solidarity between them.

\subsection{Communication Issues and Their Consequences}

This section reports problems caused by the limited English ability of mechanical engineers. Though English was identified as very important in all four companies, employees in general and many mechanical engineers in particular were perceived to have limited English ability. As seen in the findings of Chapter Five, many mechanical engineers had to struggle to understand and be understood in communication. Due to their lack of English proficiency, they had to apply different adaptive communicative activities and they 
could perform their job effectively to a certain extent. However, there were many reports in the data about communication issues because of mechanical engineers' English ability and unsuccessful adaptive communicative activities, which caused minor to very serious consequences. As will be reported in detail in the following sections, mechanical engineers' lack of English proficiency not only caused communication issues, but also affected the power relationship between the interlocutors. The following section presents communication issues that caused the least serious to the most serious negative outcomes to individuals and their organisations.

\subsubsection{Communication issues identified in the interviews}

In the interviews the participants identified different contexts where communication issues occurred. Communication issues here refer to failure in exchanging information or lack of communication (Hanks \& McLeod, 1986). Communication issues took place in different workplace contexts, such as in the company office, in the workshops, in the garage and at the construction sites. Also, these issues happened when the mechanical engineers had interactions with different interlocutors, such as the foreign managers, foreign experts, foreign site supervisors and managers, and suppliers.

Most of the interview participants reported misunderstandings in work communication as the most common issues in communication. They expressed their frustration over their employees' lack of communication skills. According to one manager participant, misunderstandings in communication could be caused by using the wrong vocabulary choice.

I speak. I use the wrong words or one word which is not specific or technical and so people understand it in a different way (M-Mui-C3).

According to the engineer participants, another common problem was misinterpreting the managers' instructions. Some mechanical engineers mispronounced the English vocabulary and thought these were Vietnamese words and so made simple mistakes. For example, the word "big" and the proper name "Bích" in Vietnamese could be pronounced similarly by some beginner speakers of English. This problem was reported happening at the food producing company as claimed by Dan:

My colleague in the company who was an engineer and his manager was a South Asian. Because the water supply was not strong, the manager asked him to run the big pump. He got the command and went to the safety room which was controlled by an employee named Bich. He thought the manager asked him to tell Mr Bich to run the pump. He didn't know that the manager wanted him to run the big pump. Mr Bich said it was not his duty to run the pump and that engineer had to go back to ask the manager again. This affects the work progress (Dan-ME-C1). 
This example supports the finding of English listening skill as very important in the context of the mechanical engineers' job. It can be inferred that the strategy of relying on single words used by the mechanical engineer in this example did not work properly. Another participant, Ngo, gave a further example:

When I was working in the garage section, the manager asked an engineer to fix the brake system, but he looked at the transmission system because he didn't understand what the manager wanted him to do (Ngo-ME-C2).

The misunderstanding reflected the limited English ability of the mechanical engineer in this case. The problem was that though he did not understand the request, he kept silent and did not ask the manager again to clarify it. Instead he looked at the transmission system. When Ngo saw that, he explained what the manager meant to the engineer. In this case, if Ngo had not been there, that engineer would have displeased the manager and slowed down the work progress.

The common negative outcomes caused by these above incidental problems could be time consuming, taking up the time of other people and slowing down the work progress. Because of their limited English ability, many mechanical engineers required more time to interpret and understand the requests, which also consumed more time of their foreign managers. In some cases, mechanical engineers needed someone whose English was better to function as an interpreter for them, and Ngo's quote is an example. The more serious problem was work productivity. Communication issues slowed down the work progress and this affected the company productivity and indirectly affected the economy.

In the interviews the participants reported some very serious problems caused by communication issues.

Ordering the wrong spare parts and failing to get other people to understand their ideas were reported to cause serious negative outcomes, such as financial loss and loss of face to not only the individuals but also the organisations. In ordering spare parts, mechanical engineers had to look for the correct items that they need. According to Thin, the mechanical engineers in his department made many mistakes in their ordering. He gave an example of looking for a gear for the gear box of a food mixer. One mechanical engineer was asked to look for the correct gear to order for the replacement. The engineer looked at the catalogue and found a similar one and he decided to order it. Though the catalogue described detailed functions and specifications about the diameter and profile, it was not the one they needed. He did not check the details carefully and made this mistake. After two days using this new gear, the gear box totally broke down and they had to order a new one. This mistake caused 
the company to lose a great deal of money and it also affected the production plan of the company.

In another case, one company's team was working at one point in the construction site. The mechanical engineer raised the idea with the foreign site supervisor of using something to hold the fence and make it higher or lower when necessary. However, he could not express his idea clearly for the supervisor to understand and the idea was not approved. He said that the idea could have been approved if the mechanical engineers' English ability was better.

But if their English is good, they just need to explain what they want simply and the supervisor will understand immediately (Tuat-M-C4).

Tuat further stated that his mechanical engineers' limited English ability caused many communication problems in his company and below is an example:.

The foreign site supervisor asked a mechanical engineer when the instrument will be available for installation. Actually, we need about 30 days to finish, but the engineer raised his fingers to say 40 days, but the supervisor only saw four fingers and he thought four days. He asked four days? And the engineer said ok, ok. So after four days the supervisor came back to check but could not see the instrument so they cut that article because the engineer said four days (Tuat-M-C4).

This misunderstanding caused a serious problem in that the head contractor cut off that article in the contract and this affected the company's schedule and finances. It should be noted that many of the participants claimed the importance of body language and gestures as an adaptive strategy to support their inefficient English ability and this worked in different contexts, except in this case. The mechanical engineer in the above example also used his fingers as a gesture but he failed in sending the information. Though the mistake seemed to be simple, his company was forced to stop executing that article in the project as a result. More seriously, this affected the company's face, that is, the company's reputation in their field of business. The foreign supervisor might claim that the company could not complete the work as scheduled and this might not leave a good impression with the foreign manager.

Below is another example of affecting the company's reputation, which took place at the construction site where the building construction company was a sub-contractor.

When the foreign supervisors reminded the workers to wear safety shoes and the mechanical engineer said yes. When he said yes, they thought he had understood. However, the next day they still saw that workers didn't wear safety shoes and they knew this problem had not been solved. They were very angry and they reported to the work superintendent to complain that we don't take the safety rules seriously and this would affect the image of the company (HoiME-C4). 
Safety has the first priority at construction sites. In the observations, safety talks were observed to happen in the morning as soon as the employees started their working day. Although the reminder about wearing safety boots might have been considered a minor and less important issue by the mechanical engineer and he could have forgotten to ask his workers to wear them the next day, this failure to take seriously safety concerns could also have potentially been interpreted as an indication of lack of professional concern on the part of the mechanical engineer and the workers and their company as well. Such an indication of lack of professionalism could result in a bad impression on the foreign supervisor.

In one case I was told that there were issues in communication in bidding for projects. The manager of the building construction company said that his staff sometimes failed in making the business partners understand their proposal presentations and explanations. This led to the company losing the bid, which affected not only the company's finance but also its face.

When communicating with business partners in English, if you don't understand their ideas, requests, you can't prepare enough and good documents to join the bidding (Tuat-M-C4).

Similar losses were also reported in the observation findings in the next section. To be qualified to take part in the bidding ceremony, bidders have to prove their ability and they have to spend a lot of money preparing the documents and paying the bidding fee. Sometimes they have to follow the bidding procedure for a long time. More serious is the loss of the company's face. If they fail in bidding for projects many times, the company's ability will be questioned and it is likely that they will have a higher possibility of failing in bidding for other projects. This is to say the company also has positive needs.

\subsubsection{Communication issues and underlying power relationships identified in the observations}

As has been presented in the findings of Chapter Six, data from all the workplaces in which the study was conducted showed the dynamic relationship between foreign managers and Vietnamese employees. Most of the foreign employees held management positions, from supervisors and managers to general directors, so the interactions between them and the local employees revealed varying degrees of power relationships. This issue is illustrated in various situations and communication issues are one of them.

During the observations, I observed two communication issues in the mechanical engineers' communication with their foreign managers. The first occurred at the food producing company when the foreign engineering manager visited the worksites in the 
morning to check his staff's work. Below is a conversation between him and one of the mechanical engineers which took place at the boiler area of the company. This was in the centre of the factory in the open air. There was a small table with two chairs where the engineer was sitting and having a cup of tea when the manager came. The original conversation consisted of both Vietnamese and English.

Example 7.3

$\begin{array}{ll}\text { 1 Manager: } & \text { X ơi ra đây! } \\ \text { 2 ME: } & \text { Lai ngồi đây uống nước đã } \\ \text { 3 Manager: } & \text { Mấy giờ kiểm tra hydraulic? } \\ \text { 4 ME: } & \text { Mây giờ à? } \\ \text { 5 Manager: } & \text { Hydraulic. } \\ \text { 6 ME: } & \text { Hai mươi ba ni à? Hôm nay à? } \\ \text { 7 Manager: } & \text { Hydraulic - áp lực } \\ \text { 8 ME: } & \text { Ấ, áp lực nước à? } \\ \text { 9 Manager: } & \text { Áp lực nước. } \\ \text { 10 ME: } & \text { Member Vietnam thứ } 2 \text { thứ } 3 \text { tuần sau mới đến. } \\ \text { 11 Manager: } & \text { Uhm. }\end{array}$

Below is the English version of the conversation:

1 Manager: (called the name of the ME in Vietnamese). Come out here X!

$2 \mathrm{ME}: \quad$ Come and sit here to have a cup of tea

3 Manager: What time do you test hydraulic? Hydraulic testing?

$4 \mathrm{ME}$ : What time?

5 Manager: Hydraulic.

$6 \mathrm{ME}: \quad$ This $23^{\text {rd }}$ ? Today?

7 Manager: Hydraulic.

8 ME: $\quad$ Ah, hydraulic?

9 Manager: Hydraulic

10 ME: $\quad$ Vietnamese member will come to test it next Monday or Tuesday

11 Manager: Uhm.

When the manager came to the boiler area, he asked the mechanical engineer about when hydraulic testing of the boiler would take place. The engineer did not understand the question. First he asked in Vietnamese about the time because he was not sure about the question. The manager repeated the word "hydraulic" but he did not remember this word and he thought the manager was asking him about the date $23^{\text {rd }}$. He mispronounced the word "hydraulic" as "twenty-third" in Vietnamese and therefore he asked the manager in his language "hai mươi ba ni à?" (means: this $23^{\text {rd }}$ ?). The manager could not understand what the engineer was asking because it was in Vietnamese, so he repeated the word "hydraulic". He kept repeating this word three times until he remembered the Vietnamese equivalent "áp lực nước" and used this Vietnamese word phrase. Thanks to the Vietnamese equivalent, the mechanical engineer understood the question and told the manager that he had checked with the Vietnamese member (he meant the Vietnamese authority whose job was to test the 
hydraulic to see if there was any leaking in the boiler) and that they would come to test it on the next Monday or Tuesday.

Though this communication issue did not cause any serious outcomes, it resulted in two obvious problems, the issue of work productivity and the issue of loss of face, which are presented in more detail in the next section. The former issue slowed down the communication between the foreign manager and the mechanical engineer and affected the work progress. It took the time of both participants. The latter issue made the mechanical engineer embarrassed because he misunderstood the manager's question, especially in my presence. The engineer was observed smiling and smoothing his hair with his hand while saying the Vietnamese equivalent "áp lực nước". His actions revealed his embarrassment due to his limited English ability. He told me that he had difficulty in communicating with the foreign manager because he was not proficient in English. He had to rely on key technical words to guess what the manager was asking or wanted him to do. He knew most of the common technical words in his area because he used these words every day.

Failure in understanding the manager's request and instruction led to the second example of communication issues at work. This was observed at the dairy company when the foreign manager visited the workshop to check his staff's work. The workshop was in front of the manager office. I was told that engineers, technicians and workers often gathered at this place before they started their working day. They came here to be given tasks for the day. When the manager came, some workers were hammering and grinding the connect part of a tractor. He talked to the mechanical engineer, who was the supervisor of the workshop on that day.

Example 7.4

1 Manager: $\quad$ I told you every time that you need to open and look inside.

2 Mechanical engineer: I will ask them (the workers) again.

3

4 Manager:

5

6
Sometimes I talk about ...(was interrupted by the manager).

Not sometimes, all the times. I talk to you all the times.

I talk same same all the times. Check check check.

You talk same same your guys all the times. Check check check.

What can be inferred from the conversation is that the manager was not pleased with his workers, especially the mechanical engineer. He was angry because the mechanical engineer did not take heed of his verbal instructions. This was because that morning the manager dropped in and asked him to look inside carefully and require his people to hammer and grind the connection between two parts of the tractor smoothly but they did not do it well enough. That afternoon the manager came and checked again and saw the technician 
was hammering the outside surface instead of the inside surface. He was very displeased with them and was angry with the supervisor. He talked to the supervisor in a loud voice with some repetitions, "all the times", "check check check". His facial expressions revealed that he was angry with rising eyebrows and an angry glare. This was because the supervisor misunderstood his request and instruction and therefore asked the technician to hammer the outside part. He did not listen to the instruction carefully or did not fully understand the manager's instructions, and for some reason he did not ask again to clarify it. Also, he could have misinterpreted the manager's instruction and made the mistake. This could also because he was too confident that he knew what to do. He wanted to explain the situation but the manager interrupted his speech by stressing "not sometimes", but "all the times". The supervisor felt the power pressure from the manager not only in the words he said but especially in his manner of delivery. This was not the first time the supervisor made this mistake, but I was told they had had this problem many times, and I was told that was because of the supervisor's English ability. Because of this, the manager required him to do it again and focus on the inside surface, not the outside one. This also meant that the supervisor and his technicians had to spend a couple more hours to finish the task. This communication issue slowed down the work progress and affected the work productivity of the department.

A similar situation was observed at the morning meeting at the motorbike company. The cause of the communication issue was because the mechanical engineers failed to follow their foreign manager's request to copy all the data to a register. He got angry as he seemed to understand when his employees talked to each other in Vietnamese that they could not copy and copy the data every day. He made his voice louder to show his disagreement as "every time you speak the same, hah". The use of "hah" showed his anger and displeasure.

There was an important difference in the use of language in this second conversation compared with the first issue in communication described above. The foreign manager used some directives in his sentences. According to Vine (2009) a directive is defined as "an attempt to get someone to do something - in each case a manager is asking a member of their staff to complete an action" (p. 1396). In this conversation, the manager asked the mechanical engineer to open the part of the tractor and look inside carefully, not just hammer and grind the outside part. The realisations of directives in their communication included the imperative "check, check, check" and modals of obligation "need to".

The use of directives and the way they were delivered showed the role and power of the manager over his staff. From the manner of the manager's delivery of directives, I could 
see an obvious imbalance in power and knowledge between the manager and mechanical engineers. Because of the lack of English proficiency, the mechanical engineer misunderstood his manager's instruction and this made the manager displeased. In this case, the English ability of the engineer affected the power relationship in their workplace context. If the mechanical engineer's English ability had been better, he would not have misinterpreted the manager's request and instruction and the manager would not have been displeased. In that case, they both would have had a normal and informal conversation, which could have resulted in a high degree of solidarity between them. But the conversation revealed a significant increase of power. It is clear that the higher degree the power is, the lower degree of solidarity appears.

It was also at this department where I was told that the mechanical engineers could not report technical issues or work progress on the phone. Instead, they had to come to the foreign manager to report in person to avoid breakdowns in communication in the workplace. I was in the manager's office at the time and watched their communication. They said that this was because they did not know the right words to express the ideas they wanted to report. They had struggled to understand and be understood, as has been reported in the findings of Chapter Six, and face-to-face communication was one of the strategies they applied. Face-to-face interactions reveal issues of formality, solidarity and power relationships, which have been described in more depth in the findings of Section 7.3 above.

\subsection{Chapter Summary}

This chapter has presented the English communication needs required by mechanical engineers in the workplace, which not only included linguistic needs such as specific English language skills, different types of English and the language for specific communicative events, but also the ability to use English socially through humour and to express power relationships, as reported in the interviews and observations. The purpose of communication, the forms of English language use and the varying levels of English proficiency could affect to the social dimensions of the use English in the multilingual and multicultural workplace. The issue of humour, although was found unexpectedly, became of importance in the study as it related to informality and high solidarity relationships between the participants, and informality and high solidarity relationships in turn could help avoid communication issues.

The chapter has also described how the lack of English could result in communication issues with serious consequences, and how inappropriate understanding of social uses of English could lead to the disempowerment of the users of this language. 


\section{CHAPTER EIGHT: DISCUSSION}

\subsection{Introduction}

With the aim of examining the real-world English communication needs of mechanical engineers to provide pedagogical implications, this methodologically pragmatic study sought to bring together the specificity of the Communication Needs Processor (CNP) model of needs analysis proposed by Munby (1978) with the more integrated and contextualised model of the Common European Framework (CEF) model proposed by Huhta et al. (2013). In order to address the main research question about the English communication needs required by Vietnamese mechanical engineers, the following three sub-questions guided the analysis of the findings and discussion.

1. What kinds of real-world English skills are required by Vietnamese mechanical engineers to function effectively in the workplace?

2. What social factors and social dimensions affect the English skills that mechanical engineers use in their workplace and how do these affect this use of English?

3. Where and when do breakdowns or other issues in communication occur and what are the effects of these issues?

What this study describes is a dynamic process of adapting varying levels of English language proficiency to the context of getting things done practically in a lingua franca, plurilingual and pluricultural workplace. It looks first primarily at the communicative events of the English lingua franca workplace for Vietnamese mechanical engineers using the lens of the needs analysis study. It then considers the implications of the adaptive process of language use for the social and power relationships of the workplace in a context where the potential for communication issues is high. Communication issues in other words provide a helpful lens through which to see other aspects of language use in the lingua franca, plurilingual and pluricultural or "poor English" (Govindarajan \& Gupta, 2001, p. 68) worksite. It shows the extreme importance of flexible and adaptive language use but also that there is a stage when flexibility and adaptability are not enough and communication stretched too far will inevitably snap like a rubber band. Tensions caused by limited English and communication issues also provide a lens through which to examine high and low solidarity and power relationships in the workplace. It is an important finding of this study that high solidarity relationships can help mitigate communication issues or potential 
communication issues but also that Vietnamese mechanical engineers can be seriously disempowered through limited English skills.

Adapting language use and negotiating power relationships interact in a complex way in this study and the theoretical perspectives that underpin the study attempt to capture this complexity. The diagram (see Figure 4) in Chapter Two conceptualises this relationship. For this reason, the study finds itself at the intersection between needs analysis models which have come out of English for Specific Purposes and the model provided by the Wellington Language in the Workplace Project (LWP) (Holmes, 2000). Behind the LWP project's analyses lie the principles of social constructionism, that is, that language can best be understood in relation to the social contexts of its use. In this study the context is the lingua franca workplace with the inevitable affordance and constraints of communication in a language which is not the first language of almost all the participants.

The variable of differing levels of proficiency in English in this study complicates or makes different some of the dynamics of social workplace interactions described in the LWP.

The linguistic needs that emerged in this study were, consistent with previous research in similar workplace contexts (Al-Khatib, 2005; Bhattacharyya, Nordin, \& Salleh, 2009; Kassim \& Ali, 2010; Radzuan \& Kaur, 2011), for proficiency in listening and speaking in worksites in the context of 'getting things done practically', and communicating with foreign managers, experts, business partners and clients, and suppliers. The key communicative events were also consistent with those reported in previous studies (Kaewpet, 2008; Kassim \& Ali, 2010; Spence \& Liu, 2013). Through observation data, this study has focused most strongly on a variety of types of meeting. The need for reading and writing, particularly of emails, technical reports and technical and supply manuals, supplemented the prioritisation of listening and speaking skills. A feature of the lingua franca worksites' context was that the mechanical engineers had to negotiate a variety of accents and idiomatic language use. What emerged, particularly through the observation data, was the constant process of adapting and negotiating through varied levels of proficiency, from extremely limited to more sophisticated. Communication issues in this process of negotiated common understandings of language sometimes revealed a larger hidden or 'shadow' power structure within the workplace affected by English language proficiency (Marschan-Piekkari et al., 1999). As in the Wellington Language in the Workplace Project, approaching such communication issues through different lenses, those of critical discourse analysis for an 
analysis of power and pragmatics for an analysis of the implications for loss of face and workplace solidarity for example, help reveal the complexity of the interactions (Holmes \& Stubbe, 2015).

This chapter will first summarise the key needs analysis findings in relation to the research literature. The rest of the chapter will discuss the underlying power and social relationships of the use of English in the lingua franca workplace. Specifically, the 'shadow structure' power of English, as well as the implication of issues in communication in relation to losing face and low solidarity, and the implication of adaptive uses of English to avoid communication issues in interaction with saving face and high solidarity, will be discussed.

\subsection{Summary of Key Needs Analysis Findings in Relation to Research Literature}

This study confirms several key findings from other research in the area of needs analysis in the English lingua franca workplace.

The study confirms the high demand and urgency for English in workplaces in ASEAN (Association of Southeast Asian Nations) countries seen in Hao and Moore (2015), Kaewpet (2011b), Kirkpatrick (2008), and Rajprasit and Hemchua (2015). The demand for proficiency in English is increasing in Vietnam, a developing country with the target of becoming a fully industrial country by 2020. The country has attracted many foreign investors and multinational organisations to invest in its marketplace. The study also confirms how strongly Vietnamese workplaces can be lingua franca workplaces, where English is the means of communication between the indigenous working population and non-native speaking or foreign employees, because English is not the first language of either the employees or some of their managers. This has also been seen in studies by Kaewpet (2009a) and Louhiala-Salminen et al. (2005). The need for the lingua franca workplace context to be recognised in English language teaching pedagogy has already been recognised by Hao and Moore (2015), Huong and Hiep (2010) and Matsuda (2003).

In this paragraph, I am using and adapting the language of needs analysis used by Hutchinson and Waters (1987), which divides needs analysis into needs, lack and wants. Here I am looking at the needs, lacks and wants identified within the workplace. The managers and mechanical engineers in the study recognised the need for improving English language skills, which was also found by Weng (2015) and Stevens (2005) in their studies of foreign managers' perceptions of their communication with the local people at the international workplaces in Vietnam and the kinds of communication skills that employers 
want. Both the mechanical engineers and their managers were highly aware of the varied lacks of sufficient English ability of mechanical engineers. This recognition was translated into the 'wants' that the participants expressed in the current study. The mechanical engineers wanted to have better English ability to enable them to function more effectively in their jobs. In the workplace, being able to communicate effectively, especially in English, is a very significant advantage for the employees (Mohamed et al., 2014; Rajprasit \& Hemchua, 2015). English has become a necessity in their daily workplace communication (Riemer, 2007).

The findings from the study were consistent with existing studies about the people with whom mechanical engineers communicated (Ab.Rahim, 2008; Kaewpet, 2009a; Kassim \& Ali, 2010; Louhiala-Salminen et al., 2005; Rajprasit \& Hemchua, 2015; Talif \& Noor, 2009; Zaid \& Kamarudin, 2011). As has been reported in the findings chapters, the variety of groups of people that mechanical engineers communicated with indicated that the companies in the study were multicultural and multilingual not only because of the foreign employees working there but also because of their foreign suppliers and clients. Question 10 in the questionnaire for the manager participants revealed the diversity of home countries of staff. The engineers in studies by Ab.Rahim (2008) and Kassim and Ali (2010) had more interactions with clients and customers, and those in the study by Rajprasit and Hemchua (2015) had more communications with foreign colleagues in Thailand and other countries, while mechanical engineers in the current study had more interactions with foreign suppliers and foreign managers or the indigenous workers. This reflects the fact that Vietnam often has to import machines or machinery devices (spare parts) from foreign suppliers around the world and Vietnamese companies employed a considerable number of foreign staff.

The study was similar to other studies in its findings about the amount of the local language spoken between local people (that is, Vietnamese used between Vietnamese speakers) (Kaewpet, 2009a; Louhiala-Salminen et al., 2005; Zaid \& Kamarudin, 2011). In their investigation, Louhiala-Salminen et al. (2005) found that when other nationalities were involved in the interaction, English was used instead of the participants' mother tongue. This study found the same pattern. On the other hand, Vietnamese employees preferred speaking their mother tongue when they were together, which made it easy for everyone; this was evident from the interview data and was confirmed during observations in the workplaces. Managers who had been in Vietnam for over five years used some Vietnamese. 
Oral language (listening and speaking) was used more frequently than written language (reading and writing) as in other studies (Al-Khatib, 2005; Bhattacharyya et al., 2009; Kassim \& Ali, 2010; Radzuan \& Kaur, 2011; Rajprasit \& Hemchua, 2015). This finding is consonant with numerous previous studies about the importance of oral communication in the engineering workplace (for example Bhattacharyya et al., 2009; Kaewpet, 2009a; Kassim \& Ali, 2010; Lehtonen \& Karjalainen, 2008; Rajprasit \& Hemchua, 2015), but contrasts with findings from the research of the English needs of Taiwanese engineers by Spence and Liu (2013), who found that writing and reading were the most frequently used skills. This also contrasts with findings of Kaneko et al. (2009) that reading of manuals and instructions and writing of emails, faxes and business letters were the most frequent English-language tasks. As previously discussed, this study of four Vietnamese factories indicated that the participants in the worksites used English more frequently because of the involvement of foreign business partners in doing business, which was also evident in another study in Vietnam by Dung (2011). Dung concludes that the participants who worked in companies that had business relationships with foreign business partners used English speaking and listening skills more frequently than those in other companies. Though reading and writing were reported to be used less frequently than speaking and listening skills, they were also reported to be significant in this study as in other studies (Ab.Rahim, 2008; Evans, 2013; Kaewpet, 2009a; Kaneko et al., 2009; Kassim \& Ali, 2010; Spence \& Liu, 2013; Stevens, 2005). This significance was shown in the frequency of the communicative events involving reading and writing that the participants were engaged in (see Table 6).

Listening and speaking were also reported as the English language skills that the participants lacked most in this study (as can be seen in previous studies, such as Chia-Jung (1991), Stevens (2005) and Spence and Liu (2013)). This finding echoes research conducted with tertiary students, where Al-Tamimi and Shuib (2010) and Salehi (2010) report that engineering students perceived themselves to have lower performance for listening, speaking and communication compared to other skills. This is to say, the participants' lack of listening and speaking skills probably originated from their learning of English at the university (Spence \& Liu, 2013), which may have placed greater emphasis on written rather than oral language and they wanted to improve these skills (Al-Tamimi \& Shuib, 2010; Chia-Jung, 1991). 
As well as confirming the importance of English language skills to these particular workplaces in Vietnam, the study also clarified the specific situations or contexts which required mechanical engineers to use English in their daily tasks and duties (otherwise known as communicative events). On the one hand, the study confirms communicative events similar to those which have been identified by a considerable number of researchers (for example Kaewpet, 2008; Kassim \& Ali, 2010; and Spence \& Liu, 2013). On the other hand, some unique communicative events involving mechanical engineering were found in the specialised context of these workplaces. These included listening to safety instructions, bidding for contracts, interpreting English into Vietnamese and vice versa, and interpreting technical drawings. They also included deciding on the suppliers for spare parts, ordering spare parts, analysing errors of the incoming spare parts, chairing morning meetings, organising daily manpower, copying and saving data on the personal computer, and joining English training courses provided by the company.

The complexities of English required as the lingua franca in the factory workplaces were highlighted by findings indicating the importance of being able to negotiate a variety of accents and styles of international English and the importance of adaptability in language use. Working in a lingua franca context means that English is spoken by people from different geographical regions with different accents, and mechanical engineers were required to listen and communicate with speakers with various English accents and different intonations.

It is here that Munby's (1978) category of 'dialect' comes into play. Dialect in this study could refer to the international English which was reported in Kaewpet (2008) or described as world 'Englishes' in Hao and Moore (2015). In Kaewpet's study of Thai civil engineers, 'international English' was spoken by Thai in interactions with both native and non-native speakers of English. My study revealed that mechanical engineers mostly communicated with non-native speakers of English. This is useful knowledge for students of mechanical engineering, a finding consistent with the claim of Hao and Moore (2015) that the teachers perceived their students were more likely to communicate with non-native speakers of English than native speakers. On the other hand Huong and Hiep (2010) found that students wanted to learn the kind of English that native speakers used more than the kind of English that helped them to communicate with non-native speakers of English from different parts of the world. As has been reported in the literature review in this study, the variety of dialects has been identified as one of the causes leading to miscommunication 
among the speakers (Kell et al., 2007; Le et al., 2016). The findings in this study that mechanical engineer participants found it hard to understand and interpret the variety of English accents spoken by foreign people with whom they had to communicate becomes of particular urgency around workplace safety. Because factories are potentially dangerous workplaces, it was crucial for mechanical engineers to interpret and understand safety instructions, as well as meetings which were given in different English accents. It is a finding of this study that this is the skill for which mechanical engineers may need to be more carefully prepared so that they can communicate more confidently and work more effectively.

The study also revealed the importance of acquiring a corpus of technical words and phrases frequently used in the workplace, which was consonant with the findings of Weng (2015). Technical vocabulary was also perceived to be of importance by students of Computer Science (Rahman, 2012). However, what should be noted is that this study found that mechanical engineers needed to use some academic words as well.

In summary, these above-discussed findings were the results of using the traditional lens of needs analysis research, an approach still widely used to attempt to analyse the challenge of insufficient English in the international workplace. With some workplacespecific variation, this study confirms the findings of similar studies in the field.

\subsection{The Demand for English Courses for Specific Purposes}

Findings of the study revealed that mechanical engineers required sufficient English language skills for a range of communication events including English for technical communication and English for social communication. This brings into focus the need to design and develop relevant English courses for specific purposes to prepare mechanical engineering students relevant English proficiency and types of English to enter the mechanical engineering workforce. Zohrabi (2011) argues for the need for the selection of a separate textbook for each discipline and Kaewpet (2011b) claims that subject content should be discipline-specific and that "the course content should consist of material that the learner can authentically use outside class" (Kaewpet, 2009a, p. 266). In the context of Taiwan, Spence and Liu (2013) also suggested the inclusion of authentic training in specific areas such as email and report writing, telephony and teleconference communication, and presentation delivery, the kinds of real-world communicative events required in the today's globalisation workplaces. These claims together with the findings of the study help me to 
conclude that ESP courses are significant for mechanical engineering students and that there should be ESP courses for students of different disciplines such as mechanical engineering to adequately prepare them sufficient and relevant English language skills and knowledge to function effectively in their future jobs in the plurilingual and pluricultural workplace. This conclusion frames my discussion of useful pedagogical implications which are presented in the next chapter.

\subsection{The Underlying Power and Social Relationships in the Workplaces}

To this point, the discussion has considered the language in the workplace sites from the needs analysis perspectives provided through the lens of English for Specific Purposes approaches. From this point, as indicated in the conceptual diagram provided in Chapter Two (see Figure 4), the discussion will broaden to a consideration of underlying power and social relationships in the workplaces and how these are related to language use to inform policy making and course design. This section of the discussion will first consider this study in relation to language in the workplace studies that look at language and the structure of international companies, studies that have a sociological focus, and then, at more length, the social interactions within the workplace and power relationships within workplace sites and how these are reflected in the use of language.

The idea of 'expert power' becomes important for both parts of this discussion. In this study 'expert power' is often due to good language capabilities. Language is a source of expert power in structural ways in international companies and also at the level of communication within the worksite. Two different sources of literature inform these two parts of the discussion. The first is a developing set of studies about the way language affects the structure of companies, some of which is directly concerned with the lingua franca context. The second is the Wellington Language in the Workplace Study and similar studies which look in detail at workplace interactions.

Marschan-Piekkari et al. (1999) establish in their study of a 'shadow structure' in a Scandanivian-language based company that language in the workplace is so important that it "imposes its own structure on communication flows and personal networks" (p. 421). Govindarajan and Gupta (2001) cite the CEO of ABB, a Swedish-Swiss multinational cooperation, as suggesting that the official language of his company was 'poor English'. For this CEO, Goran Lindahl, recognising, understanding and naming a 'poor English' language environment became an affordance for communication within the company. He argued, "No 
one should be embarrassed to forward an idea because of a lack of perfection in English" (p. 68). This discussion then looks at two countervailing trends [that move in different directions]. The first is the way people are disempowered by lack of English in ways that can affect the loss of face and financial reward, and can often be best seen in relation to communication issues. The second is more interesting and at times slightly surprising and involves the way people in lingua franca, plurilingual and pluricultural or, if we adopt this term, 'poor English' workplaces, use a range of strategies to mitigate the potential harm that could result from problems in communication. What is interesting about this is that these attempts to mitigate limited English and potential problems in communication interact with low and high solidarity relationships. Some of the expectations of a L1 workplace for the exercise of 'expert power' may become different in the lingua franca or 'poor English' environment.

\subsubsection{English language knowledge is a source of power in the 'poor English' workplace}

As has been described in the literature, power refers to the ability to control others as well as the ability to accomplish goals. In this section of the discussion, the power of English in the worksites in the study is shown both in terms of the wide 'shadow' structure and a source of the 'expert power' of the participants.

The 'shadow' structure of power relationships:

It is a key finding of this study that the analysis of the English communication needs of mechanical engineers in the four Vietnamese factories revealed a 'shadow' structure of power relationships based on English language knowledge and skills. The interviews in particular established that those mechanical engineers with good English ability had greater access to vital company information. Thus, most of the communication occurred first between those who could effectively communicate in English, and it was then transferred to others. The mechanical engineers who could communicate effectively were reportedly sent to meetings with the foreign head contractor, to company meetings or even to important meetings such as bidding for contracts. They conducted the communication with foreign business partners on behalf of the department or company. This is consonant with other studies. In the context of an English-only language policy, Japanese engineers with fluent English in SanAntonio's (1987) research could access scarce resources and power in an American company, including interacting with American managers, accessing information and gaining promotion and approval in the company. Japanese employees who spoke English well became mediators in meetings. Though the young Japanese engineer in 
SanAntonio's study was not a senior Japanese manager, he was fluent in English and was sent to escort the American technical expert to function as an interpreter. In this position, he "was involved in higher level meetings than he would ordinary attend" (p. 197). In the eye of his Japanese colleagues, he was being appreciated and admired because of his expertise in interacting with foreigners. In the study of language management and social interaction within the multilingual workplace by Tange and Lauring (2009), superior language ability also created dependencies across the social networks in the workplace. Kassim and Ali (2010) and Zaid and Kamarudin (2011) also report that good or healthy communication could maintain a good relationship and help to keep disagreements to a minimum. Foreign managers in the current study came to talk to the mechanical engineers with good English and these engineers also had good opportunities for job promotion and pay rises (Kassim \& Ali, 2010; Rajprasit \& Hemchua, 2015; SanAntonio, 1987).

Obvious examples of these dependencies in the current study were the interpreting roles undertaken by those mechanical engineers who had better English ability. Without these unofficial interpreters, communications between foreign managers and local staff became very difficult and sometimes failed.

Through the report of the mechanical engineers in the study it seemed that those who were proficient in English found themselves in what is described in the Finnish study as "a powerful communication node position" (Marschan-Piekkari et al., 1999, p. 432) and had more influence in the company than people who knew less English. In this sense knowledge of English could be described as a manifestation of 'expert power' and the lack of power of those with limited English also became apparent.

Observation in this study provided more of an opportunity to examine power relationships as one of the dimensions of workplace interactions, a subject investigated as part of the Language in the Workplace Project (LWP) conducted by Victoria University of Wellington.

As in the discussion of power in workplace communication in the studies of Holmes et al. (1999), Holmes and Stubbe (2015), and Vine (2004), the managers in this study used explicit discourse strategies, speech acts and workplace meetings to exercise power. Vine (2004) focused on investigating the use of directives and requests and found that the managers used a wide range of forms to express control acts as well as expressions of mitigation. In Vine's study people in higher status positions were seen as "having the right 
to use direct forms such as imperatives to subordinates" (p. 165) and these were accepted by the subordinates. However, these managers were also found to use mitigation in their use of control acts to empower their staff. Thanks to both mitigated and unmitigated directives, they could develop and maintain positive working relationships. Similarly, Holmes and Stubbe (2015) found that people in positions of authority could 'do power' by issuing rules for people to follow. Their use of linguistic manifestations such as directives showed direct and explicit power relationships. Similar to the findings of Vine (2004), Holmes and Stubbe (2015) report that the managers used various linguistics and pragmatic devices to mitigate their use of directives. Most of the foreign managers in the current study were foreign speakers of English and so praise, positive reinforcements and softening uses of language such as hedges were less apparent. Instead, there was a strong use of imperatives, which seemed to be easier for their employees to understand because these imperatives were often very brief and contained the key words with which the employees were familiar.

\subsubsection{Communication issues, losing face and low solidarity relationships}

In this study, communication issues became a lens through which to study other dimensions of the power and social relationships in the workplace. In these workplaces adaptation of language to avoid miscommunication was like a rubber band. It was stretched as far as possible but after being stretched to the maximum extent it broke. Miscommunications were seen in the observations and were also reported in the interviews. These communication issues caused workplace problems, which led to angry responses from foreign managers. Some of these miscommunications were reported in the interviews as serious problems in the workplace.

The two examples in this study where the foreign managers got angry and so appeared to lack all concern for the face of the worker become interesting when compared to examples of communication reported in the Language in the Workplace Project. Holmes and Stubbe (2015) report a problem on the factory floor to do with a misunderstanding about packing codes which disrupted the output of the factory. As in the incident observed in this study the verb "check" plays a central role in the discourse of the manager "Ginette". Ginette was reported by Holmes and Stubbe as being 'direct and directive' when angry and as playing "the tough boss" (p. 141). In other words it becomes apparent from this example that this kind of mistake on the factory floor can also occur in a L1 workplace and that managers' responses to this kind of mistake may be fairly similar regardless of the context. The difference in the two examples relates to saving face. Holmes and Stubbe (2015) report that 
despite Ginette 'doing power' through an angry tone and direct description and instructions, she also addresses the face needs of the team by making the responsibility for the mistake a collective one for the team rather than any one individual within in it. This kind of mitigation of face loss did not occur in Vietnamese workplaces in this study in the example of the foreign manager's anger with a mistake, as described in Example 7.4, Section 7.3.2. My field notes, taken as an insider in terms of Vietnamese culture, suggest that in this case the loss of face for the Vietnamese workers was severe. This interaction may have been typical of this manager's practice. Le et al. (2016) report in their study that foreigners use more direct language markers in their interactions. In this case, however, loss of face was also involved for the foreign manager and the level of anger and displeasure may have been an effect of the presence of the observer (Hawthorne effect).

Weng (2015) argues that there is a high tolerance of the non-softened use of directives and associated loss of face in the context of 'getting things done' when English language proficiency is limited. It may be that in the Vietnamese workplaces of this study bald and unmitigated use of directives is a natural result of the limited English of workers and managers alike, and so it is something for which there is a higher level of tolerance in the context of 'getting things done'. It may also be the case that such mitigation of face was a characteristic of the New Zealand workplace and an egalitarian ethos, which might not be manifested in other L1 or international workplaces when mistakes occur that disrupt production. Interestingly, Holmes and Stubbe (2015) also found that instances of miscommunication in their L1 worksites were "far less common in our data than our informants' reported perceptions might lead us to expect." (p. 139) The deep concern with communication issues reported in this study may similarly not be as large in scale if a longitudinal ethnography was undertaken in the style of the LWP and some of the production issues may not have been entirely the fault of issues in understanding of the English language if similar issues also occur in L1 workplaces. Some caution in other words needs to be applied in attempting to draw conclusions from the level of data in this study.

Despite this note of caution, a clear implication is that prospective mechanical engineers need to be prepared for a high level of flexibility in their application of English language skills in the workplace so that issues in communication can be minimised. The same finding was reported in Le et al. (2016) that Vietnamese Information Technology employees had poor pronunciation which caused conversation breakdowns. The comparison of the example in this study and the Holmes and Stubbe's example of Ginette also suggests 
that mitigation of loss of face is more likely when solidarity between managers and employees has been built in other ways, something which other parts of the data suggested had occurred in the case of Ginette and her fellow workers.

What was consistent with the findings of the LWP was that the length of the relationship between the participants was observed to affect the power relationship between them (See example 3.10 in Holmes and Stubbe, 2015, pp. 38-39). In the current study, foreign managers and Vietnamese mechanical engineers who had been working together for a long time were observed to be informal and closer to each other, and each side seemed to accept rudeness and directness in communication with each other. The length of the relationship at work helped these foreign managers to be aware of their local mechanical engineers' limited English language ability and so they could communicate in English with them to a certain extent, of course together with their appropriate adaptive communicative activities. It is of course hard to interpret how far this amounts to authentic solidarity and how far, from a critical discourse analysis perspective (Holmes \& Stubbe, 2015), these more relaxed interactions involve a kind of 'repressive discourse' which is a "more covert means of exercising 'top-down' or coercive power, in which superiors minimise overt status differences and emphasise solidarity in order to gain their interlocutor's willing compliance and goodwill" (p. 100). In terms of redressing power imbalances on the mechanical engineers' side, English ability helped them have more power in building and maintaining the relationships with their foreign managers.

Observations in the formal meeting context in this study showed low solidarity relationships. In this context the degree of formality was high. Here the stakes for the individuals and the companies were very high and so the consequences of miscommunication were also very high. To function effectively in this context the participants were required to use quite sophisticated English. People who attended this kind of meeting were required to be able to communicate in formal oral English. The participants knew what it was appropriate to say and write, something typical of 'workplace discourse' (Kassim \& Ali, 2010; Koester, 2010). In this case, it became apparent how the participants could bring financial benefits for the companies if they possessed good English communication skills (Kakepoto et al., 2012).

As reported in the data it cannot be overlooked that the high-stakes and face-losing consequences of communication issues that were reported in the interviews included loss of contracts in bidding negotiations. This could cause serious consequences not only in terms 
of financial loss but also the company's image. Once they fail in contract bidding negotiations, companies may not have enough work for their employees and will not bring the financial benefits for the company. This seriously affects both the company and its employees. As has been described in Chapter One, Vietnam is a developing country which is calling for foreign investments and cooperation, so failure such as in bidding puts Vietnamese companies at a disadvantage in the global market-place. In this sense, the implications of the lack of English are very high. At the managerial level then it became clear how critical English language use is for the success of companies. As for individuals, poor or limited English ability will affect not only their job productivity, salary and promotion, but also develop their poor image at the workplace, as has been reported in Kakepoto et al. (2012).

\subsubsection{Avoiding communication issues: adaptive strategies, saving face and high solidarity}

A significant finding that emerges from the data of this study, particularly from the interviews and observations, is how important it is for English language users to be able to adapt their usage in the lingua franca workplace in order to avoid the kinds of communication issues described above. The capacity to adapt language use is considered one of the indicators of good language skills (Lehtonen \& Karjalainen, 2008). Because the worksites were lingua franca and plurilingual where both Vietnamese engineers and foreign managers had limited English, in order to get things done they relied on various strategies, which I named as successful interactive uses of English or adaptive communicative activities. The adaptive communicative activities used by the participants in the study (as described in the findings of Chapter Six), included using body language and drawings and minimal English with technical language, a level of tolerance of bald directives, informal translation from English into Vietnamese and vice versa by Vietnamese mechanical engineers with a level of fluency in English, and code-switching. The managers and mechanical engineers described using and were observed to use technical drawings and photos as a successful means of communication. This was one of the solutions suggested by Harzing et al. (2011) who found that there were a smaller number of misunderstandings among engineers who were able to communicate "largely by using numbers and drawings rather than words" (p. 283). In this case Harzing et al. argue that, "functional culture helps overcome the language barrier" (p. 286). This idea that functional culture helps overcome the language barrier may in fact be the explanation for the degree of successful communication with minimal English which 
was observed in this study. This is reflected in the lists of technical words and the examples of telegraphic language in the data.

The tolerance of bald directives has been discussed above. It may be too strong to suggest that angry directives do not lead to loss of face as they might in a normal workplace and especially in relation to the Vietnamese culture where preserving face is of great importance. Saving one's face is a matter of culture in Vietnam and understanding this is an aspect of working in a pluricultural context. The term 'face' in this study refers to image and the identity of the speaker. Saving one's face means maintaining identity and preserving reputation and avoiding embarrassment. According to Kamoche (2001) the issue of 'face' "is particularly important in Vietnamese culture" and "what is remarkable is that Vietnamese managers have extended it to the organizational level. They talk about saving the 'company's face' by not laying people off or reducing wages" (p. 645). Similarly, saving others' face was reported to happen in an American company in Japan. SanAntonio (1987) found that competent English speaking Japanese employees helped their colleagues who had difficulty expressing their ideas in meetings. They spoke for each other to keep the meeting continuing smoothly rather than helping them overtly. In his research about the foreign managers' perspectives of communication at the international workplaces in Vietnam, Weng (2015) found that in communication, "it is most important to not offend or embarrass important others when speaking" (p. 86) and that the communication should be indirect to build and maintain good relations and harmony.

On the other hand there may be a recognition that some rudeness is a natural result of a 'poor English' or 'limited English' (see below) context. The managers in this study, as well as sometimes contributing to their employees' loss of face in the example previously discussed, seem also to have implicitly acknowledged and been aware of their employees' limited English ability as well as accepted their baldness in communication. This was particularly true when there was a low degree of formality but high solidarity relationships between the manager and mechanical engineer participants. There was a tolerance between them. This was in part because neither of the groups spoke English as their first language. This is consistent with a finding revealed by Harzing et al. (2011) that "when both parties have to speak a non-native language, they are more tolerant of the difficulties that the other party might encounter" (p. 286).

We have already discussed the significance of the 'node' position, the term established by Freely and Harzing (2003) and Marschan-Piekkari et al. (1999), held by those 
Vietnamese mechanical engineers with some fluency in English in the companies in this study. In the observation data there was also some tolerance of code-switching (a common feature of plurilingual communication) into Vietnamese to avoid miscommunication and especially when solidarity was high. SanAntonio's (1987) study of a Japanese context where code-switching was prohibited by an English-language only policy in the corporation revealed the disadvantages of not allowing code-switching especially for clarifying information. In this study the priority given to 'getting things done' allowed a variety of approaches to be adopted as necessary.

Code-switching, was observed in one of the meetings between a foreign manager and his local mechanical engineers. Mechanical engineers used Vietnamese for discussion, information clarification and consultation before addressing the manager's question. Harzing et al. (2011) state that code-switching is "present when second language users revert to talking between themselves in their native language" (p. 283). This could be the effect of inadequate linguistic skills of the employees, and the German manager in Harzing et al.'s study accepted 'the practice' even though he did not understand his employees' discussion in Japanese. Although some foreign managers in the current study seemed to accept their employees' code-switching in meetings, in one case the Southern European manager was not happy with his engineers talking in Vietnamese, and he wanted them to talk in English instead. It seemed that he did not want to be excluded from the discussion and wanted to know what was going on. These Vietnamese mechanical engineers, however, wanted to make sure that they fully understood what the issue was and that they had to come to an agreement before addressing the manager's query. This is similar to the findings of Tange and Lauring (2009) that when people encounter work-related problems they often consult someone in their language group. This study in other words reveals some of the complexity of code-switching in practice in the plurilingual context.

Besides these more functional approaches to a shared experience of 'poor English', the fact that most of the mechanical engineers had limited English ability also affected the social dimensions of the use of English in the workplace. A very strong contribution to the development of high solidarity relationships with accompanying tolerance for limited English seemed to be length of time working together. A clear example of this was seen in the interchange between the South Asian manager and his mechanical engineers. He was observed using some very positive face saving acts (see Section 7.3.2). He was very patient and tried to interpret his engineers' speech, and the effect was similar to Ruth's behaviour 
in Vine's (2004) research, when Ruth, one of the managers, even expressed her thanks to Irene (the subordinate) when she had not completed the assigned task in order to save her face.

The South Asian manager in this study not only repeated the question but also used code-switching from English into Vietnamese. This in turn demonstrated the length of his time in Vietnam, which had allowed him to develop his own knowledge of the indigenous language of his mechanical engineers. Length of time working together, Holmes and Stubbe (2015) argue, using the example of Hera, can also mitigate against baldness in directives. "Hera used very explicit directives, reflecting the fact that these two women had worked closely together for a long time and could afford to dispense with elaborate politeness strategies" (p. 38). Length of time together is probably also explanatory of the development of uses of humour, including sarcasm and affectionate teasing, in the relationship shown in the meeting in this study with the Southern European manager. Weng (2015) argues that managers should build relations not only by showing interest in the employees but also 'hanging out' with them at informal events. This was exactly what was reported of one of the foreign managers in this study. Weng further suggests that it is of vital importance to understand the employees deeply and adapt "their ways of doing things to that of the employees" (p. 87). This kind of understanding and adaptation shows respect and encourages the employees to work more closely with the managers (Weng, 2015).

In the observations, especially in meetings, humour emerged as one indication of harmonious and high solidarity relationships in the worksites in the study.

\subsubsection{Humour and the high solidarity relationship in the lingua franca workplace}

Where the data revealed humour it was mostly from the observation of meetings in the worksites of the study. The two foreign managers in the two worksites in this study frequently used humour, as described in the findings of Chapter Seven. Their use of humour in meetings could be seen as serving the different functions which were reported in Holmes and Stubbe (2015), of "a dynamic means of expressing and constructing solidarity" (p. 15) and a way of "enhancing the speaker's status within the group" (p. 111). The obviously observed results were the harmonious workplace atmosphere, high solidarity relationships and good work relations, which are similar to findings from the workplace context in the Wellington Language Project. In contrast to a claim made by Harzing and Freely (2008) that the use of humour requires a high level of fluency, this study found that humour was present 
in meeting contexts where not everyone's English was good or in other words, in the 'poor English' workplace.

In the lingua franca workplace in this study, both high and low solidarity relationships between the engineers and managers could be observed. These kinds of relationships need to be negotiated for successful workplace interactions. As has been discussed, where long-term relationships developed between Vietnamese engineers and foreign managers, high solidarity interactions were observed. So was humour. Humour helped to break the stress and power distance between the manager and his engineers. It built and maintained a high solidarity relationship between them. Power seemed to be more evenly shared when there was high solidarity. The Vietnamese workers were comfortable speaking to each other in Vietnamese within the meeting, and the foreign managers were observed not to be offended by this. This may have indicated that the length of the working relationship helped these managers understand their employees' behaviours and habits, including the use of humour and code-switching as observed. The employees' discussion of work-related issues in Vietnamese for clarification before talking with the foreign manager did not matter to their manager. Moreover, it seemed to show the understanding between the two parties and contribute to the high solidarity interaction between him and the engineers. Code-switching was perceived as a positive solution to the language barrier (Harzing et al., 2011).

The observed examples of humour suggested that humour was possible in the lingua franca workplace and showed the high solidarity relationship between foreign managers and their local engineers. However, despite the mechanical engineers' awareness of adapting their use of English for people of higher status than them, most of them had no choice except to use broken, word-by-word and technical English. They were informal even with their managers. Less offence seemed to be taken than might normally be the case when directives were given baldly by managers with minimal English to workers who also had minimal English. On some occasions, however, breakdowns or issues led to angry outbursts, which were not conducive to high solidarity.

\subsection{Chapter Summary}

The English communication needs required by mechanical engineers in the Vietnamese context were numerous when they were explored in the lens of sociolinguistics which emphasised the context of language use. These needs were reported in the 
questionnaire data and deepened in the interview and especially through the real-world observations of the participants' working days. These needs were complex in the lingua franca workplace where the engineers not only required sufficient English language skills to engage in numerous communicative events, particularly listening and speaking skills, use English for technical communication, and enact plurilingual repertoires but also an understanding of the social dimensions of this language in order to function effectively in their jobs. It was complex because of the power relationships which were closely related to the English ability of the participants. Most of the managers have acknowledged the limited English ability of most of their engineers, and so did the mechanical engineers themselves. Both groups had used different interactive uses of English and adaptive communicative activities to get rid of communication issues to a minimum extent. The managers seemed to accept their employees' rudeness and the use of humour in communication, which led to a low degree of formality but a high solidarity relationship. People seemed to be more tolerant towards other people's mistakes in using English. However, despite this agreement, things were worse when communication issues happened, even though the participants all tried to adapt their use of English.

A conclusion that can be derived from this is that if people understand why they need a specific type of English and the effect of not acquiring this type of English for the workplace, they may be motivated to learn it. What is clear is that lack of English may lead to problems in communication and that people must adapt their existing knowledge of English as much as possible to avoid miscommunication. Problems in communication and adaptive uses of English to avoid these problems are interrelated with the issue of face, whether losing or saving face, and low and high solidarity relationships. These issues together affect the power relationships in the workplace. On the contrary, possessing good English language skills means that people are equipped with a source of power. Acknowledging and understanding problems in communication is important, but finding out appropriate ways to prevent these problems is more important in the context of the lingua franca and plurilingual workplace. This is similar to the claim made by Freely and Harzing (2003) that it is important to "understand the language barrier well and to mix and match the solutions into a blend that is right for the company context" (p. 50). 


\section{CHAPTER NINE: CONCLUSIONS AND IMPLICATIONS}

\subsection{Introduction}

This chapter presents conclusions and pedagogical implication and recommendations based on the findings. These implications will be useful for tertiary institutions where undergraduates are studying engineering and for employers and mechanical engineers in the multinational workplace who are providing training for their employees. The chapter also suggests implications for future research.

The development goal of Vietnam to become a fully developed industrial country and a member of globalised organisations such as WTO and ASEAN. This mixed methods pragmatic study has shown the high frequency of the daily use of English by mechanical engineers in lingua franca worksites in the Vietnamese context and the extent of the urgent demand for an improvement in English language skills. Because the English of both the Vietnamese mechanical engineers and their foreign managers can be limited, this study has suggested the term 'poor English workplace' borrowed from Govindarajan and Gupta (2001) may be more appropriate than English lingua franca for these workplaces. It was also a finding of this study that there was a dynamic interaction among employees in the worksites because of the variety of backgrounds and cultures of the foreign managers and supervisors. This dynamic interaction creates a plurilingual and pluricultural workplace environment in the worksites in this study. Communication may be dependent on functional adaptation, such as a reliance on technical vocabulary, and using body language to convey meaning. Mechanical engineers effectiveness in the workplace may be enhanced by greater proficiency in English for the practical purpose of getting things done. Their functioning as engineers would also be assisted with increased English skills to meet the social dimensions of language use.

This study supports the Wellington Language in the Workplace Project (LWP) and similar studies (Marschan-Piekkari et al., 1999; Tange \& Lauring, 2009) in finding that social and functional dimensions of language use interact with each other in ways which can be at times empowering and at times disempowering for language users. The study suggests that adaptability of language use, especially in high solidarity relationships developed over time between managers and mechanical engineers in the lingua franca (or 'plurilingual') workplace can help to mitigate some of the potentially costly problems of communication issues in these workplaces. 


\subsection{Conclusions and Implications of the Study}

Based on the findings of this study and in comparison with the outcomes of previous research, the following conclusions and implications are provided.

Firstly it is clear that the use of English in lingua franca, plurilingual and 'poor English' workplaces is not an issue for language teachers alone. It should also be an issue for language users in the workplace, language course designers and language policymakers in general and language policymakers in multinational companies. This study concludes that ESP courses which are discipline-specific are significant for university students in general and mechanical engineering students in particular. These courses should closely meet the authentic use of English in the workplace in a way that can help students prepare the plurilingual and pluricultural competence to cope with the complex communication demands in the lingua fanca and plurilingual workplace.

This study reveals that attempting to negotiate meaning with limited English in order to avoid communication issues is intimately bound up with the power relationships in the workplaces of Vietnamese mechanical engineers. Lack of sufficient English disempowers the mechanical engineers within the company. Lack of English can also disempower the whole company at the level of contract bidding or disruption to the effective meeting of contractual obligations. The chairman of the Vietnam Association of Mechanical Industry (VAMI) claims that Vietnamese mechanical engineering enterprises were often defeated in the national marketplace (Phuong, 2014). The results of this study have some far-reaching pedagogical implications in this respect. The study revealed the power relationships of English language use in the workplace. Workers and managers in the workplace understand these complex power and pluricultural relationships but the language used to display them has not usually been considered as a part of the foreign language (L2) teaching for mechanical engineering students and other university students such as business students as well.

By using this more sociological lens, the study contributes to a larger investigation into the place of language in lingua franca and plurilingual workplaces where more than one language is spoken at the managerial level of companies. Harzing et al. (2011) argue in their study of the importance of leadership around this issue. They advocate for a greater tolerance of inevitable misunderstandings arising from language barriers, citing the CEO of the Swedish-Swiss multinational cooperation (ABB) in Govindarajan and Gupta's (2001) study, who 'named' the 'poor language' workplace as a way of making it safer for people to put 
forward ideas without being embarrassed by their lack of perfect English. This way of thinking could have an impact on operational approaches. Harzing, Koster, and Magner (2011) advocate for, among other things, the need to acknowledge that additional time to make sure messages are understood and increased redundancy in messages are built into workplaces with more than one language. They stress the value of the role of interpreters or language mediators who understand both the workplace and the languages, particularly valuing bilingual employees. This is consistent with the finding by Rajprasit and Hemchua (2015) that future engineers "will need to be bilingual" (p. 122). In this study, we have seen how beneficial the potential for code-switching on the part of managers into the indigenous language can be. Thus, people entering a lingua franca workplace should be strategically prepared this kind of knowledge and skills which include plurilingual and pluricultural competence. In other words workers and managers may not need to have language skills in all areas of the language but strategic knowledge of the language (and sometimes culture) required in particular circumstances. It is also part of a wider recognition that working between and around languages needs to be taken into account as part of the fabric of working in international companies, an understanding that this study suggests should be developed. It needs, however, to be noted that a tolerant and accommodating perspective is not the only possible approach to the issue in the marketplace. SanAntonio's (1987) study of a workplace with a one-language-only policy shows that there are currently differing policy views about the best way to address language use in companies and this, in turn, suggests the importance of an on-going discussion and increased research in this area.

Applying the 'sociolinguistic and sociopragmatic' lens (Holmes \& Stubbe, 2015) of the Wellington Language in the Workplace study to the lingua franca or plurilingual workplace with its 'thin communication' characteristics helped revealed the importance of high solidarity relationships in this study which were built and maintained through social communication together with the English for technical communication purpose. Weng (2015), as we have seen, advocates particularly for the Vietnamese context for responsibility to be taken at the management level to develop high solidarity relationships which mitigate against loss of face for the employees. This study is consonant with other recent thinking in the field and this finding in particular shows the value of approaching language use in the lingua franca workplace in a socially constructionist way, something that this study again suggests warrants further work. 
The Wellington Language in the Workplace Project stated their broad objectives as: "[T] identify characteristics of effective communication in New Zealand workplaces, to identify causes of miscommunication, and to disseminate the results of the analysis for the benefit of workplace practitioners" (Holmes \& Stubbe, 2015, p. 12). The objective of this study was also to identify the complex communication needs in the multi-national companies in Vietnam, understand the causes of communication issues and to see how people cope with these issues for the benefits of both mechanical engineers and their organisations.

A key line of argument that emerges from the study is that understanding communication issues is essential as a window into understanding the language that both employees, managers and employers need and this knowledge can be used to serve pedagogical purposes. The study found that most of the mechanical engineers in the worksites lacked not only sufficient specific English language skills to enable them to effectively communicate in a series of identified communicative events, especially technical words but also the language skills to conduct the kinds of social interactions that Holmes and Stubbe have found so useful in the L1 workplace. There was a complex interaction between the language skills needed to 'get things done' and the social language skills that could help build solidarity and so help to mitigate gaps in language. Thus, English was used not only for technical communication but also for social communication purposes.

Working from social constructionist principles, Holmes and Stubbe (2015) conclude that "No pre-packaged course can hope to prepare people for such communicative diversity and the associated challenges. Rather people need assistance in developing their observational and analytic skills, so that they can identify for themselves the appropriate ways of interacting in their specific community of practice on any particular occasion" ( $p$. 173). One way of reading this conclusion is that people need to be equipped to perform their own needs analysis process in their own language context and that this needs analysis would be usefully extended to the social dimensions of language in the workplace. A recognition of the usefulness of mobilizing plurilingual repertoires would be part of this work. If this philosophy is applied to the lingua franca workplace, it brings us back to the dimensions of the complexity of context that Munby was originally trying to capture through his muchcriticised CNP model of needs analysis and the CEF model as well. In a sense what this means is that language learners must become ethnographers of their own language contexts and, in effect, the adaptive language use seen in this study amounts to this kind of personal 
ethnographical work in progress. Those who are most successful are those who can be the most adaptive.

\subsection{What are the implications of these recommendations for the language teacher of vocational English in Vietnam?}

Since the primary purpose of this study is to provide a needs analysis to inform curriculum design for teachers and students as well as implications for communication policies in multi-national companies, the following pedagogical implications are recommended:

\subsubsection{Preparing people strategically to cope with the communication demands of the lingua} franca and plurilingual workplace

This study has revealed the complex communication demands of mechanical engineers in the Vietnamese workplaces, ranging from specific English language skills to engage in a variety of communicative events to the importance of technical vocabulary, the variety of English accents, and the social dimensions hidden behind the use of English in the lingua franca and plurilingual workplace. There were a range of key communicative events in the study requiring different levels of language knowledge and formality and including: listening to the foreign manager's requests and instructions, listening to presentations and discussions in meetings, listening to safety instructions, discussing with and explaining technical problems to the manager, attending meetings, bidding for contracts, interpreting English into Vietnamese and vice versa, reading online products' specifications and descriptions, reading technical reports, interpreting technical drawings, writing reports, and email communication. The study has found that the participants, especially the mechanical engineers had struggled to understand and be understood across this range of communicative events by using many adaptive strategies to overcome the difficulties of being lacked English language proficiency.

Thus, the first and foremost recommendation of this study is that mechanical engineers and mechanical engineering students should be strategically prepared to cope with the high communication demands of the lingua franca and plurilingual workplace. This preparation includes the English language skills to help them to approach opportunities in employment and mobility as well as to dynamically participate in the social and political practices in today's multilingual societies (Council of Europe, 2006). Relevant preparation of English language skills will help mechanical engineers and mechanical engineering 
students to function effectively in many communicative events and tasks but more practically the ability to adapt the use of English to "get things done" and to avoid communicative issues which can be costly to both individuals and their organisation. For example, people who are going to enter the lingua franca and plurilingual workplace as a mechanical engineer should be able to use English for technical communication such as key standard technical terms and the ability to interpret technical drawings. They should also be prepared how to use code-switching as well as asking for help from those who have better English ability in the company. They should learn to respect the plurilingual and cultural identities of others, the importance of language and language varieties, and the cultures embodied in languages. Moreover, they should also prepare an ability to recognise and facilitate the relationships embodied in languages and cultures (Council of Europe, 2006). People in today's lingua franca and plurilingual workplaces which require intercultural communication should be prepared for such simple strategies as taking photos of the technical problems and show the photos to the foreign manager to report the problems and using body language.

The lingua franca and plurilingual workplace requires mechanical engineers to be able to communicate in the domain of "World Englishes" including a variety of English accents as a matter of real-life communication, something which was reported by Rajprasit and Hemchua (2015) in their study of Thai computer engineers. In their study about Vietnamese teachers' perceptions of World Englishes Hao and Moore (2015) suggest that World Englishes should be incorporated and "considered a crucial task in language teaching and learning to prepare English users for effective and intelligible communication" (p. 107). This also means that ESP teachers have to learn and be aware of what is it like in an engineering firm to help their students prepare relevant English language skills, plurilingual and pluricultural knowledge to perform their job effectively. As a teacher I consider the ESP course for mechanical engineering students at my university, for example, does not seem to strategically prepare students for the variety of English communicative events, as well as the required specific English-language skills to engage in these communicative events. As a result, the students may not aware of how English is used in real-world workplace contexts or what to do when problems in communication occur, as well as the potential consequences of these problems.

To suggest a focus on the potential for communication issues is to take further current suggestions that language courses should focus as much as possible on authentic real-life 
situations in worksites, and on content over form. Rajprasit and Hemchua (2015) for example suggest that "setting the main learning objectives of English language courses for engineering students should be based on real-world workplace situations for strategically effective communication and accuracy" (p. 122). Similarly, Kilickaya (2004) argues that authentic texts "enable learners to interact with the real language and content rather than the form. Learners feel that they are learning a target language as it is used outside the classroom" (p. 4). An aspect of authenticity highlighted by this study is that university students should be equipped with sufficient English ability, including an understanding of very common aspects of the lingua franca working environment such as the variety of English accents spoken. Matsuda (2003) has previously argued that students should be offered opportunities to be exposed to various 'Englishes' in their English learning programme and if possible given the opportunity of communicating with speakers of different varieties of English. This is a good way of helping students to be used to the lingua franca workplace requiring intercultural communication.

\subsubsection{Articulating the balance between technical communication and social communication}

Besides the key finding of the crucial role of English for technical communication, English for social communication was of critical significance too. This study has highlighted the need for mechanical engineering students to develop the skills to learn and develop knowledge of technical words (Dong, 2011) as part of an emergency survival kit for language use. It has also shown the advantage for mechanical engineering students to develop some rudimentary skills in small talk which is significant in building and maintaining relationships in the lingua franca and plurilingual workplace.

This study is strongly concerned with the question of WHY people need to learn languages, something that Munby (1978) tries to answer in his CNP model of conducting a needs analysis research. More recently Huhta et al. (2013) introduced the CEF model which puts more focus on the contexts of language use and in part answers the question WHY. Huhta's model, however, does not strongly investigate the power relationships that are expressed through and derive from language use. How the WHY question can be translated into learning needs has always been a concern in the field of needs analysis, and is seen from the point of view of the learner in the work on learning needs of Hutchinson and Waters (1987).

It is worth remembering in the English for Specific Purposes (ESP) context that when language learning is for a specific purpose, the question of why people need to learn a 
particular sort of English is of crucial importance. If language teachers take the issue of social dimensions of the English language for both work and social communication into account, then they would need to plan for preparing students for this issue in English language teaching. A possible way to do this is to be more explicit about what Munby (1978) names the 'communicative key' to answer the question of why people need that language. Illustrations of the 'communicative key' have been described in the findings chapters. Since 'communicative key' refers to the manner of the person who does the activity in an event. It identifies that person's identity, role-set identity as well as social relationships and the psychosocial setting. These identifications enable us to specify the attitudes that person needs to be produced which will affect his/her linguistic choices (Munby, 1978).

In other words, people often use different types of linguistic realisations to communicate with different kinds of people in different contexts and this explains why the participants in the study adapted their use of English as much as they could depending on their English proficiency. It is also clear from the analysis of the snapshots that the social dimensions of the use of English in the workplace are pedagogically significant. The snapshots show a picture of English use in the lingua franca workplace in the study where there was a dynamic of intercultural communication among the participants even though most of them had limited English language ability. They had to code switch between English and Vietnamese to manage the communication. There were times when people got angry which affected their use of English, for example and so language use can change under pressure. Therefore, if engineering students and professional engineers as well are prepared certain types of English and the specific features of the lingua franca workplace, they will be able to adapt better and function more effectively and avoid the kinds of communication issues that could involve them in loss of face, loss of production for the company and opportunities for on-going and future employment.

It has been a trend in work on motivation in learning, in general, to avoid focusing on mistakes and rather to focus on successful learning. In language learning, this approach has underpinned the whole movement with a focus on meaning over form in communicative language teaching. There may, however, be an argument that an understanding of the consequences of communication issues and the need to avoid these issues through the strategic adaptive use of language could itself be motivating. Thus, language training can be seen as an adaptive strategy to avoid communication issues (Govindarajan \& Gupta, 2001). 
It is here that a transfer may be possible from the L1 context of much of the Wellington Language in the Workplace Project.

Holmes and Stubbe (2015) argue that the use of humour can help address issues of breakdowns in communication caused by misunderstanding, "based on the notion that if mistakes are presented humorously, workers can identify them without getting defensive" (p. 169). They suggest using the example of John Cleese's humorous training videos as a possible model for preparing workers for workplace breakdowns and low solidarity resulting from poor social language skills. This suggestion may transfer even more powerfully for preparation for the lingua franca or 'poor English' context and language teaching that prepares for it. The ground for the reality of communication issues could be set through language teaching, but in a low-key and humorous way that might also help workers become more resilient to the consequences of issues in communication in workplaces that, the Wellington Language in the Workplace study shows, also occur when workers mostly share the same first language. Similarly, digital technologies could help prospective workers learn some of the skills to negotiate social contexts in the workplace to help build the solidarity in workplace relationships that in turn helps mitigate communication issues when they do occur. In other words, the findings of the Wellington Language in the Workplace Project may apply even more urgently to the kinds of language contexts seen in this study.

\subsubsection{Mobilizing plurilingual repertoires in the workplace}

Findings revealed that all the worksites in this study were plurilingual and that the plurilingual repertoires were mobile. This mobility included codeswitching and interpreting from English into Vietnamese and vice versa. In the 'poor English' workplaces, people have to struggle to communicate and this fact requires them to be prepared with plurilingual repertoires, something which has been integrated in language teaching and learning in the European school of Luxembourg where students have different first languages (Ziegler, Durus, \& Sert, 2013). As described in the Common European Framework of Reference for Languages (CEFR) by the Council of Europe, the aim of language education is "to develop a linguistic repertory, in which all linguistic abilities have a place" and "that the languages offered in educational institutions should be diversified and students given the opportunity to develop a plurilingual competence" (Council of Europe, 2001, p. 5). Policies for education should take plurilingualism into account to help teachers and students be aware of the importance of being prepared a plurilingual competence not only for work and leisure purposes but also for their social and political inclusion in society (Council of Europe, 2006). 
Findings also revealed that language skills were significant if the participants were to benefit from employment and mobility opportunities. Language skills were also necessary for them to participate actively in the social relationships in the lingua franca and plurilingual workplace. Thus, the development of the individual's plurilingual repertoire is a lifelong enrichment (Council of Europe, 2006).

The Council of Europe states:

This repertoire is made up of different languages and language varieties at different levels of proficiency and includes different types of competences. It is dynamic and changes in its composition throughout an individual's life. The use and development of an individual's plurilingual competence is possible because different languages are not learned in isolation and can influence each other both in the learning process and communicative use. Education systems need to ensure the harmonious development of learners' plurilingual competence through a coherent, transversal and integrated approach that takes into account all the languages in learners' plurilingual repertoire and their respective functions. This includes promoting learners' consciousness of their existing repertoires and potential to develop and adapt those repertoires to changing circumstances. (Council of Europe, 2006, p. 5)

Findings of this study suggest a similar pedagogical implication as specified by Council of Europe in terms of developing the plurilingual and pluricultural competence for professional mechanical engineers, mechancial engineering students, and other learners as well. Talking about this kind of competence means something to do with the communicative competence of people who are named as 'social actors' who have "a complex body of knowledge, skills, attitudes and values which, by controlling and using the resources of language" (Coste et al., 2009, p. 9) to perform themselves and interact with others in a specific setting.

\subsubsection{Implications for teaching}

It is difficult to provide specific direction for course design and teaching at the end of this thesis because of the principle that planning should ideally be informed by an analysis of students' learning needs. This analysis proved to be beyond the scope of this thesis. However, this is a natural next step. From the findings of this study, it is possible to suggest some general directions in current approaches to teaching and learning which may most naturally align with the other recommendations made to this point. In their support for the CEF Professional Profile approach Gollins-Kries et al (2015, p. 124) argue for course design "characterised by project work, simulations and holistic communicative activities." 
Teaching and learning activities which are able to access both the functional task aspects of the life of the mechanical engineer and the social interactions in mechanical engineering workplaces could be helpful. The emphasis in learning task design should be on the adaptability and flexibility central to language negotiation in the plurilingual and pluricultural workplace.

In this case the current Teaching Method approach which may be most useful could be Task-Based Language Teaching (TBLT). This possible approach to language teaching if seen from the perspective of language teaching methods might then best align with TaskBased Language Teaching (TBLT). A Task-Based Language Teaching approach "refers to the use of tasks as the core unit of planning and instruction in language teaching" (Richards \& Rodgers, 2014, p. 174). In the light of the TBLT, students are given functional tasks with a focus on meaning exchange and for real-world language use, and not for linguistic purposes (Van den Branden 2006: cited in Richards \& Rodgers 2014). The CEFR also recommends a task-based approach, describing tasks as "a feature of everyday life in the personal, public, educational or occupational domains" (Council of Europe, 2001, p. 157). Tasks then can become "a unit of design in a communicative curriculum" (Crabbe, 2007, p. 117). In general terms such tasks may involve language activities such as story writing, problem solving, interpreting a role in a play, taking part in a discussion, giving a presentation, email communication. These communication activities are an integral parts of tasks where people are involved in interaction (Council of Europe, 2001). Examples of 'real-life' interaction are: "interacting with a public service official and completing a form, reading a report and discussing it with colleagues in order to arrive at a decision on a course of action, following written instructions while assembling something, and if an observer/helper is present, asking for help or describing/commenting on the process; preparing (in written form) and delivering a public lecture, interpreting informally for a visitor, etc." (Council of Europe, 2001, p. 157).

The current study has revealed a range of real-world communicative events that mechanical engineers engaged in such as listening to the foreign manager's requests and instructions, discussing work issues, reading manual instructions, attending meetings, and interpreting from English into Vietnamese and vice versa. A language programme could be designed around these types of communicative events.

Chowda, Chilakapati, and Parthu (2014) argue that project work can involve and form a culture of working together to accomplish certain goals and this can lead to considerable practice of English. In this case, students will have to find relevant information and data to complete their project which help their mastery of language. Once a class is 
organised around tasks, the teacher of that class is providing his/her students with learning opportunities organised around communication (Crabbe, 2007). Crabbe argues that the teacher plays an important role in helping learners to manage learning and that both teachers and learners need to understand the concepts of 'tasks' and 'learning opportunities' to make the language learning transparent and well managed (Crabbe, 2007). Project work for mechanical engineering students could be built around authentic workplace scenarios.

Together with project work, it is important that simulations and holistic communicative activities for mechanical engineering students involve technical vocabulary. Students could be given tasks in terms of such workplace scenarios as a manager telling a mechanical engineer to do something or assigning a task for him/her. Role playing realworld workplace scenarios could also involve people greeting each other and being involved in small talk. Other possible teaching tasks could include interviews with real professional mechanical engineers or videos of scenarios or even real-life recording of situations which take place in today's lingua franca, plurilingual and pluricultural workplace.

\subsection{Limitations of the Study and Suggestions for Further Research.}

It is clear from the discussion above that a limitation of this study is the lack of data from mechanical engineering students of English and their teachers, collected but not yet analysed in this project. This has meant that the 'learning needs' dimension of the model for language learning curriculum design suggested by Hutchinson and Waters (1987) has not been able to be addressed in this study, and suggestions and implications for developing language-teaching courses based on the needs analysis work of the study come from findings of the target needs only. This is a clear area for future research.

The main limitation is in the scope of the study. The ability to generalise from questionnaire data is affected by the size of the sample. In this study, the findings from the survey can only be treated as indicative. The study was unable to gain the depth of examination of some of the studies in the Wellington Language in the Workplace Project in which data were collected over a long period of time, using digital recorders to both audio and video record the actual workplace interactions. A more fully ethnographic study of language in these or similar workplaces would be invaluable. As mentioned in Section 4.4 on ethical considerations, a more distanced role by the researcher in the ways set up by the LWP study would also be helpful to avoid any distortion of findings due to the direct presence of the researcher. More detailed data could also enable a case-study approach to be taken to different worksites to enable a comparison between them. This would be particularly 
useful to ascertain how important variants in contextual factors within the same industry are for language use.

Finally, a very interesting area of research is the power relationships in lingua franca and 'poor English' workplaces from an eclectic approach as employed by the LWP, especially a critical discourse analysis perspective. Critical discourse analysis (CDA) has not been used as an analytical analysis approach in this study. The current study has uncovered the importance of possessing good English language skills for career advancement and so to improve levels of empowerment. However, the study has only cast a little light into this area by using a thematic analysis approach but has not gone deep enough to capture a fuller picture of the power relationships in these particular lingua franca workplaces. Taking the Kone context examined by Marschan-Piekkari et al. (1999) as an example, a CDA study on power relationships to study the power imbalance for companies run by foreign organisations in the lingua franca workplace could be a useful further area of investigation with implications for indigenous workers of international companies.

\subsection{Concluding Statement}

This study has explored the various English communication needs required by Vietnamese mechanical engineers in the lingua franca, plurilingual and pluricultural workplace, or so-called 'poor English' workplace, to inform curriculum design. Unless the more complex social aspects of English use in the workplace are examined, needs analysis studies may not reveal a fuller picture of workplace communication and therefore may not provide relevant pedagogical implications for the training of this language at multinational companies, vocational training institutions and the tertiary level as well.

My own direct experience as a teacher of English with five-years' experience teaching English for mechanical engineering students before starting to pursue this doctoral research is that the students are ill-equipped for the sort of real-world context of plurilingual and pluricultural lingua franca workplace with inevitable communication issues. The ESP course for mechanical engineering students at my university, for example, does not strategically prepare them for the variety of English communicative events, as well as the required specific English-language skills to engage in these communicative events effectively. So, what I can learn from this study is that students should be prepared for what they will actual use and encounter in their future workplace to help them meet the demands of the job required by their profession and employers. Thus, this study has filled the urgent need in exploring the complexity of language use in today's lingua franca workplace. 


\section{REFERENCES}

Ab.Rahim, S. (2008). A needs analysis on the engineering undergraduates' communication skills. Esteem: Academic Journal UiTM Pulau Pinang, 4(2), 163-184.

Abbott, G. (1980). ESP and TENOR. ELT Documents, 107, 122-124.

Adzmi, N.A., Bidin, S., \& Ibrahim, S. (2009). The academic English language needs of industrial design students in UiTM Kedah, Malaysia. English Language Teaching, 2(4), 171-178.

Aichhorn, N., \& Puck, J. (2017). Bridging the language gap in multinational companies: Language strategies and the notion of company-speak. Journal of World Business, 52(3), 386-403. doi:https://doi.org/10.1016/j.jwb.2017.01.002

Al-Khatib, M.A. (2005). English in the workplace: An analysis of the communication needs of tourism and banking personnel. Asian EFL Journal, 7(2).

Al-Tamimi, A.S., \& Shuib, M. (2010). Investigating the English language needs of Petroleum engineering students at Hadhramount university of science and technology. The Asian ESP Journal, 4(1), 6-34.

Alharby, M. (2005). ESP target situation needs analysis: The English language communication needs as perceived by health professional in the Riyadh area. (Unpublished Ph.D. thesis), The University of Georgia, Georgia.

Allen, J.A., Lehmann-Willenbrock, N., \& Sands, S.J. (2016). Meetings as a positive boost? How and when meeting satisfaction impacts employee empowerment. Journal of Business Research, 69(10), 4340-4347. doi:http://dx.doi.org/10.1016/j.jbusres.2016.04.011

Alshumaimeri, Y. (2009). Needs analysis. Course content for CI 584. Retrieved from http://faculty.ksu.edu.sa/yousif/Course $\% 20$ content $\% 20$ for $\% 20 \mathrm{CI} \% 20584 / \mathrm{Needs} \% 2$ 0Analysis.pdf

Anh, K.H.K. (2010). Use of Vietnamese in English language teaching in Vietnam: Attitudes of Vietnamese university teachers. English Language Teaching, 3(2), 119-128.

Artemeva, N., Logie, S., \& St-Martin, J. (1999). From page to stage: How theories of genre and situated learning help introduce engineering students to discipline-specific communication. Technical Communication Quarterly, 8(3), 301.

Barbara, S. (2011). Understanding English as a lingua franca. Oxford: Oxford University Press. 
Bargiela-Chiappini, F., \& Harris, S. (1997). Managing language: The discourse of corporate meetings. Amsterdam: J. Benjamins.

Barsoux, J.L. (1996). Why organisations need humour. European Management Journal, 14(5), 500-508. doi:http://dx.doi.org/10.1016/0263-2373(96)00044-8

Bayyurt, Y. (2013). Current perspectives on sociolinguistics and English language education. The Journal of Language Teaching and Learning, 1, 69-78.

Beacco, J.C. (2005). Languages and language repertoires: Plurilingualism as a way of life in Europe. Council of Europe: Strasbourg.

Belcher, D. (2006). English for specific purposes: Teaching to perceived needs and imagined futures in worlds of work, study, and everyday life. TESOL Quarterly, 40(1), 133-156.

Belcher, D. (2009). What ESP is and can be: An introduction. In D. Belcher (Ed.), English for specific purposes in theory and practice (pp. 1-20). United States of America: University of Michigan Press.

Berwick, R. (1989). Needs assessment in language programming: From theory to practice. In R. K. Johnson (Ed.), The second language curriculum (pp. 48-62). Cambridge: Cambridge University Press.

Bhattacharyya, E. (2014). Walk the talk: Technical oral presentations of engineers in the 21st century. Procedia - Social and Behavioral Sciences, 123, 344-352. doi:http://dx.doi.org/10.1016/j.sbspro.2014.01.1432

Bhattacharyya, E., Nordin, S., \& Salleh, R. (2009). Internship students' workplace communication skills: Workplace practices and university preparation. International Journal of Learning, 16(11), 439-452.

Biesta, G. (2010). Pragmatism and the philosophical foundations of mixed methods research. In A. Tashakkori \& C. Teddilie (Eds.), SAGE handbook of mixed methods in social \& behavioral research (2nd ed., pp. 95-117). Los Angeles: SAGE.

Bjorkman, B. (2008). English as the lingua franca of engineering education. Nordic Journal of English Studies, 7(3), 103-122.

Blum-Kulka, S., House, J., \& Kasper, G. (1989). Cross-cultural pragmatics: Requests and apologies Norwood: Ablex Pub. Corp.

Bogdan, R., \& Biklen, S. (1992). Qualitative research for education: An introduction to theory and methods. Boston: Allyn and Bacon.

Bonamy, D. (1994). English for technical students 2. Moscow: Longman.

Bourdieu, P. (1991). Language and symbolic power Cambridge: Harvard University Press. 
Boxer, D. (2002). Applying sociolinguistics: Domains and face-to-face interaction. Philadelphia: John Benjamins Publishing Company.

Braun, V., \& Clarke, V. (2006). Using thematic analysis in psychology. Qualitative Research in Psychology, 3(2), 77-101. doi:10.1191/1478088706qp063oa

Brewer, P. E. (2010). Miscommunication in international virtual workplaces: A report on a multicase study. IEEE Transactions on Professional Communication, 53(4), 329345. doi:10.1109/TPC.2010.2077430

Brindley, G.P. (1989). The role of needs analysis in adult ESL program design. In R. K. Johnson (Ed.), The second language curriculum (pp. 63-78). Cambridge: Cambridge University Press.

Brown, J.D. (1995). The elements of language curriculum: A systematic approach to program development: Heinle \& Heinle.

Brown, J.D. (2016). Introducing needs analysis and English for specific purposes. . New York: Routledge.

Brown, P., \& Levinson, S.C. (1987). Politeness: Some universals in language usage. Cambridge: Cambridge University Press.

Brunton, M. (2009). An account of ESP - with possible future directions. English for Specific Purposes, $8(3$ (24)).

Burton, D., \& Bartlett, S. (2005). Practitioner Research for Teachers: SAGE Publications.

Calhoun, C. (2002). Dictionary of the Social Sciences (1st ed.): Oxford University Press.

Candlin, C., \& Crichton, J. (2011). Discourses of deficit New York: Palgrave Macmillan.

Canh, L.V. (2011). Form-focused instruction: A case study of Vietnamese teachers' beliefs and practices. (Unpublished Ph.D. thesis ), The University of Waikato, New Zealand.

Caraiman, C.D. (2014). A practical approach to the methodology of ESP teaching Challenges of the Knowledge Society, 916-922.

Caudron, S. (1992). Humor is healthy in the workplace. Personnel Journal, 71(6), 63.

Chia-Jung, T. (1991). English communication skills needs of professionals in Taiwan's high-technology industries. IEEE Transactions on Professional Communication, 34(2), 79-82. doi:10.1109/47.87616

Chia, H.U., Johnson, R., Chia, H.L., \& Olive, F. (1999). English for college students in Taiwan: A study of perceptions of English needs in a medical context. English for Specific Purposes, 18(2), 107-119. 
Choi, K. (2005). Needs analysis of students of Tourism English. Proceedings of the 10th Conference of Pan-Pacific Association of Applied Linguistics, 57-68. Retrieved from http://www.paaljapan.org/resources/proceedings/PAAL10/pdfs/kyunghee.pdf

Chowda, J., Chilakapati, N.R., \& Parthu, V.V. (2014). The role of project work in language teaching. International Journal of English Language, Literature and Humanities, II(III), 311-314.

Chung, T. (2014). Development strategy for Vietnam's mechanical engineering industry.

Retrieved from http://vovworld.vn/en-US/Economy/Development-strategy-forVietnams-mechanical-engineering-industry/233031.vov

Cogo, A. (2015). English as a lingua franca: Descriptions, domains and applications. In H. Bowles (Ed.), International perspectives on English as a lingua franca: Pedagogical insights (pp. 1-12). London: Palgrave Macmillan UK.

Cohen, L. (2011). Research methods in education (7th ed.). New York: Routledge.

Coste, D., Moore, D., \& Zarate, G. (2009). Plurilingual and pluricultural competence. Strasbourg: Council of Europe.

Council of Europe. (2001). Common European framework of reference for languages: Learning, teaching, assessment. Cambridge: Cambridge University Press.

Council of Europe. (2006). Plurilingual education in Europe. Strasbourg: Language Policy Division.

Coupland, N., Wiemann, J.M., \& Giles, H. (1991a). "Miscommunication" and problematic talk. Newbury Park: Sage Publications.

Coupland, N., Wiemann, J.M., \& Giles, H. (1991b). Talk as 'problem' and communication as 'miscommunication': An integrative analysis. In N. Coupland, H. Giles, \& J. M. Wiemann (Eds.), 'Miscommunication' and problematic talk. London: Sage Publications.

Coxhead, A. (1998). An academic word list. English Language Institute Occasional Publication, 18.

Coxhead, A. (2000). A new academic word list. TESOL Quarterly, 34(2), 213-238.

Crabbe, D. (2007). Learning opportunities: Adding learning value to tasks. ELT Journal, 61(2), 117-125.

Craig, D., \& Pitts, M. K. (1990). The dynamics of dominance in tutorial discussions. Linguistics: An Interdisciplinary Journal of the Language Sciences, 28(1), 125-138. Creswell, J.W. (2003). Research design: Qualitative, quantitative, and mixed methods approaches (2nd ed.). Thousand Oaks: SAGE Publications. 
Creswell, J.W. (2007). Qualitative inquiry \& research design: Choosing among five approaches (2nd ed.). Thousand Oaks: Sage Publications.

Creswell, J.W. (2014a). Educational research: Planning, conducting and evaluating quantitative and qualitative research (4th ed.). Harlow, Essex: Pearson.

Creswell, J.W. (2014b). Research design: Qualitative, quantitative, and mixed methods approaches. Thousand Oaks: SAGE Publications.

Creswell, J.W. (2015, 7 December). [Mixed methods research seminar].

Creswell, J.W., \& Plano Clark, V.L. (2007). Designing and conducting mixed methods research. Thousand Oaks: Sage Publications.

Creswell, J.W., \& Plano Clark, V.L. (2011). Designing and conducting mixed methods research. Los Angeles: SAGE Publications, Inc.

Creswell, J.W., \& Poth, C.N. . (2018). Qualitative inquiry \& research design: Choosing among five approaches (4th ed.). Thousand Oaks: SAGE.

Daloglu, A., \& Isik Tas, E. (2007). Assessing English language learners' needs and lacks. Education and Science, 32(146), 64-79.

Deckert, S.K., \& Vickers, C.H. (2011). An introduction to sociolinguistics: Society and identity. London: Continuum.

Denzin, N.K., \& Lincoln, Y.S. (2000). The handbook of qualitative research (2nd ed.). Thousand Oaks: Sage Publications.

Diallo, M.S. (2007). English needs analysis of Science and Technology students at Cheikh Anta Diop University in Dakar (UCAD). (Unpublished Ph.D. thesis), University of Maryland, USA.

Dickie, J. (2008). An investigation of sites, uses and practices for literacy in the lives of Pasifika students. (Unpublished Ph.D. thesis), Victoria University of Wellington, New Zealand.

Dong, L.Q. (2011). Tiếng Anh chuyên ngành - Một số vấn đề về nội dung giảng dạy (English for Specific Purposes - Some issues of teaching content) [In Vietnamese]. Ngon Ngu \& Doi Song Journal, 11(193), 27-32.

Dudley-Evan, T., \& St John, M.J. (1998). Developments in English for specific purposes: A multi-disciplinary approach. Cambridge: Cambridge University Press.

Dudley-Evans, T. (2000). Genre analysis: A key to a theory of ESP? Journal of the European Association of Languages for Specific Purposes (AELFE), 2, 3-11. 
Dung, D.T.X. (2011). Dạy và học tiếng Anh chuyên ngành theo nhu cầu xã hội (Teaching and learning English for specific purposes in accordance with the social needs) [In Vietnamese]. Ngon Ngu \& Doi Song Journal, 12(194), 37-44.

Duyen, L.T.H. (2014). Learning to teach ESP: Case studies of two Vietnamese general English teachers. Language Education in Asia, 5(2), 228-337.

Evans, S. (2013). Perspectives on the use of English as a business lingua franca in Hong Kong. Journal of Business Communication, 50(3), 227-252. doi:10.1177/0021943613487073

Fairclough, N. (1989). Language and power. London: Longman.

Fatihi, A.R. (2003). The role of needs analysis in ESL program design. South Asian Language Review, 8(1\&2), 39-59.

Field, A.P. (2009). Discovering statistics using SPSS: (and sex and drugs and rock ' $n$ ' roll) (3rd ed. ed.). London: SAGE Publications.

Finch, G. (2005). Key concepts in language and linguistics (2nd ed.). Basingstoke: Palgrave Macmillan.

Fontana, A., \& Frey, J.H. (2000). The interview: From structured questions to negotiated text. In N. K. Denzin \& Y. S. Lincoln (Eds.), Handbook of qualitative research (2nd ed., pp. 645-672). Thousand Oaks: Sage Publications, Inc.

Freely, A.J., \& Harzing, A.W. (2003). Language management in multinational companies. Cross Cultural Management: An International Journal, 10(2), 37-52.

Garcia, L.G. (2013). The importance of needs analysis in syllabus and course design. The CMC-E Project: A Case in Point.

Garcia, L.G. (n.d.). The importance of needs analysis in syllabus and course design. The CMC_E project: A case in point. Retrieved from http://www.spertus.es/Publications/Lidia/valladolid.pdf

Geimer, J.L., Leach, D.J., DeSimone, J.A., Rogelberg, S.G., \& Warr, P.B. (2015). Meetings at work: Perceived effectiveness and recommended improvements. Journal of Business Research, 68(9), 2015-2026. doi:http://dx.doi.org/10.1016/j.jbusres.2015.02.015

General Statistics Office of Vietnam. (2015). Dân số Việt Nam năm 2014 vượt mốc 90 triệu người (Vietnam Population exceeded 90 million in 2014) [In Vietnamese]. Retrieved from https://www.gso.gov.vn/Default.aspx?tabid=382\&ItemID=15148

Gollin-Kies, S., Hall, D., \& Moore, S. (2015). Language for specific purposes. London: Palgrave Macmillan. 
Govindarajan, V., \& Gupta, A. (2001). Building an effective global business team. MIT Sloan Management Review, 42(4), 63-71.

Guba, E.G. (1990). The paradigm dialog. Newbury Park: Sage Publications.

Ha, L.P. (2004). University classrooms in Vietnam: Contesting the stereotypes. ELT Journal, 58(1), 50-57.

Ha, L.P. (2005). Munby's 'needs analysis' model and ESP. Asian EFL Journal, 7(1), 150158.

Hadley, G. (2014). Needs analysis for language course design: A holistic approach to ESP (Book review) (Vol. 35, pp. 89-90).

Hall, D.R. (2013). Introduction. In D. R. Hall (Ed.), Needs analysis for language course design: A holistic approach to ESP (pp. 1-8). Cambridge: Cambridge University Press.

Hanh, H. (2016, June 13). Sẽ đóng cửa Trung tâm khảo thí tiếng Anh yếu kém, có biểu hiện tiêu cực (Unqualified and cheating English testing centres will be closed) [In Vietnamese]. Dan Tri Newspaper. Retrieved from http://dantri.com.vn/giao-duckhuyen-hoc/bo-giao-duc-ra-soat-co-so-dao-tao-tien-si-tu-nam-201320160613155047306.htm

Hanks, P., \& McLeod, W.T. (Eds.). (1986) Collins dictionary of the English language (2 ed.). London: Collins.

Hao, T.T., \& Moore, P. (2015). Vietnamese English teachers' perceptions on incorporating world Englishes into their teaching. Language Education in Asia, 6(2), 107-121.

Harzing, A.W., \& Freely, A.J. (2008). The language barrier and its implications for HQsubsidiary relationships. Cross Cultural Management: An International Journal, 15(1), 49-61.

Harzing, A.W., Köster, K., \& Magner, U. (2011). Babel in business: The language barrier and its solutions in the HQ-subsidiary relationship. Journal of World Business, 46(3), 279-287. doi:https://doi.org/10.1016/j.jwb.2010.07.005

Hiep, P.H. (2005). University English classrooms in Vietnam. ELT Journal, 59(4), 336338.

Hoai, P.A., \& Binh, T.T. (2016). Developing theoretical framework for ESP teacher training in Vietnam. The Asian ESP Journal, 12(1).

Hoang, V.V. (2010). The current situation and issues of the teaching of English in Vietnam. Retrieved from www.ritsumei.ac.jp:

Holmes, J. (1992). An introduction to sociolinguistics. New York: Longman Publishing. 
Holmes, J. (2000). Victoria University of Wellington's language in the workplace project: An overview. Language in the Workplace Occasional Papers, (1). Retrieved from http://www.victoria.ac.nz/lals/centres-and-institutes/language-in-theworkplace/publications/occasional-papers

Holmes, J. (2006). Sharing a laugh: Pragmatic aspects of humor and gender in the workplace. Journal of Pragmatics, 38(1), 26-50. doi:http://dx.doi.org/10.1016/j.pragma.2005.06.007

Holmes, J. (2007). Making humour work: Creativity on the job. Applied Linguistics, 28(4), 518-537. doi:10.1093/applin/amm048

Holmes, J., Marra, M., \& Schnurr, S. (2008). Impoliteness and Ethnicity: Māori and Pākehā Discourse in New Zealand Workplaces. Journal of Politeness Research: Language, Behavior, Culture, 4(2), 193-219. doi:10.1515/JPLR.2008.010

Holmes, J., \& Meyerhoff, M. (1999). The community of practice: Theories and methodologies in language and gender research. Language in Society, 28(2). doi:10.2307_4168923

Holmes, J., \& Stubbe, M. (2015). Power and politeness in the workplace: A sociolinguistic analysis of talk at work (2nd ed.). New York: Routledge.

Holmes, J., Stubbe, M., \& Vine, B. (1999). Constructing professional identity: "Doing power" in policy units. In S. Sarangi \& C. Roberts (Eds.), Talk, work, and institutional order: Discourse in medical, mediation, and management settings (pp. 351-385). New York: Mouton de Gruyter.

House, J., Kasper, G., \& Ross, S. (2003). Misunderstanding talk. In J. House, G. Kasper, \& S. Ross (Eds.), Misunderstanding in social life: Discourse approaches to problematic talk. Harlow: Longman.

Huhta, M. (2010). Language and communication for professional purposes - Needs analysis methods in industry and business and their yield to stakeholders. (Unpublished Ph.D. thesis), Helsinki University of Technology, Finland.

Huhta, M., Vogt, K., Johnson, E., Tulkki, H., \& Hall, D.R. (2013). Needs analysis for language course design: A holistic approach to ESP. Cambridge: Cambridge University Press.

Hung, L.T. (2006). Cơ khí Việt Nam: Thách thức trước "cuộc chơi lớn" (Vietnamese mechanical engineering: Challenge before "a big game") [In Vietnamese]. Retrieved from http://www.vusta.vn/vi/news/Thong-tin-Su-kien-Thanh-tuu-KHCN/Co-khi-Viet-Nam-Thach-thuc-truoc-cuoc-choi-lon-9932.html 
Huong, N.T. (2015). An investigation into students' motivation to learn English in higher education in Vietnam. (Unpublished Ph.D. thesis), Queensland University of Technology, Australia.

Huong, P.T. (2009). "Students' needs \& current ESP curriculum at Marketing university: A critical look". (Unpublished Master's thesis), Ho Chi Minh City Open University, Ho Chi Minh City, Vietnam.

Huong, T.N.N, \& Hiep, P.H. (2010). Vietnamese teachers' and students' perceptions of global English. Language Education in Asia, 1, 48-61.

Hutchinson, T., \& Waters, A. (1987). English for specific purposes: A learning-centred approach. Cambridge: Cambridge University Press.

Investment \& Trade Promotion Centre. (n.d.). Vietnam's mechanical engineering industry. Retrieved from http://www.itpc.gov.vn/importers/opportunities/Engineering/overview/Engineering _industry/mldocument_view/?set_language=en

Irvine, F., Roberts, G., \& Bradbury-Jones, C. (2008). The researcher as insider versus the researcher as outsider: Enhancing rigour through language and cultural sensitivity. In P. Liamputtong (Ed.), Doing cross-cultural research ethical and methodological perspectives. Dordrecht: Springer Netherlands.

Iwai, T., Kondo, K., Limm, S.J.D., Ray, E.G., Shimizu, H., \& Brown, J.D. (1999). Japanese language needs analysis. Retrieved from http://nflrc.hawaii.edu/NetWorks/NW13.pdf

Jasone, C., \& Durk, G. (2013). Towards a plurilingual approach in English language teaching: Softening the boundaries between languages. TESOL Quarterly, 47(3), 591-599. doi:doi:10.1002/tesq.121

Jasso-Aguilar, R. (1999). Sources, methods and triangulation in needs analysis: A critical perspective in a case study of Waikiki hotel maids. English for Specific Purposes, 18(1), 27-46.

John, A. (1991). English for specific purposes: Its history and contribution. In M. CelceMurcia (Ed.), Teaching English as a second or foreign language (pp. 67-77). Boston, MA: Heinle \& Heinle.

Johnson, B., \& Christensen, L. (2008). Education research: Quantitative, qualitative, and mixed approaches (3rd ed.). Los Angeles: SAGE Publications.

Jordan, R.R. (1997). English for academic purposes: A guide and resource book for teachers. Cambridge Cambridge University Press. 
Kaewpet, C. (2008). Meeting the needs of engineering students in an ESP EFL Thai university context. (Unpublished Ph.D. thesis), The University of Melbourne, Australia.

Kaewpet, C. (2009a). Communication needs of Thai civil engineering students. English for Specific Purposes, 28, 266-278.

Kaewpet, C. (2009b). A framework for investigating learner needs: Needs analysis extended to curriculum development. Electronic Journal of Foreign Language Teaching, 6(2), 209-220.

Kaewpet, C. (2011a). Learning needs of Thai civil engineering students. The Asian ESP Journal, 7(3), 79-105.

Kaewpet, C. (2011b). A sociolinguistic approach to oral and written communication for engineering students. Asian Social Science, 7(10), 183-187.

Kakepoto, I., Omar, N.A.M., Boon, Y., \& Iqbal, S.M.Z. (2012). Perspectives on oral communication skills for engineers in engineering profession of Pakistan. International Journal of Applied Linguistics \& English Literature, 1(5), 176-183.

Kamoche, K. (2001). Human resources in Vietnam: The global challenge. Thunderbird International Business Review, 43(5), 625-650. doi:10.1002/tie.1019

Kaneko, E., Rozycki, W., \& Orr, T. (2009). Survey of workplace English needs among Computer Science graduates. Paper presented at the Institute of Electrical and Electronics Engineers (IEEE) International Professional Communication Conference 2009 (IPCC 2009), Honolulu, HI.

Karimi, P., \& Sanavi, R.V. (2014). Analyzing English language learning needs among students in Aviation training program. Procedia - Social and Behavioral Sciences, 98, 852-858. doi:http://dx.doi.org/10.1016/j.sbspro.2014.03.491

Kasper, G. (2004). Misunderstanding talk. Retrieved from www2.hawaii.edu

Kassim, H., \& Ali, F. (2010). English communicative events and skills needed at the workplace: Feedback from the industry. English for Specific Purposes, 29, 168182.

Kassim, H., \& Radzuan, N.R.M. (2008). Resolving conflict: Enhancing engineering students' English fluency through workplace situation. The International Journal of Learning, 14(11), 51-60.

Kaur, S. (2007). ESP course design: Matching learner needs to aims. English for Specific Purposes, 6(1). 
Kaur, S., \& Ayub Khan, A.B.M. (2010). Language needs analysis of Art and Design students: Considerations for ESP course design. ESP World, $9(2$ (28)), 1-16.

Kell, S., Marra, M., Holmes, J., \& Vine, B. (2007). Ethnic differences in the dynamics of women's work meetings. Multilingua: Journal of Cross-Cultural and Interlanguage Communication, 26(4), 309-331. doi:10.1515/MULTI.2007.016

Khuong, L.Q., \& Chi, T.T.P. (2008). Exploring the learning needs of electronics students at Hue Industrial College: Towards a suggested syllabus. Journal of Science and Technology, Da Nang University, 4(27), 153-159.

Kilickaya, F. (2004). Authentic materials and cultural content in EFL classrooms. The Internet TESL Journal, 10(7), 1-5.

Kirkpatrick, A. (2008). English as the official working language of the Association of Southeast Asian Nations (ASEAN): Features and strategies. English Today: The International Review of the English Language, 24(2), 27-34.

Kirkpatrick, A. (2010). English as a lingua franca in ASEAN: A multilingual model. Hong Kong Hong Kong University Press.

Kirkpatrick, A. (2012). English in ASEAN: Implications for regional multilingualism. Journal of Multilingual and Multicultural Development, 33(4), 331-344. doi:10.1080/01434632.2012.661433

Koester, A. (2010). Workplace discourse. London: Continuum International Publishing Group.

Korovyakovskaya, I., \& Chong, H. (2015). An empirical study of the relationships between miscommunication and conflict in culturally diverse work groups. Journal of International Business Research, 14(3), 41-54.

Kumari, P., \& Rahman, M. (2012). A needs analysis of underprivileged technical students at Indian school of Mines, Dhanbad, India. The Asian ESP Journal, 8(4), 93-124.

Lambert, C. (2010). A task-based needs analysis: Putting principles into practice. Language Teaching Research, 14(1), 99-112.

Le, V.T.H., Wyatt, M., \& McCullagh, M. (2016). Exploring the gap between Vietnamese workplace communication in English and English language teaching at a university. The Asian ESP Journal, 12(1), 8-38.

Lehtonen, T., \& Karjalainen, S. (2008). University graduates' workplace language needs as perceived by employers. System, 36(3), 492-503. doi:http://dx.doi.org/10.1016/j.system.2008.01.003 
Linderman, S. (2005). Who speaks "broken English"? US undergraduates' perceptions of non-native English. International Journal of Applied Linguistics, 15(2).

Liyong, Z. (2006). Developing listening and speaking skills in ELT classroom Journal of China English Language Education Association (CELEA), 29(4), 112-115.

Loi, N.V. (2011). Dynamic conceptions of input, output and interactions: Vietnamese EFL lecturer learning second language acquisition theory. (Unpublished Ph.D. thesis), The University of Waikato, Hamilton, New Zealand.

Long, M.H. (2005a). Methodological issues in learner needs analysis. In M. H. Long (Ed.), Second language needs analysis (pp. 19-78). Cambridge: Cambridge University Press.

Long, M.H. (2005b). Overview: A rationale for needs analysis and needs analysis research. In M. H. Long (Ed.), Second language needs analysis. Cambridge: Cambridge University Press.

Louhiala-Salminen, L., Charles, M., \& Kankaanranta, A. (2005). English as a lingua franca in Nordic corporate mergers: Two case companies. English for Specific Purposes, 24(4), 401-421. doi:http://dx.doi.org/10.1016/j.esp.2005.02.003

Louhiala-Salminen, L., \& Kankaanranta, A. (2011). Professional communication in a global business context: The notion of global communicative competence. Professional Communication, IEEE Transactions on, 54(3), 244-262. doi:10.1109/TPC.2011.2161844

Lung, J. (2014). A blended needs analysis critical genre analysis and needs analysis of language and communication for professional purposes. In V. K. Bhatia \& S. Bremner (Eds.), The Routledge handbook of language and professional communication (pp. 257-273). New York: Routledge.

Macalister, J. (2012). Narrative frames and needs analysis. System, 40, 120-128.

Macalister, J., \& Nation, I.S.P. (2011). Introduction. In J. Macalister \& I. S. P. Nation (Eds.), Case studies in language curriculum design: Concepts and approaches in action around the world. New York: Routledge.

Macefield, R. (2007). Usability studies and the Hawthorne effect. Journal of Usability Studies, 2(3), 145-154.

Marschan-Piekkari, R., Welch, D., \& Welch, L. (1999). In the shadow: The impact of language on structure, power and communication in the multinational. International Business Review, 8(4), 421-440. doi:http://dx.doi.org/10.1016/S0969$\underline{5931(99) 00015-3}$ 
Matsuda, A. (2003). Incorporating world Englishes in teaching English as an international language. TESOL Quarterly, 37(4), 719-729. doi:10.2307/3588220

McKenzie, C.L., \& Qazi, C.J. (1983). Communication barriers in the workplace. Business Horizons, 26(2), 70-72. doi:http://dx.doi.org/10.1016/0007-6813(83)90088-5

Mertens, D.M. (2005). Research and evaluation in Education and Psychology: Integrating diversity with quantitative, qualitative, and mixed methods (2nd ed.). London: SAGE Publications.

Mertens, D.M. (2010). Research and evaluation in education and psychology: Integrating diversity with quantitative, qualitative, and mixed methods (3rd ed.). Los Angeles: SAGE.

Meyer, J. (1997). Humor in member narratives: Uniting and dividing at work. Western Journal of Communication, 61(2), 188-208. doi:10.1080/10570319709374571

Miles, M.B., Huberman, A.M., \& Saldaña, J. (2014). Qualitative data analysis: A methods sourcebook (3rd ed.). Thousand Oaks: SAGE Publications, Inc.

MOET. (2009). Ban hành bộ khung chưong trình giáo dục đại học khối ngành kỹ thuật, trình độ đại họ (Promulgating the training program for technology majors, undergraduate level). Ha Noi Retrieved from http://thuvienphapluat.vn/vanban/Giao-duc/Thong-tu-38-2009-TT-BGDDT-Bo-chuong-trinh-khung-giao-ducdai-hoc-khoi-nganh-ky-thuat-trinh-do-dai-hoc-100738.aspx.

MOET. (2014). Article $N^{0}$ 01/2014/TT-BGDĐT issued the 6 levels framework for foreign languages proficiency assessment for Vietnam. Hanoi: MOET.

Mohamed, A.A., Radzuan, N.R.M. , Kassim, H., \& Ali, M.M.A. (2014). Conceptualizing English workplace communication needs of professional engineers: The challenges for English language tertiary educators. International Journal of Contemporary Business Management, 1(1), 1-9.

Mohd Omar, N.A., \& Mohd Jan, J. (2013). Building academic relations and solidarity through humour at work. The Southeast Asian Journal of English Language Studies, 3, 21-34.

MOIT. (2002). Phê duyệt Chiến lược phát triển ngành cơ khí Việt Nam đến năm 2010, tầm nhìn tới 2020 (Approval on the development policy for the Vietnamese mechanical engineering to 2010, vision to 2020) [In Vietnamese]. Retrieved from http://www.moit.gov.vn/vn/pages/VanBanDieuHanh.aspx?TypeVB=1\&vID=277

Morrison, G.R., Ross, S.M., \& Kemp, J.E. (2004). Designing effective instruction (4th ed.). Hoboken, NJ: J. Wiley \& Sons. 
Moslehifar, M.A., \& Ibrahim, N.A. (2012). English language oral communication needs at the workplace: Feedback from Human Resource Development (HRD) trainees. Procedia - Social and Behavioral Sciences, 66, 529-536. doi:http://dx.doi.org/10.1016/j.sbspro.2012.11.297

Munby, J. (1978). Communicative syllabus design. Cambridge: Cambridge University Press.

Murata, K. (2014). An empirical cross-cultural study of humour in business meetings in New Zealand and Japan. Journal of Pragmatics, 60, 251-265. doi:http://dx.doi.org/10.1016/j.pragma.2013.09.002

Nation, I.S.P., \& Macalister, J. (2010). Language curriculum design. London: Routledge.

Ngah, E., Radzuan, N.R.M., Fauzi, W.J., \& Abidin, N.A.Z. (2011). The need for competent work ready English language learners. Procedia - Social and Behavioral Sciences, 29, 1490-1499. doi:http://dx.doi.org/10.1016/j.sbspro.2011.11.389

Nha, V.T.T. (2015). Should an ESP course be specific or general? A literature review of the specificity debate. VNU Journal of Science: Foreign Studies, 31(4), 37-45.

Nunan, D. (1988). The learner centered curriculum. Cambridge: Cambridge University Press.

P'Rayan, A. (2008). Engineering English: A critical evaluation. (Unpublished Ph.D. thesis), Annamalai University India.

Parveen, S., \& Asim, M. (2013). A study on attitudes towards varieties of spoken English in Pakistani context. Language in India, 3(13), 652-667.

Patton, M.Q. (1990). Qualitative research and evaluation methods (3rd ed.). London: SAGE Publications.

Patton, M.Q. (2002). Qualitative research and evaluation methods. Thousand Oaks: Sage Publications.

Phuong, T. (2014). Doanh nghiệp cơ khí vẫn "thua" trên sân nhà (Mechanical engineering enterprises "defeated" in the national market) [In Vietnamese]. Cong Thuong Newspaper. Retrieved from http://baocongthuong.com.vn/doanh-nghiep-co-khivan-thua-tren-san-nha.html

Piccardo, E. (2013). Plurilingualism and curriculum design: Toward a synergic vision. TESOL Quarterly, 47(3), 600-614. doi:10.1002/tesq.110

Plester, B. (2009). Healthy humour: Using humour to cope at work. Kōtuitui: New Zealand Journal of Social Sciences Online, 4, 89-102. 
Radzuan, N.R.M., \& Kaur, S. (2011). Technical oral presentations in English: Qualitative analysis of Malaysian engineering undergraduates' sources of anxiety. Procedia Social and Behavioral Sciences, 29, 1436-1445.

doi:http://dx.doi.org/10.1016/j.sbspro.2011.11.383

Rahman, M. (2012). The English language needs of Computer science undergraduate students at Putra University, Malaysia. English for Specific Purposes World, 12(34).

Rajprasit, K., \& Hemchua, S. (2015). The English language \& communication in the international workplace: An examination of Thai computer engineering professionals. 3L: The Southeast Asian Journal of English Language Studies, 21(3), 109-124.

Richards, J.C. (2001). Curriculum development in language teaching. New York: Cambridge University Press.

Richards, J.C., \& Rodgers, T.S. (2014). Approaches and methods in language teaching (3rd ed.). Cambridge Cambridge University Press.

Richards, J.C., \& Schmidt, R. (2010). Longman dictionary of language teaching and applied linguistics (4th ed.). Harlow: Longman.

Richterich, R., \& Chancerel, J. (1980). Identifying the needs of adults learning a foreign language. Oxford: Pergamon Press.

Riemer, M.J. (2002). English and communication skills for the global engineer. Global Journal of Engineering Education, 6(1), 91-100.

Riemer, M.J. (2007). Communication skills for the 21st century engineer. Global Journal of Engineering Education, 11(1), 89-100.

Robinson, P.C. (1991). ESP today: A practitioner's guide New York: Prentice Hall International.

Rogerson-Revell, P. (2007). Humour in business: A double-edged sword: A study of humour and style shifting in intercultural business meetings. Journal of Pragmatics, 39(1), 4-28. doi:http://dx.doi.org/10.1016/j.pragma.2006.09.005

Rosa, D.F. (2008). Meeting students' needs: An analysis of ESP teaching at the department of Computer Science. (Unpublished Master thesis), Mentouri University of Constantine, Algeria.

Salehi, M. (2010). Investigating the English language needs of engineering students. English for Specific Purposes World, 10(31), 1-16. 
SanAntonio, P.M. (1987). Social mobility and language use in an American company in Japan. Journal of Language and Social Psychology, 6(3 \& 4), 191-200.

Sattar, A., \& Zahid, S. (2011). The linguistic needs of textile engineering students: A case study of National Textile University. English for Specific Purposes World, 11(33), $1-24$.

Serafini, E.J., Lake, J.B., \& Long, M.H. (2015). Needs analysis for specialized learner populations: Essential methodological improvements. English for Specific Purposes, 40, 11-26. doi:http://dx.doi.org/10.1016/j.esp.2015.05.002

Shklarov, S. (2007). Double vision uncertainty: The bilingual researcher and the ethics of cross-language research. Qualitative Health Research, 17(4), 529-538. doi:10.1177/1049732306298263

Singh, G.K.G., \& Singh, S.K.G. (2008). Malaysian graduates' employability skills. UNITAR E-JOURNAL, 4(1), 14-44.

So-Mui, F.L., \& Mead, K. (2000). An analysis of English in the workplace: the communication needs of textile and clothing merchandisers. English for Specific Purposes, 19, 351-368.

Songhori, M.H. (2008). Introduction to needs analysis. English for Specific Purposes World(4), 1-25.

Spence, P., \& Liu, G.Z. (2013). Engineering English and the high-tech industry: A case study of an English needs analysis of process integration engineers at a semiconductor manufacturing company in Taiwan. English for Specific Purposes, 32(2), 97-109. doi:http://dx.doi.org/10.1016/j.esp.2012.11.003

Stapa, M., Murad, N.A., \& Ahmad, N. (2014). Engineering technical oral presentation: Voices of the stakeholder. Procedia - Social and Behavioral Sciences, 118, 463467. doi:http://dx.doi.org/10.1016/j.sbspro.2014.02.063

Stevens, B. (2005). What communication skills do employers want? Silicon valley recruiters respond. Journal of Transnational Management, 10(4), 2-9.

Stubbe, M. (2010). "Was that my misunderstanding?": Managing miscommunication and problematic talk at work. (Unpublished Ph.D. thesis), Victoria University of Wellington, New Zealand.

Swales, J.M. (2004). Research genres: Explorations and applications. Cambridge: Cambridge University Press.

Tahir, A. (2011). Learning needs - A neglected terrain: Implications of needs hierarchy theory for ESP needs analysis. English for Specific Purposes, 11(33), 1-18. 
Talif, R., \& Noor, R. (2009). Connecting language needs in the workplace to the learning of English at tertiary level. Pertanika Journal of Social Science and Humanities, $17(2), 65-77$.

Tange, H., \& Lauring, J. (2009). Language management and social interaction within the multilingual workplace. JOurnal of Communication Management, 13(3), 218-232.

Tashakkori, A., \& Teddilie, C. (2003). Handbook of mixed methods in social and behavioral research. Thousand Oaks: SAGE.

Tasic, M. (2009). English language teaching in mechanical engineering. Linguistics and Literature, 7(1), 101-112.

Teddlie, C., \& Tashakkori, A. (2003). Major issues and controversies in the use of mixed methods in the social and behavioural sciences. In A. Tashakkori \& C. Teddilie (Eds.), The handbook of mixed methods in social \& behavioural research (pp. 350). Thousand Oaks: Sage Publications.

Thanh, H. (2016, May 4). Hơn 200.000 cử nhân vật vã tìm việc làm: Ước mơ chỉ là mơ ước (Over 200.000 graduates struggle to look for works: Dream is just dream) [In Vietnamese]. Cong An Nhan Dan Newspaper. Retrieved from http://cand.com.vn/Xa-hoi/Vi-sao-cu-nhan-that-nghiep-ngay-cang-tang-391324/

Thorndike, R.M. (2005). Measurement and evaluation in psychology and education (7th ed.). Upper Saddle River: Pearson Merrill Prentice Hall.

Tien, L.H. (2013). ELT in Vietnam general and tertiary education from second language education perspectives. VNU Journal of Foreign Studies, 29(1), 65-71.

Twinn, D.S. (1998). An analysis of the effectiveness of focus groups as a method of qualitative data collection with Chinese populations in nursing research. Journal of Advanced Nursing, 28(3), 654-661. doi:10.1046/j.1365-2648.1998.00708.x

Tzanne, A. (2000). Talking at cross-purposes: The dynamics of miscommunication. Philadelphia: John Benjamins Publishing Company.

Venkatraman, G., \& Prema, P. (2007). English language skills for Engineering students: A needs survey. Retrieved from http://www.ESPWorld.infor/aritcles_16/skills.htm

Verdonik, D. (2010). Between understanding and misunderstanding. Journal of Pragmatics, 42(5), 1364-1379. doi:http://dx.doi.org/10.1016/j.pragma.2009.09.007

Vine, B. (2004). Getting things done at work: The discourse of power in workplace interaction. Philadelphia: John Benjamins Pub. 
Vine, B. (2009). Directives at work: Exploring the contextual complexity of workplace directives. Journal of Pragmatics, 41(7), 1395-1405. doi:http://dx.doi.org/10.1016/j.pragma.2009.03.001

Wardhaugh, R. (2001). An introduction to sociolinguistics (4th ed.). Malden: Blackwell Publishers.

Wardhaugh, R. (2002). An introduction to sociolinguistics (4th ed.). Malden: Blackwell Publishers.

Wardhaugh, R., \& Fuller, J.M. (2015). Introduction to sociolinguistics: Wiley.

Weng, A.W.T. (2015). Communication at the international workplaces: The foreign managers' perspectives. International Journal of Business and Management, 10(4), 82-91.

West, R. (1994). Needs analysis in language teaching. Language Teaching, 27(1-19), 1.

Westwood, R., \& Rhodes, C. (2013). Humour, work and organization. London: Taylor and Francis.

White, R.V. (1988). The ELT curriculum: Design, innovation, and management. Oxford: Blackwell.

Yaoharee, O. (2013). Power and politeness in intercultural workplace communication: Some implications for teaching English as a second language in Thailand. (Unpublished Ph.D. thesis), University of California California, USA.

Young, N.M. (1995). Communication skills in the workplace: Employers talk back. Paper presented at the 1995 CEI Fall Conference, North Carolina.

Yusoff, Y.Md., Zaharim, A., Omar, M.Z., Mohamed, A., Muhamad, N., \& Mustafa, R. (2009). Employers' selection skills in recruiting fresh engineering graduates. Paper presented at the 2009 International Conference on Engineering Education (ICEED 2009), Kuala Lumpur, Malaysia.

Zaid, Y.B.H., \& Kamarudin, H.B. (2011). Oral communication needs of Mechanical engineering undergraduate students in UTM: As perceived by the learners. Retrieved from http://eprints.utm.my/20270/

Ziegler, G., Durus, N., \& Sert, O. (2013). Plurilingual repertoires in the ESL classroom: The case of the European school. TESOL Quarterly, 47(3), 643-650. doi:10.1002/tesq.123

Zohrabi, M. (2011). An evaluation of the needs analysis component in an academic setting. The Asian ESP Journal, 7(4), 153-182. 


\section{APPENDICES}

Appendix A: Needs analysis questionnaire for employers and managers of mechanical engineers

This questionnaire aims to collect data for my $\mathrm{PhD}$ research on English for mechanical engineering students. I would like to have your views about the real-world use of the English language by mechanical engineers in the workplace. Your views will be very valuable to my research.

INSTRUCTIONS: Please provide answers to the following questions, by ticking either a single option or more if necessary, and writing short answers. The non-sequential nature of the questions relates to data entry.

\section{PART ONE: PERSONAL INFORMATION}

1. Gender: $\quad$ Male $\square \quad$ Female $\square$
2. Age:
a. $20-30 \square$
b. $31-40 \square$
c. $41-50 \square$
d. $51-60 \square$
e. Over 60 口

3. Name of the company/factory:

4. Position:

5. Years of working:
a. $0-5 \square$
b. $6-10 \square$
c. $11-15 \square$
d. $16-20 \square$
e. Over $20 \square$

6. Your main responsibilities:

7. What type of ownership is your company/factory?
a. Privately owned $\square$
b. State owned $\square$
c. Joint venture $\square$
d. Foreign owned $\square$
e. Multinational corporation $\square$
f. Other $\square$ (Please specify)
8. How many employees are there in your workplace in Vietnam?

9. How many mechanical engineers are there in your workplace in Vietnam?

10. Are there employees from English speaking countries employed in your company in Vietnam?
a. Yes $\square$
b. No $\square$

If yes, are they in management positions?

a. Yes $\square$

b. No $\square$

11. Who are your company's customers?
a. Local customers
b. International customers
c. Both $\square$ 
12. Who are your company's main suppliers?
a. Local suppliers $\square$
b. International suppliers
c. Both $\square$

\section{PART TWO: ENGLISH COMMUNICATION NEEDS}

13. I am satisfied with the English ability of the mechanical engineers in my workplace
a. Strongly agree $\square$
b. Agree $\square$
c. Slightly agree $\square$
d. Slightly disagree $\square$
e. Disagree $\square$
f. Strongly disagree $\square$

14. How frequently do mechanical engineers in your company need to use English in their job?
a. Daily (Many times in a day) $\square$
b. Frequently (Several times in a week) $\square$
c. Sometimes (More than 5 times in a month) $\square$ d. Occasionally (Less than 5 times in a month) $\square$
e. Rarely (Less than 5 times in a year)
f. Never $\square$

15. To what extent do you agree or disagree that highly effective mechanical engineers have good communication skills in English?
a. Strongly agree $\square$
b. Agree $\square$
c. Slightly agree $\square$
d. Slightly disagree $\square$
e. Disagree $\square$
f. Strongly disagree $\square$

16. This is a list of English communicative events/skills that engineers or engineering students are likely to perform worldwide. Please choose the frequency and the setting to which you think that the mechanical engineers in your workplace are likely to engage in the communicative events

( $1=$ Never, $2=$ Rarely (Less than 5 times in a year), $3=$ Occasionally (Less than 5 times in a month), $4=$ Sometimes (More than 5 times in a month), $5=$ Frequently (Several times in a week), 6= Daily (Many times in a day))

\begin{tabular}{|c|c|c|c|c|c|c|c|c|}
\hline \multirow[b]{2}{*}{ Communicative events } & \multicolumn{5}{|c|}{ Frequency } & \multicolumn{3}{|c|}{ Setting } \\
\hline & 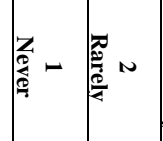 & 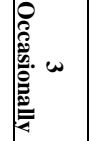 & 昘 & 列 & 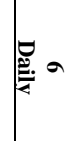 & $\frac{\pi}{\frac{\pi}{2}}$ & 号 & $\stackrel{\square}{\stackrel{\varpi}{E}}$ \\
\hline 1. Listening to English-speaking boss's instructions & & & & & & & & \\
\hline $\begin{array}{l}\text { 2. Listening to presentations and discussions in a } \\
\text { meeting, seminar or conference }\end{array}$ & & & & & & & & \\
\hline 3. Delivering oral presentations on projects & & & & & & & & \\
\hline 4. Making telephone conversations & & & & & & & & \\
\hline 5. Group meetings & & & & & & & & \\
\hline 6. Public speaking & & & & & & & & \\
\hline $\begin{array}{l}\text { 7. Engaging in professional conversations (this } \\
\text { includes elements of informal, casual, and/or business } \\
\text { conversations) }\end{array}$ & & & & & & & & \\
\hline 8. Talking about everyday tasks and duties & & & & & & & & \\
\hline
\end{tabular}




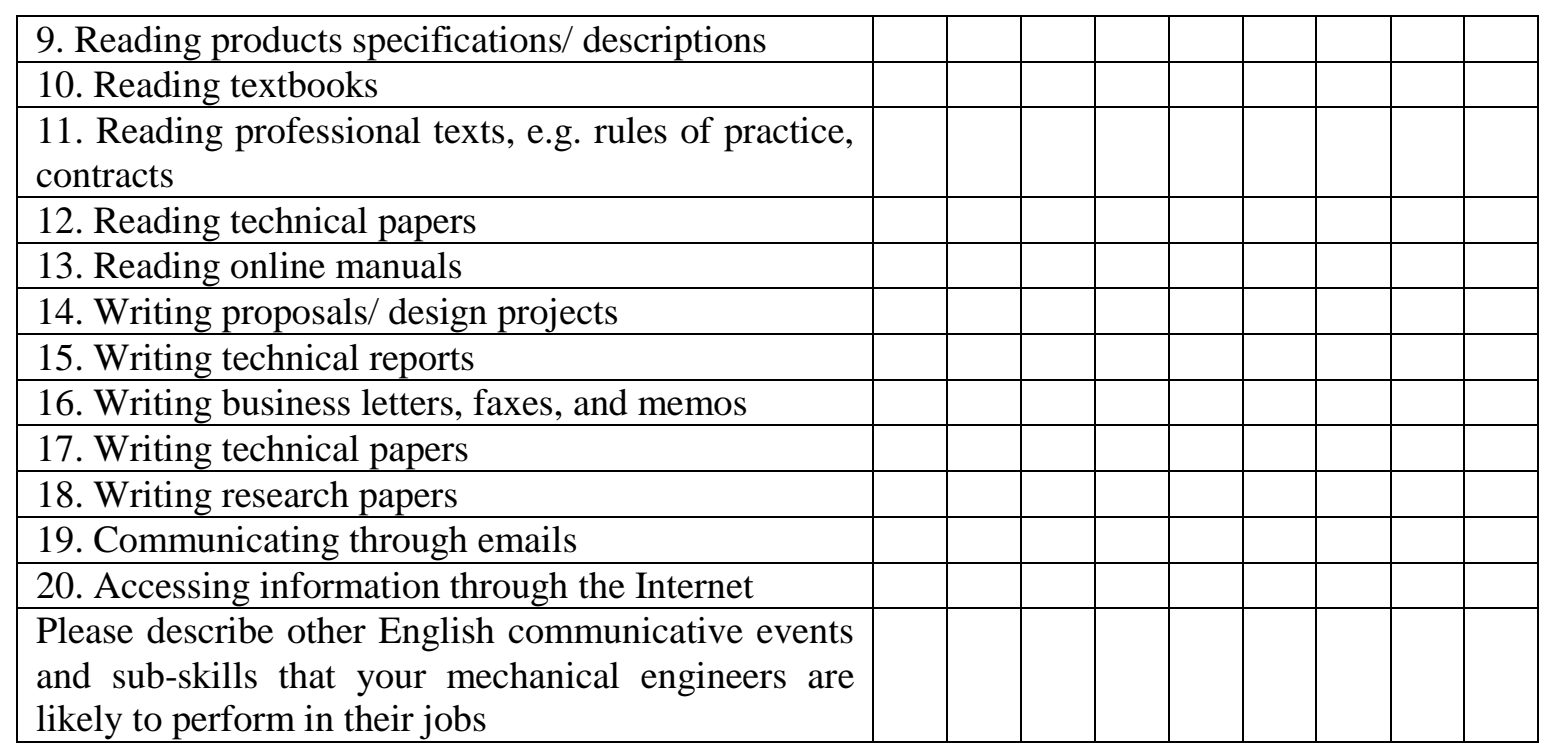

17. In their job, who do your mechanical engineers usually communicate in English with? (You can tick more than one answer)
a. Managers $\square$
c. Colleagues $\square$
e. Suppliers $\square$
b. Supervisors $\square$
d. Clients $\square$
f. Other $\square$

If other, please specify.

18. What kind of English do mechanical engineers use in the presence of you/their boss?

(You can tick more than one answer)
a. Formal $\square$
b. Informal $\square$
c. Colloquial $\square$
d. Other $\square$

Please comment.

19. What kind of English do mechanical engineers use when they communicate with their colleagues? (You can tick more than one answer)
a. Formal $\square$
b. Informal $\square$
c. Colloquial $\square$
d. Other $\square$

Please comment.

20. What kind of English do mechanical engineers use when they communicate with their clients and business partners? (You can tick more than one answer)
a. Formal $\square$
b. Informal $\square$
c. Colloquial $\square$
d. Other $\square$

Please comment

21. How important do you think it is for mechanical engineers to adapt their workplace use of English for someone of higher status than them?
a. Very important $\square$
b. Important $\square$
c. Of little importance $\square$
d. Not important 
Please comment

22 How important do you think it is for mechanical engineers to adapt their workplace use of English for someone of lower status than them?
a. Very important $\square$
b. Important $\square$
c. Of little importance $\square$
d. Not important

Please comment.

For questions 23-26, please indicate the extent to which you agree or disagree:

23. English listening skills are very important for mechanical engineers in your company to perform their job effectively.
a. Strongly agree $\square$
b. Agree $\square$
c. Slightly agree $\square$
d. Slightly disagree
e. Disagree $\square$
f. Strongly disagree $\square$

24. English speaking skills are very important for mechanical engineers in your company to perform their job effectively.
a. Strongly agree $\square$
b. Agree $\square$
c. Slightly agree $\square$
d. Slightly disagree $\square$
e. Disagree $\square$
f. Strongly disagree $\square$

25. English reading skills are very important for mechanical engineers in your company to perform their job effectively.
a. Strongly agree $\square$
b. Agree $\square$
c. Slightly agree $\square$
d. Slightly disagree $\square$
e. Disagree $\square$
f. Strongly disagree $\square$

26. English writing skills are very important for mechanical engineers in your company to perform their job effectively.
a. Strongly agree
b. Agree $\square$
c. Slightly agree $\square$
d. Slightly disagree
e. Disagree
f. Strongly disagree $\square$

27. What English language skills do your mechanical engineers use most? (Please rank them in order of frequency. Number 1 is the most frequently used and number 4 is the least frequently used).

Listening skills $\square \quad$ Speaking skills $\square \quad$ Reading skills $\square \quad$ Writing skills $\square$ 28. What English language skills do your mechanical engineers lack most? (Please rank them in order of lack. Number 1 is the most lacking and number 4 is the least lacking). Listening skills $\square \quad$ Speaking skills $\square \quad$ Reading skills $\square \quad$ Writing skills $\square$ 29. What specific English language expertise and skill sets do you look for in your prospective mechanical engineers and why? 


\section{PART THREE: SUGGESTIONS}

30. From the performance of your mechanical engineers in the workplace, do you have suggestions to improve the English for specific purposes course for mechanical engineering students at university?
a. Yes
b. No $\square$

Please give comments:

31. Would you be willing to join an individual interview with the researcher? This will take about 30 minutes.
a. Yes
b. No $\square$

If yes, please provide the following information:

Full name:

Email address:

Phone number:

Thank you very much for your cooperation! 


\section{Appendix B: Needs analysis questionnaire for mechanical engineers}

This questionnaire aims to collect data for my $\mathrm{PhD}$ research on English for mechanical engineering students. I would like to have your views about the real-world use of the English in your job in the workplace context. Your views will be very valuable to my research.

INSTRUCTIONS: Please provide true answers to the following questions, by ticking either a single option or more if necessary, and writing short answers. The non-sequential nature of the questions relates to data entry.

\section{PART ONE: PERSONAL INFORMATION}

1. Gender: $\quad$ Male $\square \quad$ Female $\square$
2. Age:
a. $20-30 \square$
b. $31-40 \square$
c. $41-50 \square$
d. $51-60 \square$
e. Over $60 \square$

3. Name of the company/factory:

4. Position:

5. Years of working:
a. $0-5 \square$
b. $6-10 \square$
c. $11-15$
d. $16-20 \square$
e. Over 20 口
6. Responsibilities:

7. What kinds of work are you involved in? (You can tick more than one answer)
a. Design
b. Manufacturing $\square$
c. Maintenance $\square$
d. Testing $\square$
e. Customer service $\square$
f. Marketing $\square$

8. What English courses or English training have you had at university and at your workplace? (You can tick more than one answer)
a. General English in the university $\square$
b. English for specific purposes course for mechanical engineering in the university
c. English language skills $\square \quad$ (Please specify, eg., speaking skills)
d. Other short courses $\square$ (Please specify)

\section{PART TWO: ENGLISH COMMUNICATION NEEDS}

13. I am satisfied with my English ability for workplace use.
a. Strongly agree $\square$
b. Agree $\square$
c. Slightly agree $\square$
d. Slightly disagree $\square$
e. Disagree $\square$
f. Strongly disagree $\square$

14. How often do you use English in the context of your job?
a. Daily (Many times in a day) $\square$
b. Frequently (Several times in a week) 
c. Sometimes (More than 5 times in a month) $\square$ d. Occasionally (Less than 5 times in a month) $\square$
e. Rarely (Less than 5 times in a year) $\square$
f. Never $\square$

15. To what extent do you agree or disagree that highly effective mechanical engineers have good communication skills in English?
a. Strongly agree $\square$
b. Agree $\square$
c. Slightly agree $\square$
d. Slightly disagree $\square$
e. Disagree $\square$
f. Strongly disagree $\square$

16. This is a list of English communicative events/skills that engineers or engineering students are likely to perform worldwide. Please choose the frequency and the setting to which you and other mechanical engineers in your workplace are likely to engage in the communicative events. ( $1=$ Never, $2=$ Rarely (Less than 5 times in a year), $3=$ Occasionally (Less than 5 times in a month), $4=$ Sometimes (More than 5 times in a month), $5=$ Frequently (Several times in a week), 6= Daily (Many times in a day))

\begin{tabular}{|c|c|c|c|c|c|c|c|c|c|}
\hline \multirow[b]{2}{*}{ Communicative events } & \multicolumn{6}{|c|}{ Frequency } & \multicolumn{3}{|c|}{ Setting } \\
\hline & & $-\mid$ & 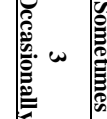 & 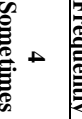 & Un & 毞 & 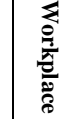 & $\stackrel{0}{E}$ & 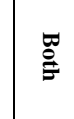 \\
\hline 1. Listening to English-speaking boss's instructions & & & & & & & & & \\
\hline $\begin{array}{l}\text { 2. Listening to presentations and discussions in a } \\
\text { meeting, seminar or conference }\end{array}$ & & & & & & & & & \\
\hline 3. Delivering oral presentations on projects & & & & & & & & & \\
\hline 4. Making telephone conversations & & & & & & & & & \\
\hline 5. Group meetings & & & & & & & & & \\
\hline 6. Public speaking & & & & & & & & & \\
\hline $\begin{array}{l}\text { 7. Engaging in professional conversations (this } \\
\text { includes elements of informal, casual, and/or business } \\
\text { conversations) }\end{array}$ & & & & & & & & & \\
\hline 8. Talking about everyday tasks and duties & & & & & & & & & \\
\hline 9. Reading products specifications/ descriptions & & & & & & & & & \\
\hline 10. Reading textbooks & & & & & & & & & \\
\hline $\begin{array}{l}\text { 11. Reading professional texts, e.g. rules of practice, } \\
\text { contracts }\end{array}$ & & & & & & & & & \\
\hline 12. Reading technical papers & & & & & & & & & \\
\hline 13. Reading online manuals & & & & & & & & & \\
\hline 14. Writing proposals/ design projects & & & & & & & & & \\
\hline 15. Writing technical reports & & & & & & & & & \\
\hline 16. Writing business letters, faxes, and memos & & & & & & & & & \\
\hline 17. Writing technical papers & & & & & & & & & \\
\hline 18. Writing research papers & & & & & & & & & \\
\hline 19. Communicating through emails & & & & & & & & & \\
\hline 20. Accessing information through the Internet & & & & & & & & & \\
\hline $\begin{array}{l}\text { Please describe other English communicative events } \\
\text { and sub-skills that you are likely to perform in your } \\
\text { jobs }\end{array}$ & & & & & & & & & \\
\hline
\end{tabular}


17. In your job, who do you usually communicate in English with? (You can tick more than one answer)
a. Managers $\square$
c. Colleagues $\square$
e. Suppliers $\square$
b. Supervisors $\square$
d. Clients $\square$
f. Other $\square$

If other, please specify.

18. What kind of English do you use in the presence of your boss? (You can tick more than one answer)
a. Formal $\square$
b. Informal $\square$
c. Colloquial $\square$
d. Other $\square$

Please comment.

19. What kind of English do you use when you communicate with your colleagues? (You can tick more than one answer)
a. Formal $\square$
b. Informal $\square$
c. Colloquial $\square$
d. Other $\square$

Please comment.

20. What kind of English do you use when you communicate with your clients and business partners? (You can tick more than one answer)
a. Formal $\square$
b. Informal $\square$
c. Colloquial $\square$
d. Other $\square$

Please comment

21. How important do you think it is to adapt your workplace use of English for someone of higher status than you?
a. Very important $\square$
b. Important $\square$
c. Of little importance
d. Not important

Please comment.

22. How important do you think it is to adapt your workplace use of English for someone of lower status than you?
a. Very important $\square$
b. Important $\square$
c. Of little importance $\square$
d. Not important

Please comment

\section{For questions 23-26, please indicate the extent to which you agree or disagree:}

23. English listening skills are very important for you to perform your job effectively.
a. Strongly agree $\square$
b. Agree $\square$
c. Slightly agree $\square$
d. Slightly disagree $\square$
e. Disagree $\square$
f. Strongly disagree $\square$ 
24. English speaking skills are very important for you to perform your job effectively.
a. Strongly agree $\square$
b. Agree $\square$
c. Slightly agree $\square$
d. Slightly disagree
e. Disagree $\square$
f. Strongly disagree

25. English reading skills are very important for you to perform your job effectively.
a. Strongly agree $\square$
b. Agree $\square$
c. Slightly agree $\square$
d. Slightly disagree $\square$
e. Disagree $\square$
f. Strongly disagree $\square$

26. English writing skills are very important for you to perform your job effectively.
a. Strongly agree $\square$
b. Agree $\square$
c. Slightly agree $\square$
d. Slightly disagree $\square$
e. Disagree $\square$
f. Strongly disagree $\square$

27. What English language skills do you use most in your workplace?

(Please rank them in order of frequency. Number 1 is the most frequently used and number 4 is the least frequently used).

Listening skills $\square \quad$ Speaking skills $\square \quad$ Reading skills $\square \quad$ Writing skills $\square$ 28. What English language skills do you lack most in your workplace? (Please rank them in order of lack. Number 1 is the most lacking and number 4 is the least lacking).

Listening skills $\square \quad$ Speaking skills $\square \quad$ Reading skills $\square \quad$ Writing skills $\square$ 29. What specific English expertise and skill sets do your employers look for in their prospective mechanical engineers?

\section{PART THREE: SUGGESTIONS}

30. From your workplace experience, do you have suggestions to improve the English for specific purposes course for mechanical engineering students at university?
a. Yes
b. No

Please give comments:

31. - Would you be willing to join an individual interview with the researcher? This will take about 30 minutes.
a. Yes
b. No $\square$

- Would you give the researcher permission to observe your working days?
a. Yes
b. No $\square$

If yes, please provide the following information:

Full name: Email address: Phone number: 


\section{Appendix C: Interview schedule for employers and managers of mechanical engineers}

(Depending on the data collected from the questionnaire in appendix A, the questions in this interview may be refined)

1. Could you please provide some general information about your company/factory?

2. In your company/ factory, what do mechanical engineers require English for?

3. What do you think about your mechanical engineers' English ability?

- To what extent does their English ability meet the requirements of the job?

- Does your company offer any English training course for mechanical engineers?

- What do you see as the advantages and disadvantages of the increasing use of English in the company/in mechanical engineering? Why is that?

- What incentives are there for the mechanical engineers to use English at work including with customers and suppliers?

4. What drives the use of English in your company?

- What determines whether or not the mechanical engineers use English?

- What determines who, when and how the engineers and other staff communicate in

English with English speaking bosses, suppliers, customers, officials?

5. How do you think social dimensions such as status and power relationship may affect your mechanical engineers' use of English?

6. You indicated in the questionnaire that the most common communicative events are.... can you explain them further? How important are these soft skills for mechanical engineers?

7. You indicated the specific English expertise and skill sets that you look for in mechanical engineers, could you please explain in details why they are important?

8. Please describe a problem that has arisen because of a weakness in the mechanical engineers English language skills? What happened? Who was involved? How was it resolved?

9. Regarding English for specific purposes of mechanical engineering, what do you think university should do to prepare students for the workplace? 


\section{Appendix D: Interview schedule for mechanical engineers}

(Depending on the data collected from the questionnaire in appendix $\mathrm{B}$, the questions in this interview may be refined)

1. In your job, what do you require English for? Please comment in details.

2. What do you think about your English ability?

- Is it good enough for you to perform your job effectively?

- Have you had any English training courses offered by the company in the workplace?

- What do you see as the advantages and disadvantages of the increasing use of English in the company/in mechanical engineering? Why is that?

- What incentives are there for you and other mechanical engineers to use English at work including with customers and suppliers?

3. What drives the use of English in your company?

- What determines whether or not you use English?

- What determines who, when and how you and other mechanical engineers communicate in English with English speaking bosses, suppliers, customers, officials?

4. How do you think social dimensions such as status and power relationship may affect your use of English in the workplace?

5. What do you think about the English for specific purposes course for mechanical engineering that you studied at the university? Is it of much help for your work now and to what extent?

6. You indicated in the questionnaire that the most common communicative events are.... can you explain them further? How important are these soft skills for mechanical engineers? Were you trained in these kinds of events at university?

7. Could you please describe in details the kinds of oral and written communication skills that you need to perform effectively in your job?

8. Please describe a problem that has arisen because of a weakness in your English language skills? What happened? Who was involved? How was it resolved?

9. Regarding English for specific purposes of mechanical engineering, what do you think university should do to prepare students for the workplace?

10. From your experience in using English at the workplace, what skills would be useful to develop at university? 


\section{Field notes}

\begin{tabular}{|l|l|l|l|}
\hline \multirow{3}{*}{ Date } & \multicolumn{2}{|c|}{ Descriptive notes } & \multirow{2}{*}{ Reflective notes } \\
\cline { 2 - 4 } & Kinds of work/activities & $\begin{array}{c}\text { Purposes, forms and levels of } \\
\text { English use }\end{array}$ & \\
\hline & & & \\
\hline & & & \\
& & & \\
\hline
\end{tabular}

\section{Checklist}

\begin{tabular}{|c|c|c|c|c|c|c|c|c|c|}
\hline \multirow[b]{2}{*}{ Communicative events } & \multicolumn{6}{|c|}{ Frequency } & \multicolumn{3}{|c|}{ Setting } \\
\hline & $\mid$ & 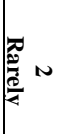 & 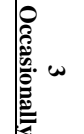 & 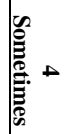 & 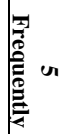 & a & 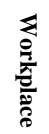 & $\frac{\mathscr{D}}{\tilde{z}}$ & $\stackrel{\square}{\rightleftarrows}$ \\
\hline 1. Listening to English-speaking boss's instruct & & & & & & & & & \\
\hline $\begin{array}{l}\text { 2. Listening to presentations and discussions } \\
\text { meeting, seminar or conference }\end{array}$ & & & & & & & & & \\
\hline 3. Delivering oral presentations on projects & & & & & & & & & \\
\hline 4. Making telephone conversations & & & & & & & & & \\
\hline 5. Group meetings & & & & & & & & & \\
\hline 6. Public speaking & & & & & & & & & \\
\hline $\begin{array}{l}\text { 7. Engaging in professional conversations } \\
\text { includes elements of informal, casual, and/or bu } \\
\text { conversations) }\end{array}$ & & & & & & & & & \\
\hline 8. Talking about everyday tasks and duties & & & & & & & & & \\
\hline 9. Reading products specifications/ descriptions & & & & & & & & & \\
\hline 10. Reading textbooks & & & & & & & & & \\
\hline $\begin{array}{l}\text { 11. Reading professional texts, e.g. rules of pra } \\
\text { contracts }\end{array}$ & & & & & & & & & \\
\hline 12. Reading technical papers & & & & & & & & & \\
\hline 13. Reading online manuals & & & & & & & & & \\
\hline 14. Writing proposals/ design projects & & & & & & & & & \\
\hline 15. Writing technical reports & & & & & & & & & \\
\hline 16. Writing business letters, faxes, and memos & & & & & & & & & \\
\hline 17. Writing technical papers & & & & & & & & & \\
\hline 18. Writing research papers & & & & & & & & & \\
\hline 19. Communicating through emails & & & & & & & & & \\
\hline 20. Accessing information through the internet & & & & & & & & & \\
\hline
\end{tabular}


TE WHARE WĀNANGA O TE ŪPOKO O TE IKA A MĀUI

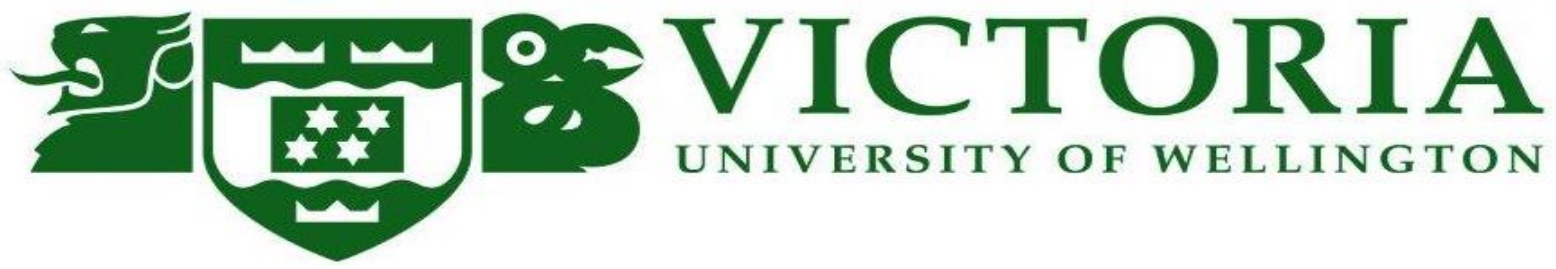

\section{Faculty of Education}

Appendix F: Letter of invitation for the director of the selected company/factory

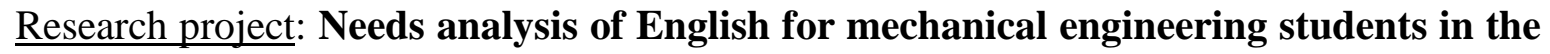
Vietnamese context

Dear Sir/Madam,

My name is Le Cao Tinh and I am a doctoral student at the Faculty of Education, Victoria University of Wellington in New Zealand. I am undertaking a research project leading to a Ph.D. thesis. I am seeking your permission to conduct my research project at your company/factory. The research will be conducted from $15^{\text {th }}$ August 2013 to $31^{\text {st }}$ December 2013. I would also like to invite you to answer a questionnaire and take part in an individual interview.

The research aims to examine the English communication needs and learning needs of mechanical engineering students in the Vietnamese context. The University requires that ethics approval be obtained for research involving human participants.

My study will take place in two phases: the workplace situation and the university situation. Each phase consists of three parts. The first is a survey of a large number of stakeholders. All the questionnaires will be in Vietnamese. The second is to interview a small number of participants following the questionnaire to explore in more depth the perception of English communication needs and learning needs of mechanical engineering students. All interviews will be transcribed in Vietnamese. The third is to observe the real-world use of English of mechanical engineers in the workplace and the teaching and learning of English for specific purposes course at university.

I am inviting you, or the vice-director, or the personnel manager who can be on behalf of your company/factory, the manager of mechanical engineers, and mechanical engineers to participate in my study.

Three methods of data collection will be employed in my study. You and your staff will be invited to answer a questionnaire in Vietnamese and those who indicated in the questionnaire that they are willing to participate in an individual interview with me will take part in the 
second part. I will base the selection criteria on gender, position, working experience, and information provided in the questionnaires. I will invite four representatives from the four companies/factories, especially those managers who directly manage mechanical engineers and four mechanical engineers. In addition, the priority goes to those who have a lot of experiences in the field. More importantly, I will use the information provided in the questionnaires to select those whose answers can represent as close as possible the range of information given by other participants in the questionnaire. After that I, the researcher, would like to ask for your permission and your mechanical engineers' permission to spend two days observing the mechanical engineers' work.

The participation is:

- voluntary, and you can withdraw the company up to the end of data collection in early December 2013; and individuals within your company are able to do this also.

- confidential, and you and your company/factory will not be identified in the thesis;

- all interviews will be audio taped and transcribed in Vietnamese for the purposes of maintaining an accurate record of your responses. You and your mechanical engineers will be given the opportunity to check your interview transcript to ensure it is accurately recorded and to make amendment if you wish. The tapes will be kept secure for a period of 5 years to protect you and your company identity; and all data will not be used for any other purpose.

- mechanical engineers will be given the opportunity to check the field notes and checklists of observations to ensure they are accurately recorded and to make amendment if they wish. - you and your mechanical engineers can request feedback such as a summary of findings from me via email at tinh.le@vuw.ac.nz.

- no other person except me and my supervisors, Dr John Dickie and Dr Gillian Hubbard, and two transcribers and translators, will see the interview transcripts. The transcribers and translators will all sign confidentiality agreements. The thesis will be deposited in the University Library. It is intended that articles will be submitted for publication in scholarly journals.

This research project has been approved by the Faculty of Education Human Ethics Subcommittee under delegated authority from the Victoria University Human Ethics Committee, and approval number is

You will be asked to sign a "Consent Form" to formalize your willingness to participate in my study and your consent to your company's participation. The questionnaire will require 30 to 45 minutes of your time. The same amount of time will be needed for the interview. 
If you have any questions or would like to receive further information about the project, please contact me at (+84)913272079, or email: letinhktv@gmail.com/tinh.le@vuw.ac.nz.

You could also contact my supervisors:

\section{Dr John Dickie}

School of Education Policy and Implementation,

Victoria University of Wellington

PO Box 17-310, Karori, Wellington 6147, New

Zealand

Phone +64-4-463 9767

email: john.dickie@vuw.ac.nz

\section{Dr Gillian Hubbard}

School of Education Policy and Implementation, Victoria University of Wellington

PO Box 17-310, Karori, Wellington 6147, New

Zealand

Phone: + 64-4-463 9690

email: gillian.hubbard@vuw.ac.nz

If you have any ethical concerns about this research, please contact Dr Allison Kirkman (Allison.kirkman@vuw.ac.nz), phone number: +64-4-4635676, Chair of the Human Ethics Committee, Victoria University of Wellington.

Your permission to conduct the research at your factory/company is highly appreciated.

Thank you very much for your support.

Yours sincerely,

Le Cao Tinh 
TE WHARE WĀNANGA O TE ŪPOKO O TE IKA A MĀUI

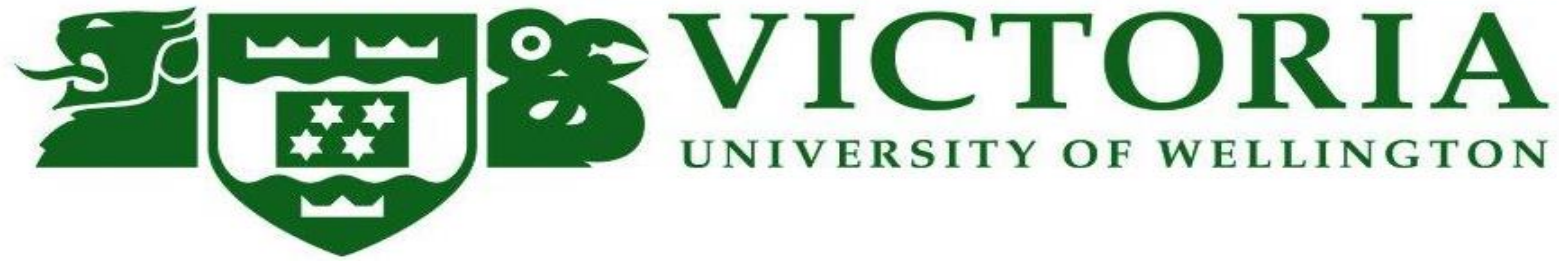

Faculty of Education

Appendix G: Consent form for directors of the selected companies

Research project: Needs analysis of English for mechanical engineering students in the Vietnamese context

I have been given information about this project by Le Cao Tinh who is carrying out this research for a doctoral degree supervised by Dr John Dickie and Dr Gillian Hubbard in the Faculty of Education at the Victoria University of Wellington. I have had an opportunity to ask questions and have them answered to my satisfaction. I understand that I may withdraw my company and myself (or any information I have provided) from this project (before data collection and analysis is complete) without having to give reasons or without penalty of any sort.

I understand that:

- if I consent to participate in this project I and some of my staff will be invited to complete a questionnaire.

- participation will take from 30 to 45 minutes.

- $\quad$ any information I and my staff provide will be kept confidential to the researcher, the supervisors, and the transcribers and translators who will sign confidentiality agreements.

- the published results will not use my name or my company's name, and that no opinions will be attributed to me in any way that will identify me, my staff or my company.

- the recording of data will be wiped five years after the end of the research.

- I and my staff may choose not to respond to any question(s).

- I and my staff can contact the researcher for a summary of the results of this research if we want.

- I and my staff may be invited to take part in an interview. 
- a doctoral thesis will be written and that I, my staff and my company will not be identified in the thesis.

- I can withdraw my company and myself at any time up until end of data collection, and individuals within your company are able to do this also.

I have read the information sheet and I understand the contents and the points in this consent form. By ticking this box, I am indicating my consent to my company's participation in the research.

If you have any questions or would like to receive further information about the project, please contact me at (+84)913272079, or email: letinhktv@gmail.com/tinh.le@vuw.ac.nz.

Name of participant:

Signed:

Date:

(The subject will be given a copy of this to keep after signing this form) 
TE WHARE WĀNANGA O TE ŪPOKO O TE IKA A MĀUI

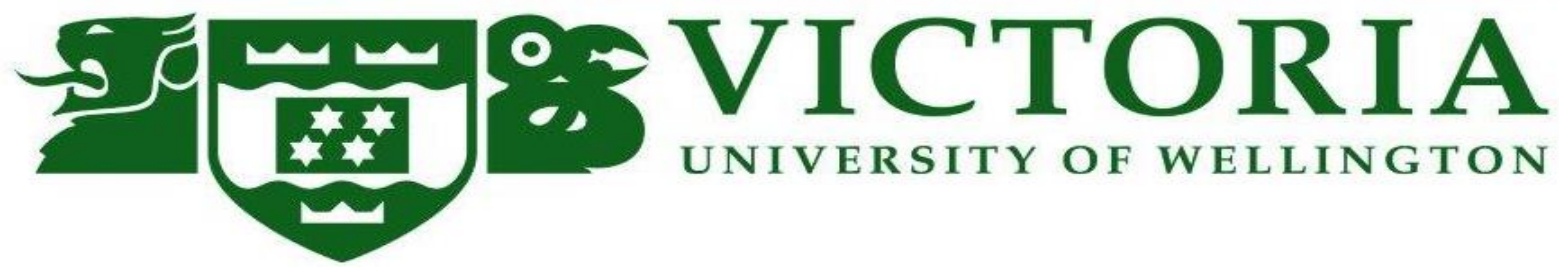

Faculty of Education

\section{Appendix H: Information sheet for employers and managers of mechanical engineers and mechanical engineers}

Research project: Needs analysis of English for mechanical engineering students in the Vietnamese context

My name is Le Cao Tinh and I am a doctoral student at Faculty of Education, Victoria University of Wellington in New Zealand. I am undertaking a research project leading to a Ph.D. thesis.

The research aims to examine the English communication needs and learning needs of mechanical engineering students in the Vietnamese context. It does not aim to evaluate the universities' course books. Victoria University of Wellington requires that ethics approval be obtained for research involving human participants.

I am inviting employers of mechanical engineers, mechanical engineers, teachers of English for specific purposes (ESP) and mechanical engineering students to participate in my study. My study will take place in four workplaces in the centre north and north provinces in Vietnam, and two universities in the centre north and north provinces in Vietnam province from $15^{\text {th }}$ August to $31^{\text {st }}$ December, 2013. Each phase consists of three parts. The first is a survey of a large number of stakeholders. All the questionnaires will be in Vietnamese. The second is to interview a small number of participants following the questionnaire to explore in more depth the perception of English communication needs and learning needs of mechanical engineering students. All interviews will be transcribed in Vietnamese. The third is to observe the real-world use of English of mechanical engineers in the workplace and the teaching and learning of English for specific purposes course at university.

Three methods of data collection will be employed in my study. You will be invited to answer a questionnaire and those who indicated in the questionnaire that they are willing to participate in an individual interview with me will take part in the interview section. I will 
base the selection criteria on gender, position, working experience, and information provided in the questionnaires to invite interviewees from the four companies/factories and two universities. More importantly, I will use the information provided in the questionnaires to select those whose answers can represent as close as possible the range of information given by other participants.

Also, I will ask for the permission to observe at least two working days of mechanical engineers to get a better understanding of their working context, and some class hours to have a better understanding of the teaching and learning of the English for specific purposes course for mechanical engineering students.

The participation is:

- voluntary, and you are free to withdraw at any time up until end of data collection in early December 2013;

- confidential, and you and your company/university will not be identified in the thesis;

- participants may choose not to respond to any question(s).

- all interviews will be audio taped and transcribed into Vietnamese for the purposes of maintaining an accurate record of your responses. You will be given the opportunity to check your interview transcript to ensure it is accurately recorded and to make amendment if you wish. The tapes will be kept secure for a period of 5 years to protect you and your company/university identity; and all data will not be used for any other purpose.

- participants will be given the opportunity to check the field notes and checklists of observations to ensure they are accurately recorded and to make amendment if they wish.

- participants can request feedback such as a summary of findings from me via email at tinh.le@vuw.ac.nz.

- no other person except me, my supervisors Dr John Dickie and Dr Gillian Hubbard, and two transcribers and translators, will see the interview transcripts. The transcribers and translators will all sign confidentiality agreements. The thesis will be deposited in the University Library. It is intended that articles will be submitted for publication in scholarly journals.

This research project has been approved by the Faculty of Education Human Ethics Subcommittee under delegated authority from the Victoria University Human Ethics Committee, and approval number is..........

You will be required to sign a "Consent Form" to formalize your willingness to participate in my study. The questionnaire will require 30 to 45 minutes of your time. You will need to spend the same amount of time for the interview. 
If you have any questions or would like to receive further information about the project, please contact me at (+84)913272079, or email: letinhktv@gmail.com/tinh.le@vuw.ac.nz.

If you have any ethical concerns about this research, please contact Dr Allison Kirkman (Allison.kirkman@vuw.ac.nz), phone number: +64-4-4635676, Chair of the Human Ethics Committee, Victoria University of Wellington.

Le Cao Tinh

Signed: 
TE WHARE WĀNANGA O TE ŪPOKO O TE IKA A MĀUI

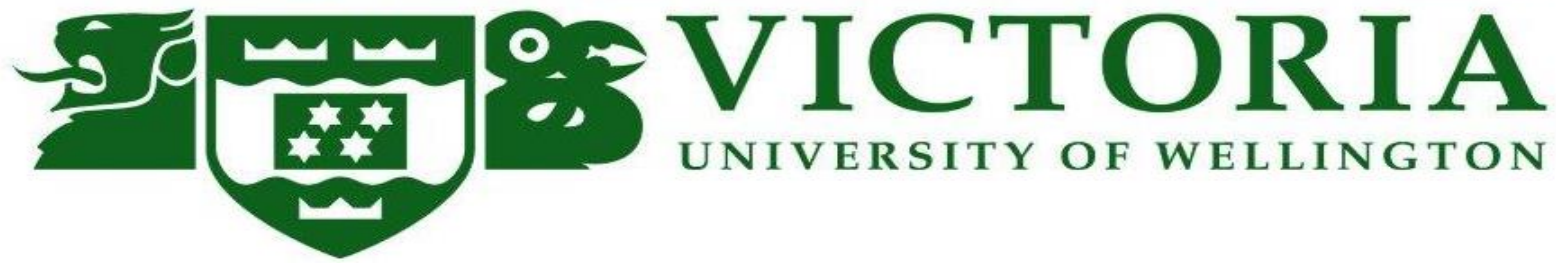

Faculty of Education

Appendix I: Questionnaire consent form for employers and managers of mechanical engineers and mechanical engineers

Research project: Needs analysis of English for mechanical engineering students in the Vietnamese context

I have been given information about this project by Le Cao Tinh who is carrying out this research for a doctoral degree supervised by Dr John Dickie and Dr Gillian Hubbard in the Faculty of Education at the Victoria University of Wellington. I have had an opportunity to ask questions and have them answered to my satisfaction. I understand that I may withdraw myself (or any information I have provided) from this project (before data collection and analysis is complete) without having to give reasons or without penalty of any sort.

I understand that:

- if I consent to participate in this project I will be invited to complete a questionnaire.

- participation will take from 30 to 45 minutes for employers of mechanical engineers and mechanical engineers, and 45 to 60 minutes for teachers of English for specific purposes and mechanical engineering students.

- any information I provide will be kept confidential to the researcher, and the supervisors, and the transcribers and translators who will sign confidentiality agreements.

- the published results will not use my name or my company/university's name, and that no opinions will be attributed to me in any way that will identify me or my company/university.

- the recording of questionnaires will be wiped five years after the end of the research.

- I may choose not to respond to any question(s).

- if I want I can contact the researcher for a summary of the results of this research.

- I may be invited to take part in an interview. 
- a doctoral thesis will be written and that I will not be identified in the thesis.

- I am free to withdraw at any time up until end of data collection

I have read the information sheet and I understand the contents and the points in this consent form. By ticking this box, I am indicating my consent to participate in the research. If you have any questions or would like to receive further information about the project, please contact me at (+84)913272079, or email: letinhktv@gmail.com/tinh.le@vuw.ac.nz. Name of participant:

Signed: Date:

(The subject will be given a copy of this to keep after signing this form) 
TE WHARE WĀNANGA O TE ÜPOKO O TE IKA A MĀUI

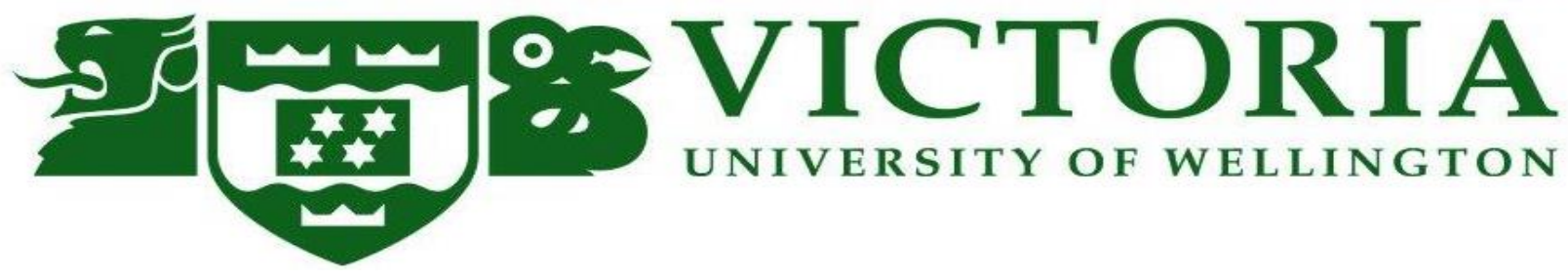

Faculty of Education

Appendix J: Interview consent form for employers and managers of mechanical engineers and mechanical engineers

Research project: Needs analysis of English for mechanical engineering students in the Vietnamese context

I have been given information about this project and discussed the research project with Le Cao Tinh who is carrying out this research for a doctoral degree supervised by Dr John Dickie and Dr Gillian Hubbard in the Faculty of Education at the Victoria University of Wellington. I have had an opportunity to ask questions and have them answered to my satisfaction. I understand that I may withdraw myself (or any information I have provided) from this project (before data collection and analysis is complete) without having to give reasons or without penalty of any sort.

I understand that:

- if I consent to participate in this project I will be invited to join an individual interview.

- participation will take from 30 to 45 minutes.

- any information I provide will be kept confidential to the researcher, the supervisors, and also to the transcribers and translators who will sign confidentiality agreements.

- the published results will not use my name or my company/university's name, and that no opinions will be attributed to me in any way that will identify me or my company/university.

- the audio recording of interviews will be electronically wiped five years after the end of the research.

- I will be given a copy of the transcript of my interview in order to check it for accuracy and will be able to make changes if I wish.

- I may choose not to respond to any question(s). 
- if I want I can contact the researcher for a summary of the results of this research.

- a doctoral thesis will be written and that I will not be identified in the thesis.

- my participation is voluntary and I am free to withdraw at any time up until end of data collection

I have read the information sheet and I understand the contents and the points in this consent form. By ticking this box, I am indicating my consent to participate in the research. If you have any questions or would like to receive further information about the project, please contact me at (+84)913272079, or email: letinhktv@gmail.com/tinh.le@vuw.ac.nz.

Name of participant:

Signed:

Date:

(The subject will be given a copy of this to keep after signing this form) 
TE WHARE WĀNANGA O TE ŪPOKO O TE IKA A MĀUI

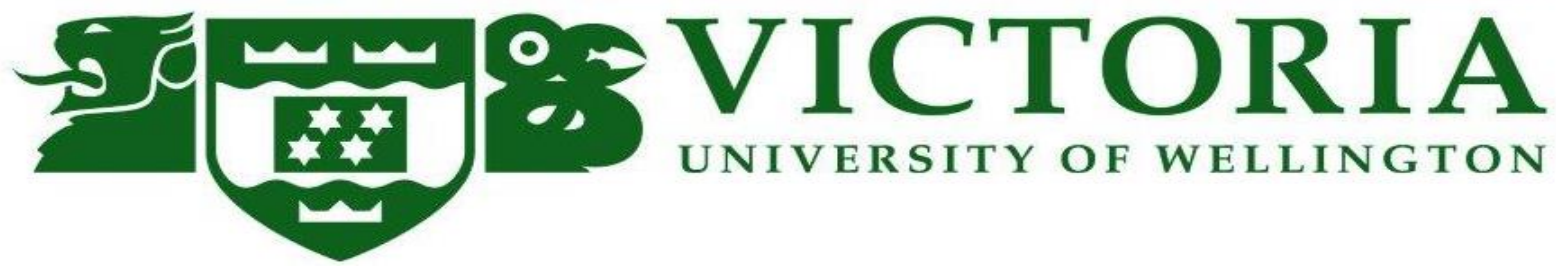

\section{Faculty of Education}

Appendix K: Observation consent form for managers of mechanical engineers and mechanical engineers

Research project: Needs analysis of English for mechanical engineering students in the Vietnamese context

I have been given information about this project and discussed the research project with Le Cao Tinh who is carrying out this research for a doctoral degree supervised by Dr John Dickie and Dr Gillian Hubbard in the Faculty of Education at the Victoria University of Wellington. I have had an opportunity to ask questions and have them answered to my satisfaction. I understand that I may withdraw myself (or any information I have provided) from this project (before data collection and analysis is complete) without having to give reasons or without penalty of any sort.

I understand that:

- if I consent to participate in this project, the researcher will observe my use of English and my staff's use of English in the company/my teaching and learning of English in the classroom, take field notes and use a checklist of my uses of English

- observations will be conducted for at least two days.

- any information I provide will be kept confidential to the researcher and the supervisors,

- the published results will not use my name or my company/university's name, and that no opinions will be attributed to me in any way that will identify me or my company/university.

- the field notes and checklists will be wiped five years after the end of the research.

- if I want I can contact the researcher for a summary of the results of this research.

- a doctoral thesis will be written and that I will not be identified in the thesis.

I have read the information sheet and I understand the contents and the points in this consent form. By ticking this box, I am indicating my consent to participate in the research. 
If you have any questions or would like to receive further information about the project, please contact me at (+84)913272079, or email: letinhktv@gmail.com/tinh.le@vuw.ac.nz.

Name of participant:

Signed:

Date:

(The subject will be given a copy of this to keep after signing this form) 
TE WHARE WĀNANGA O TE ŪPOKO O TE IKA A MĀUI

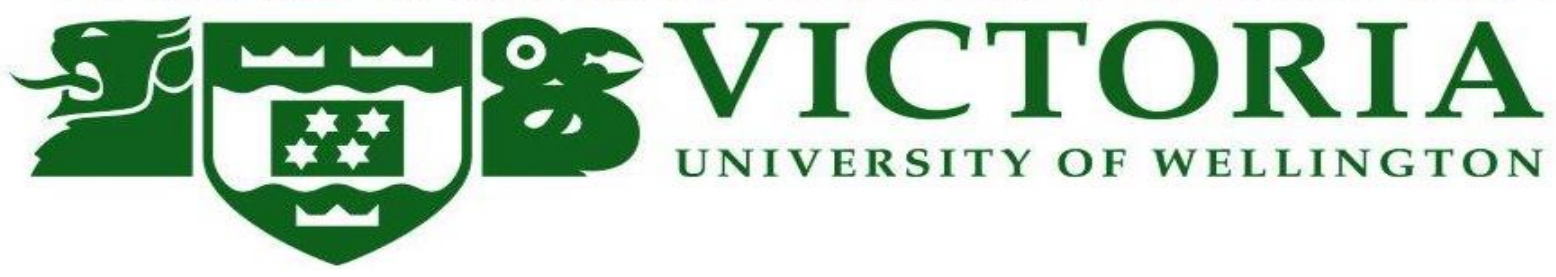

\section{Faculty of Education}

Appendix L: Transcriber and translator's confidentiality agreement

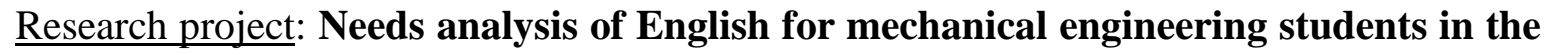
Vietnamese context

Researcher: Le Cao Tinh, Faculty of Education, Victoria University of Wellington

I hereby agree to keep all information that I hear, see and document as a result of my work as a transcriber and a translator, confidential. I agree not to disclose or communicate any of the information or material that was used in the process of the transcription and translation to anyone. I will store all materials securely in the process of my work and not retain any information involving this research project once my work has been completed.

Signature:

Full name:

Date: 
Observations at the food producing company

\begin{tabular}{|c|c|c|c|c|}
\hline $\mathbf{N}$ & Sub-codes & Codes & Sub-categories & Categories \\
\hline \multirow[t]{4}{*}{1} & $\begin{array}{l}\text { 1- communicating in English with the } \\
\text { foreign manager }\end{array}$ & \multirow{4}{*}{$\begin{array}{l}\text { Office mechanical } \\
\text { engineers need } \\
\text { the ability to } \\
\text { communicate } \\
\text { daily with the } \\
\text { foreign manager }\end{array}$} & \multirow{8}{*}{$\begin{array}{l}\text { Common } \\
\text { communicative } \\
\text { events of } \\
\text { mechanical } \\
\text { engineers } \\
\text { working in the } \\
\text { office }\end{array}$} & \multirow{17}{*}{$\begin{array}{c}\text { Common } \\
\text { communicative } \\
\text { events required } \\
\text { by mechanical } \\
\text { engineers }\end{array}$} \\
\hline & 11- using short, informal English & & & \\
\hline & 9- listening to the manager's request & & & \\
\hline & $\begin{array}{l}\text { 12- listening and understanding } \\
\text { Southern Asian English accent spoken } \\
\text { by the manager }\end{array}$ & & & \\
\hline 2 & 2 - ordering spare parts & \multirow{4}{*}{$\begin{array}{l}\text { Common } \\
\text { responsibilities of } \\
\text { office mechanical } \\
\text { engineers }\end{array}$} & & \\
\hline & $\begin{array}{l}10 \text { deciding supplier for the new } \\
\text { motors }\end{array}$ & & & \\
\hline & $\begin{array}{l}\text { 13- assisting the manager with the } \\
\text { office work }\end{array}$ & & & \\
\hline & $\begin{array}{l}\text { 5- reporting the status of machines and } \\
\text { spare parts }\end{array}$ & & & \\
\hline \multirow[t]{5}{*}{4} & $\begin{array}{l}\text { 21- having the manager come to check } \\
\text { their work plan for the day }\end{array}$ & \multirow{5}{*}{$\begin{array}{c}\text { Common } \\
\text { responsibilities of } \\
\text { worksite } \\
\text { mechanical } \\
\text { engineers }\end{array}$} & \multirow{9}{*}{$\begin{array}{c}\text { Common } \\
\text { communicative } \\
\text { events of } \\
\text { mechanical } \\
\text { engineers } \\
\text { working at the } \\
\text { construction site }\end{array}$} & \\
\hline & $\begin{array}{l}\text { 64- communicating with the foreign } \\
\text { manager to report their daily work }\end{array}$ & & & \\
\hline & 44- doing work as scheduled & & & \\
\hline & $\begin{array}{l}51 \text { - having the manager come to their } \\
\text { worksite }\end{array}$ & & & \\
\hline & $\begin{array}{l}\text { 69- following the manager's visit and } \\
\text { check }\end{array}$ & & & \\
\hline \multirow[t]{8}{*}{5} & 59- managing a group of workers & \multirow{4}{*}{$\begin{array}{l}\text { Having good } \\
\text { English ability } \\
\text { may have better } \\
\text { position }\end{array}$} & & \\
\hline & 61- managing a group of 5 workers & & & \\
\hline & 16- holding morning meetings & & & \\
\hline & 3 organising daily man power & & & \\
\hline & 22- greeting the manager in English & \multirow{4}{*}{ Greeting } & \multirow{13}{*}{$\begin{array}{c}\text { Specific } \\
\text { communicative } \\
\text { events required } \\
\text { English listening } \\
\text { and speaking } \\
\text { skills }\end{array}$} & \multirow{13}{*}{$\begin{array}{l}\text { The requirement } \\
\text { of listening and } \\
\text { speaking skills } \\
\text { to perform } \\
\text { specific } \\
\text { communicative } \\
\text { events }\end{array}$} \\
\hline & 70- greeting the manager in English & & & \\
\hline & 62- greeting the manager in English & & & \\
\hline & $\begin{array}{l}\text { 35- Greeting the manager in both } \\
\text { English and Vietnamese }\end{array}$ & & & \\
\hline 6 & 17- talking about safety requirements & \multirow{9}{*}{$\begin{array}{l}\text { Communicative } \\
\text { events required } \\
\text { speaking skills }\end{array}$} & & \\
\hline & $\begin{array}{l}\text { 18- checking if workers meet the } \\
\text { safety requirements (helmet, safety } \\
\text { boots, goggles) }\end{array}$ & & & \\
\hline & $\begin{array}{l}\text { 19- orally reviewing work done the } \\
\text { previous day }\end{array}$ & & & \\
\hline & 20- presenting work plan for today & & & \\
\hline & $\begin{array}{l}\text { 7- reporting the time it takes to repair } \\
\text { the motors }\end{array}$ & & & \\
\hline & 39- reporting the broken pump & & & \\
\hline & $\begin{array}{l}\text { 68- reporting the time schedule of the } \\
\text { maintenance work }\end{array}$ & & & \\
\hline & $\begin{array}{l}\text { 71- addressing the manager's } \\
\text { questions }\end{array}$ & & & \\
\hline & $\begin{array}{l}57 \text { - talking about the work plan for the } \\
\text { day }\end{array}$ & & & \\
\hline
\end{tabular}




\begin{tabular}{|c|c|c|c|c|}
\hline & 14- good English communication skill & & & \\
\hline \multirow[t]{3}{*}{7} & $\begin{array}{l}\text { 32- interpreting the manager's } \\
\text { questions into Vietnamese for } \\
\text { everyone to understand }\end{array}$ & \multirow{3}{*}{$\begin{array}{l}\text { Interpreting } \\
\text { English into } \\
\text { Vietnamese and } \\
\text { vice versa }\end{array}$} & & \\
\hline & $\begin{array}{l}\text { 31- anyone can answer the manager's } \\
\text { questions freely if they know }\end{array}$ & & & \\
\hline & $\begin{array}{l}\text { 33- helping each other to answer the } \\
\text { manager's questions to the best of their } \\
\text { English knowledge }\end{array}$ & & & \\
\hline \multirow[t]{6}{*}{8} & 6- listening to the manager' requests & \multirow{6}{*}{$\begin{array}{l}\text { Communicative } \\
\text { events required } \\
\text { listening skills }\end{array}$} & & \\
\hline & $\begin{array}{l}\text { 37- having the manager asked } \\
\text { questions about the morning meeting }\end{array}$ & & & \\
\hline & $\begin{array}{l}\text { 53- receiving job requests from the } \\
\text { manager }\end{array}$ & & & \\
\hline & $\begin{array}{l}\text { 54- Listening to formal English spoken } \\
\text { by the manager (Can I know/ May I } \\
\text { know...) }\end{array}$ & & & \\
\hline & $\begin{array}{l}\text { 24- listening to the manager's } \\
\text { questions and answering them }\end{array}$ & & & \\
\hline & $\begin{array}{l}23 \text { - listening to using sentences that } \\
\text { are not framed as questions but } \\
\text { become questions through intonation } \\
\text { as well as wh-questions }\end{array}$ & & & \\
\hline \multirow[t]{3}{*}{9} & $\begin{array}{l}\text { 4- using sentences that are not framed } \\
\text { as questions but become questions } \\
\text { through intonation }\end{array}$ & \multirow{3}{*}{$\begin{array}{l}\text { Using sentences } \\
\text { which are not } \\
\text { framed as } \\
\text { questions but } \\
\text { become questions } \\
\text { through } \\
\text { intonation }\end{array}$} & \multirow{8}{*}{$\begin{array}{l}\text { Using informal } \\
\text { spoken English } \\
\text { which are not } \\
\text { always correct } \\
\text { in terms of } \\
\text { grammar } \\
\text { structures }\end{array}$} & \multirow{8}{*}{$\begin{array}{l}\text { Different types } \\
\text { of English } \\
\text { required by } \\
\text { mechanical } \\
\text { engineers }\end{array}$} \\
\hline & $\begin{array}{l}\text { 8- using sentences that are not framed } \\
\text { as questions and do not follow correct } \\
\text { grammar structures }\end{array}$ & & & \\
\hline & $\begin{array}{l}\text { 49- using broken English which does } \\
\text { not always follow correct grammar } \\
\text { structures }\end{array}$ & & & \\
\hline \multirow[t]{5}{*}{10} & $\begin{array}{l}\text { 25- answering the manager's questions } \\
\text { using short, broken English }\end{array}$ & \multirow{5}{*}{$\begin{array}{l}\text { Using short, } \\
\text { informal broken } \\
\text { English that can } \\
\text { be understood }\end{array}$} & & \\
\hline & $\begin{array}{l}\text { 29- speaking informal, simple, broken } \\
\text { and technical English }\end{array}$ & & & \\
\hline & $\begin{array}{l}\text { 40- Using short broken English to } \\
\text { answer the manager's questions about } \\
\text { the pump, oil filter, and the roller teeth }\end{array}$ & & & \\
\hline & $\begin{array}{l}\text { 49- using broken English which does } \\
\text { not always follow correct grammar } \\
\text { structures }\end{array}$ & & & \\
\hline & $\begin{array}{l}\text { 72- communicating with the manager } \\
\text { using simple English and key technical } \\
\text { terms }\end{array}$ & & & \\
\hline \multirow[t]{3}{*}{11} & $\begin{array}{l}\text { 26- using both English and Vietnamese } \\
\text { in the answer }\end{array}$ & \multirow{3}{*}{$\begin{array}{l}\text { Struggling to } \\
\text { understand and be } \\
\text { understood using } \\
\text { both English and } \\
\text { Vietnamese }\end{array}$} & \multirow{3}{*}{$\begin{array}{l}\text { Struggling to } \\
\text { communicate } \\
\text { with the foreign } \\
\text { manager }\end{array}$} & \multirow{3}{*}{$\begin{array}{c}\text { Adaptive } \\
\text { communicative } \\
\text { activities }\end{array}$} \\
\hline & $\begin{array}{l}\text { 43- speaking both English and } \\
\text { Vietnamese words to communicate } \\
\text { with the manager }\end{array}$ & & & \\
\hline & $\begin{array}{l}\text { 56- Using Vietnamese instead of } \\
\text { English when he doesn't know to use } \\
\text { English equivalent }\end{array}$ & & & \\
\hline
\end{tabular}




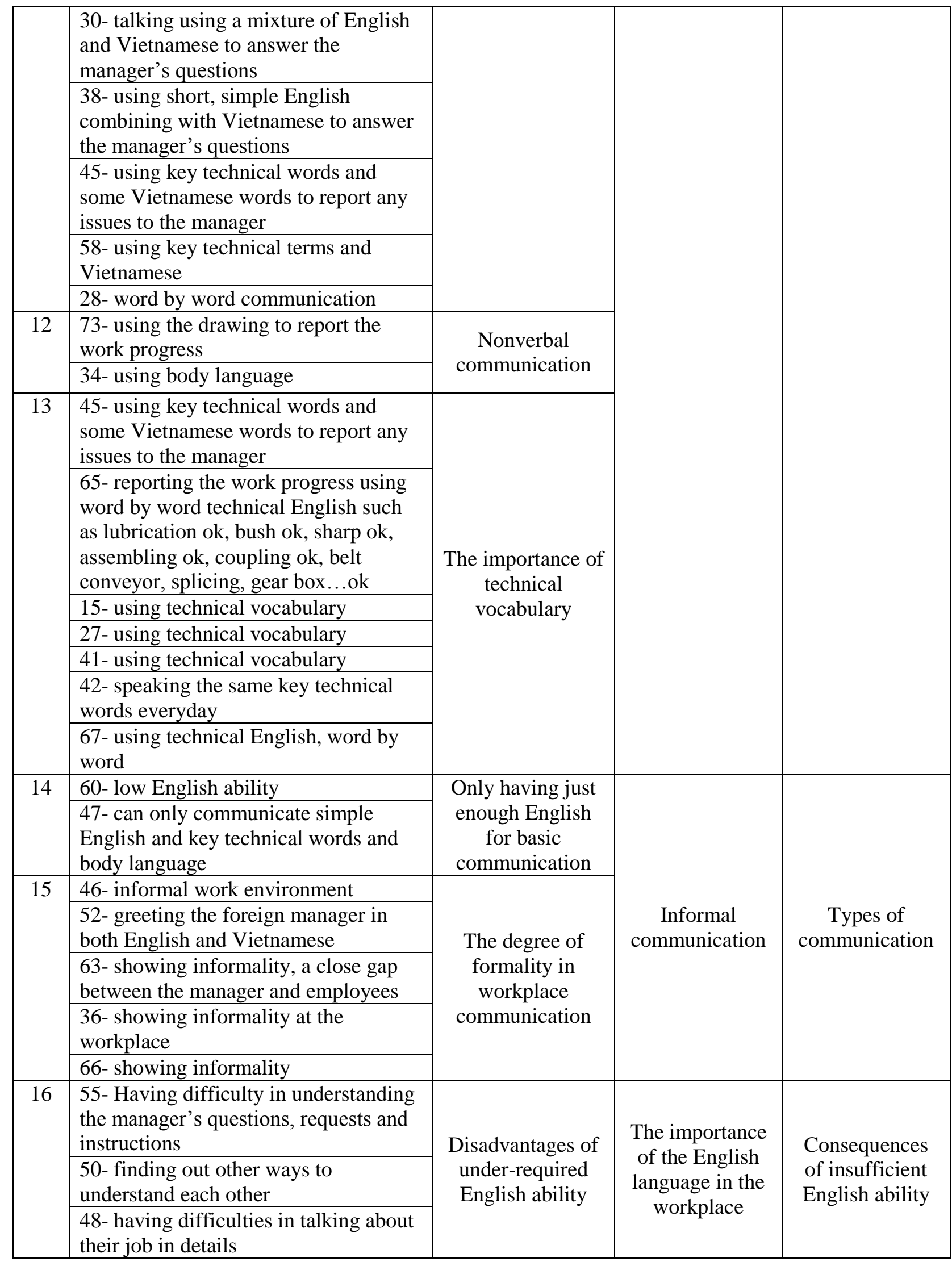

